\title{
Teaching in the Age of Covid-19
}

\section{Petar Jandrić, et al. [full author details at the end of the article]}

Published online: 7 August 2020

(C) Springer Nature Switzerland AG 2020

\section{Teaching in the Age of Covid-19 \\ Petar Jandrić, Zagreb, Croatia, 1 June}

Petar Jandric is a professor at the Zagreb University of Applied Sciences, Croatia, and visiting professor at the University of Wolverhampton, UK. He is founding editor-inchief of Postdigital Science and Education. Petar is 42 years old, and lives in Zagreb, Croatia, with his partner and son.

After several months of personal journey towards accepting that the coronavirus pandemic is real (see Jandrić 2020a, b), in early March, it dawned on me that the pandemic does not need only so-called essential workers. Self-quarantined after returning from abroad weeks before the Croatian government locked down the country, I immediately wrote an editorial for Postdigital Science and Education and argued that 'While doctors, nurses, politicians, food suppliers, and many other brave people self-sacrifice to support our daily survival, this editorial argues that academics have a unique opportunity, and a moral duty, to immediately start conducting in-depth studies of current events.' (Jandrić 2020c: 234)

I had no idea how to even approach these studies, yet I had a strong feeling that something needed to be done urgently. So, I just did what I know best and issued calls for 3 different types of Covid-19-related material to be published in Postdigital Science and Education: short testimonies, longer commentary articles, and full-length original articles. I had no idea how much material I would receive, what this material would look like, and what I would do with this material. I just had a deep gut feeling that we are witnessing a unique time in human history, a once-in-a-lifetime event, that needs to be recorded as it unfolds. For better or for worse, I decided to follow that feeling.

This general vision, without a clear idea of what I was doing, paved a bumpy road for the development of this collection. On 17 March 2020, I shared the Call for Testimonies on Postdigital Science and Education social network sites and I emailed it to the journal's mailing list. Based on my previous experience with similar calls, I expected to receive 10 to 15 contributions and produce a standard-length collective article aiming at postdigital dialogue (Jandrić et al. 2019) about the pandemic. Yet my call went 'viral', at least for academic standards, and a couple of weeks later, I had more than 50,000 words written by more than 80 authors. So how do I make sense of all that material?

My dear friend and Associate Editor of Postdigital Science and Education, Sarah Hayes, came to my rescue. We first tried to make sense of the contributions using critical discourse 
analysis - and we epically failed. Sarah's computer analysis found wonderful linguistic concordances, yet we struggled to breathe any meaning into them. In the process, we also managed to annoy some of the contributors, who objected that they had submitted authored texts rather than data for our analyses. Of course, these people were completely right, and I deeply apologise for this first, unthoughtful attempt. We reshaped the project, obtained ethical clearance from Zagreb University of Applied Sciences, and went on to work. But the collection stubbornly refused to reveal its nature, and all our attempts were unsuccessful.

While we waited for ethical clearance, and emailed back and forth with the authors, I have been writing a lot about various inequalities pertaining to a sudden global switch of teaching and learning online (see Jandrić 2020a, b, c; Peters, McLaren, and Jandrić 2020; Peters, Jandrić and McLaren 2020). Words seemed inadequate to describe these inequalities, so I came up with an idea to request a photograph of each contributors' workspace during the lockdown. Many authors obliged, and we soon ended up receiving a torrent of images. Now Sarah and I had even more important material, and even less of an idea of what to do with this material!

Obviously, publishing a standard academic article of such length was out of the question. Sarah and I proposed a book, and after many email exchanges, Springer's Nick Melchior kindly agreed to publish the collection in the Postdigital Science and Education Book Series. ${ }^{1}$ Sarah and I had long Skype conversations about the book's concept and outline, yet again, our ideas just did not feel right. This material stubbornly rejected all our attempts at making sense! I finally contacted my journal contacts at Springer, Puja Dayal and Hendrikje Tuerlings, and explained the problem. Puja and Hendrikje invested a lot of work to understand the question, and even more work to investigate the available opportunities for publishing this material. Finally, all of usSarah, Nick, Puja, Hendrijke, and I-agreed that the current format lain in front of you will be the best available option for presenting this collection.

This article presents a collection of short testimonies and workspace photographs received between 18 March and 5 May in response to my Call for Testimonies reproduced in the next section. The testimonies are lined up in order of when they were received. Each section starts with the place and time of writing, followed by a brief author biography, their testimony, and one workspace photograph. In numbers, the collection consists of 81 textual testimonies and 80 workspace photographs submitted by 84 authors from 19 countries: USA (13), UK (11), China (9), India (7), Australia (7), New Zealand (7), Denmark (6), Sweden (6), Croatia (5), Canada (2), Spain (2), Nigeria (2), Finland (2), Ireland (2), Malta (1), Tanzania (1), Malaysia (1), Latvia (1), and South Africa (1). As it is common in the academia, many authors are expats and carry multiple identities; the collection reflects places of writing their testimonies rather than places of their origin.

The Covid-19 pandemic is still far from over, and there is no doubt that educational sciences will analyse this sudden global shift of teaching and learning online for many years to come. Yet this collection makes a unique and important contribution to all future analyses, because it presents real-life testimonies of people's struggles and feelings experienced at the very beginning of the first wave of the sudden shift online. These testimonies could have been collected only at that specific moment in time; all later analyses will inevitably depend on various forms of individual and collective memory such as Internet sources and personal recollections. This article is therefore a valuable historical document, which provides important insights into a crucial moment

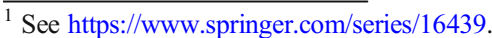


in the Covid-19 pandemic. Furthermore, the testimonies provide highly relevant and non-replicable inputs for researchers, policy-makers, governments, and everyone else interested in the present and future of global education.

I extend my sincere gratitude to all contributors who had the patience to bear with our uncertainties and conceptual wanderings during the collection of these testimonies and the production of this work. I am deeply indebted to Sarah Hayes, Nick Melchior, Puja Dayal, and Hendrikje Tuerlings, who selflessly contributed to its ideation and realization amongst many personal and professional challenges at the peak of the pandemic. In our messy and unpredictable postdigital age (Jandrić et al. 2018: 895), we managed to collectively produce this messy and unpredictable collection. With all its imperfections, rawness, honesty, and occasional brutality, this collection is a genuine snapshot of the challenges facing worldwide teachers and students at the beginning of the first wave of the Covid-19 pandemic. I sincerely hope that this collection will contribute to making sense of our present, and to the development of more informed responses to similar challenges in the future. Some of our preliminary ideas in that direction can be found in the editorial for this collection (Jandrić and Hayes 2020).

\section{Call for Testimonies: Teaching in the Age of Covid-19} Petar Jandrić, Zagreb, Croatia, 17 March

This is a verbatim transcript of the Call for Testimonies sent out on 17 March 2020 to the Postdigital Science and Education mailing list and posted on social networking sites.

The first case of the coronavirus disease, Covid-19, was officially reported from Wuhan, China, on 31 December 2019. On 13 March 2020, Europe has become the epicentre of the coronavirus pandemic, and the USA and Australia are not far behind. Worldwide governments are responding in radically different ways - the government of Montenegro has closed down the whole country before it registered the first patient within its borders, while the UK has opted for a laissez faire approach which is hoped to result in herd immunity. The Covid-19 pandemic has brought a huge social experiment into our homes, streets, cities, and countries, and we, academic researchers, have a moral and professional duty to record current events and try to make sense of them.

As I write these words on 17 March 2020, schools, universities, and research centres around the globe are moving partially or completely online. For families, children, and students in self-isolation, an opportunity to successfully complete this academic year is hugely important. However, making this opportunity happen brings about a lot of additional stress on teachers and families. Some academics are well prepared for online teaching and research; others work nights and weekends on developing online materials and supporting their students and colleagues. Some academics teach easy-to-move-online topics, or topics which can be supported by a lot of existing online material. Those who teach individually, and contextually, are facing radically different challenges. Academics and students alike can suffer from poor connectivity, inappropriate equipment, and other access issues. They may not have access to own workspace, or they may need to care for young or elderly family members. Many academics are also parents, so they need to juggle working from home and caring for own children. Arguably, this sudden and unprepared shift of millions of worldwide teachers and 
students online is an unprecedented educational and social experiment — and we would like to make a record of this experiment as it unfolds in front of our eyes.

In this collective article, we would like to hear about ways in which you-teachers at all levels, researchers, academics - experience this shift in the moment here and now. This is not an academic exercise, although you can freely share your academic insights if you feel like sharing them. In your response, we are interested in hearing real-time testimonies about challenges, and issues, you are experiencing as your academic work suddenly moves online. Your 500-word contributions should contain roughly the following:

- Where, and when, are you writing this testimony?

- A sentence or two about context. Where do you work? How has your university reacted? What is expected from you at this stage?

- How are you dealing with these expectations? Which major challenges (professional, private, personal, family...) are you finding along the way?

- What are your main feelings at the moment (stress, anxiety, excitement, happiness...)? How are you coping with those feelings?

- And, of course, anything else you would like to tell the world about your experience.

Please write your ca 500-word response and return it to Petar Jandrić. Responses will be collated into a collectively authored article and prepared for publication in Postdigital Science and Education. If you wish to respond anonymously, please indicate this in your email.

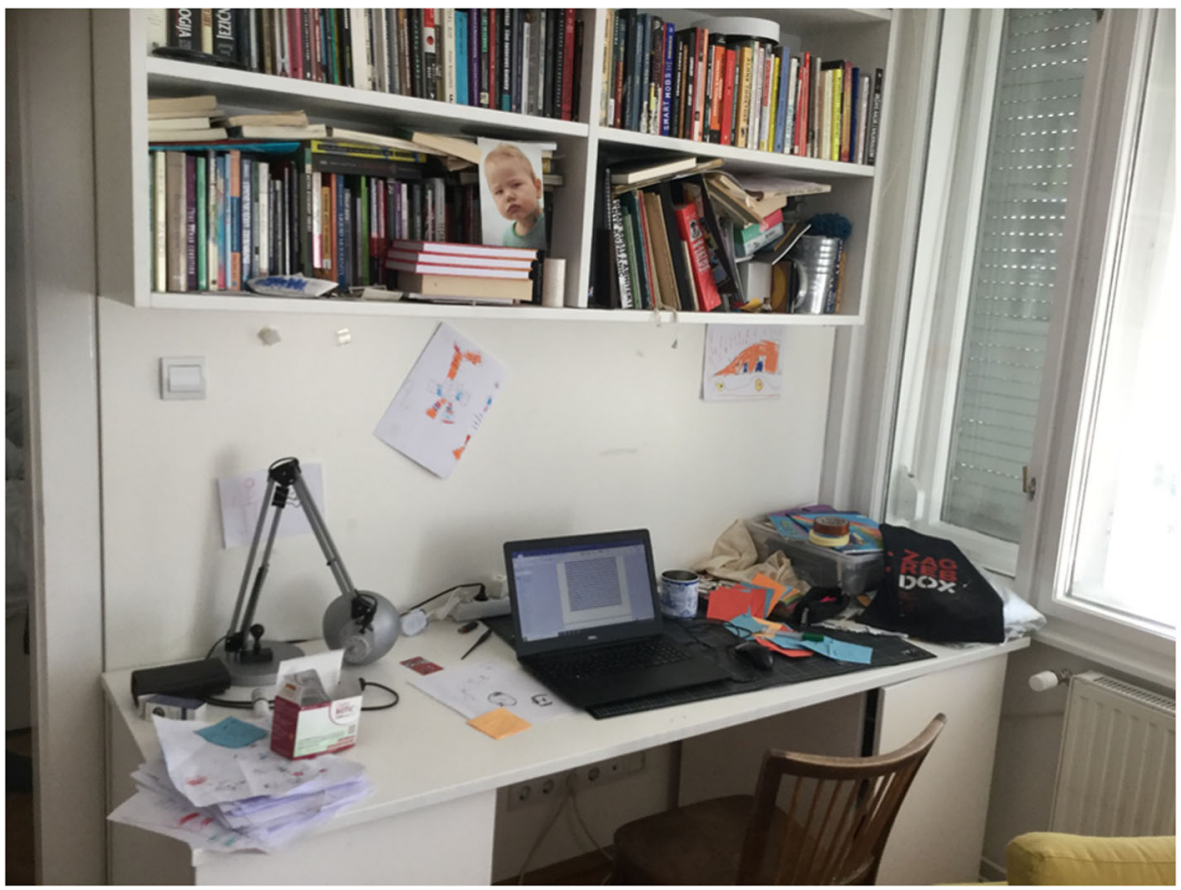

Fig. 1 This is my workspace in our living room, where I take turns in working with my partner Ana, and where our son Toma writes his homework 


\section{Volunteering and Covid-19}

David Hayes, Further Education, Worcester, UK, 18 March

David Hayes felt privileged to teach for over thirty years. He found those he taught, and taught with, more interesting than his subject. That subject was often mathematics. Originally from Scotland, Dave enjoys life in Worcester, UK, with an all-too-observant partner, two sons and a disrespectful cat called Jasmine.

Having retired from teaching mathematics in schools and colleges a few years ago, it seemed to be a natural wish to offer volunteer support to students. It has been a fairly positive experience: I would not have continued to volunteer, if it had not been so. Students at a local college, where I had taught for many years, benefited from some extra one-to-one support and I felt good about myself for volunteering, or something like that. We all gained, well a bit, anyway. Due to the financial constraints within the UK Further Education sector, this type of assistance is no longer the norm. The students, in particular, have always appeared to be grateful for personal help. It is hard to overestimate the impact that it had on me, shopping in Aldi, when the very young person behind the till said 'you helped me in those support sessions. They were really useful. I got a C in my A'level and am off to University next year.' Providing such assistance, without having to jump through all those hoops that employees have to navigate, is intrinsically enjoyable. It is why most of us went into teaching, all those years ago.

My most interesting experience has been supporting the teaching of Further Maths in the local school that my own children attended. Further Maths is a second or further A'level studied by those students who like Maths and are generally pretty good at it. The school in question has not been able to commit a teacher to such a small group, so they buy in various on-line packages as support. My role has been to provide face-to-face contact, for a couple of hours each week, to complement their self-study through on-line provision. I try to help them with particular questions that have given them problems, or try to offer them further explanation. It has involved some marking of mock exams and a little preparation, mostly to check that I can still do the questions myself! It has, however, been standard fare and it has been all the better for it. I have merely been the mortar between the bricks: the students and the on-line packages taking most of the strain, to continue the metaphor.

So what is happening now that Covid-19 has emerged in the way it has? The support that students have appreciated so much is mostly on hold. There is little point providing that help online: that is there already. It is the support that can be given with a pen and scraps of paper that seems to mean so much to these students. I feel confident that there will be a way through, eventually. The system will adapt, both during and after this crisis. Some provision may indeed be better. To say though that all provision should be put online seems rather glib. It is in danger of devaluing what students value most, human contact. We may as well say that all parenting should now be put online. 


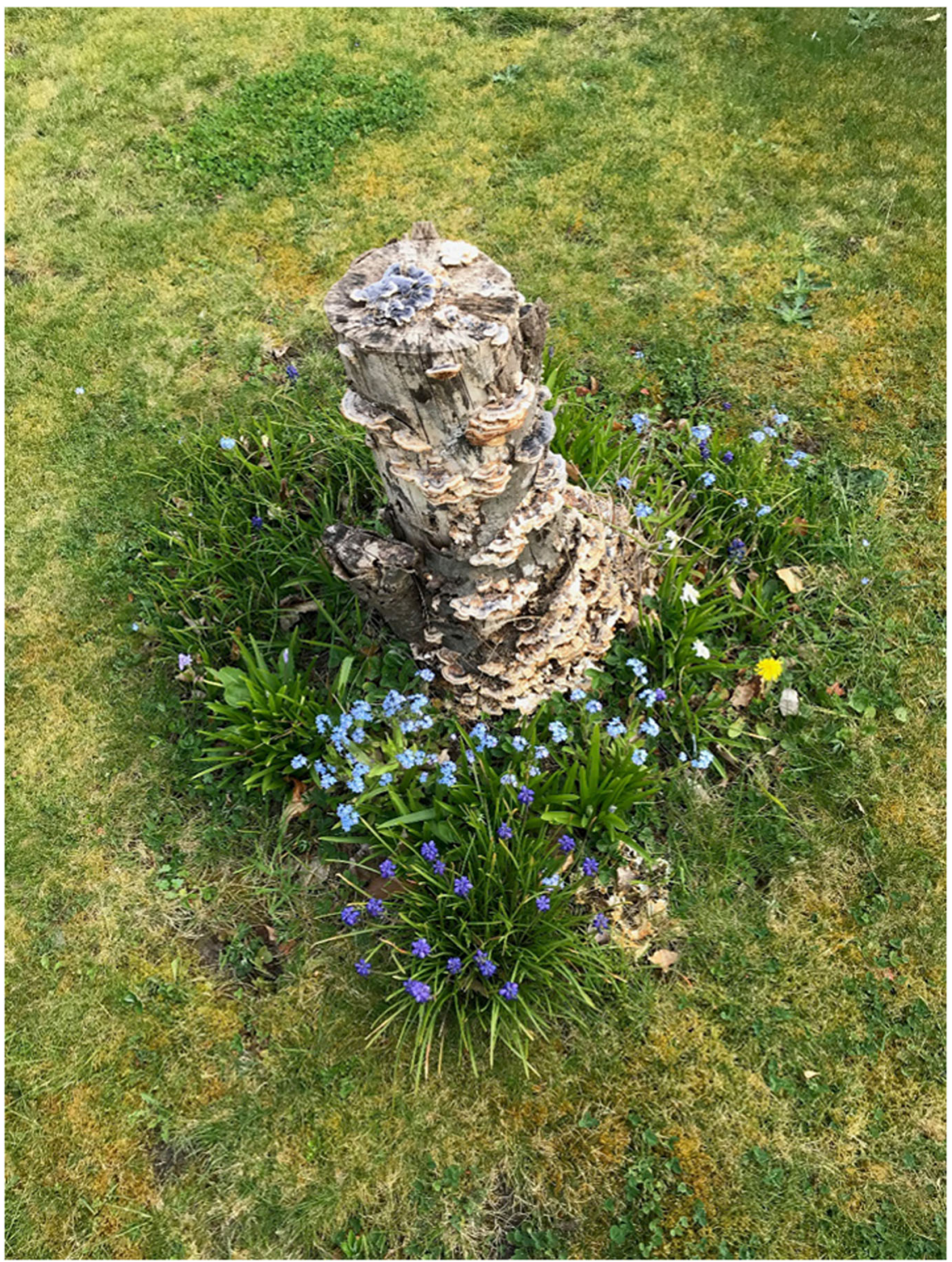

Fig. 2 Past and present

\section{Home-Time}

Ian Truelove, north-east coast of England, 19 March

Ian Truelove is a course director at Leeds Beckett University, UK. Ian is 49 years old and normally only lives by the sea at weekends and during holidays. 
I am typing this testimony on my home on the north-east coast of England on Thursday, 19 March 2020. It is my first day of home working, but I moved my Illustration and Graphic Design students to online learning last week.

I work in the Leeds School of Arts at Leeds Beckett University. The university has been following the UK government's advice, but as I have experience of both home working and online leaning, I decided to move my students online a week earlier than the rest of the university so I could help other courses as they came online.

Fortunately, fifteen years ago, annoyed with WebCT and its ilk, we started building our own Virtual Learning Environment, which we call CAGD. This is so well embedded in our teaching and learning practices that the move to online learning has been smooth so far. Students are used to frequent interactions with the CAGD platform - this is where they share their artworks and reflect on their predominantly studio-based learning. The studios are now offlimits, but the students are continuing to use CAGD to share their homemade visual outcomes, and we are using CAGD to conduct online classes at the usual scheduled times.

I have a CAGD-based class this afternoon-I'm going to teach the BA Illustration students how to edit audio in Premiere. I'll show them the Chuck Jones animation 'Duck Amuck' and a film about the continuity system, and we'll have a discussion. By the end of the class, they will have all created an audio piece and shared it with one another via CAGD. The mechanics of the class will be very similar to the real-life version, but it will not be the same: it will suffer from a distinct lack of human contact. CAGD was built to blend with real-life, and as great as it is, it is not a substitute. My Teams-video class earlier in the week with MA Graphic Design did have a human touch, but there are only a handful of them. I think I'm going to struggle to scale that up to my much larger Illustration group.

I have spent this week working in the physical spaces I normally teach in, without the students physically present, but interacting with them online. Until it was agreed I should work from home, I wanted to have a transition phase where the real and the virtual collided. I wanted to form a clear memory of the old ways to hold in my head during the months of online teaching that lie ahead.

My feelings swing between optimism about the creative potential in this challenging set of circumstances and pessimism about the long-term effects on my students' futures. Right now, I feel good that I can help them maintain some sense of normality and stability. I worry about students with preexisting anxiety issues and how they are coping with a barrage of terrifying news. My aim is to offer a calm and upbeat voice as an uncertain situation unfolds. 


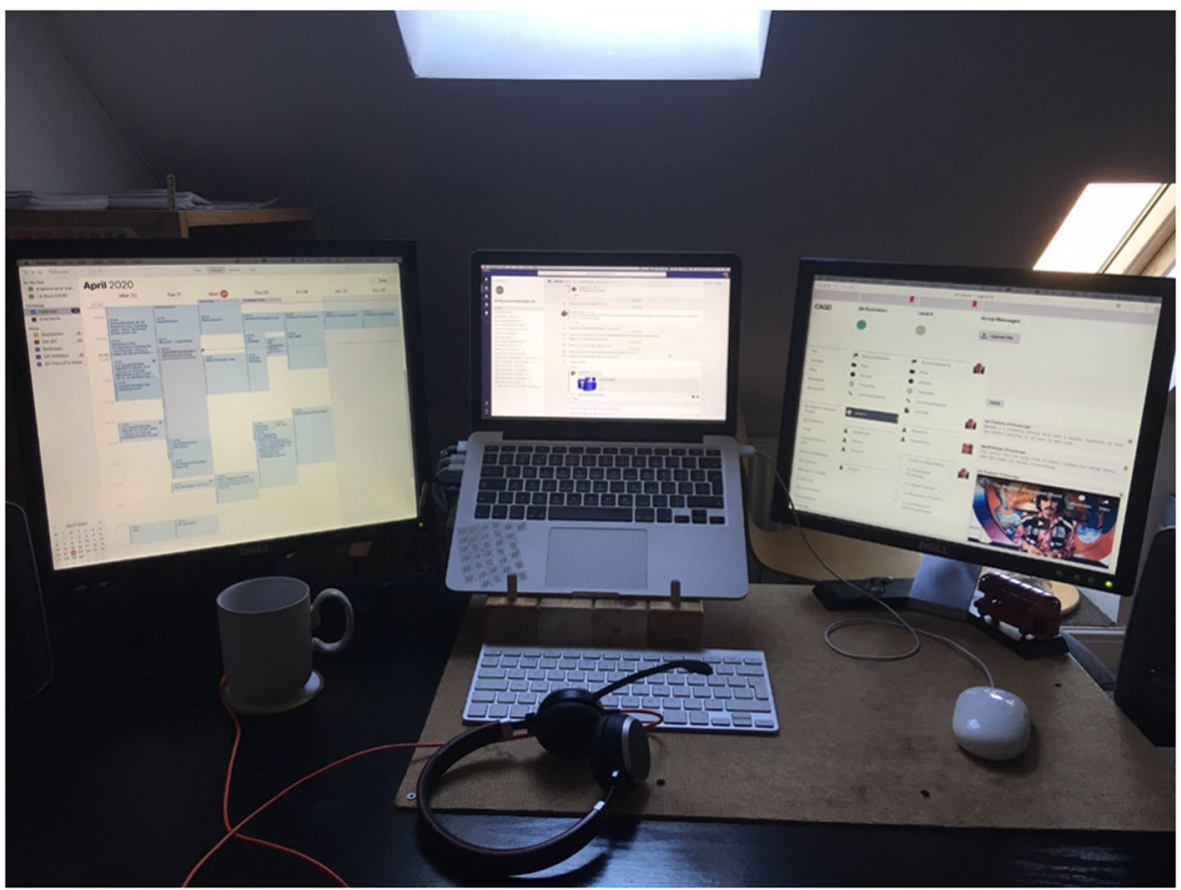

Fig. 3 This is my workspace in my loft at home. The skylight necessitates the wearing of a flat-cap at all times

\section{Online Salvation}

Paul Levinson, New York City, USA, 19 March

Paul Levinson has published 10 books about media theory (e.g., The Soft Edge, Digital McLuhan, New New Media) translated into 15 languages and 6 science fiction novels (e.g., The Silk Code, The Plot to Save Socrates), and is a singer-songwriter (Twice Upon a Rhyme, Welcome Up: Songs of Space and Time). He is a professor at Fordham University in New York City and appears on CNN, MSNBC, NPR, the BBC, and numerous news outlets.

I taught my first online class to CEOs for the Western Behavioral Sciences Institute in 1984. That gave me the idea to start Connected Education — aka Connect Ed—which offered online courses for academic credit provided by the New School in New York City, the Bath College of Higher Education in the UK, and other schools from 1985 to 
1995 (Percival, 1995). My wife Tina and I ran Connect Ed from our home, where we could be close to our young kids. We had students from 40 states around the USA and 20 nations around the world. All courses were taught asynchronously, which, among other advantages, made it easy to teach across time zones.

Little did I know that this experience in the 1980s and 1990s would prepare me so well for the coronavirus pandemic which is now raging across our globe. When Fordham University, which is where I teach in person, switched to all online classes several weeks ago, I knew immediately how to proceed. In both of my classes, students would present reports to class and give written versions to me. The students now present their reports to the class via video- which they record - and then send to me, so I can post them to the class, after making sure that the video links work. Both of my classes are proceeding as smoothly as can be expected in these anxiety-producing times.

The virtual world has often been criticized as a distraction from or evasion of the real physical world. But when a deadly pandemic afflicts us, the virtual world, including not only teaching but also telemedicine and online ordering of food, is a salvation. 


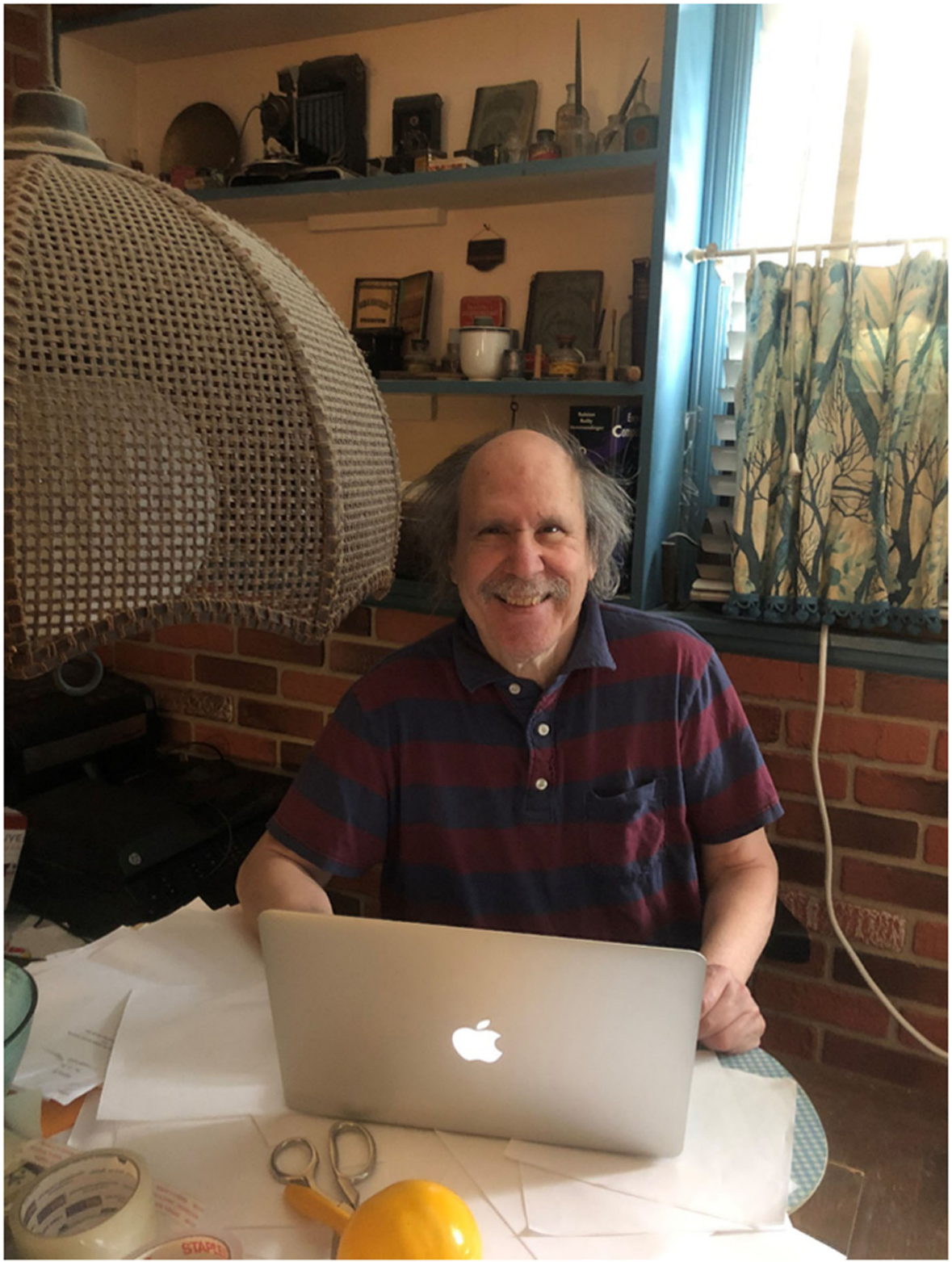

Fig. 4 This is one of my workspaces in our home, about seventeen miles north of where I teach in person at Fordham University. This workplace is in our family room. I have another workplace three floors above, in my office 


\section{Zooming Out in a Time of Covid}

Peter Mayo, Malta, 19 March

Peter Mayo is professor at the University of Malta and is the author of Higher Education in a Globalising World: Community Engagement and Lifelong Learning (2019). Peter lives with his wife and cat in Paola.

$* * *$

All schools and higher education institutions are closed over here in Malta. All our teaching is done online from home. This is a new adventure for many of us. We use Zoom for the most part and one-to-one dissertation interaction on Skype, though other platforms are used by teachers and students alike.

I gave my first class online last Tuesday and it went well. Actually, I felt it was more focused and tight than in the face-to-face sessions. I found this a most rewarding experience. Too early to gather whether students, especially international ones, feel comfortable with speaking freely online. We were told late in the day that sessions are recorded for the benefit of those who could not participate in real time and want to catch up. I do not doubt the genuine nature of the motive behind this recording. However, it remains to be seen whether awareness of being recorded makes students less free to express themselves. They may perceive this as another surveillance mechanism. You never know who gets hold of these recordings and I mean internationally.

A number of academics are used to and prepared for online interaction, and our university offers courses in this mode of delivery. Others are not. I wonder whether this sudden widespread online teaching experience will lead to more university courses online internationally, post Covid-19. The institution might see this as an attractive and lucrative proposition. The worst-case scenario is that they will go the whole hog and continue to take higher education down the business route. Now I am not rejecting new digitally mediated learning platforms, far from it: I recognise great possibilities. I would tread warily, however, into what for some is a 'brave new world'.

I cling steadfast to the view that higher education, as all education for that matter, should be a public and not a consumption good. Critical educators have an even greater role to play in this scenario ensuring that criticality remains a key ingredient of the educational experience whatever the platform used. And of course, there is always the danger that many academics take the plunge without adequate preparation. One prominent scholar on higher education who worked for the Open University in the UK in the past told me that she had to go through an entire year's preparation before she could join the teaching staff. Throwing many uninitiated staff at the deep end, because of the crisis, is like throwing young, immature brigadistas into a three-month literacy campaign in a revolutionary context.

Once the crisis is over, we need to sit back and take stock of the situation critically. How does this fit into the blended approach including genuine 'in the flesh' social and human restof the-cosmos interaction? After all, there is such a thing as society. I feel that the lack of eye contact, which is a characteristic of face-to-face teaching, diminishes the vitality of classroom interaction. Often, a shy or reserved student can be encouraged, by my approving eye contact, to give verbal expression to what the person's body language seems to suggest. This is impossible to achieve via virtually mediated interaction. On the other hand, this period 
allows me to extend my teaching, via friends, to all corners of the world. Yesterday I interacted with a lovely group of graduate students in a class in the USA. I was a guest of the class teacher, a former professor of mine and friend.

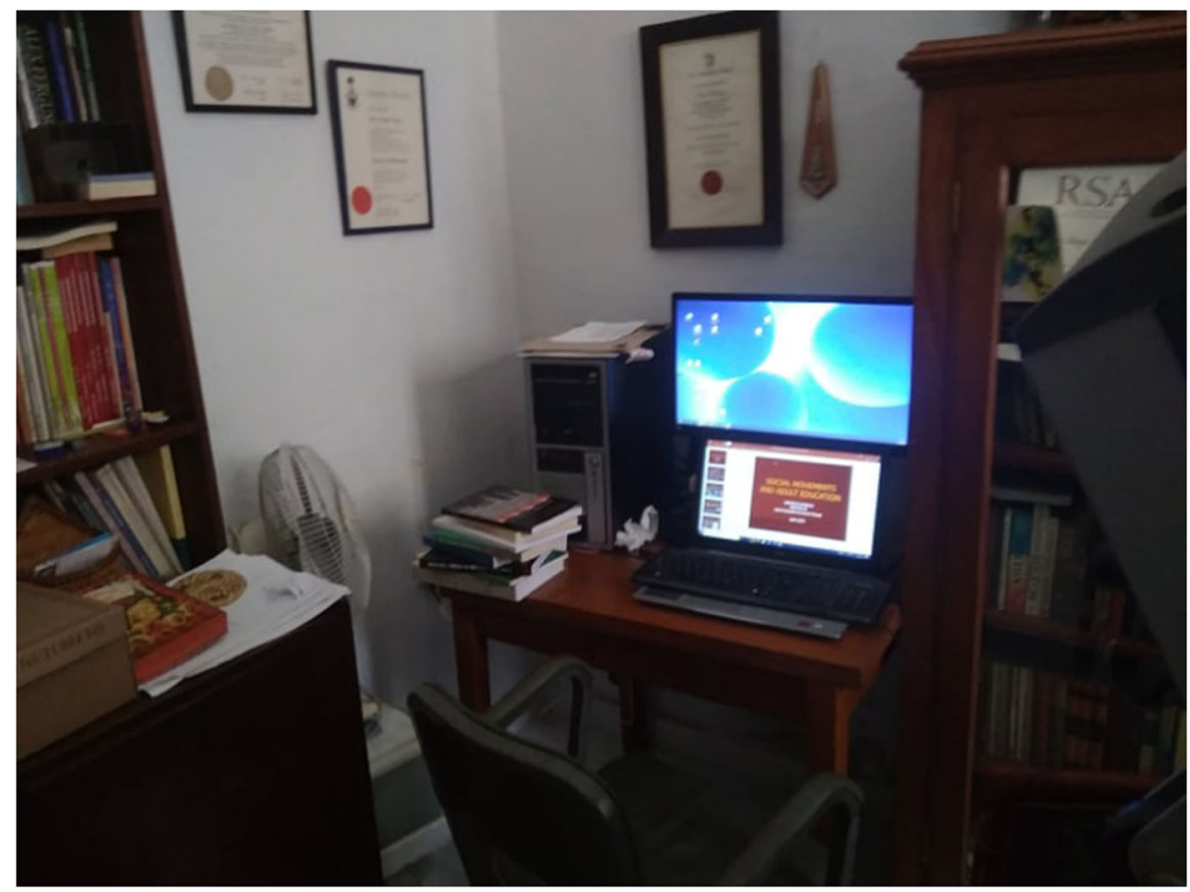

Fig. 5 This is the computer corner in my study at home where I write my research and teach online with students in Malta and abroad

\section{Untitled}

Thomas Ryberg, Aalborg, Denmark, 19 March

Thomas Ryberg is professor of digital learning in the Department of Communication and Psychology at Aalborg University (AAU), Denmark. Thomas is 43 years old and lives in Aalborg, Denmark, with his partner and their two daughters.

$* * *$

Writing these words on March 19, 2020. Oldest daughter sits across the table wearing headphones and watching YouTube. She is in third grade, and since Thursday 12th, she and her little sister have been home from school. From that day, the Danish government more or less shut down all educational institutions and non-critical staff from all public offices were instructed to work from home. Following Wednesday evening's press conference with the Danish Prime Minister Mette Frederiksen, Aalborg University 
(where my wife and I both work) instructed us to stay home. Teaching would have to be carried out online. Same for supervision. Effective immediately.

On that very day, I had my last onsite session before the shutdown. I conveyed the seriousness of the situation and said that next week I would teach online to minimize unnecessary contact. Also, I was speculating that we might soon see a shutdown of schools and universities ( $\mathrm{O}$ my prophetic soul!). Thursday was the first day at home, and while being used to working from home, doing online meetings and all that jazz, this has previously not included having two kids aged 6 and 9 at home and trying to figure out what they are supposed to do in terms of school.

Danish digital infrastructure is quite good, yet Thursday morning left the school-to-home communication platform AULA screaming in agony. Traffic was now diverted onto various commercial online platforms used occasionally by the schools - one by one now falling to their knees and begging for mercy. Messages were posted in the now occasionally working, but loudly wailing, AULA platform reporting this or that platform 'not working at the moment' until they managed to set up digital queues to accommodate for the collective parental concern for our children's education.

Now, amidst everything else, was also the time to prepare for the two online sessions I would be hosting Monday and Tuesday. I initially settled on Adobe Connect, which is an online meeting room that can facilitate dialogue, but also breakout groups, so the students could discuss in smaller groups. The challenge is to transform a design that was originally conceived for onsite teaching to an online setting, and the optimal solution would be to completely redesign and rethink activities, structure, temporality and relations between teachers and students. But time did not permit such restructuring; the entire digital infrastructure was under an unusual pressure... so I had to use Skype for Business on Monday, switching to Microsoft Teams on Tuesday, to allow for more peerto-peer activity. Frustrating? Yes! And yet I am fortunate. A professor of digital learning, with limited teaching obligations (compared to teachers in primary or upper secondary schools), digitally literate and used to online teaching. This must be really trying to those completely exploring new territory.

Although it is difficult to juggle work, children, cat and other obligations, I also feel privileged and lucky. Unlike people in the service industry or the selfemployed, my job security and payment are not immediately affected by the Covid-19 pandemic. I live in a country with universal access to a good health care system (still), and the Government seems to act swiftly and decisively (whether too much is to be seen in retrospect). But we are still in the very early stages of the spread, and we may now be in the eye of the hurricane. Healthcare workers and hospitals are bracing for impact. While no one I know has been affected by the virus, this might change for the worse, or the unbearable even. Yet, I am hopeful and optimistic. Apart from panic buys, occasional absurd conspiracy theories and the Orange idiot-in-chief, we have also witnessed helpfulness, resourcefulness, resilience and the will to collectively help the weakest. Let us hope this helpfulness will extend beyond the borders of the richest countries, for there are places where a pandemic may strike even harder. 


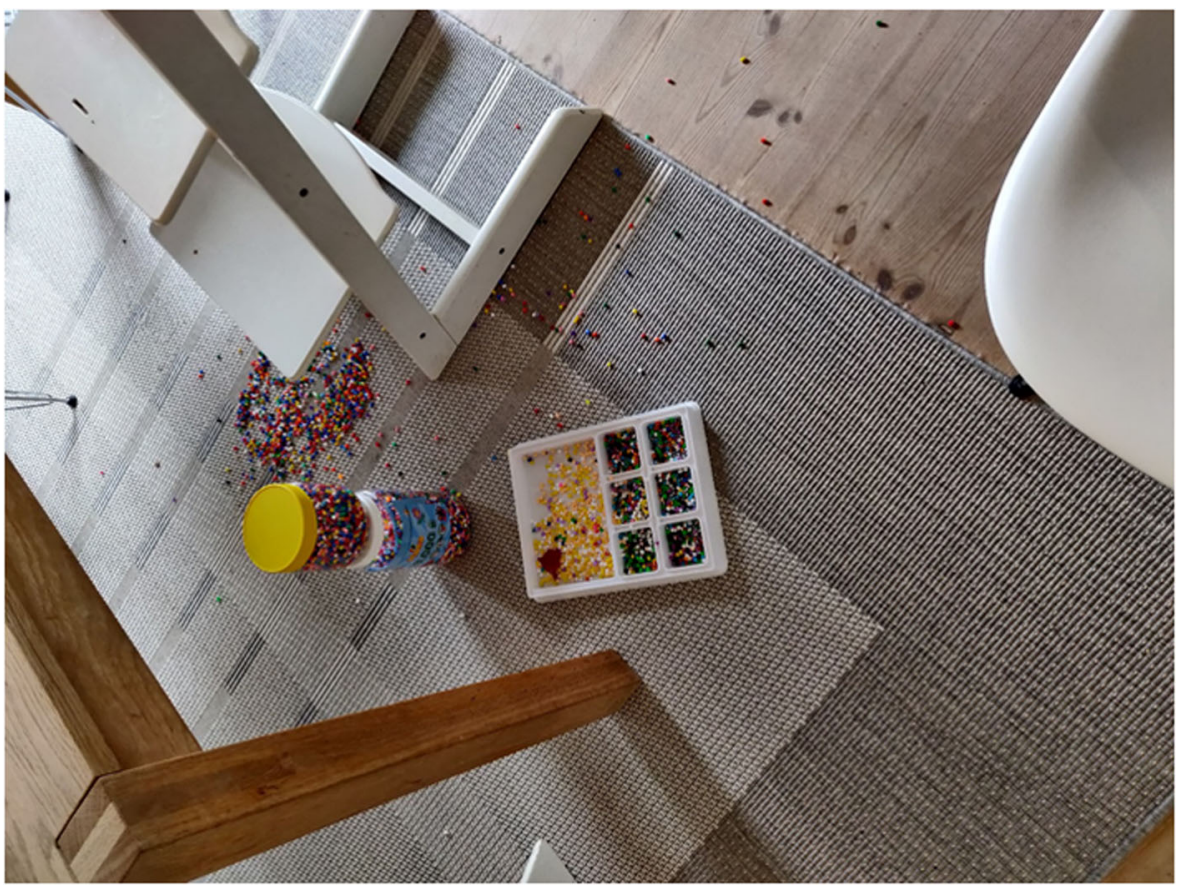

Fig. 6 This is my workspace in our living room. The space is also shared with the kids $;$

\section{Pandemic Exacerbates Inequalities}

Lilia D. Monzó, Orange, CA, USA, 20 March

Lilia D. Monzó is Associate Professor of Education at Chapman University. Lilia draws on Marxist-humanism and critical pedagogy to engage questions of social transformation and liberation.

My days have certainly been turned over as a result of the threat of Covid-19 and the local and state responses to contain the spread. In California, it has just been estimated that 56 percent of the population will get the virus and all but essential businesses (grocery stores, hospitals, pharmacies, banks, take-out restaurants) have been closed down. We are urged to remain home as much as possible. Chapman University has gone online, and faculty, students, and many staff are urged not to come to campus at all. My son is home; all K-12 schooling has gone online. Unlike university classes that actually meet virtually, his schooling has become a series of assignments that he can complete in a couple of hours a day. At 15, I worry about the effects of social isolation on him, when he has not been with anyone other than his parents for close to two weeks now, and is spending much of his time watching TV and playing video games. My husband is a physician so he continues to go to work daily.

My daily worry is for my parents who are 80 years old and living in a lowincome urban community, with its common socioeconomic conditions of 
overcrowding and food deserts. The many doctor appointments they have to manage chronic illnesses, including diabetes and heart disease, have been cancelled in order to keep them home and away from potential carriers of the virus. I worry that preventative appointments to monitor any sign of my mother's recurring cancer or the worsening of my father's eyesight, a result of a botched-up surgery for glaucoma, may also be cancelled during this time. I worry even more that the demand for social isolation may lead them to depression. At their insistence, my sister and I continue to visit separately once per week, leaving behind our children and husbands to minimize my parents' exposure.

And still we have it very easy in comparison to many. In the USA, class significantly mediates exposure to the virus, the social and economic impact of social isolation and business closures, and access to health care. Our salaried positions and ability to work online reduce potential economic risk. Those with middle-class incomes or above are stocking up on foods and necessary items. Grocery stores are finding it difficult to keep their shelves stocked with meats and toilet paper. Low-income communities, many of which are Communities of Color, like that in which my parents live, are especially facing shortages of needed items due to the population density.

The majority of workers whose pay is based on hourly wages and whose work cannot be done online or at home are facing an economic drain and worry that will increase as the weeks go by in social isolation. Many of these workers do not have the benefits of paid vacation time or health care. They are being forced to stay home without pay. Those working in the informal market, as street vendors or day workers, are usually living day to day and have no access to unemployment or other social benefits. They will soon find it difficult to pay their apartment rents, cars, food, and other necessities. School closures especially negatively impact low-income children whose parent(s) may not be able to stay at home to care for them and who may need the free and reduced lunches they typically receive in schools. School districts, including the one my son goes to, are providing free 'grab and go' breakfast and lunch to the children who need it at various locations throughout the area the district serves (Plachta 2020). However, this does not guarantee complete access, especially for children who may not have anyone at home to care for them, if parents are able to continue working.

Most exposed and affected are the homeless who have little access to handwashing and clean clothing. Those who seek out shelters are also at significant risk since these are often crowded spaces where people come in from the streets to eat and sleep and whose risk of exposure is high. The issue of what to do with the homeless to ensure social isolation, for both their safety and the rest of the population, is of critical importance (Oreskes et al. 2020).

Activists are of course wondering what this all means for the important political work that we do. The demand for social isolation and fear have put a legal halt to protests and even meetings, but for the most vulnerable, the economic conditions they face are likely to become worsened in a system that does not care for its neediest populations. Many of these activists, a majority of whom are People of Color, but also working-class whites who live economically precarious lives, plan to continue to meet and organize, believing that while the virus is of grave concern, economic justice (and therefore racial justice) is perhaps a greater and long-standing necessity. Others are moving their organizing efforts online and wondering what these changes may mean to how we continue our work for social justice. 


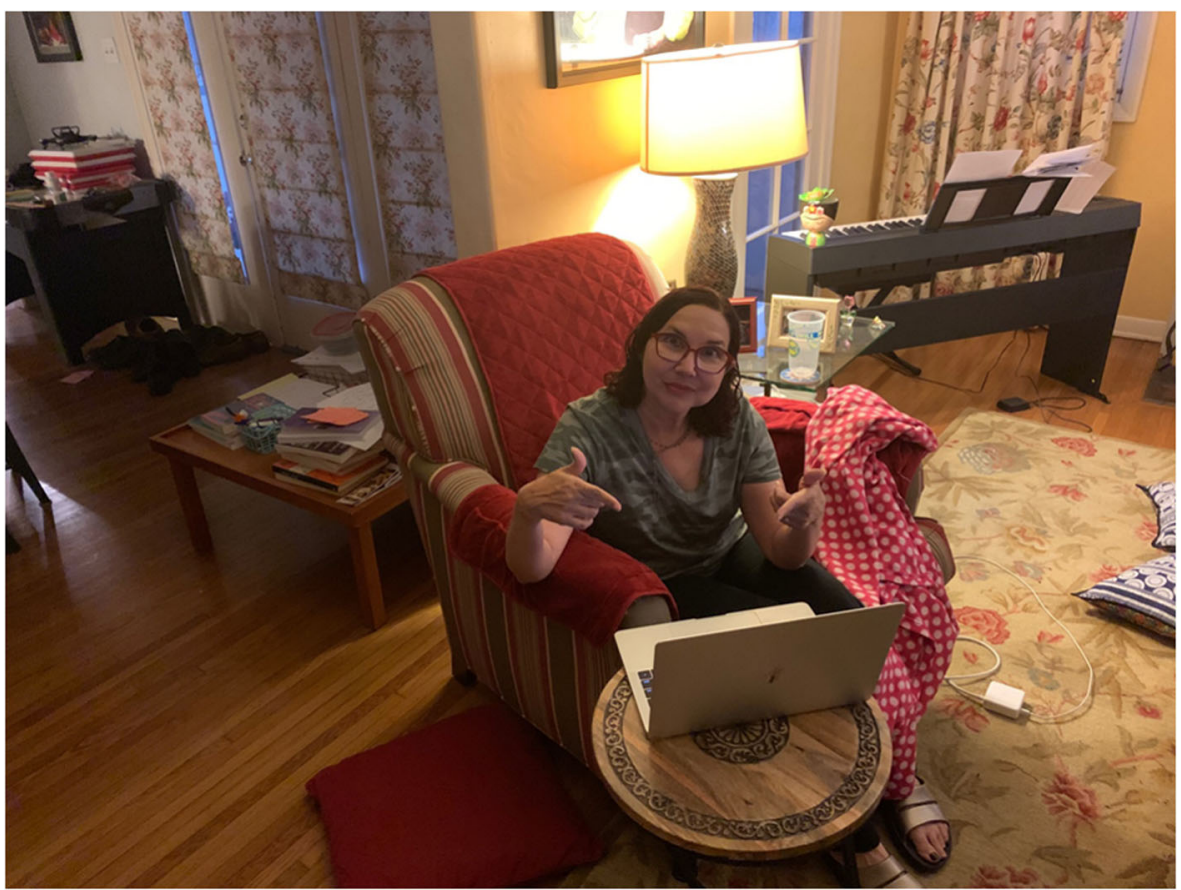

Fig. 7 This is my workplace in our living room, where I zoom with my classes, advisees, and committees. My partner and son take to their rooms so that I may have quiet

\section{Untitled}

Quaylan Allen, Orange, CA, USA, 20 March

Quaylan Allen is an associate professor in the Attallah College of Educational Studies at Chapman University and Director of First-Generation Programs. He lives in Southern California with his partner, two children, and dog.

I am writing this testimony on March 20 from my home in the USA, where Governor Gavin Newsome of the state of California has recently ordered a state-wide lockdown in order to contain the spread of the Covid-19 coronavirus. Chapman University, where I am an Associate Professor of Education, had already responded to rising concerns about the spread of the virus and made the decision early to move all instruction online beginning March 12. Students living on campus were strongly encouraged to move back home if they could, and the university would refund their fees. In response to the governor's announcement of the state-wide lockdown, the university decided to run all operations virtually and only have essential staff present on campus. The president of the university communicated that instruction would continue but in a virtual setting, but cautioned that we should all be reasonable in our expectations.

This rapid shift to online instruction has placed many faculty in a bind, depending on their educational technology expertise and the type of content they were teaching. I have converted both of my education fieldwork classes into virtual classes, which required 
significant modifications, since students are no longer working in the field. The class will now focus on using digital tools to study the community of the fieldwork site and put our findings in conversation with relevant literature. The closure of elementary schools also impacts my own work schedule as both of my children are now being schooled virtually, and my family must now balance this new schedule of concurrently working, schooling, and parenting. The rapid shift to online instruction has further exemplified the many educational inequalities that exist in education. Many students across the country lack access to home computers and reliable Internet provision, and rely heavily on many of the social services that schools and universities provide (e.g., food, health care, safety, etc.).

Currently, I feel angst regarding the health of our world and the spread of the virus within the current global political climate. I'm angered by the continued racist rhetoric that comes from the President of the USA towards China and people of Chinese descent. His reference to the virus as the 'Chinese Virus' stokes fears of the racialized other, and attempts to create a villain in the midst of a pandemic that impacts us all. I'm also curious about how the pandemic will change the way we conduct schooling. It's clear that the rapid conversion to virtual schooling and work, and the development and refinement of digital tools to help us accomplish this reality, will create new possibilities and reveal new challenges in how we educate students at all academic levels. Finally, I am cognizant of the rarity of this moment, where we are all asked to stop and remain still, which is unprecedented in a capitalist society where production is often pursued at all costs. For this, I am grateful for the opportunity to stop and connect with those around me even in the midst of this global pandemic.

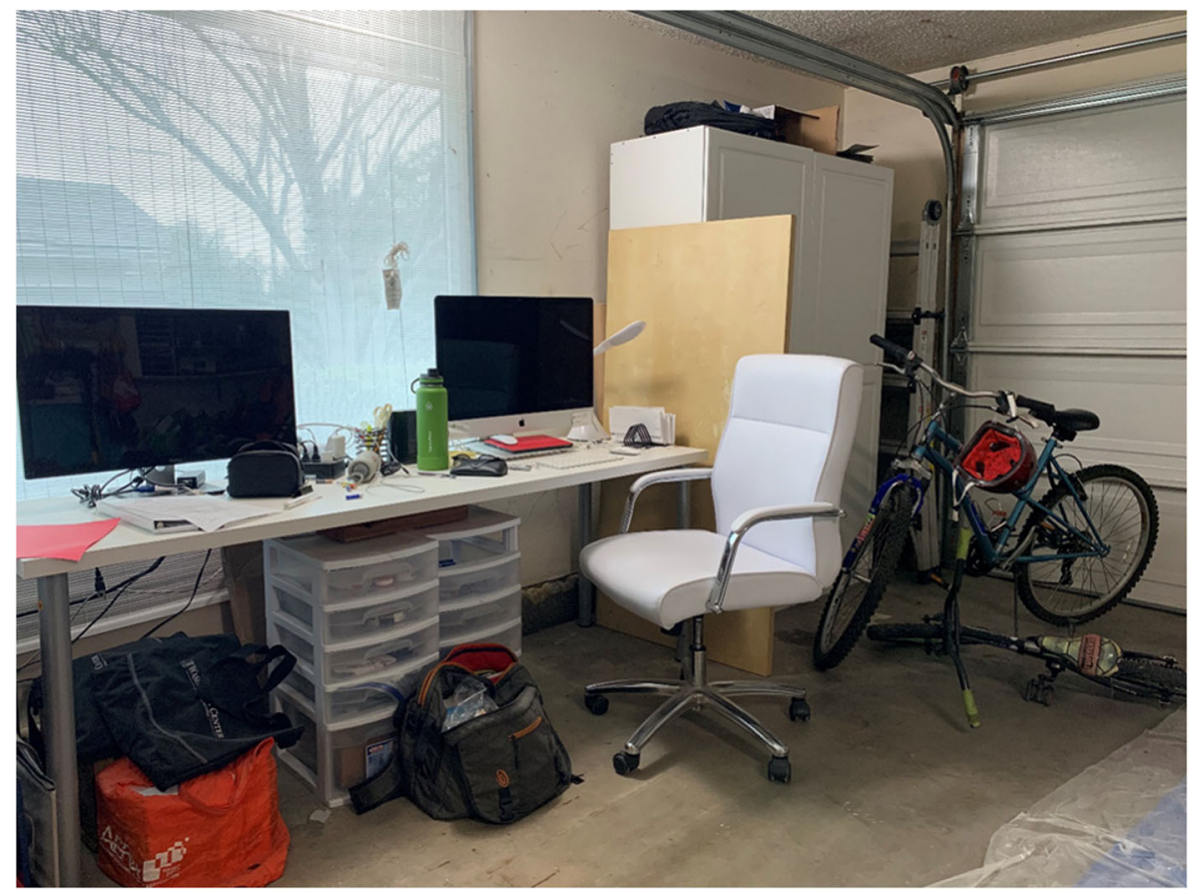

Fig. 8 I typically work in my office on campus. I am now using my garage as an office and share the space with bikes, laundry machines, and exercise equipment 


\section{Untitled}

Paul Alexander Stewart, Gateshead, UK, 20 March

Paul Alexander Stewart is an artist and lecturer at MIMA School of Art and Design, Teesside University, UK and co-founder of the Middlesbrough Art Weekender, and runs Bad Spirits with Dawn Bothwell. Paul is 29 years old and lives in Gateshead, England, with his partner who is due to give birth to their first child in June 2020.

I write this testimony from my spare room in Gateshead, England. Both my partner and I are working from home; she is currently seven months pregnant, and we will probably welcome our beautiful daughter to the world by the time of publication. It is a Friday and I am trying to understand, or at least work out, how to use Microsoft Teams, and how to make a podcast to deliver a meaningful teaching seminar for Monday. It's much more difficult than I had assumed, even the location for a video call-do I do it in the living room or in front of a book case? The students will see my private space, my home-where is neutral and public in my home?

I work full time at Teesside University and co-run the BA Fine Art course. It has been weeks of extreme stress and planning to fathom how to deliver a practical, studio-focused learning experience through digital platforms with minimal or no access to materials or workshops for the production of any further art works. This may not be fully possible in the same way as we do when physically together, but one exciting element, for me personally, is how to reconsider a degree show and an art public experience in digital and virtual space away from the gallery? What does it look like, smell like, feel like-will it just end up being a PDF or will it be something more? The university has taken measured steps based on the government's advice, our team has pulled together and our priority is our students and protecting them the best we can. At the minute I am expected to work as normal from home, to teach, to attend meetings remotely, to do my research and so on (all of which are constantly interrupted by my cats). The one funny thing I have realised is that all those meetings that could have just been emails are finally just emails.

I have only broken down or felt the emotional toil of the circumstances twice so far, and it has not been due to work; it has been from trying to buy cat litter but having to visit 7 shops to find 1 bag due to panic buyers, and the other time was in realisation that we will be having our daughter in quarantine from our friends and family, in a physically isolated existence. This is a new world we are entering, and my hope is that we find ways to be social and together again, it is not the amount of time that separates us physically but how we continue to connect and share our lives, knowledges, experiences - this is what matters. 


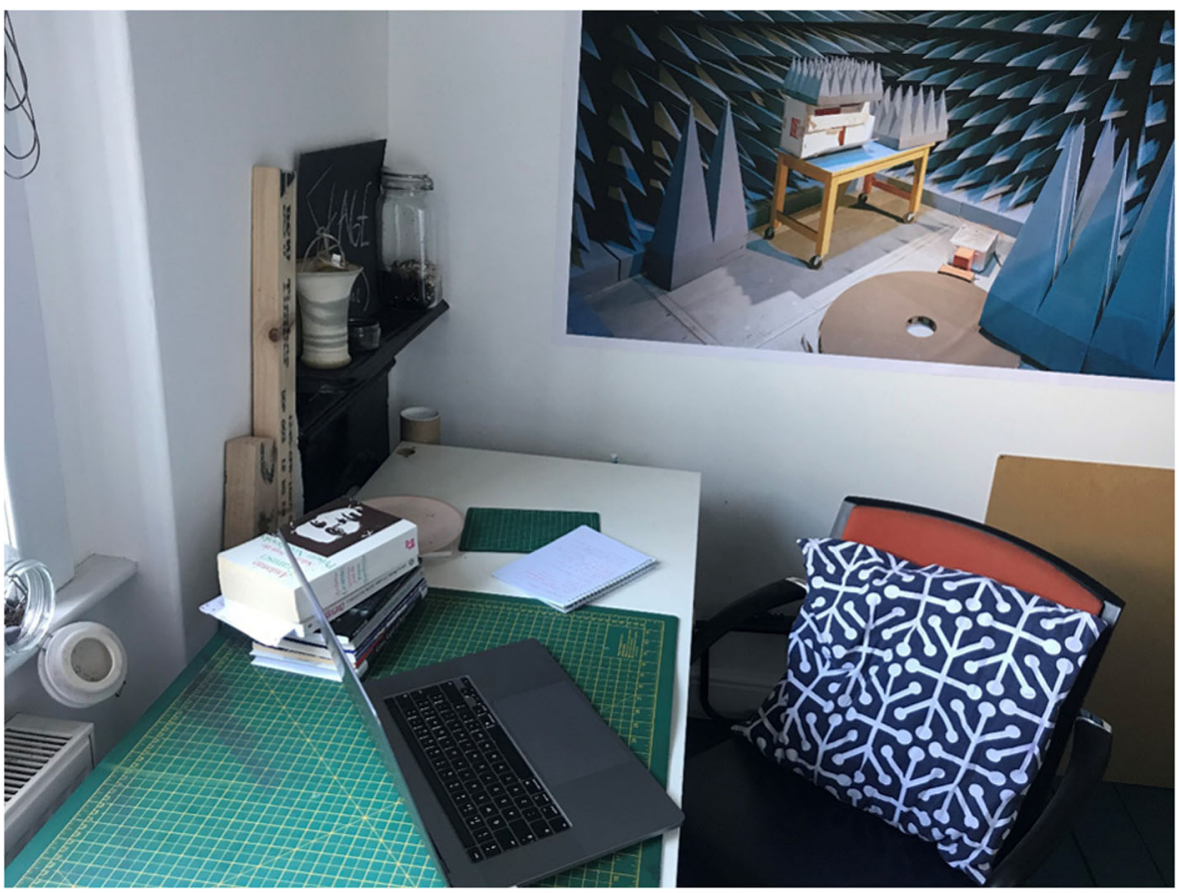

Fig. 9 This is my workspace in our spare room; it doubles up as a bedroom and also will become our nursery

\section{Attempting to Make Sense of Global Confinement}

Paul R. Carr, Montréal, Canada, 20 March

Paul R. Carr is a full professor in the Department of Education at the Universite du Québec en Outaouais, Canada, and is also the chair-holder of a UNESCO Chair in Democracy, Global Citizenship and Transformative Education (DCMÉT). He lives in Montréal with his partner, Gina Thésée, who is a professor at the Université du Québec à Montréal.

$$
\text { **** }
$$

I am writing this testimony from home, in Montréal, self-distancing, not interacting with the outside world, beside my wife, who is in the same position, as her university, and all other schools and education institutions here, are closed until the end of March as a first step. Everything leads us to believe that the suspension of professional, social and leisure activities will continue for some time. Today is March 20, 2020, the first day of spring, re-birth, the change of seasons for us in Canada.

I am a full professor and the chair-holder of the UNESCO Chair in Democracy, Global Citizenship and Transformative Education (DCMÉT) at the Université du Québec en Outaouais, roughly two hours from Montréal in Gatineau, which is part of the nation's capital with Ottawa. My university, like others in Canada, is closed for the next several weeks. There are almost daily communications and directives about 
what we should be doing at the health and security levels and, of course, in relation to academic responsibilities. We are not permitted to enter the university at this time, classes have been suspended, meetings have been cancelled, and there are some activities that are ongoing but there is a lot of grey area about all of this at this time. There is a lot of discussion about distance education and concerns about being able to complete this academic semester. The university is following the rapidly evolving events like everyone else, and is also responding to, and implementing, measures announced by the provincial and federal governments. The faculty union is also offering constant and extremely pertinent information about our teaching, supervision and research responsibilities.

I have been working diligently for the past five months on an international Symposium of the UNESCO Chair DCMÉT, which was to take place in late May 2020, and we have just cancelled it, like all other academic events/ conferences/meetings for the near future. It is hard to prioritize academic and research projects at this time. Although extremely engaged and passionate about my research life as well as my relationships, collaborations and interactions with colleagues at home and abroad, in addition to the students with whom I work closely, I'm questioning what it is all about. What was important yesterday does not seem to be so today. I'm not a pessimistic person, nor am I fatalistic or alarmist, but I am extremely concerned about how many people may ultimately fall victim to Covid-19. I am also increasingly ruminating about how disproportionately the vulnerable will be affected, and how social solidarity is simultaneously our greatest hope as well as our phantom nemesis. I am concerned about people close to me contracting the virus, and am also concerned about anyone being enmeshed into this dystopian web of invisible contamination. I am doing lots of things I normally do not have a lot of time for, such as writing poetry, reading stuff far outside of my academic interests, playing the drums, cooking some exotic dishes (at least in my mind) and talking on the phone to family and friends. My research projects have not been dropped but I am having some trouble prioritizing them at this time.

I am surprised at how much I am reading about Covid-19 as well as watching videos, reports and programs on this health emergency/catastrophe. I am also really interested in the political economy of how everything is playing out. Social media, a central area of my research, is an incredible laboratory through which to understand what is going on. I am also overwhelmed by the attention paid to the economic context-overlapping with insane reports about the toilet paper shortage - that some decision-makers, corporations and labor sectors have focused on, almost exclusively, at this time. I have been following with extreme interest how militarization is continuing in some areas, and how some countries, such as Cuba, are exemplifying true solidarity despite limited resources but with exceptional vigour, tenacity, expertise and care. I'm concerned about the environment, about social inequalities, about the Global South and many other things, and I cannot stop thinking about how education is not a full part of the equation of building critically engaged social solidarity. I do not mean this to seem too academic as I believe that this is the key to ending the transmission of the virus, and, importantly, to building a more resilient, decent and just society. 
Although there are efforts locally to diminish and stop the propagation of Covid-19, I cannot help but think of this emergency in the same way that I would consider the environmental catastrophe that we are facing: this is a global problem, necessitating global resources, engagement, education and solidarity. Re-imaging our political and economic systems needs to take place, if not now, soon. Lastly, the numbers are increasing everywhere (although it looks like, for today anyway, that South Korea and China have started to slow down the trajectory), and there is a lot of uncertainty in my mind and heart as to when and how this will end. I send my solidarity to colleagues around the world.

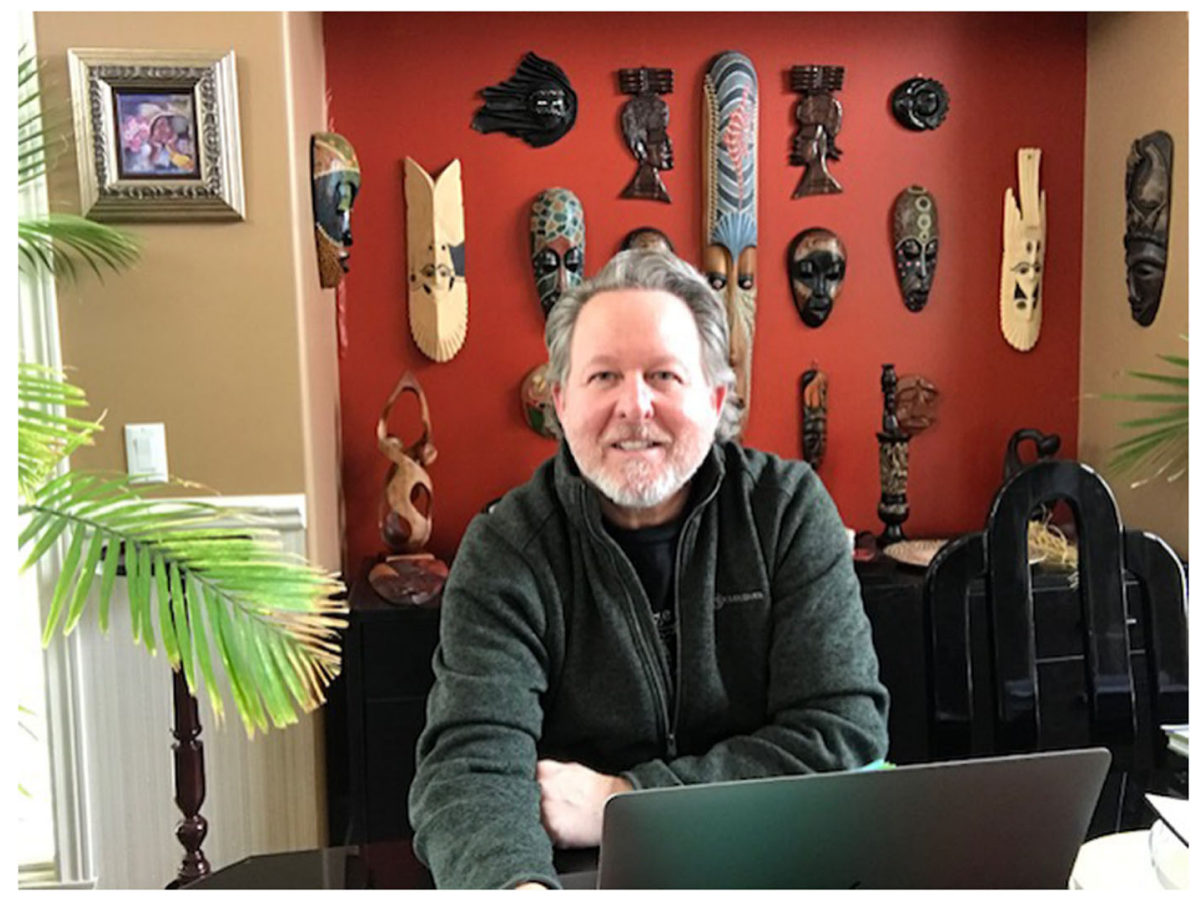

Fig. 10 This is my workspace in our living room, where I drink tea, engage in Zoom/Skype video conferences, discuss life with my wife and try to interpret/address everything that piles up in front of me

\section{Debating Face Masks in Hong Kong}

Liz Jackson, Hong Kong, 20 March

Liz Jackson is associate professor at the University of Hong Kong and director of the Comparative Education Research Centre. Liz is also currently the president of the Philosophy of Education Society of Australasia.

Covid-19 hit Hong Kong in mid-January, coinciding with the beginning of the semester. After the past semester ended in turmoil and classes were cancelled due to the protests 
(Jackson, 2020), I was eager to see students again. At the same time, academics speculated about whether students would return. Protests were ongoing. Normal winter flu was surfacing, as well as a novel coronavirus. The Chinese New Year would start soon, which usually sees many students leave campus for a few weeks to visit family, often in the mainland. Given these factors, my colleagues and I wondered whether students would show up.

So, I was surprised and delighted when 35 students (30 enrolled and 5 hopefuls) arrived at my class on Professional Ethics for Educators. Many wore surgical masks, but this is not a strange sight in Hong Kong in winter. Usually it means one is recovering from a cold or flu, or anxious to be around others who may be unwell. As a greeting, I asked the students how they were and whether they were planning to travel to the mainland for New Year, which could impact my classes. When the students shook their heads no, I showed relief - 'phew!' - to many giggles.

As the class proceeded, I explained the difference between moral and nonmoral judgment, and gave time for students to develop their own examples. As we went around the room, the first student example was given: 'You should wear a face mask'. This was a novel example for me despite teaching the class several times. In place of a clear-cut discussion, I felt obliged to discuss grey areas in this case. I was not wearing a face mask that day, and I did not want the discussion to shift into judgments of students not wearing masks. Was it an esthetic preference, a culturally relative judgment, or a moral judgment? I tried to move the class forward, aware that coronavirus and scientific judgments on mask use were still being discussed in small groups.

By the end of class, many more students were wearing masks. 'Were you convinced by your peers?' Yes, they nodded. They were persuaded by one another.

A week later, we received an email from the university: There would be no in-person classes in February, ideally returning to campus in March (since then, we have moved fully online for the term). Another email: No one should go to campus. If you do, wear a mask.

I proceeded with online lectures in those weeks, returning to the topic of masks, which had flourished in society since our discussion. Does wearing masks lead to scarcity, risking the lives of health professionals on the frontlines? Is it a cultural preference, based on the local experience of severe acute respiratory syndrome (SARS)? Does it support the welfare of all, particularly for those working in crowded places (e.g., schools) and traveling on public transport? Or is it a symbol of solidarity and community care?

I also debated mask use with colleagues. It has since become a topic of global conversation, and a reference point in the cultural politics of Covid-19. Has Hong Kong done so well with the virus due to mask use? Maybe. Is it due to a culture of Confucian obedience? Hardly! Before now, masks were a sign of the anti-government protests. Masks were banned in January, and my students were judging me on the first day of my class! Is it a communitarian ethic? Maybe... and so on.

Later in the term, I got a reusable N95 mask. While the international community continues to debate, it indicates to those around me that I care about them, take responsibility for my actions, and am part of the unfolding local story of managing this crisis with calm and rationality. 
Since that first class, I continue debating with myself whether I should encourage my students to dwell on the case of mask use, compared to other topics in professional ethics for educators. As I would not wear a mask at home while recording lectures, they do not yet know of my personal change in heart. If only my students could see me now.

\section{Two Months In}

Susan M. Bridges (nee Hawthorne), Hong Kong, 20 March

Susan Bridges is an associate professor at The University of Hong Kong who teaches qualitative methodology. Her adult family has been separated between Australia and Hong Kong due to Covid-19 border closures so they started enjoying weekly 'zoom wine tastings' with dad as Sunday night sommelier.

This poem is my personal account as an Anglo-Australian expatriate resident of the Hong Kong Special Administrative Region (HKSAR) working in academia during the Covid19 global health crisis. I often refer to myself as 'bi-located' between my two homes of Hong Kong, China, and Queensland, Australia. Living and working near the epicenter of the virus, my family and academic colleagues in Hong Kong had adapted to the "new normal' practices of partially closed borders, social distancing, self-isolation, forced quarantines, online learning, and working from home. After two months, Hong Kong had managed to contain community spread while we tracked with growing dismay the escalating cases as the contagion impacted on home countries across the globe. In March 2020, many residents returned to the HKSAR with public outcry over cases of breaching self-quarantine regulations. Simultaneously, the expatriate community was criticized for their lack of adherence to public health recommendations regarding social distancing and the wearing of face masks. Both the influx of returned citizens and the nonadherence to local norms have been attributed to our recent spike of new cases. This poem shares one academic's account of life with Covid-19 in March 2020.

\section{Two Months In: Covid-19 in Hong Kong}

Focus shifts, wanders, skims and dives into streams and threads of lives and countries in disarray

Bi-located is now bifurcated waiting to be shattered

Eyes prick, ears buzz, neck aches in sanitized comfort

We are 'expats'; white immigrants in our 2nd home

Circles in the water from the heaviest stone expand and engulf:

China, Hong Kong, Gold Coast, Townsville, Brisbane, London

2 months in and our 2nd wave becomes their first

Alert family (try not to frighten)

We are 2 months in and we have worked through the stages

But now the ripples wash back, friends are enveloped

Our 2nd wave brings us closer to the contagious spread

Folksy aphorisms, 'stock up supplies for 14 days'

We are 2 months in and I wonder when this will ever end 


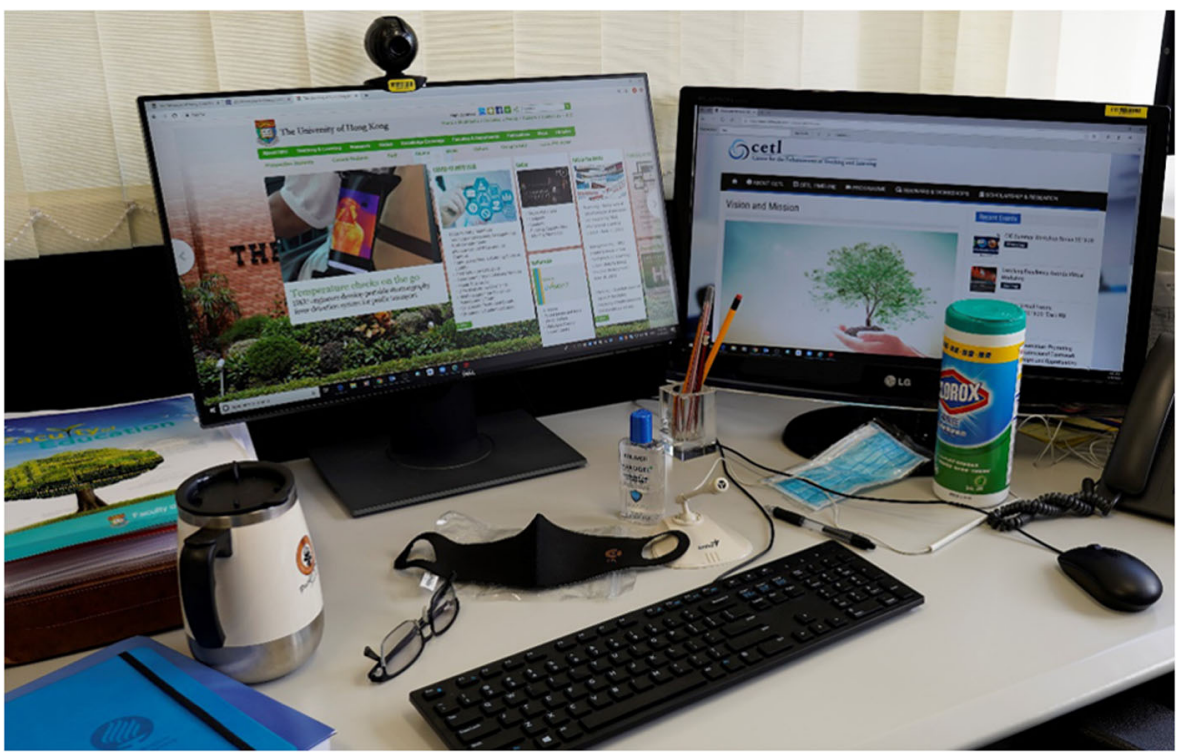

Fig. 11 On my return to campus, new workspace features include an extra microphone, facemasks, sanitiser, and disinfectant wipes

\section{Applause from Windows}

Carlos Escaño, Seville, Spain, 21 March

Carlos Escaño is an associate professor of art education at the University of Seville, Spain, and visiting professor at UNED, Spain. He lives and works in Seville, but also lives and works on the Internet.

Seville. Spain. $50 \mathrm{~m}^{2}$ of space for creative freedom. A computer. Network connection. That's my space of action during the days we have been in corporeal isolation (and presumably these are just the first of many more days of isolation to come). A context very similar to so many others. Spain has closed its borders and doors of every house. We are in a state of alert. The University of Seville, my main employer, has digitised all work. We are in a state of alert to the other one. We are all suspected of contagion, whether we have Covid-19 in our bodies or not. The article 116.2 of the Spanish Constitution allows the government to declare a state of alarm when serious national disturbances related to disasters occur. The only precedent in democratic Spain was the 2010 air traffic controller crisis, which affected more than 600,000 people and burnt an economic hole in the tourism sector. The second state of alarm in Spain is the coronavirus pandemic. That state of alarm goes beyond the tremendous economic crisis that is supposed to start. That state of alarm affects people and their social relationships at an international level. That state of alarm makes us question relations between our bodies and the bodies of others. It makes us question the needs of individuals in relation to our affections, professional ties, sense of solidarity, and current governmentality. 
These days, the weakness of our physical nature in the face of a viral pandemic is evident. Days of reflection on the essential needs of a globalised society, which is based on the omnipresent law of laissez faire competition and the idea of the self-made man. A framework of action defined by the neoliberal ecosystem. But these days, the need for cooperation and solidarity has overshadowed patterns of individual competition. Public health services, those safeguards of our society, have become more visible than ever. Every day at 8 p.m., a moving applause can be heard from windows and balconies in every neighbourhood of every Spanish city. With this window applause, citizens pay tribute to the corps of health workers at the frontline of the pandemic. Community and public services are now clearly perceived as necessary goods, which generate group and individual strength. The state of alarm alerts us to the need to understand each other as connected bodies, even though we cannot touch each other. Tele-leisure and tele-working are meaningless without the underlying social networks (links between people) and supporting digital networks (links between computers). These links are both digital and analogue-they are postdigital.

I am in Seville, Spain, inside $50 \mathrm{~m}^{2}$ of space for creative freedom. A computer. Network connection. This is my corporeal space of action during lockdown. But corporeal isolation has sounded a very different (and positive) alarm: in the words of Kropotkin (1902), the need for mutual aid. Solidarity made flesh, solidarity made body.

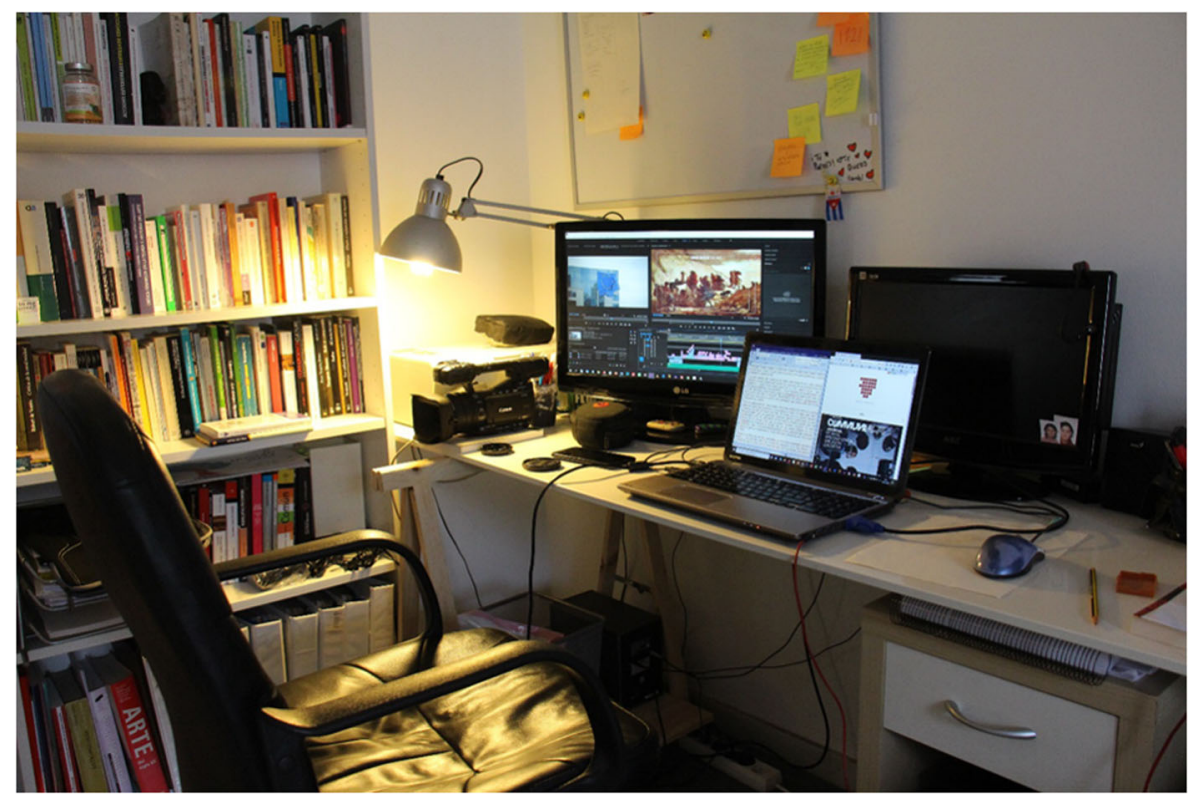

Fig. 12 My workspace, my network node, my main social gateway in these days of confinement 


\section{Dealing with Happiness and Stress at the Same Time: What I Do}

Dennis Grauslund, Aalborg, Denmark, 21 March

Dennis Grauslund is an assistant lecturer at the University College of Northern Denmark, Denmark. Dennis is 30 years old and lives in Aalborg, Denmark, with his partner and two children.

\section{$* * *$}

As I write this testimonial, I am sitting in my home office with a beautiful view on my completely dark garden. It is 21:48 in Aalborg, Denmark, and pitch-black outside. I have been placed here, at my home desk, for the past week - since our government closed down schools, universities, etc., and asked Danes to work from home if possible. By my side, at nearly all times, I have my partner and two small children aged 1 and 4 .

My institution's expectations are clear: we need to continue teaching and researching. I truly empathise with these expectations, yet it is difficult to be as productive as BC (before Covid-19). My family is with me all the time, and even though we work in shifts and through the evening, I struggle to keep up with my own deadlines. So far, I managed to uphold every deadline I had with others, however that will become more difficult as the quarantine continues.

My family's expectations are also clear: we must get the best out of a bad situation. To make work/family life more manageable, we have established a daily routine. Our children are unaware of the crisis and believe that we are on vacation. That places a nice, unspoiled filter over the Covid-19 crisis. It also provides some sort of hope. We obviously spend a lot of time with our children; they are far too young to just read a novel or go outside and play football. We have extended our working week towards Saturday and Sunday, working every day for approximately 5-6 hours. In this setup, we can get our jobs done and we still manage to have nice days with laughter and playtime with our children.

My feelings have been shifting back and forth between happiness and excitement of being with the children, stress and sadness caused by the Covid-19 pandemic, and of course, the downgrade of my research in this new online reality. Students before research, right? A way of coping with this stress is to turn to online academic communities, especially on Twitter. There is something soothing in seeing that I am not alone with my anxiety, and it definitely helps to see many academics helping each other and sharing resources, thoughts, and gentle encouragement. I have heard a lot about the traditional competitiveness of academia, however these online communities challenge old rumours in a very positive way.

Why not turn to colleagues instead? That would be an easy solution, yet colleagues are also overwhelmed by this situation. I do not wish to burden people under difficult circumstances, thus it seems better to turn to online communities. After all, they are eager to help. 


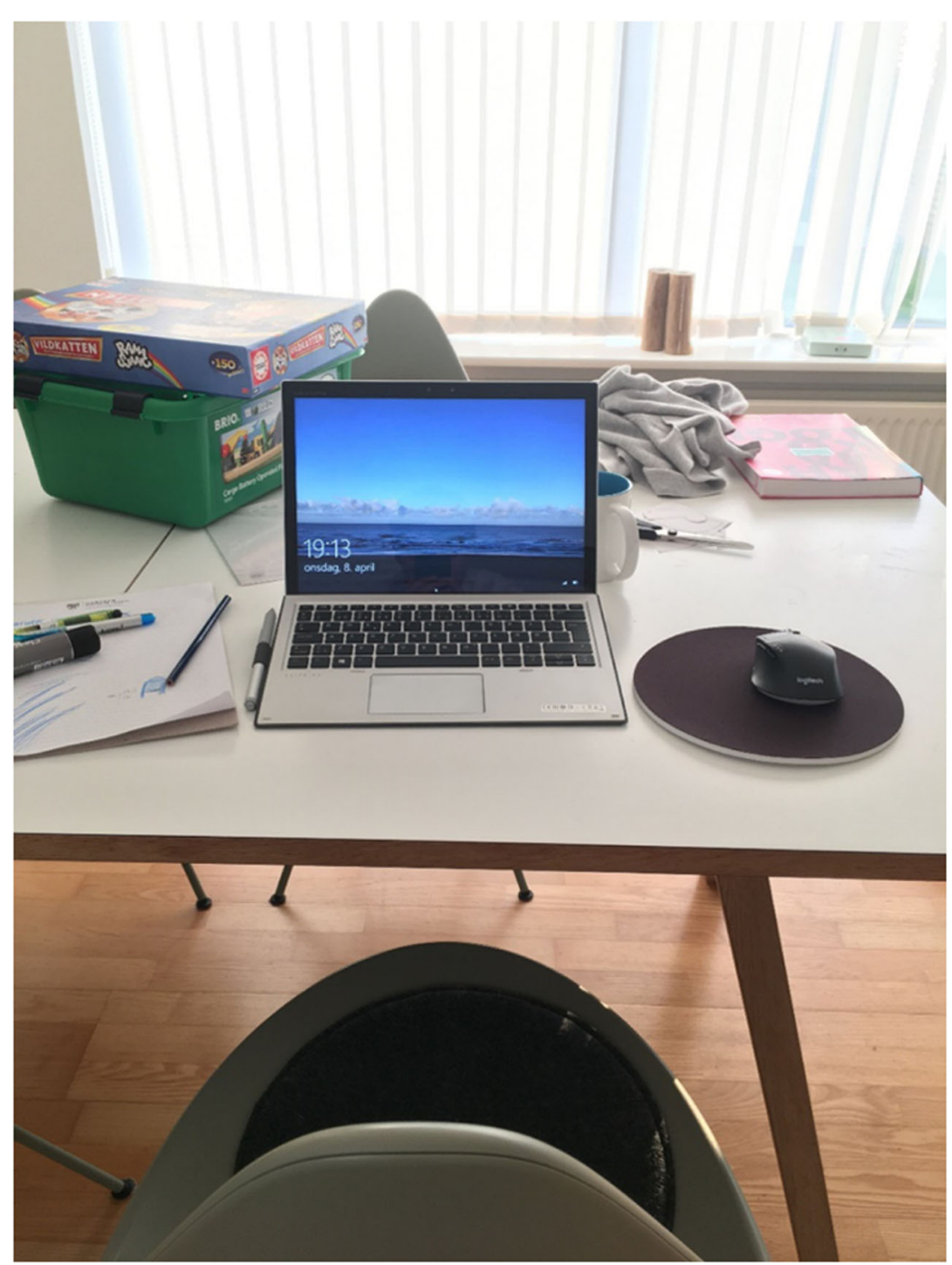

Fig. 13 This is one of my workspaces, placed in the living room. When working, my family is usually in the other end of the house, but when taking a break, we sit together and play or make drawings 


\section{Pandemic Thoughts Against Extended Silence}

Julia Mañero, Seville, Spain, 21 March

Julia Mañero is a $\mathrm{PhD}$ student at the University of Seville (Spain). Her principal research interests are in art education and digital education. She is an active member in Communiars collective through which she has evolved educational cooperation projects in India and Greece.

$* * *$

During these days in which the state of alert has been proclaimed in Spain, I received on my mobile phone a heart-warming poem that shook me and now I am able to connect with these words. Written by Walt Whitman, one of its verses reads:

Do not make the worst mistake:

silence.

Most people live in awful silence.

Do not resign yourself.

Finishing a $\mathrm{PhD}$ and teaching college classes remotely are not the most motivating tasks when one seems to be immersed in a dystopian reality. Seville is asleep, apparently. No one is allowed to leave house except for basic needs or medical emergencies. Restaurants, shops, educational institutions, hotels... practically everything is paralyzed. Numbers of dead and infected people increase considerably by the day, and in the same way increases social panic. Economic crisis. Hospitals overflowed. Layoffs and temporary suspensions of employment. These are fresh news that occupy the media, displacing other emergent global issues such as climate change and refugee crisis.

I am trying to stick to my tasks and develop a routine, but there is no longer a need for rushing and lack of moderation. Social isolation incites us to pause, think, and reflect. What kind of society do I want to be a part of? I firmly believe that this unprecedented situation clearly shows the human condition. On one side are those who take advantage of the free market, negotiate with health, and charge excessive amounts of money for facemasks and antiseptic soap. On the other side are those who act collectively, refresh ways of living and being in a community, and acknowledge the importance of the social as a meeting point with ourselves and others. Activist actions are taking place from our windows, balconies, and rooftops: messages of encouragement, applauses of gratitude, collective games, and even protests against the monarchy. Digital environments offer free live music festivals. Solidarity emerges and so does creativity. It has been demonstrated that in common spaces and with a tendency to collaborate, social movements and social change arise.

I do not want to remain in silence. I need to raise my voice. Far from conspiracies and disputes, this global pandemic is an opportunity to discover potentials of collaborative policies, of the defence of the welfare state, of positioning ourselves against privatization and market deregulation. I do not want to remain silent. These social conflicts need to be dealt with, deconstructed and analysed, during lectures. I do not want to remain silent. I want to show my students that their actions can be 
transformative and decisive for the future. I want them to know that momentary solidarity should become a fixed condition in the hearts of the human being.

There are still difficult days ahead. The struggle continues, individually and collectively. Voices and the stories hidden in this struggle have never been so necessary, and that is why we must not silence them.

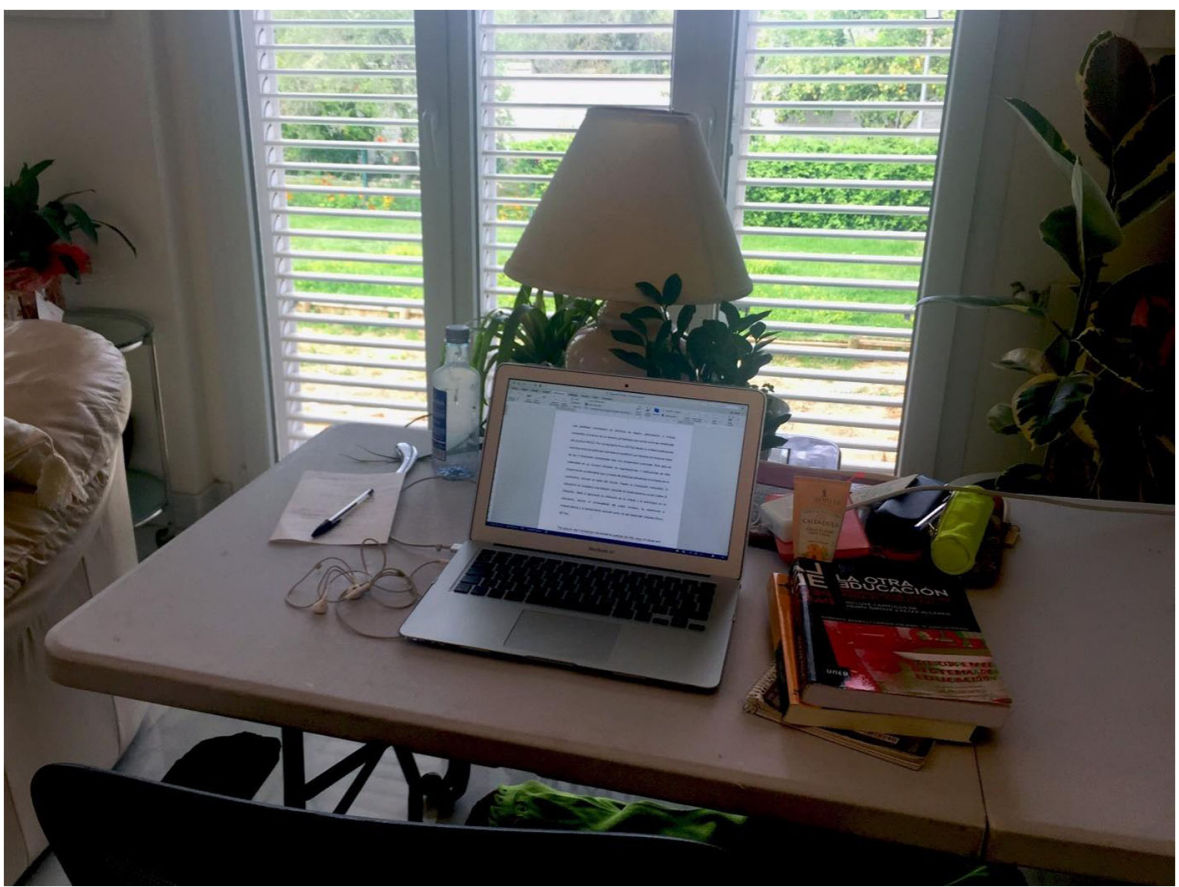

Fig. 14 My home during confinement has not been the usual one, so my workplace has been improvised. A folding table that is compensated with lots of natural light and a view of the garden

\section{Untitled}

Happiness Onesmo Lukoko, Beijing, China, 22 March

Happiness Onesmo Lukoko is a master student, researcher and tutorial assistant at Beijing Normal University, China. Happiness is 25 years old and from Tanzania, and currently lives in China for her studies.

$$
* * *
$$

Covid-19 has brought a total life change to all people around the world. As I write these words on 22 March in Beijing, it has been almost two months I have not stepped outside the university campus. I do not know what is going on outside of the campus environment. As a researcher, tutorial assistant and master student writing my final thesis, the lockdown has affected me in different ways. To strengthen their control over 
Covid-19, the university required students who live in the dormitories not to leave the university unless they want to go home or, for international students, to their countries. Students living outside the university, outside Beijing and abroad should not return to campus without university approval. Furthermore, all students in and outside Beijing are required to submit daily health reports which include measurement of bodily temperature. All non-university personnel are banned from entering the campus. Dormitory visitations and gatherings are prohibited. Going out to the canteen or supermarket, you are required to wear your mask. Temperature checkpoints are everywhere when you leave the dormitory, when you come back, and in the supermarket. People with fever and a cough are sent to quarantine and the medical observation centre. The fear and nervousness of getting the disease is all over us especially when we heard two people were sick around our campus as we go to the same supermarket. Therefore, it does not feel safe.

Dealing with these sudden changes is not easy for a student in a foreign country far away from family. Working in the dormitory is a challenge; especially if you are living with a roommate. She wants to sleep while you want to work and you cannot go to the library or in class because they are all closed. It is even difficult to have some privacy or alone time. I must say this feels like being in jail and it is not easy at all. As a tutorial assistant helping students in their online classes, the network goes bad and there is nothing you can do about it. You want to communicate with a student about an urgent matter and you find out that they are not online. Sometimes you send readings or a video to students and they cannot access the material due to a bad Internet connection. Looking on the positive side, it has helped me to do some exercise and learn new recipes.

My family was fearful at first but gradually they came around. Now I am at peace, feeling that Covid-19 will be gone soon with recent improvements in prevention, especially in China. Beating this disease requires calmness and following all guidelines and control measures given by healthcare specialists such as washing hands with soap and eating healthy food for boosting the immune system. Spreading fake news, non-verified facts, and rumours only adds pressure and panic which should be avoided. Working together, we can get through anything; stay home and stay safe. 


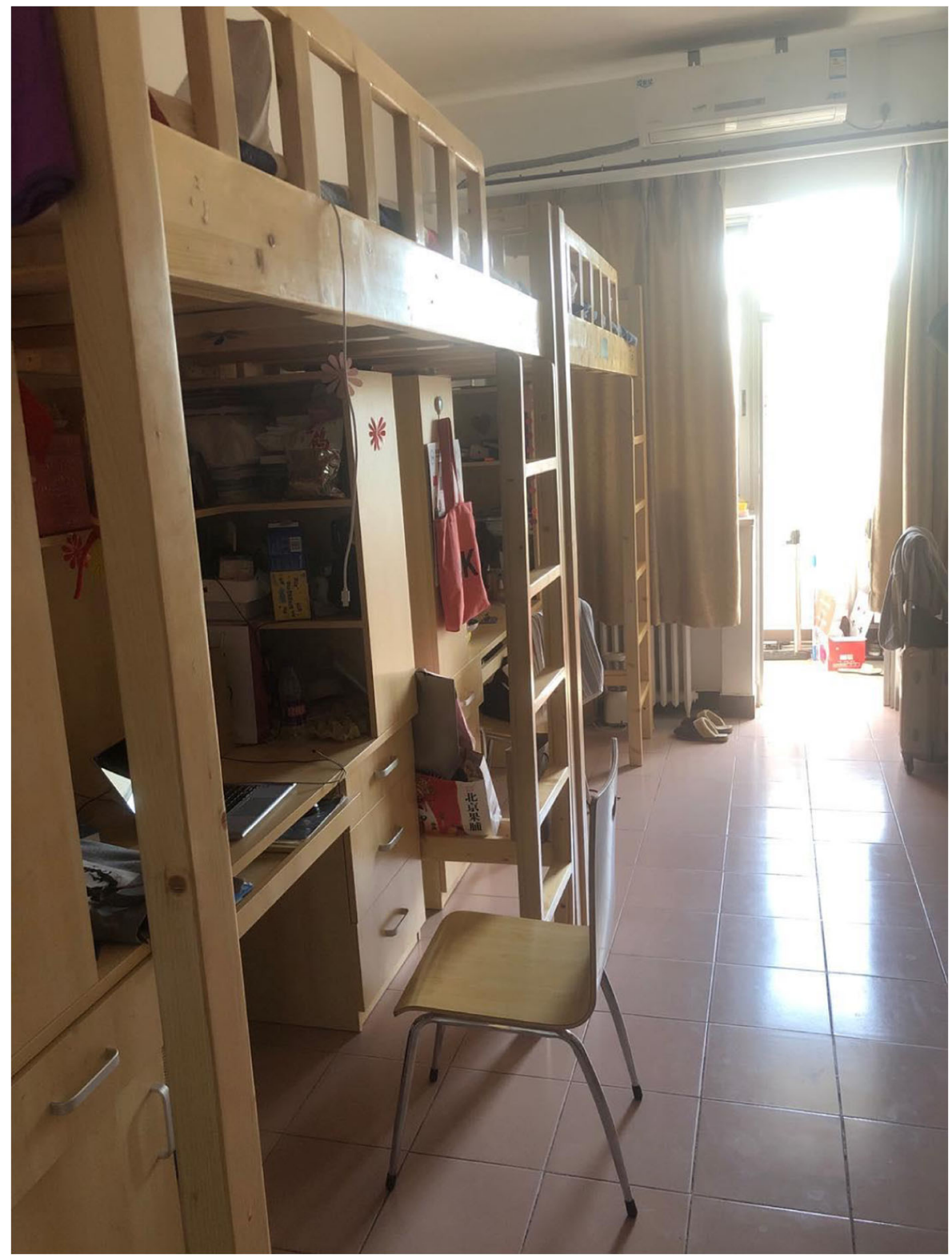

Fig. 15 This is my workspace in our living room where I live with my roommate. This is where I work, eat, sleep, and spend time 


\section{London Still Exists: Resisting the Pull into the New Normal}

Peter Bryant, Sydney, Australia, 22 March

Peter Bryant is Associate Professor of Business Education and Associate Dean Education at the Business School of the University of Sydney (Australia). He recently returned to Sydney after living and working in various universities in London.

$* * *$

London still exists. This line from a song by a Sydney band, The Aerial Maps, has been going around in my head on repeat. I have been locked down in my house in Sydney for the last week after two months of frantic educational problem solving down rabbit holes created by travel bans and rapid escalations of restrictions. Then a week ago, it all changed, and everything went from this messy intersection of normal and coping to the familiar becoming spectres of the imagination. The University of Sydney Business School (where I am Associate Dean Education) went from thousands of hours a week of face-to-face classes to running an entire semester online in less than a week. It seems an entirely unreal experience. That's why I repeat that line. London still exists. This is not and never will be the new normal. This is not a pivot; it is a response to a crisis that no one could have imagined or wished upon their community. Our community, our institutions and our work still exist outside of the rapid changes, the stupid hours and the compromises we are making every day.

In the core of this flame, everyone reacts differently. Some people stand atop their belief that they were always right, that online learning was the way forward for education. 'I told you so!' they claim on social media. Others are beset by fear, for their students, their institutions and their communities. And then there are those taking advantage of the urgency, the unknown and the panic by selling products to a desperate audience seeking help. We have had seven days to prepare finding ways to solve intractable problems of delivering an experience online that was designed for face to face. We have gone through the waves of techno-solutionist rhetoric, the uplifting engagement of the vast majority of staff to make this happen and do it well, and now we are entering perhaps the most important and dangerous phase: reflection. Just responding and acting removes you from some of the deeper considerations of the consequences of your actions, reduces the human trait to find reasons why it just will not work and through the fog and the sleep haze, find solutions coming from the most human of traits: creativity, inspiration and collective wisdom.

Reflection in the midst of all this is a luxury we think we cannot afford. But London still exists. The reason we do education is still there. We have thousands of students whose learning has been interrupted. This is not the future we dreamed of. This is not the way we wanted to do online learning. This is not the way we wanted to make education better. But we have lonely, isolated people on the other end, each with their own mantra. My learning stills exists. My career will still exist. My world and my life still exist. If we remember that there is humanity and ambition at the end of the Zoom chat or watching the recorded lecture, then we have the chance to deliver the quality of learning we and our students need and that can be an inspiration to our learners, our institution and society. 


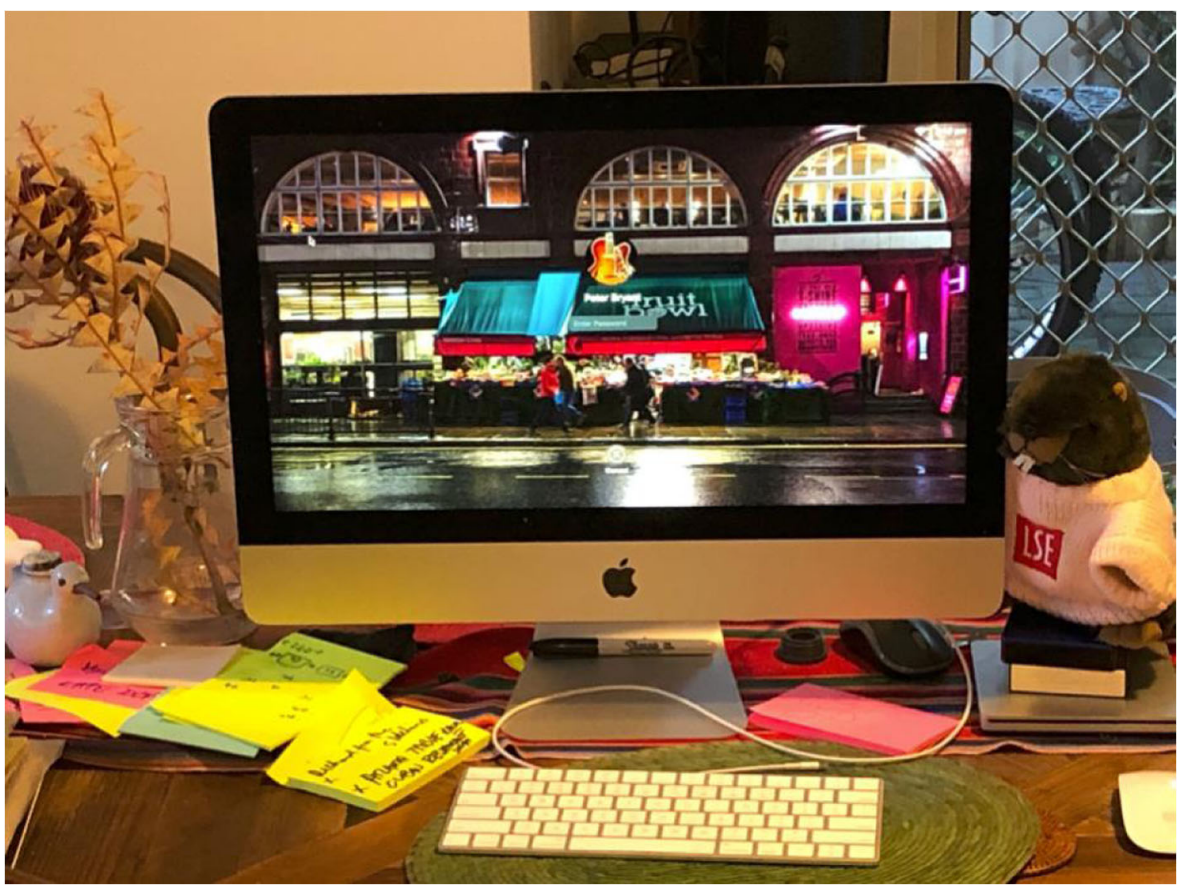

Fig. 16 Working from the dining table, with reminders that London still exists

\section{Mathematics Teachers Embrace Digital Freedom but Fear Exams Ana Fuentes-Martinez, Lund, Sweden, 24 March}

Ana Fuentes-Martinez was born in A Coruña, Spain, in 1975. She is a mathematics and computer programming teacher at Katedralskolan in Lund and a researcher at University West, Sweden. Her investigations concern the new curricular changes in mathematics from the perspective of teacher professional development.

March 24, 2020. Swedish students 15 years old and above have been online schooling for only four days. Compulsory school is still open, but teachers are moving more and more content to their online platforms to cater for a large part of their pupils who are kept at home and to prepare for an eventual lockdown. This testimony reflects the situation of mathematics teachers working in a large high school. They had just a few hours to adjust from the announcement of distance teaching to the next day's morning lesson online. Students were directly sent home for an indefinite time, and most could not even meet their teachers to discuss how their courses would continue.

This is a municipal school and all students are provided with laptops. Most have an Internet connection at home, but I guess some are using their data plans from their mobile phones to follow their class. Directly after sending the students home, the school principal gave teachers a few guidelines to follow: 
keep the schedule, make sure you know which students are participating in the activity, use the platform to communicate, and do not be overambitious-but get ready for a long-distance run. Teachers are expected to be at school and teach from an empty classroom, which most do. Having other colleagues around is invaluable in these times of uncertainty, sharing online material and trying to find solutions for the most crucial challenge that lays ahead: examination. Almost all other teaching activities in mathematics have a nearly equivalent online version with virtual meetings, breakout rooms, web-based whiteboards, and collaborative documents. However, examination in mathematics has been carried out in the same fashion for all of our working lives. Most mathematics problems given in tests have one solution, and teachers need to make sure that students know how to reach it on their own. On top of that, the government has suspended all national tests, since they too face the same issues about plagiarism. This has left an ambivalent sense of relief and anxiety.

One of the positive outcomes that the unprecedented rapid development has brought about is the proliferation of pragmatic digital solutions from each teacher to facilitate their own teaching methodology. The lack of stringent directives and central information system strategies that are otherwise mandatory allows us to choose from among a larger palette of possibilities what we find most compatible with our pedagogical views. Compliance with General Data Protection Regulation (GDPR) might prevent some applications being included in the official information system suite, but these norms are now relaxed, and nobody reacts if the teacher's chosen application requires signing in or if it occasionally shows some commercial banner. This freedom is highlighting what teaching professionalism entails, but it is also making more visible the digital divide among those teachers who feel comfortable with technology interaction and those who do not.

The deepest concern, however, is neither the examination nor the digital affordances, but how students will cope with the new state of affairs. Many lack the discipline to work alone. It becomes difficult to supervise students to see if they are struggling or not paying attention. Wi-Fi connections are strained and home environments are not always quiet. Pets jump around and their favourite YouTuber is just one click away. Parents are doing their best; some of them are also working from home, but not all. In the worst cases, the family might be worried about whether their employments will survive to the next paycheck, and in those severe situations, schools will no longer be able to provide the refuge that they used to. 


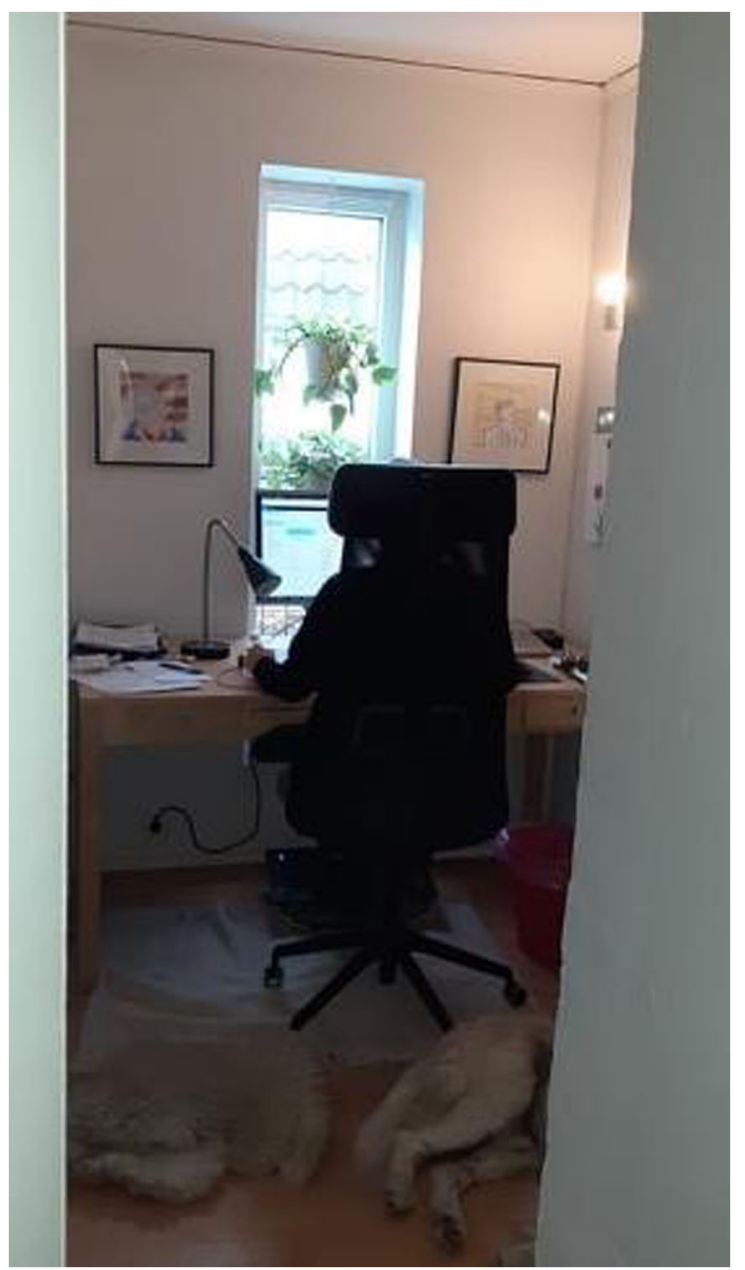

Fig. 17 My workspace was arranged in a former walk-in closet. It is so tiny that the chair needed to be assembled inside the room since it will not fit through the door. Nevertheless, our golden retriever has found his spot right behind me and he seems to enjoy having company all day long

\section{(Fleeting) Notes from the Basement}

Andrew Gibbons, Auckland, New Zealand, 24 March

Andrew Gibbons is associate professor at Auckland University of Technology, Auckland, New Zealand. He has published widely on topics including early childhood teaching, the philosophy of education, the role of technology in education, and the future of the university.

It's Tuesday, the 24th of March. In our national timeline, we are between what the New Zealand Government has categorised as level 3 and level 4 responses to Covid-19. The 
Prime Minister alerted the nation yesterday to the shift from level 2 to 3 , and that level 3 was essentially an opportunity to get ready for level 4 . In level 4 the nation, with the exception of essential services including health service providers and supermarkets, is expected to stay at home for at least four weeks.

With the requirement to work from home for the next month or more, I am writing this from the basement under my ground floor central suburban unit (apartment), where I have an office set up. It's where I already occasionally work, particularly an hour or two of early morning writing from the underground (trying to channel Dostoevsky). I'm now in the process of trying to make it a little more comfortable and more suitable for longer use, and for the month of video conferencing that is already fast filling up my calendar. While it's not a case of business as usual, all my work continues, and I am additionally helping colleagues with any transitions in their teaching requirements having had some experience in working in online-only programmes as well as working with a network of colleagues to provide support for early childhood care and education teachers during the pandemic.

I work at Auckland University of Technology. As far as I know, the university has closely adhered to government guidelines in terms of its operation and its guidance for students and staff. This means that up until the announcement yesterday, the university was open; however, it had suspended face-to-face classes for this one week. As of the 24th of March, the university has indicated that the campuses are closed and the university is very busily working towards creating online provisions for all students (which is what I have offered to help with in part because I do not have any classes this semester). The next semester break has been brought forward to this Wednesday and lengthened from 2 to 4 weeks, which gives students time to acclimatise, and the faculty time to prepare new online-only provisions for their classes. Prior to these decisions, the university had been making swift, unambiguous, and supportive decisions regarding academic staff international travel and the support of international students who had not been able to return from, predominantly, China. Over the last week, one key message from the university was targeted at academic staff who were making their own decisions about whether and how to continue their face-to-face teaching.

I have mixed feelings about this. Making one's own decisions does seem like a good idea (or at least the feeling that one's decisions are in some way one's own); however, I wonder if some of those decisions fail to take into account the impact that they will have for the wider institution. In general, I think the university has responded well in strategy and in the way it has communicated its message. I think that the communications team has done a remarkable job and deserve a lot of respect and thanks. Normally, I think the communications team are too brand focused and narrow minded, so this is a refreshing perspective in these very extreme and demanding circumstances. Similarly, my closer colleagues in the School of Education have responded quickly, positively, carefully, and innovatively. So also, a lot of respect to everyone at the School of Education. (I should point out that I do not normally think the School of Education is too brand focused or narrow minded).

Reflecting on those observations, while the events over the past weeks have been highly stressful, and certainly have contributed to a range of stress symptoms for me (and when altered breathing patterns are both a stress response and a possible symptom of the virus then there's a lot for the mind to manage), there's also lots of opportunity to see the best in people. This is somewhat coincidental because right now I am writing an encyclopaedia entry on 'Tragedy and Camus' with a focus on what we might, 
following Camus' The Plague (1960), learn from tragedy. In The Plague, there's a collection of characters who are observed by the narrator over the months of exile during the plague. The text is rich in observations of what is wonderful about the human condition that I'm seeing lived out at the university — observations that could be seen to speak to a more than human condition, but there's no space here to expand on that, so this point here is more of a signal of the limits of thinking about the human condition but still seeing the importance of the concept and experience.

Are these wonderful examples of the human condition being lived out in the community? Our Prime Minister is urging the nation to be true to its mythical 'kiwi' identity... caring, resilient, innovative, and so on. The reality I cannot help fixating on is the 'panic buying' in supermarkets and more, clambering to get as many food and other seemingly essential stores as possible in order to not miss out on those supplies for the imminent imposed domestic exile. I've been thinking about how this element of the nation's behaviour aligns with the way 'kiwis' drive their cars. The tendency to never give up space on the road, to avoid people getting in front of you in your lane, and to devise seemingly cunning ways to cut in front of people who are waiting at intersections... it all winds me up, makes me feel sad, and leads me to some questions. So now what I am asking, or what I am learning to ask thanks to the teaching of the virus, is in what ways do our education systems implicitly and explicitly reinforce these behaviours? How can this tragedy teach us about how schools and universities produce particular kinds of 'panic-buying' subjectivities? And what can we learn from the wonderful work of our comms team as we move forward in a world of higher education institutions that need not be so obsessed with their world rankings and such. And, finally, on another educational note, I'm hoping this experience helps communities realise just how important the nation's early childhood teachers are, and how they should be cherished.

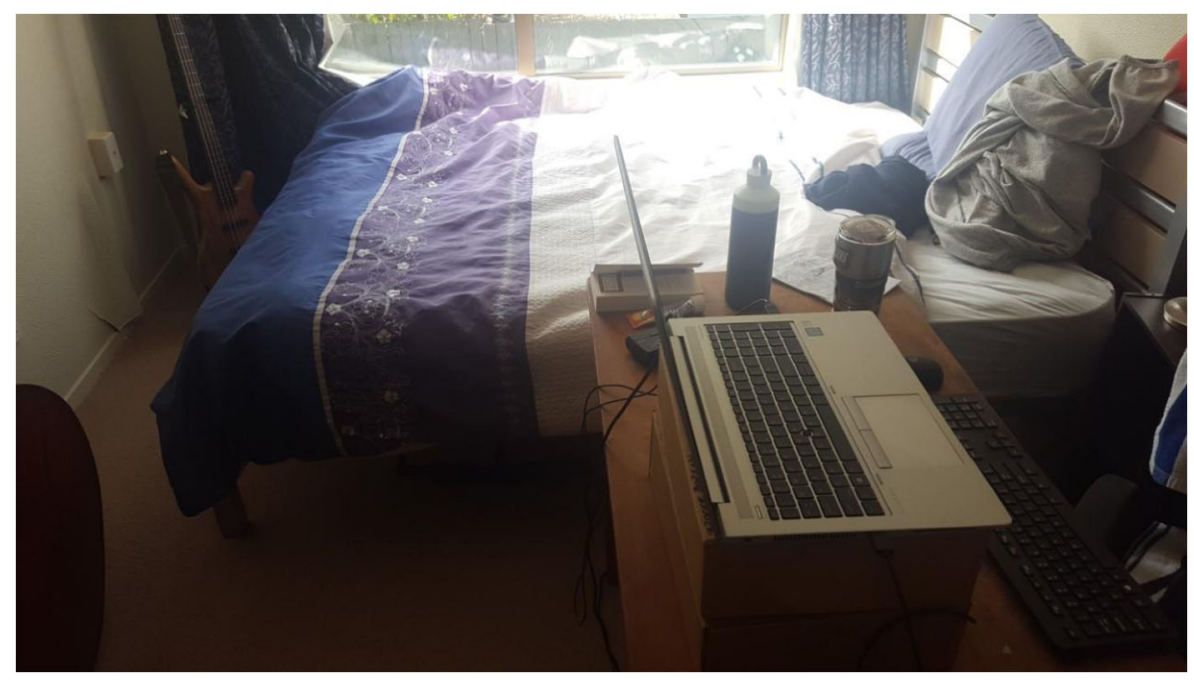

Fig. 18 This was/is the second attempt at a workspace after the romance of a cold and gloomily lit underground basement lost its appeal (sorry FD and TUM-I tried). Ironically, the optimism and sense of belonging generated by the early responses and communications from the university waned in the crispness of an Auckland autumnal sunshine 


\section{Social Distancing}

Sean Sturm, Tāmaki Makaurau/Auckland, New Zealand, 24 March

Sean Sturm is a senior lecturer at the University of Auckland in Aotearoa/New Zealand. He is 51 years old and lives in the inner suburbs of Tāmaki Makaurau/Auckland with his wife, son, daughter (sometimes), two cats and two fish.

It is late summer in the South: cicadas have ceased to sing, the wind is turning south and the sun is climbing lower. Teaching has halted for the virus, for now the hidden harbinger of a benign apocalypse descended from the North. People are panic-buying in the polite provincial way we do things here, laying in toilet paper, pasta, paracetamol and petrol. But everything feels somehow thinskinned.

I sense at once a shrinking and stretching of horizons. My sabbatical travel and conferences have been cancelled, so I feel farther than ever from Europe (I discover that the antipodes of Auckland is Andalucía, which could not be further from where I sit writing in bed). Distantiality does seem to define the decolonial experience. But because we are all in isolation for at least the next month (officially from tomorrow at one minute to midnight), I feel uncannily close to those around me. 'See you in a month!' I said to my neighbour at dusk last night, as my son and I went out for our last walk, and he and his sons came back from buying their last takeaways up the road. A light rain fell as if drawing in the darkness, and we hurried home.

Care does seem to define us in a 'crisis'. So we have drawn our little family inward-myself, my wife, our son (our daughter is with her flatmates across the valley), two cats and two fish-as others fortunate to have a home have done. And yet, outwardly, we are locked into a strangely domesticated war of all against all (Shaftesbury in cahoots with Hobbes): Parliament dissolved, 'essential services only' open, and police and army 'presence' on the streets to reassure us that order is abroad. I sense in this moment how thin our 'civilisation' is: it is for us, as it were, the innermost biosphere of the Earth, which we take as writ when whispers are all it is.

But what is vital remains: the stranger Gaia, whose intrusion on our game of life this virus is, and a strange gaiety for us others, which lights our playful way to winter. I write this note to distant cousins, listen to the tui and crows, and head to the kitchen to rustle up some pasta. 


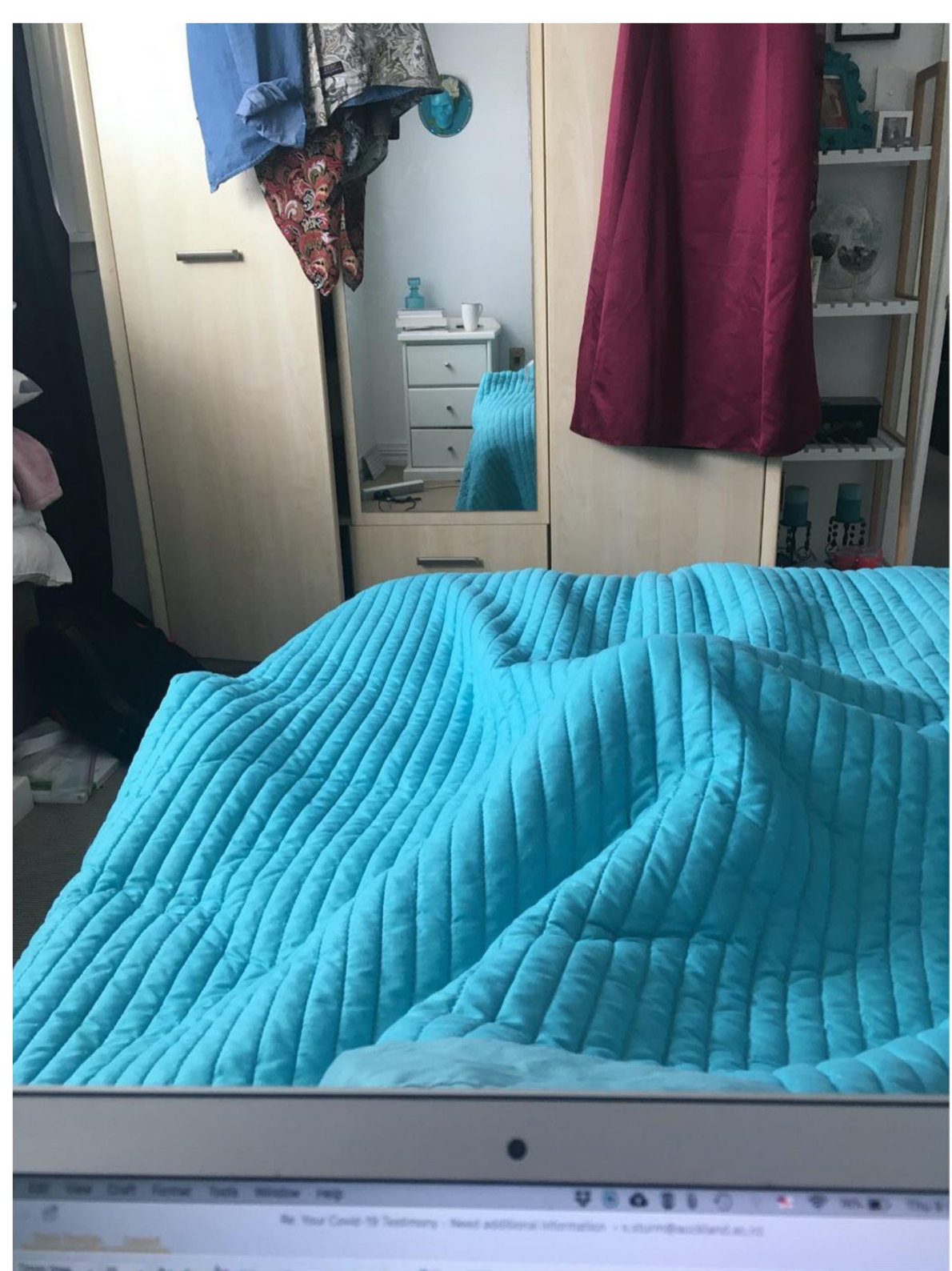

Fig. 19 This is my habitual lockdown workspace (my bed), books and mug of Rooibos tea at my side 


\section{Untitled}

Jennifer Rose, Belfast, Northern Ireland, 25 March

Jennifer Rose is a Ph.D. student at Queen's University Belfast, Belfast, Northern Ireland. She grew up in Nova Scotia, Canada, and presently lives in Alberta, Canada.

It is 5:10 a.m. on March 25th, and this is my fourth attempt at writing this testimonial. I am a final-year Ph.D. student at a UK university, and I am in the writing-up stage of my thesis. Before the pandemic, I worked in isolation from my home desk, located in Alberta, Canada. Working alone is not uncharacteristic or novel to me. I have been in isolation for the previous three months. I was immersed in my studies, only leaving home to acquire survival necessities: food, household goods, and cleaning products. Declining social activities, my proclivity was to be alone and focus on my work. I have become accustomed to solitude and interminable writing time and had few interruptions. Family and friends were at work or engaged in their daily rituals. We would contact one another at times that suited our schedules.

It might seem as if my life would be immune to Covid-19 as I was already living in isolation. However, while my solitude remains intact, with the proliferation of Covid-19 worldwide, my interminable quiet time was swallowed by the effects of Covid-19. My communication with others has increased significantly and abundantly. At 5:10 a.m., I have been interrupted three times by phone calls and social media messages from friends and family who live abroad and in different time zones within Canada. We are all concerned for each other's wellbeing and communicate several times a day as opposed to a few times a week. One might think I have the option of ignoring these messages. However, with the rampant spread of Covid-19, fear for my family's health and wellbeing is heightened because people who have always remained in their home community are now contracting the virus. We feel the necessity to check on one another.

Leading up to this moment, much of my time was spent on tracking down and procuring needed items that were in shortage on store shelves because of hoarding behaviours, determining how best to ship items across country to family members, who because of their age and health are high risk for contracting Covid-19 and ought not to expose themselves unnecessarily, and arranging deliveries of groceries. Juggling between trying to secure and deliver essential survival items, conversations, and writing is not always easy. Each time I am away from my desk, I know that my deadlines are not shifting with the array of my day.

Although my time has been hijacked, and my focus is in perpetual sway between work, fear, and survival, I still attempt to write. I am still in isolation, and my interminable quiet time is now merely a coveted modicum; however, I hold some solace in the fact that there is some solidarity in the world, and I try to do my part in helping to protect myself and others. 


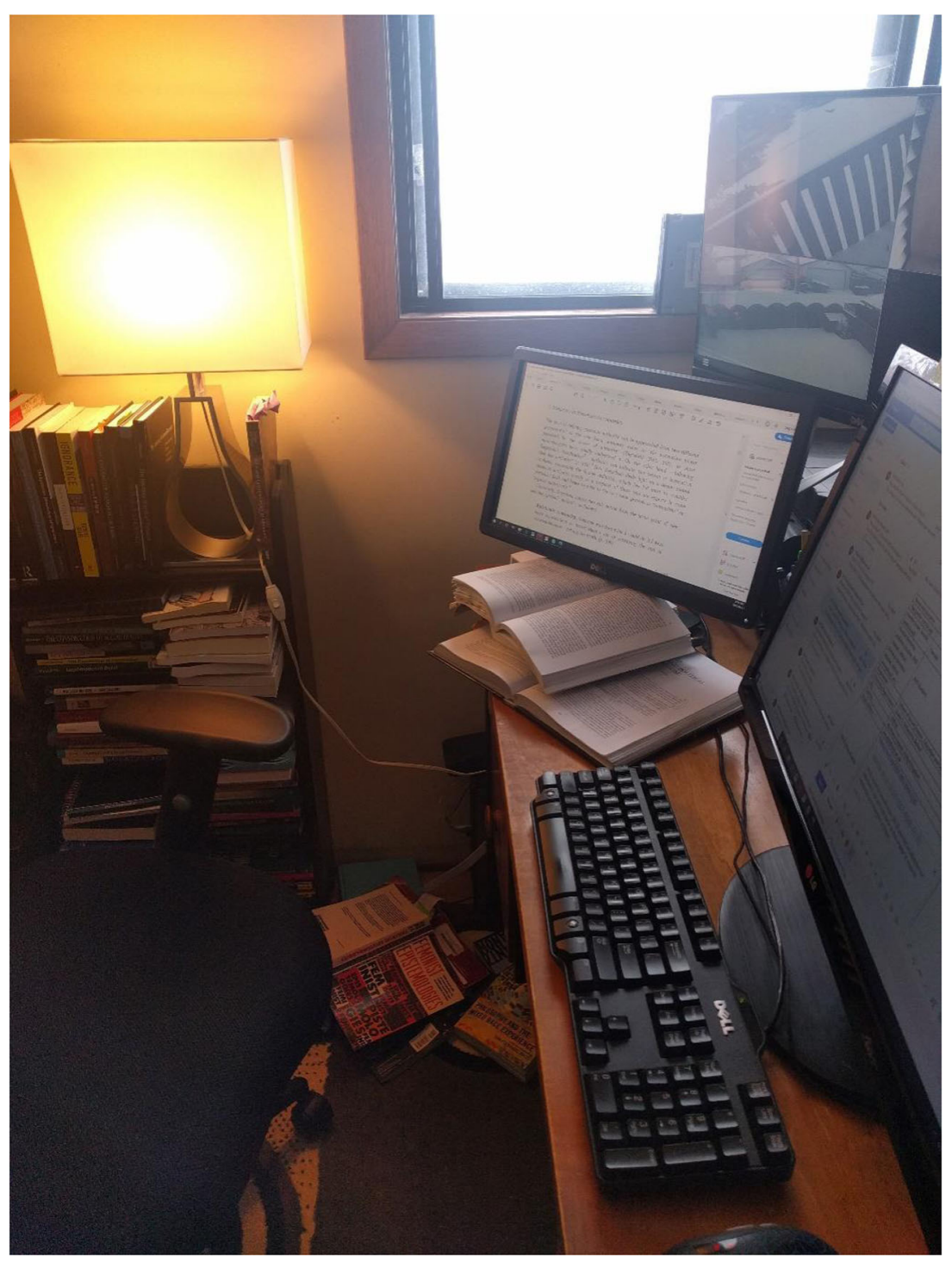

Fig. 20 This is my self-isolation Ph.D. workspace, which is reserved solely for Ph.D. activities 


\section{Life Experience in Beijing as a Foreigner During the Outbreak of the Novel Coronavirus \\ Mohamed Muhibu Chuma, Beijing, China, 25 March}

Mohamed Muhibu Chuma is a master's student at Beijing Normal University, China. He is 29 years old and currently lives in a university apartment.

In December 2019, several new cases of the novel coronavirus causing respiratory disease like pneumonia were reported in Wuhan and spread to other parts of China, quickly affecting tens of thousands of people and causing a high number of fatalities. Covid-19 has started to spread when students were on vacation and I was staying on the campus at Beijing Normal University. The situation was getting worse and the Chinese Government declared an emergency, confining people to their houses. Shortly after the declaration of the emergency, the university in collaboration with the Ministry of Education and the Beijing Municipal Government organized immediate measures to enhance and control the epidemic to ensure the safety of people and eradication of the disease. Immediate instructions included postponing the opening of the university and advising students not to return to campus until the battle against Covid-19 is over, and also protecting on-campus students to minimize risks of infection. We, on-campus students, were strictly forbidden to move around or go outside the campus. Gathering was restricted, and visiting each other within hostels was forbidden. Personal hygiene, the use of masks whenever we step outside, and physical exercises to relieve stress and keep our bodies active, were emphasized and encouraged.

I was shocked and terrified as new cases were reported with huge confirmed death tolls. I wanted to go back to my country; unfortunately, airlines cancelled flights. We stayed indoors. My family was very concerned about the situation as they heard what was happening. One day I noticed that people in Wuhan were motivated and encouraged not to give up until the arrival of victory. This caught my attention, changing my thoughts about leaving and strengthening my decision to remain in China. In my Comparative Education class, we, students, organized ourselves and made a short video to encourage, motivate, and give hope to the people of Wuhan and the whole of China. In the video, I said the following inspirational words: 'For My Good People in Wuhan and All over China, Please Don't Lose Hope and Believe That Victory is Coming Soon, Jiyou Wuhan, Jiyou China!'

The battle is almost over, and victory is near; the new challenge is online learning. I take this opportunity to explore and learn new insights into online learning, which I find to be the best way to provide skills and knowledge for students at this time. The university is working very hard to ensure everything is under control. 


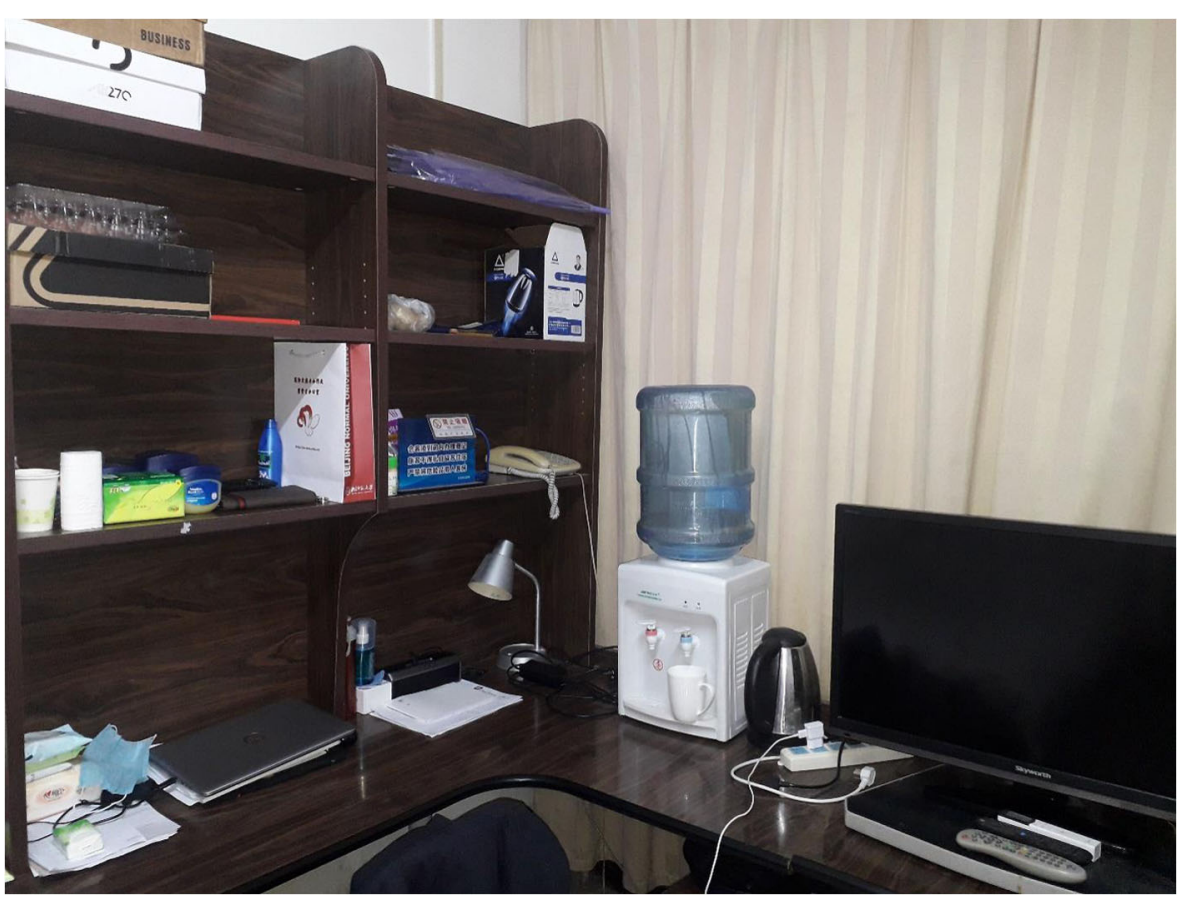

Fig. 21 This is the part of my bedroom where I usually do assignments and refresh when I'm not working

\section{Life During Coronavirus}

Eva Biličić, Zagreb, Croatia, 25 March

Eva Biličić is a student at the Zagreb University of Applied Sciences, Croatia, and is employed as a business analyst in a private company in Zagreb. Eva is 25 years old and lives in Zagreb, Croatia, with her partner.

The coronavirus has definitely hit us all in many ways. In one moment, the life we used to live has changed. In my case, the situation of staying home is definitely hard because I'm a big extrovert. With home closures, we all monitor the media and use a variety of digital aids which help us survive this situation. I spend most of time online, working and solving tasks for college. In a normal situation, I would spend that time hanging out with friends... Everything is on the computer: from socializing on social networks, watching movies, reading books, watching theatre plays, etc. A life that has already been very digitized has now become even more digitized. That helps me to endure and pass my time as quickly as possible. 
We are all literally glued to media, and large quantities of digital experiences are flowing into our physical world. Everything we read online is reflected in our behaviour. We use digital media to communicate with loved ones and friends. Current events (together with the virus, Zagreb has also recently suffered a big earthquake) bring us closer. On social networks, there is less hatred and there are more people who are ready to help, comfort others, offer accommodation, and so on. Digital media also seems to enhance some forgotten connections. Two days ago, it was my birthday, and I received congratulations from people I've known on social networks for years and they never congratulated my birthday before. Everyone has become somehow more intimate and more willing to communicate. Employers are increasingly embracing the digital world and educating their employees so that people can work from home. There is greater empathy and a willingness to help move their business online. Of course, the situation is not the same in all companies because many businesses have not the ability to switch online.

I hope this situation will open the eyes of many people so that they accept working from home much more often than they do now. I hope that we will achieve greater connection between people, spreading positive energy and willingness to help.

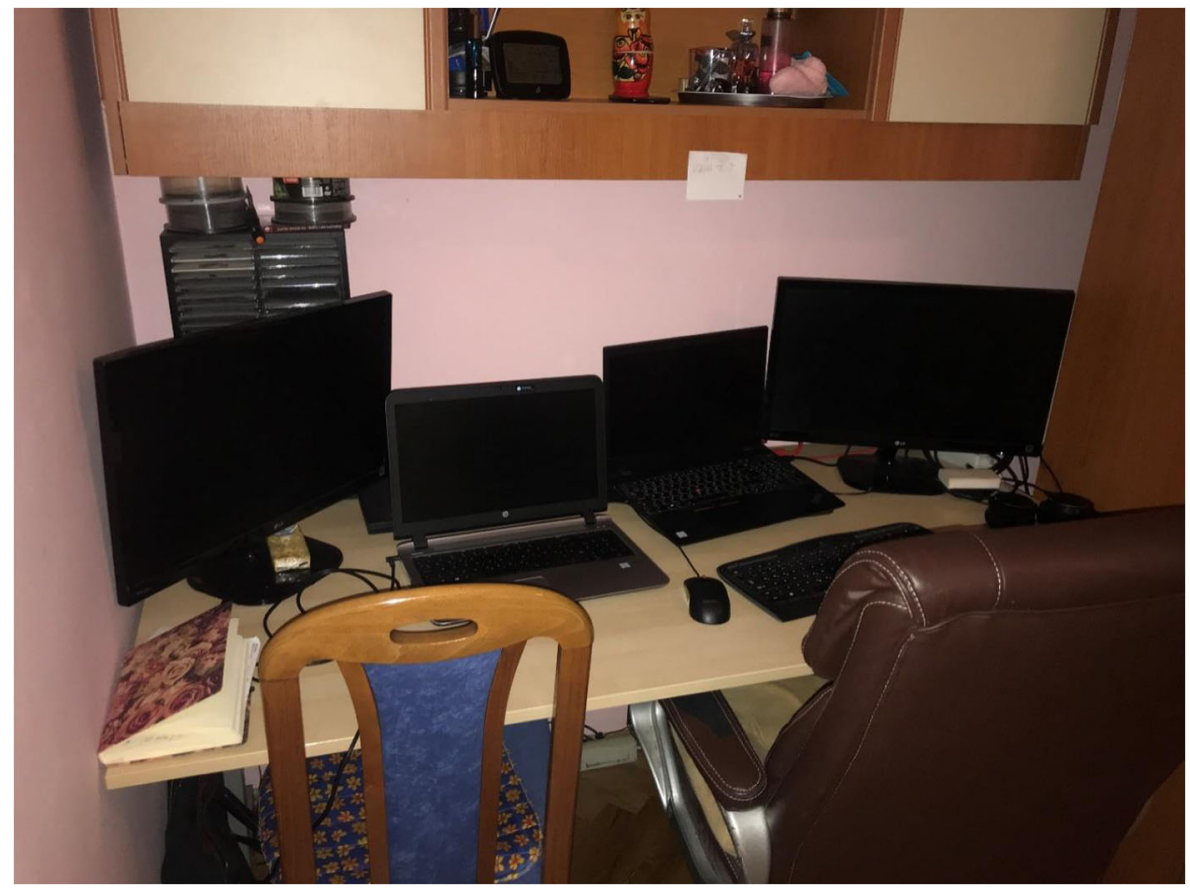

Fig. 22 This is my workspace in our bedroom, where I work on the left side of the table, while my partner Ivan works on the right side, every day for $8 \mathrm{~h}$ 


\section{On Becoming Less Disabled}

Sarah Pfohl, Indianapolis, IN, USA, 25 March

Sarah Pfohl is a disabled artist and teacher. She makes work about the value, power, and complexity of: a rural New York hill, the disabled body, and classroom teaching. Sarah runs the photo and art education areas in the Department of Art \& Design at the University of Indianapolis.

I wrote this testimony on March 25, 2020, in Indianapolis. I teach photography at the University of Indianapolis (UIndy). At UIndy, we received notification on Wednesday, March 11, that the university would transition, due to Covid-19, to emergency remote instruction with delivery beginning on Monday, March 23.

Born with osteogenesis imperfecta (OI), my bones sometimes break for little to no discernible reason. Due to this rare diagnosis, fragility permeates many parts of my physical body (bones, hearing, lungs, heart, eyes). One doctor described my skeleton as about twice my biological age, so at 74 , it's older than my Mom.

I believe in the social model of disability. The genetic reality of my specific body often does not align with ability-related social norms. The world around me disables me as I live, work, and move through spaces made to honor and uphold inflexible ability and body-related expectations. Like all ability-diverse folks, I have spent a long time, in my case a lifetime, alive in a world geared toward a social construct of health that aligns with the realities of only a narrow swath of bodies. In ways large and small, I often do not and cannot belong to the world in which I live. What is being societally named social distancing is, within the context of my own life as a person with OI and how I have learned to live in our disabling world, my everyday.

Under the power of Covid-19, I find myself suddenly located within a world reorganized in profound ways around sickness. Under the power of a pandemic, I still carry my genetic reality but am also, to my surprise, less disabled. For this moment, under terrible circumstances, I live in a world that honors social norms more aligned with the needs of people like me. Of course, I would never wish a pandemic to learn this and I am very worried about the health and wellness of us all. Folks with OI are also designated high risk relative to Covid-19 (due to the aforementioned weaker lungs), so in some crucial ways I am more fearful and careful.

Due to my OI, the primary work of my cognizant life is protecting myself from the unpredictable world around me and paying vigilant attention to my body to keep it in a public semblance of working order. I engage in this work constantly, all of my waking hours. I am not always engaged in this work consciously, many of the patterns associated with it have become reflexive.

I'm surprised by how hard it is for me to get to work and be at work, facts I would not have had revealed without a work-from-home mandate. The form of 
the taxing nature of pushing myself to integrate into social norms, a form I thought I knew very well, takes a different, larger, more nuanced, and clearer shape now. I knew life was hard in this world to which I vaguely belong, but I did not realize until now quite how much I have been trying and pushing to fit myself in.

The pandemic is expert at unearthing and pointing out very clearly the disordered ways we, individually and societally, conceive of, manage, and prepare for illness, especially in the USA.

I say this all to underline that disability is socially constructed and reproduced, related to individual bodies but brought about more so through the norms we honor and uphold.

It seems unlikely we will reach the other side of this moment without major reconsiderations of our existing social order. I hope we might take this moment to listen more closely to the stories and needs of ability-diverse folks. I hope we might take this moment to listen to the interconnected needs of the world and people around us. I hope we might take this moment to remember one body is not every body, and more precisely yet, most bodies aren't every body.

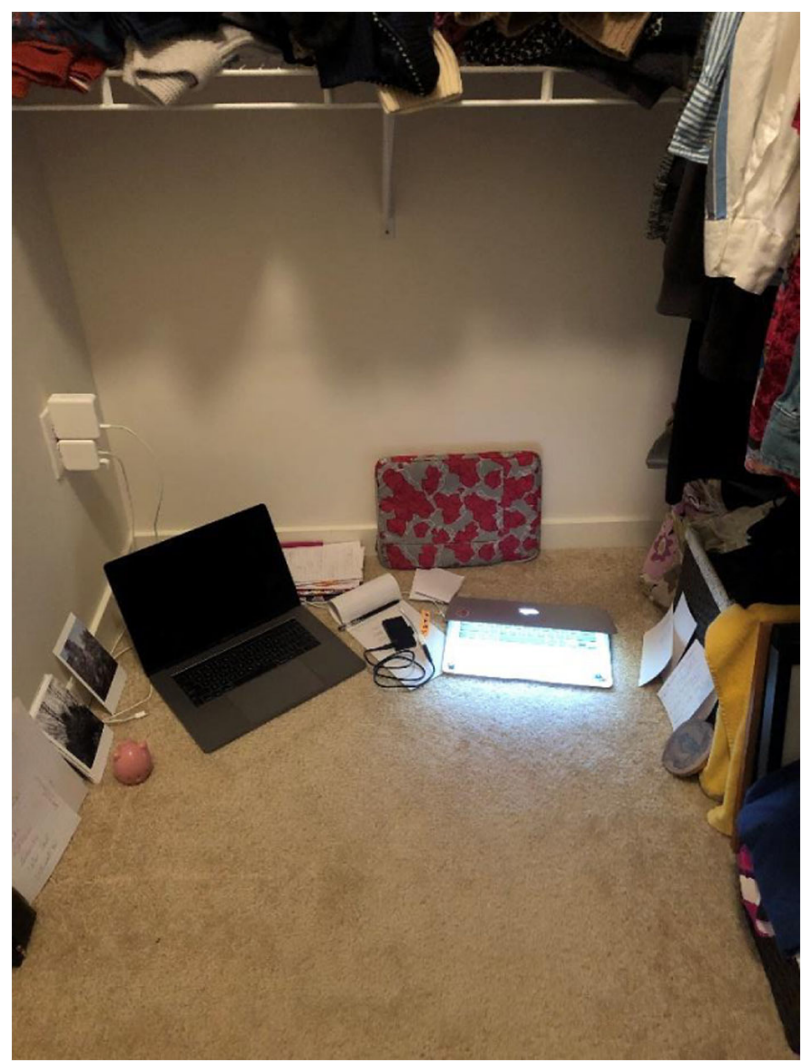

Fig. 23 This is my makeshift workspace in my walk-in closet. I located myself here in an effort to find some privacy and quiet 


\section{The Life of a Swedish Doctoral Student During the Corona Outbreak}

Ulrika Gustafsson, Umeå, Sweden, 25 March

Ulrika Gustafsson is a doctoral student at the University of Umeå, Department of Applied Educational Science, Sweden. Ulrika is 46 years old and lives in Umeå, Sweden, with her partner and their two children.

$* * *$

Tuesday 24 March. It is my first official day as a remote-working doctoral student of digital technologies in education.

Last week all teaching at Umeå University went on distance, and yesterday our vice-chancellor urged all employees to start working remotely from home. The northern regions of Sweden have not yet been much affected by the pandemic, so the restrictions are experienced as precautions and preparations for what will come. The Swedish minister of education called on everyone to 'Keep your head cold, your heart warm, and your hands clean', which by many is considered the best of advice.

On my own behalf, the timing of this situation may be considered somewhat convenient. As a doctoral student at my department, I teach part time $(20 \%)$, and this spring, I teach nothing but online courses. The empirical material in my ongoing study has been collected. Thus, my everyday work, processing results and writing up my first article, is pretty much the same. So far.

I see other doctoral students confronted with new challenges and concerns due to the pandemic. For teachers, it is a challenge when all teaching is supposed to become online in a week. For doctoral students within education, most concerns seem to be related to issues of research data and literature. Concerns related to research data are primarily based on school closures, which affect possibilities for planned data collecting. So far, the Swedish government has closed down schools and turned to online teaching and learning for higher education and upper secondary schools. K-6 and secondary schools are still running as usual (national testing is cancelled), but it is notified that this might change within short notice.

The other large concern among doctoral students are limitations related to attaining literature. At my university library, there have been cancellations of all pre-ordered books and requests. This is evident in my Inbox, where messages started to pop up with enquiries for literature with an important theory' or a general reference. Luckily, our university library provides a generous part of published material online, and they still offer (limited) 
opening hours every day. This will hopefully enable everyone to keep up their work. A closing of the university library would be a disaster for doctoral students. Luckily, my brother-in-law is a first-librarian at the university library, so in worst case, I have a string to pull.

Being a doctoral student unable to work at the university over a longer period of time is hard to imagine. To develop qualities of a good researcher, and conduct good research, I believe it is essential to work and interact in a creative and reflective environment. I hope that this situation will contribute to an increase of collaboration, strengthened networking, and better research in the long run.

I am trying to look at my own situation with an understanding that this pandemic will last for a long period of time. I feel confident about having tools to handle my doctoral studies and conduct research projects from home, advocating physical distancing and travel restrictions. I have already experienced online interviews, distant studies, and net-working. I am also blessed with a wonderful family (teacher husband, self-regulated upper-secondary daughter, son in 4th grade), supportive supervisors (not that old), and a quality Wi-Fi at home.

Comforting circumstances in these turbulent times.

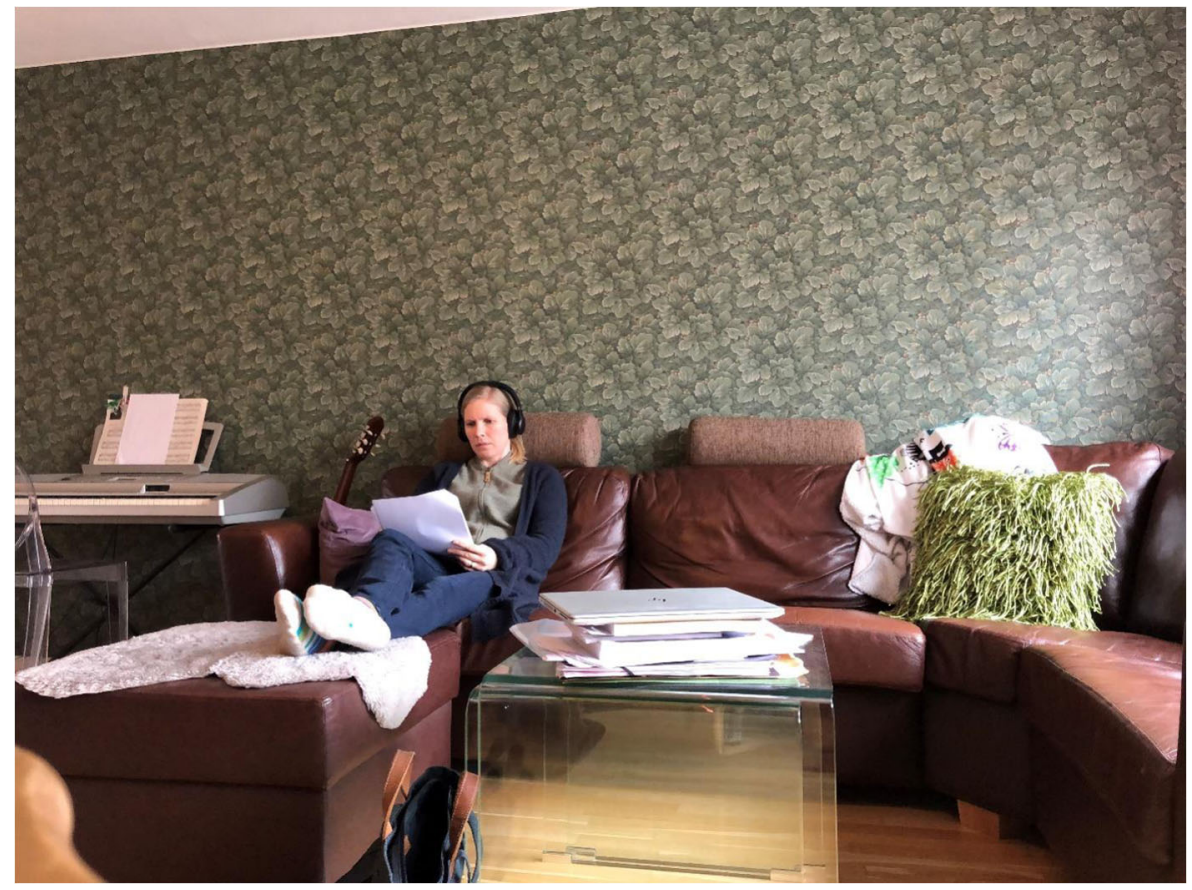

Fig. 24 This is how I work in our living room when my teenage daughter occupies the kitchen table. The headset is for avoiding listening in on her now remote studies 


\section{Are We Witnessing the Birth of a Data-Life Paradox?}

Janine Aldous Arantes, Melbourne, Australia, 25 March

Janine Aldous Arantes is a PhD candidate at the University of Newcastle, Newcastle, Australia, and Casual Academic at Victoria University, Footscray, Australia. Janine is 45 years old and lives in Melbourne, Australia, with her husband, two sons and a Kelpie.

I write these words on Wednesday 25 March from my home in Melbourne, Australia. I am a full-time $\mathrm{PhD}$ student and Casual Academic, who aims to submit my dissertation in three months. As of March 12, I have self-distanced as a result of the Covid-19 pandemic announcement. Indeed, I am now also negotiating how to homeschool two children and become an online lecturer using Zoom. Regarding expectations, I hold anxiety about the levels of commercial surveillance being enabled around me and the lack of legislation in place to guard against the nefarious use of my data by commercial platforms and state authorities.

I feel unprotected from how my data may be collected and used, during and as a result of this rapid shift to online work and education. I am concerned about the mass inequalities exacerbated as a result of technology now, and what it may mean in the future. In this current shift, technology is essential to remain employed. This has resulted in an uncontested 'trade-off' of data flows as fundamental to survival. It is nothing short of a choice between liberties and life. Although this should be recognizable and obvious to researchers in this space, concerns are arguably being quieted as a result of the speed to which the pandemic has forced people inside. People once arguing against facial recognition technologies and the power Amazon holds are now drawn to it, to make ends meet. Those who have protected their face online are freely videoed during lectures. Parents who do not sign up their children to use commercial platforms are seemingly forced to do so or not educate them, arguably for months. Understanding that there are multiple ways in which digital trace data can be used, this presents a tension, which I fear will not be loosened for years.

Therefore, it matters what platforms and protections are being used during this shift. The loss of privacy, as well as other rights and freedoms, should not be accepted as an inevitable consequence of working at home or schooling remotely. Otherwise, we may be at the birth of a data-life paradox. A paradox that forces you to decide whether to work remotely, so that you can earn a wage and survive, in exchange for being digitally profiled to within an inch of your life. Alternatively, you are faced with a decision to not work remotely, but risk being exposed to Covid-19. We, as a global community, should not be faced with such decisions. Any paradox between choosing survival now, and what appears to be an inevitable consequence of losing liberties, requires fundamental protections that I fear are simply not there. Just as we need stringent measures to flatten the curve of Covid-19, we need stringent security to protect us from the nefarious use of data produced as the world works and learns from home. 


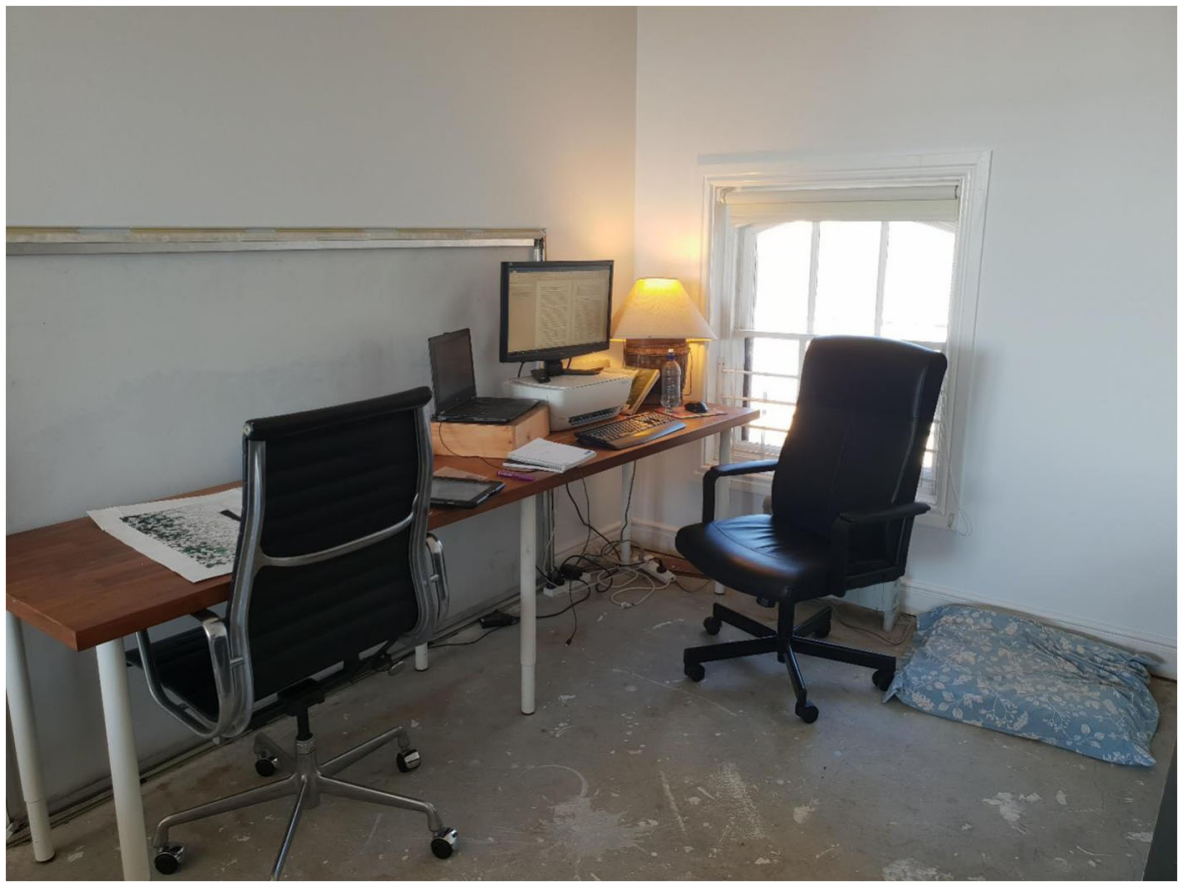

Fig. 25 This is my workspace in our living room. We were renovating our home when the shutdown occurred. The concrete floors and whitewashed walls will remain until lockdown ceases. I share my desk with my youngest son, so that I can homeschool while working. My partner and eldest son work in the bedrooms. Our dog, always close, rests on the blue pillow

\section{The Rhythm and Place of Education in a Pandemic}

Derek R. Ford, Indianapolis, IN, USA, 26 March

Derek R. Ford is assistant professor of education studies at DePauw University and an organizer with the ANSWER Coalition.

Living with higher education institutions always entails certain multiple and overlapping rhythms: of syllabi and class sessions, preparation, reflection, and grading; department work, meetings, hiring, and retreats; university service and annual reviews; publishing and conference presentations; office hours and student events; and more. Each have their own regularities and delays, continuities and interruptions, crescendos and crashes. In many ways, schools are organized more around specific conceptions of time than anything else, like content or relationships. Classes and semesters end not when we have sufficiently grappled with materials, exhaustively challenged our thinking, or asked a certain number of questions, but after a fixed amount of time has passed.

One of the most forceful transformations of the recent Covid-19 pandemic, for me, is the disruption of these rhythms and the struggle over academic 
temporalities taking place. Like all struggles, it can be distressing, disorienting, and painful, but it can also, and at the same time, be hopeful, invigorating, and generative. Crises, at conceptual and corporeal levels, always move the background and the foreground, compelling the most entrenched assumptions into open questions.

I'm writing on March 26, 2020, from my apartment in Indianapolis, IN, USA, where we just got our 'shelter-in-place' order from the state. It was March 09 that I received the first change in anticipation of the pandemic: the two days of classes before our spring break (March 19 and 20) were cancelled so faculty could prepare to move courses online if the need would arise. Just two days later, it did. They cancelled the week of classes before spring break and, since that time, have shut down most in-person activities on campus. Coursework begins again in just a few days.

The rhythm of meeting with students in the same space, where we collectively produce our classroom atmosphere over time, is integral to my teaching. At the same time, I value the twists and turns, punctuations and postponements that my students and materials introduce in both anticipated and unforeseen moments and ways. I did not fully appreciate the ways in which these two distinct-and, in some ways, divergent-tendencies rely on and need each other. But as I change my scope from the pedagogical to political, I get a better understanding. Progressive political struggles aim to make breaks in the order of things in hopes of upending them. They're risky and uncertain, promising and imaginative. While they organize to break and end some rhythms, they maintain and produce others. On the other side are reactionary forces who seek to maintain existing orders and routines.

The rushed insistence on continuity in a discontinuous state of affairs is just stubborn denial that the background has come to the fore. Yet discontinuity without any rhythm is dangerously unsound. As for me, I'm not trying to bring my classroom online, like transliteration could be any kind of adequate translation. Instead, I'm coping with the suspension of in-person meetings by finding recourse in other cadences building and resonating in my apartment, community, and world. And I'm hoping that, if we take this for what it is, we can construct new tempos and patterns in higher education from more vibrant conceptions of time. 


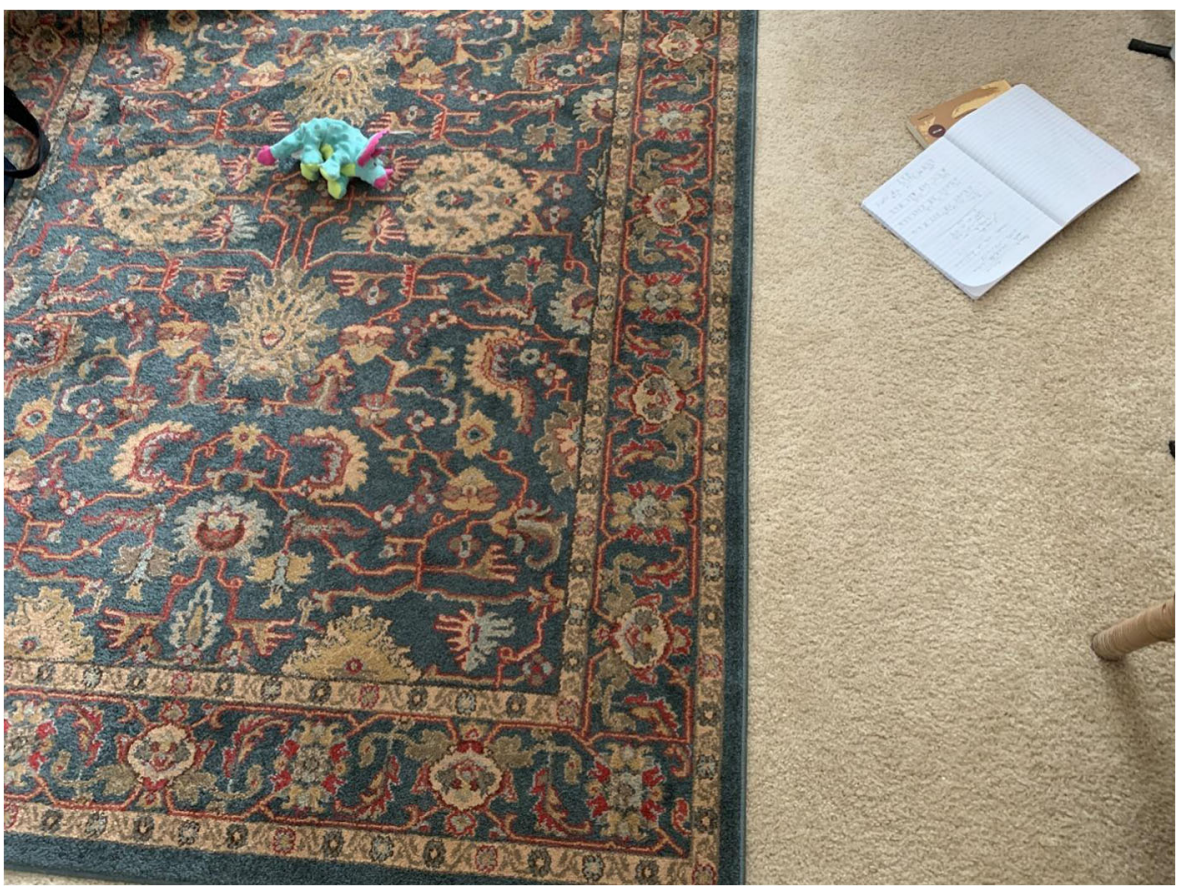

Fig. 26 This is a moment from my workspace in our office that I share with my wife and our two dogs

\section{The Testimony}

Jimmy Ezekiel Kihwele, Morogoro, Tanzania, 26 March

Jimmy Ezekiel Kihwele is an assistant lecturer at Mzumbe University, Tanzania, and a $\mathrm{PhD}$ candidate at Beijing Normal University, China. Jimmy is 35 years old and lives in Morogoro, Tanzania, with his partner and two daughters.

I am writing this testimony on March 26, in Tanzania, my home country. I am an academic working at Mzumbe University and a $\mathrm{PhD}$ candidate at Beijing Normal University. Covid-19 has reached Tanzania on March 16. Confirmed cases have increased to 12 which forced the government to close all educational institutions from pre-primary schools to universities for one month and send all students home. Due to the challenges of Internet accessibility and electricity, the university has failed to shift to online learning. Lecturers have been directed to minimize unnecessary interactions, and some have opted to work from home.

I was required to start data collection for my $\mathrm{PhD}$ project. My respondents are university lecturers and students, and the lockdown has stopped the process. I have opted to conduct interviews through phone calls and create online 
questionnaires on social media. The challenge ahead is reaching fewer respondents, because not everyone will manage to access the online survey. Some respondents also feel insecure in online interviews. I have opted to stay home and keep my family safe because access to quality health services in my country is still low.

At the moment, tensions are high as the rate of confirmed cases increases. I feel stressed because I am not getting the required data and because I worry about the health of my family. I am relieved and happy that Beijing Normal University keeps in touch with its international students who are in their home countries. They offer assistance whenever it is needed or required. This shows the university's concern and commitment to safety.

The power of social media in providing information to people needs to be emphasized. Although some information is incorrect and misleading, the rates of searching for information from the right websites and social media pages is high. People started buying masks and sanitizers and used them before the first confirmed case in Tanzania. We need to emphasize social awareness about risk management, educate people to search for information from the right sources, expose the effects of creating false information which could be fatal to its readers, and reduce the prices of essential items and services to help those in need.

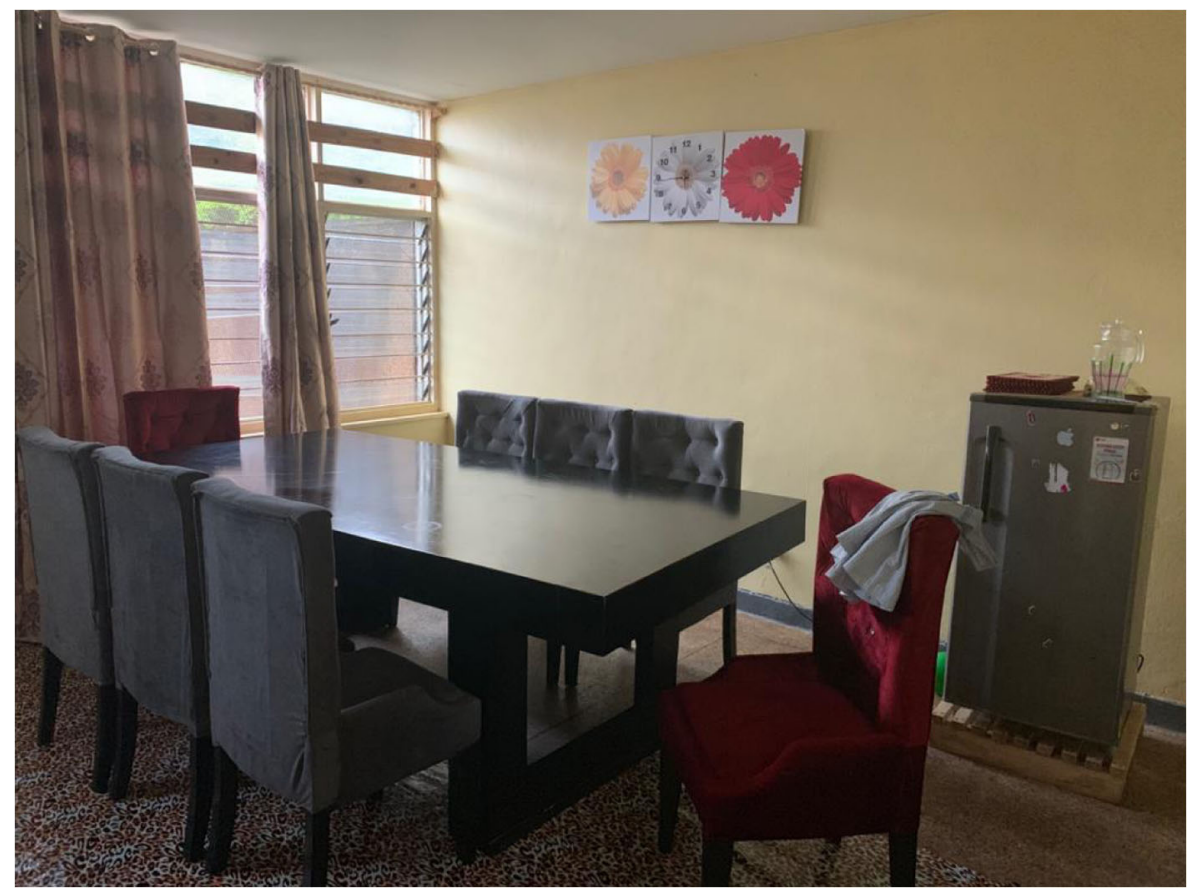

Fig. 27 This is my workspace in our living room, a dining table, where I take turns in working with my partner 


\section{Untitled}

Peter Mozelius, Stockholm, Sweden, 26 March

Peter Mozelius is a senior lecturer and researcher at the Mid Sweden University in Östersund, Sweden. After a visit to Spain in early March 2020, Peter has been working at a distance, from his home quarantined in Stockholm.

My testimony is written from the western parts of Stockholm in Sweden, around $500 \mathrm{~km}$ away from where I normally work at the Mid Sweden University in Östersund. Due to the spread of Covid-19, working by distance with a lot of online meetings will be a fact for me during the coming months. As a computer scientist, this is not particularly new to me; I have conducted large parts of my teaching and research in virtual online environments during the last two decades. However, what is new is to work $100 \%$ by distance in a time where the common agreement is via blended learning. What I see as the most problematic issue in the educational field is how to handle students' planned internships.

The general recommendation from the Mid Sweden University is to work remotely from home in consultation with the head of the department. Furthermore, the recommendation is to use Zoom for teaching and learning activities, and Skype/Teams for staff and research meetings. In my case, the agreement is to work $100 \%$ and to find distance alternatives for all activities. This has so far worked out well since the course I'm running has completed all face-to-face meetings and that the remaining activities should have been carried out in the Moodle virtual learning environment anyway. Research collaboration has also worked surprisingly well by distance for the writing part, but data collection in some cases has been postponed. In one project, planned face-to-face interviews were instead conducted in the video conference tools that the informants had access to.

On the more private family level, we are lucky to have a large apartment where all three of us have our own desk and personal work space. Sweden has, as frequently discussed in the media, a general policy that in comparison to other countries has been classified as laissez. faire. But at the same time this builds on the Swedish tradition of listening to experts in a model with more of public authority rule than merely politicians taking all decisions in a crisis. In our country, the experts from the Public Health Authority (Folkhälsomyndigheten) have had a huge influence on decisions such as not to close down primary schools and kindergartens. The Swedish model for coping with the Covid-19 crisis depends much on the citizens' voluntary responsibility and on their willingness to help and collaborate. However, there are of course stricter regulations for the older adults and for persons in other at-risk groups.

Compared to our neighbour countries, we have so far done quite well, and the decisions and policies that are best have to be evaluated in the future. Finally, Stockholm gives the impression of a ghost town now with almost empty cafés and many stores with signs saying 'temporarily closed'. To be a teacher and a researcher seems relatively easy these days when compared to the harsh reality for people working at restaurants or in the cultural area. The opera house is locked down, the concert house is locked down, cinemas are closed, no football matches, no outdoor events. Now, in the end of March when the sun is shining and the spring is approaching, the human need for play, culture, and joy is suffering from lack of activities. Not everything is best done online. 


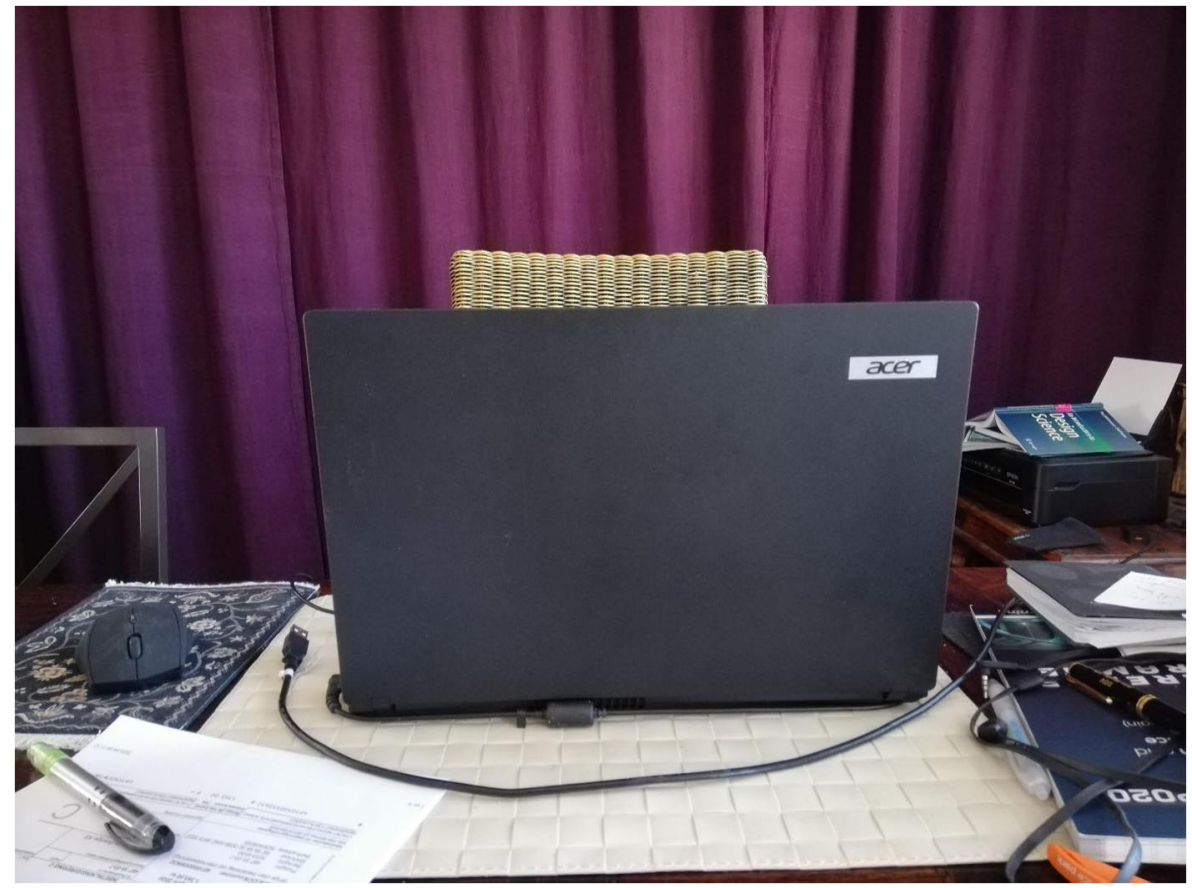

Fig. 28 This is my workspace in our living room, where I have found a nice background for my many online video sessions during the pandemic

\section{Pedagogy of Mercifulness}

Juha Suoranta, Tampere, Finland, 27 March

Juha Suoranta is Professor of Adult Education in Tampere University, Finland. He is 54 years old and lives in Tampere with his spouse Anna and their three children.

Too much noise, ruckus and furore in these days after the state of emergency in Finland (restrictions of basic rights; school, university, and border closures; cancellations of flights and cultural and sports events; limited sales of pharmaceuticals; quarantine-like conditions for the elderly). After the first week's alert mode and overdose of news media, Facebook and Twitter, I need to balance my intake. Yet, I feel a certain excitement about the state of events.

One of my colleagues abroad describes the situation as eerie. Nightmares have awakened me in the nights, and I have listened to the silence of the dawn and remembered my sins. Like Žižek (2020) reflecting on the pandemic, I have been 'afraid to fall asleep since nightmares haunt me in my dreams and make me awaken in panic nightmares about the reality that awaits me'. In the dream, one thing is repeated: my time is running out and I furiously count remaining years, 'sixteen more years and I am 
70'. I wake up terrified. I am home with my family. We are safe and healthy at least for now. However, I am fully prepared for the upcoming change.

I have switched my already planned seminars into text-based Moodle. I do not want to play with Zoom or Teams and I hope that the students' focus is on the learning content and not on digital apparatuses. There is also a danger that not everyone can be present online (for various reasons), the digital technology does not work or the students' devices are outdated. Furthermore, I need to spare the bandwidth for those who really need it.

All the massive operations and nationally led top-down ICT in education programs from the 1990s onwards have more or less turned into failures. Then comes Covid-19 and school closures, and it seems as if the digital leap has happened overnight. In reality it is not that simple. True, thousands of Finnish teachers, the best in the world according to international comparisons, who would not otherwise use ICT much in their classrooms, start to use digital tools because of the pandemic. But many students are missing and cannot be reached online: a demonstration that schooling is not only about teaching and learning but also about social control.

When it comes to our pedagogies as critical educators, I do not think we need to aim at 'pedagogy of discomfort' under the circumstances. Rather, we should look for the Freirean pedagogy of love or 'pedagogy of mercifulness' as my colleague Arja Karhumaa at Aalto University (Helsinki, Finland) recommends on Facebook (18 March 2020):

I assume we all understand that every level of performance and/or efficiency that we are used to in our lives can be decreased by $25 \%-50 \%$, now that especially people with families have really switched to multi-multi-tasking mode? Please be merciful towards yourself, your colleagues, your students and pupils, your employees, and your children - everyone. We will find out we can do with less, and then learn from that.

And the following day she continues:

To everyone, who is either aspiring to or bragging about achieving everything they would in normal circumstances - stop it, I'm not impressed. I'm concerned. We are not invincible, we are vulnerable, and if there ever was a moment to question what the current (societal, political, institutional, economic, social) system demands of us, this is it. Lower your expectations.

I have tried to do just that, for I have to confess that it's been hard to keep focus during these weeks. Of course, many of us need to be busy with online teaching, answering emails, reading, writing, and thinking. And yet, it would be essential, using the words of the poet Lynn Ungar, to

center down.

And when your body has become still, reach out with your heart.

Know that we are connected

in ways that are terrifying and beautiful. 
(You could hardly deny it now.)

Know that our lives

are in one another's hands. (Ungar 2020)

It is essential that we learn a lesson and see the ongoing pandemic as a chiasm, a turning point experience. As individuals and as humanity, this should mean a change in how we think of our material, social, political, and spiritual living and being in the world as the virus finally brings us together to critically understand how small a planet we are living in and, in the end, how short, fragile, and precious our life is.

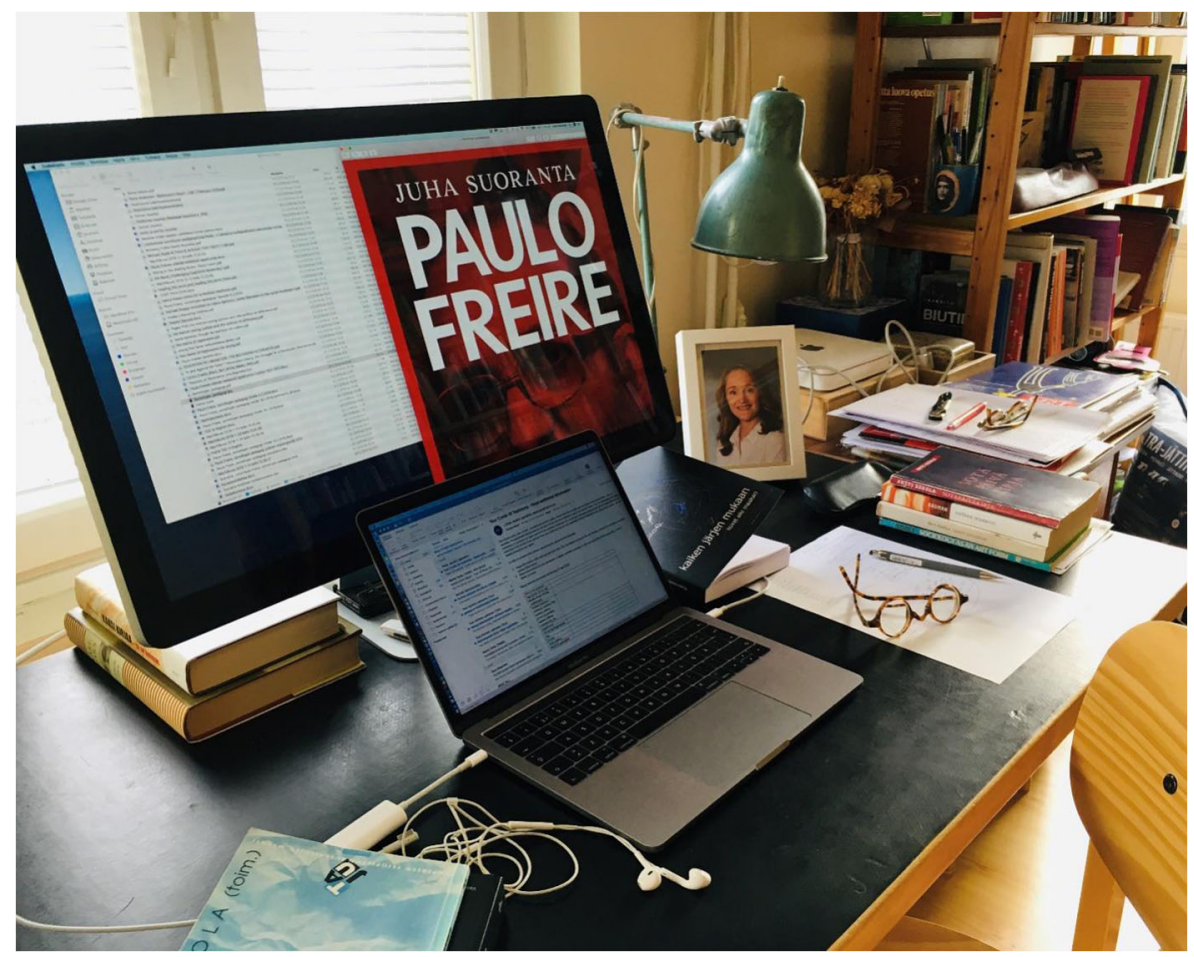

Fig. 29 This is my study in which I have written most of my texts during the years. My spouse in the picture on the right

\section{Untitled}

\section{Lucija Jurjević, Obrovac, Croatia, 27 March}

Lucija Jurjević is 22 years old, a student of information technologies at the Zagreb University of Applied Sciences in Croatia. At the moment, she is living in Obrovac, a small town near Zadar, with her family.

When the coronavirus broke out in China, it seemed so far from Croatia. I thought it was not too dangerous and that we will get over it like we get over the common flu. But when the coronavirus started to spread in Italy, I started to think about consequences for 
us here in Croatia. The virus had quickly transformed from nothing of importance to something that induces panic.

When the government switched all schools and universities online, I realized how serious the situation really is. My roommate who studies at the Faculty of Medicine said: 'You know it's serious when Medicine is cancelling lectures even before the official government decision'. I picked up my essentials, left Zagreb, and went home. However, this has not affected my learning, because all courses were already online.

Before the pandemic, I had been using the Internet and digital media in (what seemed to be at the time) normal measure. It is only now, after we entered quarantine, that we actually see how much our physical world depends on the digital world. Every new information, every statistic, comparisons with other countries, and so on are available immediately. Yet this creates a dependence on digital media, because they are our only source of information.

We're all at home. My parents do not work during the pandemic, and my brother attends online classes. During the first few days of the quarantine, we had great weather and things were really hard. A few days later, the weather had changed - it was windy, snowy, and really cold. Now I feel great being at home, doing college stuff, hanging with my family, watching movies, reading books, doing puzzles, etc. I am in everyday contact with my friends and boyfriend, who lives in the same city, but we decided it's better to stay separated. I like that we are staying connected in this time of social distancing.

After the pandemic is over, things will not return to (what used to be) normal. I hope that people will understand this crisis as a warning from nature. We must begin to appreciate nature, and what is left of it. Major historical crises have always motivated change, and there is no doubt that will happen after the coronavirus. Covid-19 is going to shape our future, both our postdigital culture and our nature. In the meantime, we can only hope for a near ending to this situation and to get back to normal life. 


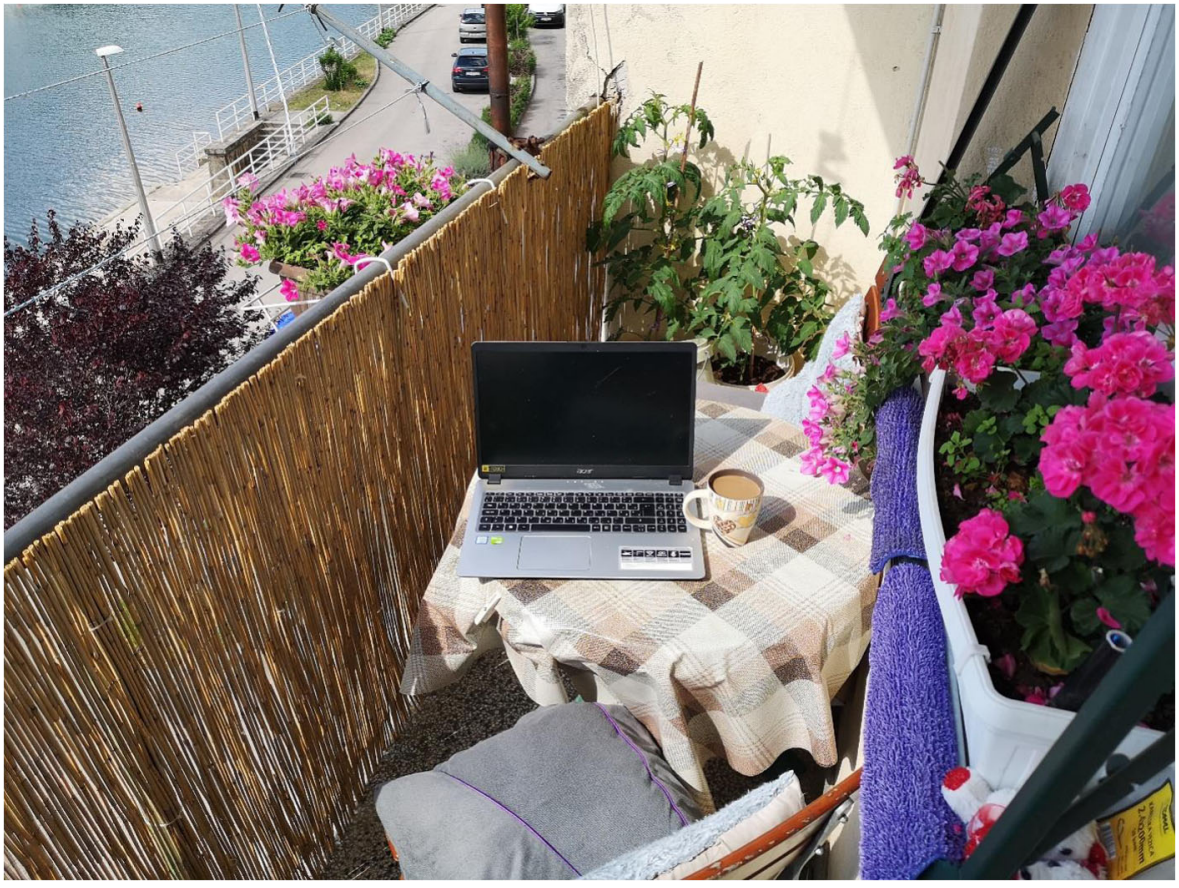

Fig. 30 This is my absolute favourite spot in the house for studying and working, at the balcony with fresh air

\section{Coronavirus Through My Keyboard}

Matija Jurčević, Petrinja, Croatia, 27 March

Matija Jurčević is an IT specialist at the Petrinja City Library. He is a first year student at the Zagreb University of Applied Sciences. He is 31 years old and is happily married to the most beautiful woman in the world.

Since the announcement of the spread of the coronavirus in China, an interesting development has taken place. Within a few weeks, we went from a classical 'it is so far from us' attitude to buying crazy amounts of yeast and flour. This development says a lot about the impact of digital cultures on individuals and communities. Fake news, apocalyptic thoughts, and unreasonable fears have led to a general panic. Such news and headlines are much more clickable, so why not write them!? 
After back surgery and then quarantine, nothing much has changed in my studies. My workplace, Petrinja City Library, has resisted the virus with disinfectants and good behaviour until the recent introduction of the general ban of all work. This has not affected me professionally because I am still on sick leave, but my social life has indeed changed to a great extent. Everyday gatherings are gone, and virtual gatherings cannot replace them-at least not for me! In Petrinja, we always find time for each other; it is easier to finish the day with barbecue and beer.

Digitization and digital transformation have become necessary for smooth functioning of the whole country. Croatia's Crisis Headquarters is doing a great job, but the team that posts bullshit on social media is a lot bigger. Unverified and inaccurate information proliferates at an insane rate and has even led to overseas deaths over the use of substances that have been claimed to cure the coronavirus. Physical quarantine works very well, but it would be great if that bullshit-expanding group could also be put into a digital quarantine.

This strange combination of the pandemic, earthquake, fire, and spring snow urges us to stop for a minute and realize how transient we are, how much we need each other's physical proximity. But while the pandemic lasts, for the sake of self and others, \#stayhome. 


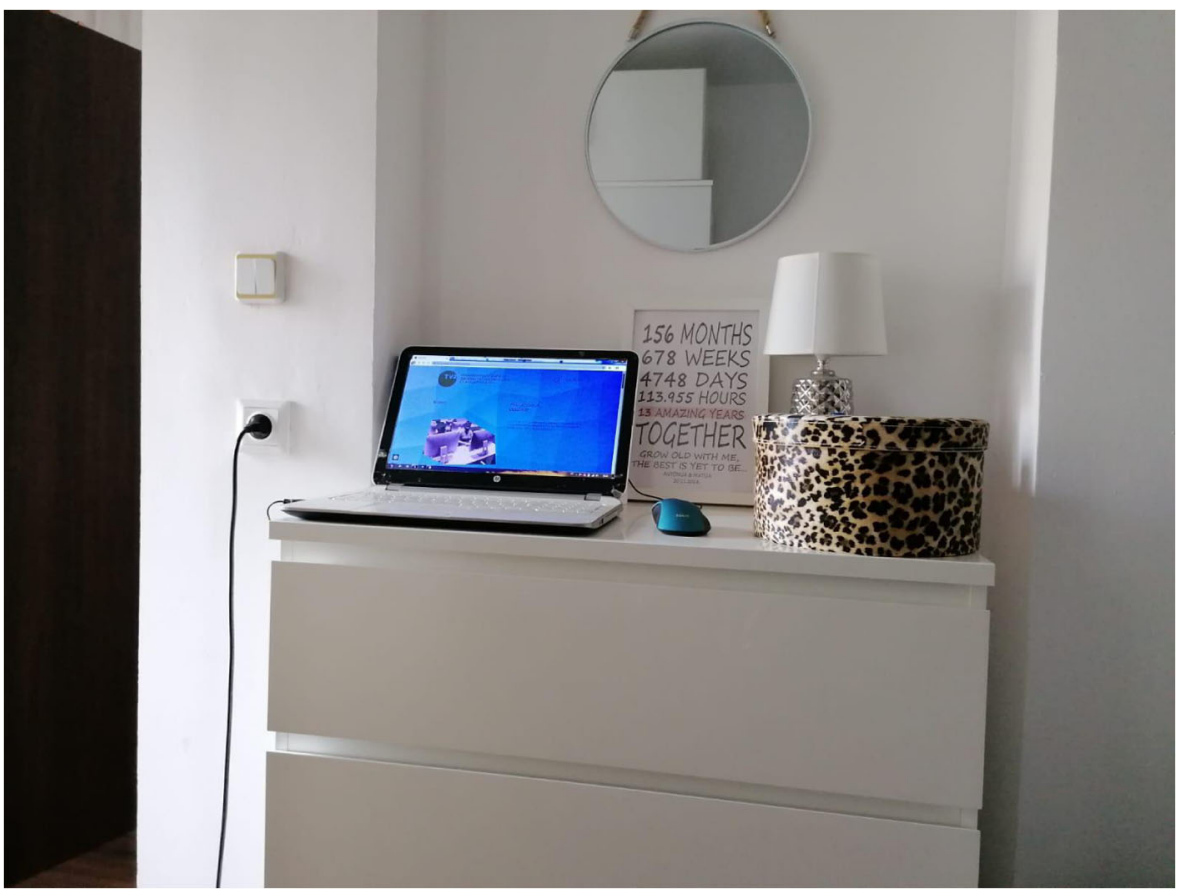

Fig. 31 This is my workspace at the time of the coronavirus pandemic; to be more precise, this is the highest area in the apartment that I could work on due to back surgery - a dresser in the bedroom

\section{Hope: an Essential Educational Service}

Anne Steketee, Orange, CA, USA, 28 March

Anne Steketee is a doctoral student in education at Chapman University in Orange, CA, USA. Anne teaches, researches, writes, and works as an educational advocate.

Workers supporting public and private childcare establishments, pre-K establishments, K-12 schools, colleges, and universities for purposes of distance learning, provision of school meals, or care and supervision of minors to support essential workforce across all sectors. (California State Government 2020).

I've now lost count. I've rewritten this piece so many times, depending on my hope or horror. I am a graduate student, months away from defending the elusive Ph.D. on the topic of secondary traumatic stress in teachers. After ten consecutive semesters teaching in higher education, this is the first semester that I am home - researching, writing, conferencing, and interviewing for jobs in anticipation of graduation. I continue to meet the additional demands of faculty and advisors, working on research, as well as writing and editing 
articles for journal submission. I also continue pro bono work as an educational advocate, with much of this work for families in need.

As soon as K-12 schools and colleges started shifting to online spaces, the texts and calls began-three mothers, all with compelling needs, none with computers. The lack of computers was the least of the issues.

The first family is a young single mom with two children, ages two and five. One child has profound disabilities from microcephaly. The mother recently started community college. But now she is home, with two children, no computer for completing her work, and no experience for educating the children. Not only did we need to get her a laptop, but we also needed to find a way to help her organize her day, her home, her curriculum, and-most important - a sense of calm.

The second family is two children and an older single mom with both physical and mental health issues. She has art supplies but no school supplies. She has a sense of fun but was surprised by her oldest child's lack of academic progress. The school finally sent computers to the house-it took mom two hours to take attendance on the laptops. I sent her screenshots of scaffolded assignments to help bridge the gap, along with readers and supplies, to maintain a sense of calm.

The third family is undocumented, over ten people living in one apartment, making it work. Three small children, no books, no paper, no art supplies, no computer. Much love. This advocacy case has involved a constant stream of non-consumable resources, pictures back and forth, and, finally, a computer with a printer and copier ordered. They will arrive in a week, and just the hope of their impending arrival has instilled in the family unit a sense of calm joy. I will brave venturing out against the 'shelter-in-place' order to set everything up for the family. California, thankfully, considers education an essential service (California Coronavirus (COVID-19) Response 2020).

I am equipped in my work life to respond to a variety of student and family needs during times of stress. I plan for difficulties, but I could not anticipate my confusing sense of rising discouragement. I ridiculously expected some semblance of government leadership, but saw brazen inhumanity as US leaders valued profits over people. Trump's words are hollow compared to these three families, and millions like them in communities all over the world, who show the calm persistence that will carry society through this horror with hope. 


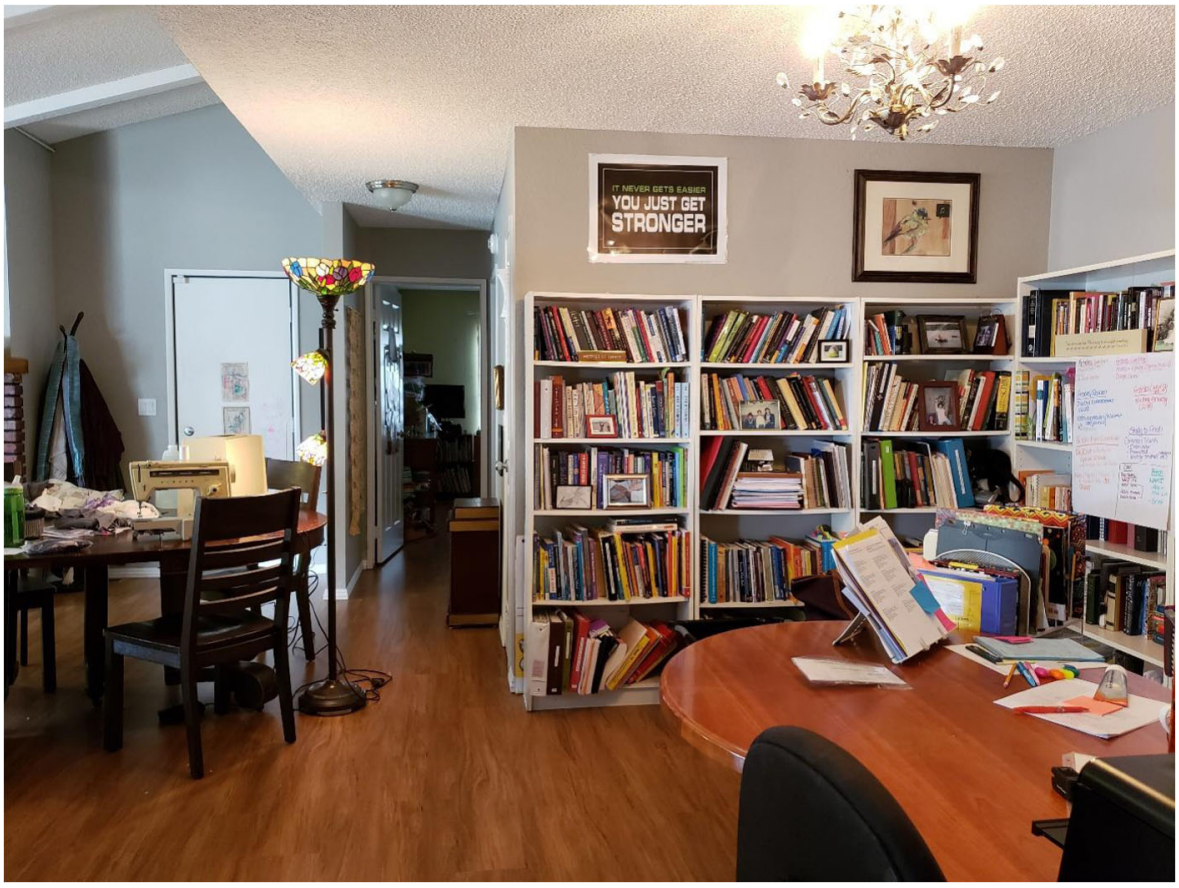

Fig. 32 I converted my dining room table to sew masks for my extended family and client community when I take breaks from working on my dissertation

\section{No Return to Normal! —Philosophy and Teaching in the Age of Covid-19 Jones Irwin, Dublin, Ireland, 29 March}

Jones Irwin is associate professor in Philosophy and Education, Dublin City University, Republic of Ireland. Jones lives in Dublin with his family.

I write this on a Sunday, 29th March 2020, mid-afternoon, in Dublin, Republic of Ireland. I've been doing some preparation on my Philosophy and Education classes for this coming week. The Irish government reacted relatively quickly to the crisis and moved schools and universities online almost two weeks ago. Gradually, the social measures have been intensified until a lockdown late last week, with restrictions on leaving your home to essential activities. Earlier, I went out with my family for exercise - the weather has been unusually sunny for this time of year, creating a strange sense of duality between a sunny exterior world and a rather challenged home life, which stumbles and rumbles between phases and spaces of playtime, school and work life (we are 6 here!).

In the socially distanced conversations I have with neighbours or fellow runners, or the Zoom chats and meetings with colleagues, we all speak of the sense of 
disorientation, pressure and low-level anxiety the situation brings. One is also very conscious of the extreme suffering experienced by particular countries and friends abroad, as well as the loss of individuals in the home country. I have worked several times in Italy over the last few years, and the decimation of the North of Italy by Covid19 has been tragic to see happening.

Nonetheless, despite the evident suffering, I have been struck by the more positive possibilities which our new appeals for world solidarity and cooperation can also bring. My own work has focused on progressive approaches to education as inspired especially by the work of the Brazilian educator Paulo Freire, seeking to move us away from more 'banking' modes of transmissive pedagogy to what he refers to as 'problem-posing' pedagogy, a radically democratic practice. For five years between 2014 and 2019, I was very lucky to have the chance of a part-time secondment as project officer developing a new multi-culturalist approach to curriculum in some of our newer schools here in the Republic of Ireland. These schools are called Community National Schools at primary level (5-13-year-old children), and my experience of working with these new and diverse communities in Ireland was of a growing grassroots energy and passion for change and renewal of our understanding of schooling and its role in the social-political space.

This particular experience has inspired me to see difficulties as also often the 'janus face' of potential change. As Lacan noted, 'obstacle is the condition of possibility'. All around us, amidst the devastation Covid-19 is wreaking on individual lives and collective security, certain truths are emerging more clearly that will be hard to rein back, once this destructive time has passed. The extraordinary bravery and social ethic of our health workers is humbling, but their huge struggles also reveal the more recent tendency to denigrate their work as somehow lesser than that of private enterprise and money-making. This denigration has of course also been accompanied by a significant diminution of public funding and downgrading of public services that extends out from healthcare to weaken the public sphere in toto (including crucially the educational sphere).

These days, when public health and public education are at the heart of the courageous response to Covid-19, these laissez faire and neo-capitalist sins against our state public ethos are shown up in all their pathetic quality. But as the revolutionaries during the May ' 68 used to warn against, there is always the danger, once such social movements for change dissipate, of a retour à la normale. Let us learn from this-after Covid-19, no return to normal, comrades! 


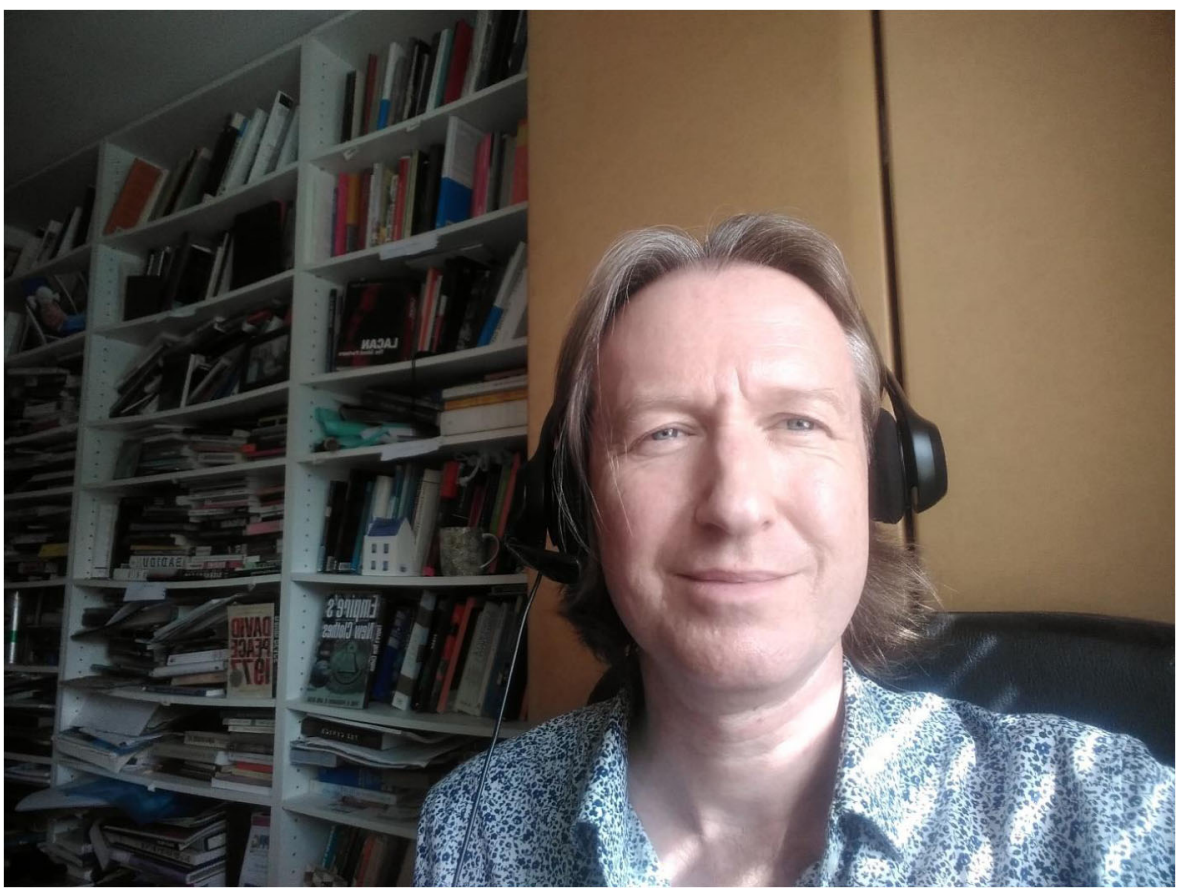

Fig. 33 Jones' photo is of our study (too many books!) where I have been giving Zoom lectures from these last weeks

\section{Ahead of the Game: Australian Universities Called to 'Play'}

\section{E. Jayne White, Melbourne, Australia, 29 March}

E. Jayne White is a Professor and Associate Dean at RMIT University, Melbourne, and II Professor at Western Norway University of Applied Sciences. Jayne is a fifthgeneration pakeha New Zealander who currently lives in Australia with her partner and two grown-up children (and another back home in NZ).

As an academic leader of an early childhood education (ECE) discipline that caters for hundreds of local and international students, I am confronted daily by the neo-liberal games that continue to play out in the wake of Covid-19. Dealing hourly, it seems, with the clumsy decisions made by federal versus state government in this country, such games - mere days ago governed by economic priorities over public safety - have now escalated into a national fight for humanity (or should I say toilet paper?). Those who relied solely on prior government assurances that everything was under control are now frantically searching for remedies that exist far beyond the bounds of Wall Street or its predictions. In these unprecedented times, universities have only to rely on their collective wit to navigate these waters where terms such as 'flattening the curve' and 'social distancing' are played out against fears of 'economic recession' and 'essential service'. Neither complacency (concerning distancing) nor blind compliance (staying at work) is a viable option if we hope to play our part in re-writing the rules of this game - even when we do not know how it will all end. 
In the midst of widespread inertia, we have had to make decisions ahead of the game. Moving swiftly to host all courses online, putting in place robust stay-at-home processes and working with authorities to ensure students are able to continue with their studies wherever possible, whilst supporting the obvious and inevitable conclusion of social isolation (which continues to bewilder Federal Government), Australian universities have galvanised into action with breakneck speed over the past three weeks. We are exploring online learning in ways that were previously resisted by some, and making mindset shifts concerning what this means pedagogically. These collapse traditional binaries between virtual and face-to-face forms of delivery, heralding new approaches for unknown futures.

Despite these nimble manoeuvres, there is a large group of students for whom such solutions will not suffice. Inequities abound in this Covid-19 world. Universities in Australia have benefitted greatly from the international students that study here, and in my view, there are additional obligations that must be upheld in this regard. As I write, we who seek to live out the impact of their decisions must be fielding multiple student concerns about their future - many having already lost jobs and/or accommodation — and remain vigilant concerning the additional challenges they now face in living in isolation, away from family, friends and country. Beyond the university community, there is little word of financial support forthcoming for anyone who cannot call themselves an Australian citizen. As a kiwi living here, I feel this vulnerability too. In this global crisis - for Australia at least - there are borders and, indeed, borders within borders to create inequities accordingly. Many are now watching and waiting to gauge if it is time to go home, and hoping that, in the absence of airlines to take us, there will be a way to get there, let alone get back in brighter utopian days. In the meantime, we wait and watch for more equitable solutions from afar whilst playing our part in the places we find ourselves trapped unawares.

In the ECE discipline, there are further games at play which call for my attention. Australia has woefully under-valued early childhood teachers. Now there has been an insistence - indeed a neoliberal demand - that ECE will carry on at 'the frontline'. The argument touted is twofold: first that young children are supposedly 'carriers' only of the virus and the second that they may infect their elderly grandparents if they stay at home. The third, largely unspoken but nonetheless pervasive, argument is that if children are in ECE their parents can work to serve the economy (and look after the children of frontline workers), whilst the fourth draws from private owners of centres who have much to lose by closing their doors. These arguments neglect the obvious fact that ECE teachers are also going to be infected if they continue to work, as are their families and communities. Social distancing is not an option when you are holding a sneezing baby! Suddenly, ECE teaching has become an 'essential service' when sector counterparts in primary schools are, in some states at least, dubbed 'unessential' (or can at least turn to online alternatives as many are doing), yet this vital work passes by unnoticed and woefully underpaid as it always has before, and we continue to field mounting pressures to ensure the pipeline keeps feeding this need.

These are just some of the many challenges facing a society, indeed a globe, where local, national and global leaders juggle lives against livelihood (and profit). In these Covid-19 days, we must be ahead of a neo-liberal game that tethers necessary manoeuvres in the interests of humanity. Like many at this time, no doubt, I feel overwhelmed with this burden of responsibility, but know it is one we must continue to uphold with passion and purpose - supported by universities who we call upon to 
keep us and, by association, our students, safe too. I can only hope we are not too late to the game for there are surely no winners at the end of it all—despite economic greed that might suggest otherwise.

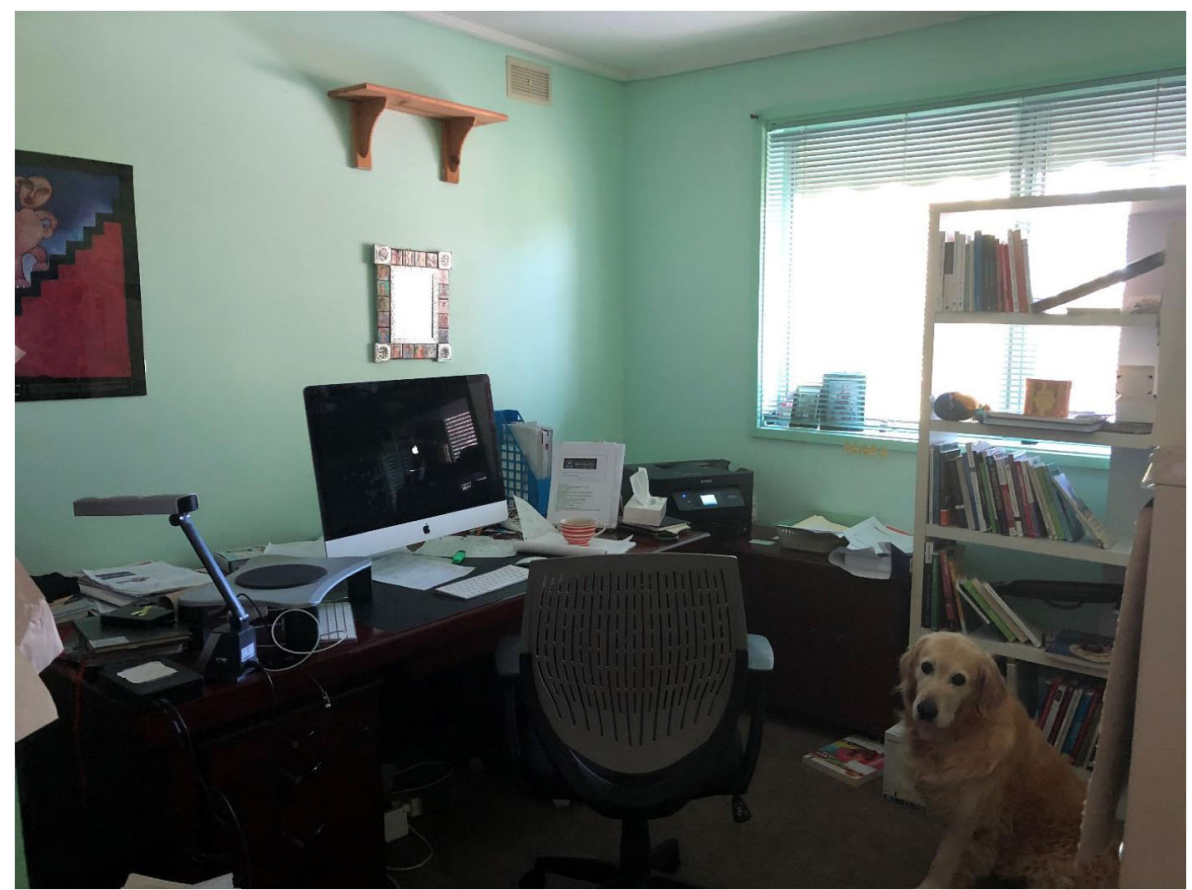

Fig. 34 The scene that awaits me every morning as I stumble from bed to work in less than 2 min with my coffee. I am greeted by my golden retriever, Bella, who sleeps at my feet while I work - in anticipation of her daily walk around the neighbourhood which grounds us both

\section{The Seen, but Unnoticed, Details of My Academic Life} Jacob Davidsen, Aalborg, Denmark, 29 March

Jacob Davidsen is Associate Professor at Aalborg University, Denmark. Jacob is 36 years old and lives in Aalborg, Denmark, with his wife and three children.

I have moved my office into the basement of our house - more precisely, I am sitting next to my power tools, screwdrivers, and a lot of mess in a small workshop. I am sitting here in the cave to make as little presence of myself as possible. With 2-year-old twins and a 6-year-old daughter, I need to hide to work during daytime. But so does my wife, who is also a teacher at a university college. We struggle to find time to work during daytime. Evenings are no longer for Netflix - we sit opposite to each other for hours, working and drinking coffee to keep us awake.

The Danish government sent all employees home on 12th March-we are now working and taking care of our children at the same time. We are expected to fulfil 
all our teaching obligations at Aalborg University, including supervising groups for the next two months. Perhaps we will even have to host online group exams in June. The outlook is extremely foggy. I had to change my final classes completely-I am quite familiar with teaching online, but this is just different. As one of the students told me after an online class - it is just awkward compared to what we were doing 14 days ago. I tried to involve students in different activities, but the mediated dialogue is just different. And I refuse to convert my teaching into broadcast lectures, even though that would be an easy solution. I think that the abrupt transition from on-campus teaching to online teaching resembles an extreme educational breaching experiment. On the 10th of March, I just finished teaching a $\mathrm{PhD}$ course; the next day, the university was closed, and online activities became the only option.

I am more social than ever-I take care of my three kids with my wife. But I really miss something in my academic life. While I participate in meetings with colleagues online and while we continue working together, I miss walking to the coffee shop with my close colleague, chatting about the state-of-situation. I miss informal meetings in hallways and the kitchen and the possibility of knocking on a colleague's door to chat about research and teaching. The question is what we can learn about our work life from being a part of this postsocial period. What will happen when we go back to normal? What will educational institutions become after this lockdown? What can we learn from this educational experiment and how can this experience lead to a better university in the future?

Finally, I have to admit that I have been taking the structure of my life for granted-that pedagogues take care of my children, that teachers are teaching my schoolgirl-I miss the structure of normal everyday life.

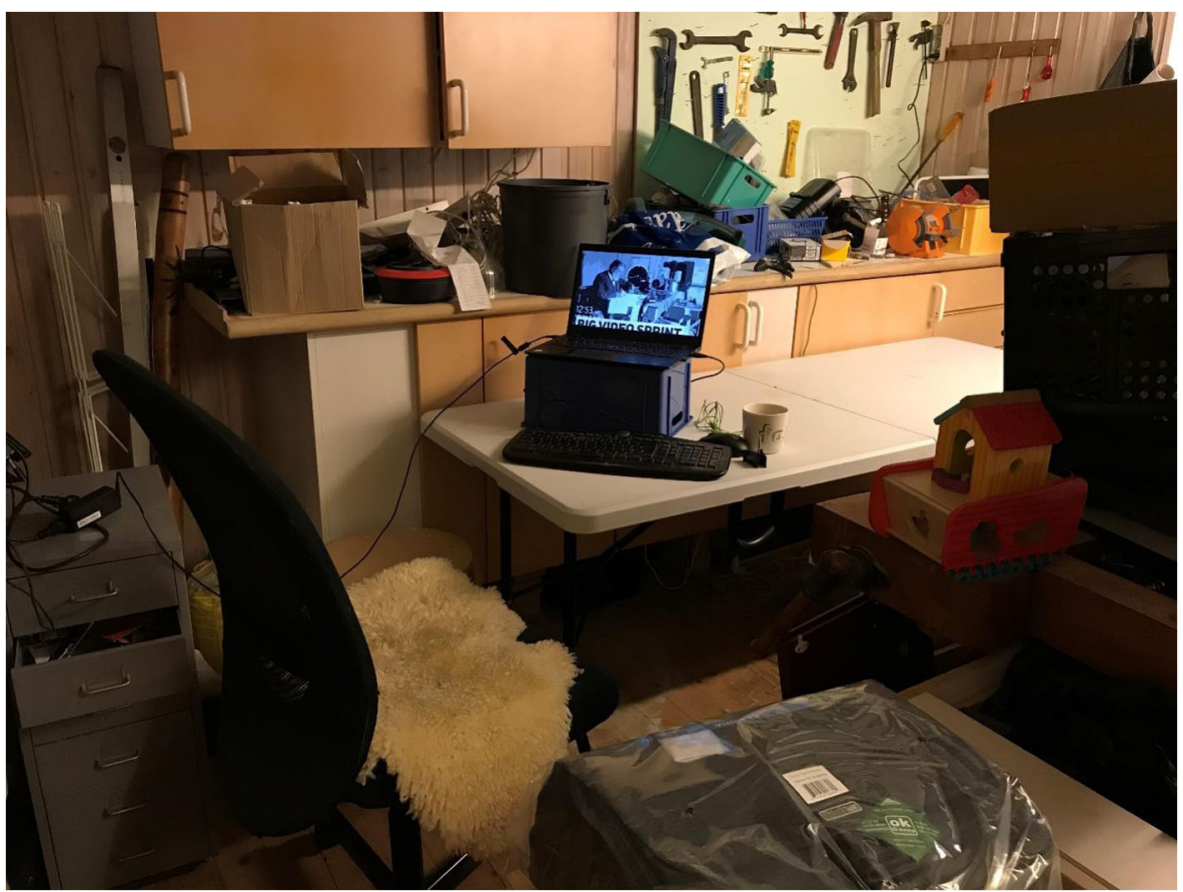

Fig. 35 This is my temporary workspace in the basement of our house surrounded by tools. I hide here to minimise presence to the rest of the family 


\section{To Avoid an Even Deeper Crisis}

Jimmy Jaldemark, Härnösand, Sweden, 30 March 2020

Jimmy Jaldemark is associate professor of education at Mid Sweden University. He is a 49-year-old homeowner living in Härnösand, Sweden, with his wife and their five children. He commutes to the office by train 50 minutes one way.

\section{$* * *$}

It is Sunday afternoon late March, and a chilly wind is blowing outside in the cloudy late winter weather typical of the mid-Sweden region climate during this time of the year. This report is written from my home using the office laptop that I luckily brought home on the last day before my long-awaited vacation. In early March, I went to Italy with my wife. By that time, the Swedish Ministry for Foreign Affairs had no negative recommendations for mid-Italy and Southern Italy, the regions we planned to visit. This advice changed on the last day of our trip to 'avoid visiting all Italy'. On our way back home to Sweden, I received an email from the head of my department, telling me that I will be quarantined because of my trip to Italy. So, my fate here was to work from home for at least two weeks. During my trip, worried colleagues had contacted both me and the head. The message was: stay away, something I felt was strange while I followed given security advice during the trip including being at least more than $500 \mathrm{~km}$ from the outburst in Northern Italy.

Without any choice, the house became a fulltime office including minor printing and IT service level, less comfortable working environment, and without daily physical meetings with my colleagues at Mid Sweden University (MSU). Much work is not problematic because MSU is known for its work within the field of distance education. At the Department of Education, roughly $80 \%$ of our students are distance students, and our model of distance education includes a blend of on-campus meetings and online activities. Students and teachers meet at campus three or four times each semester, each meeting lasting three to five days. A government decision changed these conditions, and from the 18th March, universities were not allowed to teach on-campus.

Thanks to our long experience of distance education and the application of tools such as learning management systems and web-based video-conferencing, we managed to quickly adapt to the new conditions. On-campus teaching and assessment were quickly moved online. Simultaneously, university management systematically worked on revising policies and arranging support for teachers and students. For example, assessment policy was changed including the allowance to switch already planned oncampus assessments to online assessment forms. Moreover, planned on-campus activities such as lectures, seminars, and workshops were allowed to be changed to online teaching. This made it possible for students and teachers to be productive.

Since the start of my isolation, I have participated in two to three video meetings per day. I still work from home but while showing no symptoms of Covid-19 I am allowed to commute to office. The campus I work at is still open for faculty. Nevertheless, it might in a later stage be closed down completely. At the moment, we are advised to minimize travelling. I like being at the office and usually commute at least four days a week. Working from home works quite well, yet issues such as a less reliable Internet connection make access to critical applications and information services shakier. Moreover, reading an extended number of documents on the screen is less effective, 
particularly if they are longer and rely heavily on theoretical discussions and reflections.

During these weeks, I have tried to keep my routines including getting up early and taking daily walks. During these walks, I have reflected on the role of the university and its role of being a critical reliable voice in society. In these times, disinformation is easily spread through the discourse of social media panic while people are looking for strong political leaders instead of leadership built on knowledge. To be able to uphold a critical knowledge discourse, I believe monitoring ourselves is fundamental to avoid being a loudspeaker for the panic. Moreover, to avoid an even deeper crisis in the aftermath of the current situation, the critical voice from the university might be crucial. A critical question is, will we be allowed by society to take that role?

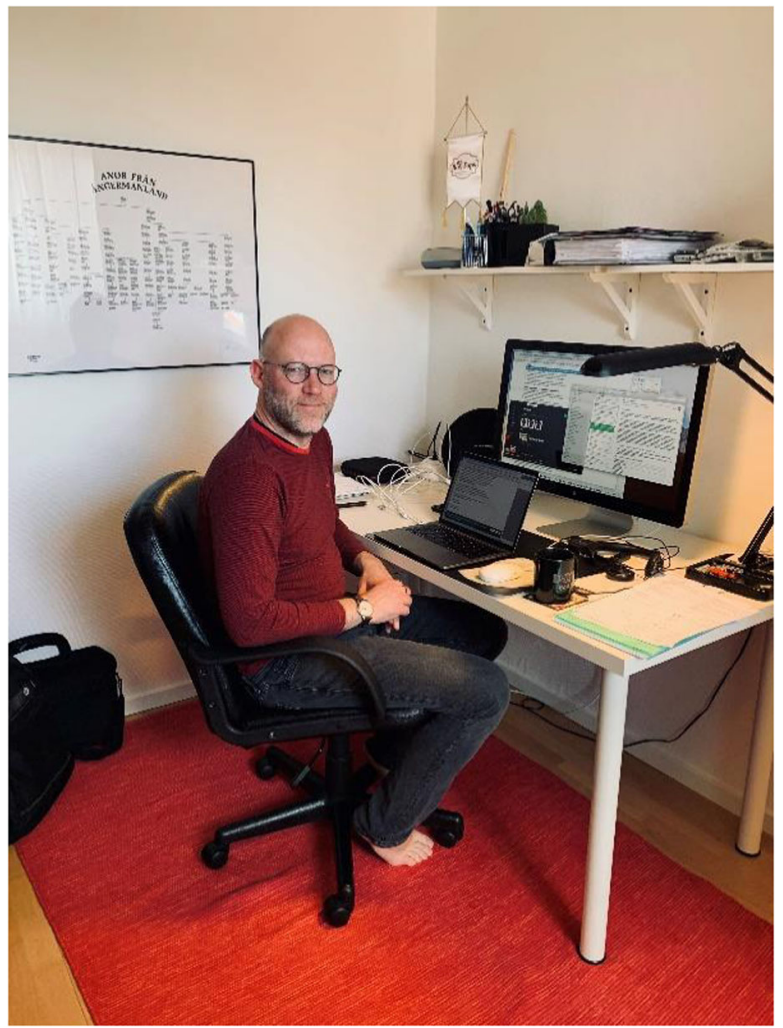

Fig. 36 A view of my workspace, a small office next to our living room. The room also harbours a bookshelf and a desktop computer for the gamers in the family

\section{Covid-19: Big Responsibilities. Reduced Time. Limited Space}

Sandra Abegglen, Calgary, Canada; Tom Burns, London, UK; Sandra Sinfield, London, UK; 30 March

Sandra Sinfield, Sandra Abegglen and Tom Burns have worked and taught together at London Metropolitan University, London, UK, for many years. Sandra A. has left LondonMet in 2018 and is now based at the University of Calgary, Canada, where she 
works on a research project that looks at design studio practice. Sandra S. and Tom B. are still based at LondonMet. They teach on the PGcert and MALTHE courses for academic staff, with a special focus on praxes that ignite curiosity, harness creativity and develop power and voice.

$$
* * *
$$

In the End, we will remember not the words of our enemies, but the silence of our friends. (Martin Luther King, Jr.)

We write this as a transatlantic collaboration between a post-1992 university in central London (UK) — with a student and staff body that is very diverse - and a North American university (Calgary, Alberta) - with five campuses and over 33,000 students.

We, the authors of this piece, are engaged in learning, teaching and research with a focus on higher education, staff development, creativity and inclusion. We have written and worked together for many years, initially face to face, and later online as one of us relocated to a different continent. These days, our collaboration takes place mainly through synchronous and asynchronous writing in GoogleDocs, often accompanied by real-time conversation through Skype/Zoom or online chat.

Our collaborative online work sustains us. Even though we have been situated in different time zones and contexts for nearly two years, it has led to an active exchange, with numerous projects and publications. However, the recent changes Covid-19 brought have also influenced our working, with Internet connections becoming more perilous, pressures on daily tasks such as shopping increasing and time for joint online activity dwindling along with our bandwidth. Despite this, we try to maintain our daily exchange and writingand use the limited time online to reflect on the changes occurring in the last couple of weeks.

Both our universities tackled Covid-19 lockdown head on, with emergency training for both staff and students, making use of existing and new online platforms and social media. The pace at which this happened was both alarming and reassuring. Senior management acted decisively, maintaining good communication and supporting staff and students through this challenging process. It is not a 'pivot' or adjustment to teach virtually. It is moving whole contents and communication systems online which requires sustained action, deep thought and engaged discussion-and also technical skill. And compassion.

In these uncertain times, we especially think about students and staff and the contexts they might be in. While instructors - and researchers - are often asked to act as distant professionals, now they have private and personal lives that directly intersect with their work. Home is workplace; the workplace is home. Students, too, must juggle learning, home-schooling and caring. 
While all this is challenging, very challenging, we see also positives. Engaging online has brought joy, new experiences and unexpected outcomes. For example, whole classes attending our virtual sessions when we feared no one would login. Online teaching as 'lens', interrogating what our students and staff are going through right now, revealing how we might support them.

Despite this, there are mixed feelings. Being an academic feels somehow a privilege with a position and salary that has-at least so far-survived closures and redundancies. Academia has provided a sort of refuge for many. However, this is certainly not true for all university staff-and definitely not for those outside our walls on temporary and hourly-paid contracts.

There is certainly the concern that this virus might take us back to the Middle Ages. Hopefully not in death toll, but we fear that through expediency or panic, educators will revert to more didactic and instructional design models of pedagogy. These then become permanent fixtures with risk taking, creative methods and engaging curricula marginalised, seen again as frivolous. In the new age of austerity, who will have the courage and the resources to experiment, draw, sketch, dance and knit?

Yet, this is a time when the very nature of universities could embrace and offer something more emergent, sustainable and healthy. Our universities' mission statements are apposite here: we do have a commitment to make a difference - to bring about positive change - and social justice. Now is the time to move beyond the current narratives - to invent new stories, new purposes and new identities - ones which can address the concerns of local communities and the global society. We are in a time of 'third space' - an in-between space - with affordances for building caring institutions valuing the collective and individual: a time for 'being with' rather than against.

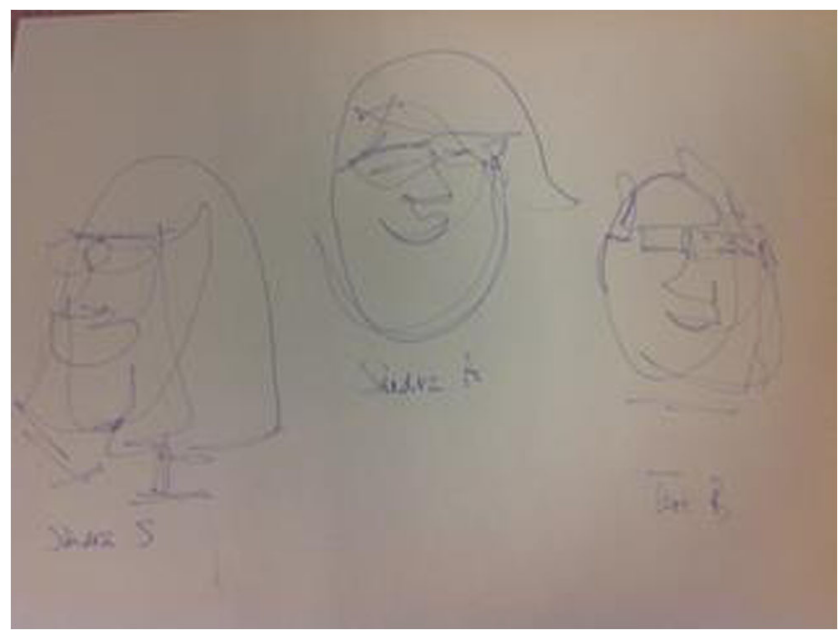

Fig. 37 This is a portrait of us three authors 


\section{Covid-19 and Our Illusion of Control}

James D. Kirylo, Columbia, SC, USA, 31 March

James D. Kirylo is Professor of Education at the University of South Carolina. $\mathrm{He}$ is editor of Reinventing Pedagogy of the Oppressed (2020) and author of Teaching with Purpose (2016) and Paulo Freire: The Man from Recife (2011), among other books.

As I am writing these reflections, pondering the impact of the coronavirus pandemic, my mind wanders in a myriad of directions. Globally, I think about family and friends I have in Italy - early on one of the hardest hit countries - who are exhorting me to let Americans know to 'not mess with this thing.' I think about the thousands who have lost loved ones to this deadly disease.

I think about the courageous healthcare workers who are on the front lines of all this, many of whom have been martyred in their dedicated efforts to take care of the other. I think about those all over the world in hospitals and clinics, desperately hanging on to life, living in the hope to beat the disease. I think about the brilliant minds of scientists, medical workers, and others who are racing against time to find a vaccine, a medicine to eradicate the spread of Covid-19.

Nationally, I think about the shortages of resources in the USA and indeed the world. I think about how underprepared we have been for this type of crisis, yet for years we had ample warnings (Sanger et al. 2020). I think about those who do not take the social distancing mandate seriously, scratching my head at that level of selfishness and irresponsibility. Clearly, many in the USA have been 'messing with this thing,' and now we are the epicenter of this pandemic (McNeil 2020). I think about the sanctity of life, yet betrayed by Texas Lieutenant Governor, Dan Patrick, who is 'all in' for lifting social distancing in a sense that is contrary to the recommendation by health officials, and suggesting that senior citizens ought to consider sacrificing their lives in exchange for keeping the economy going (LeBlanc 2020).

Locally, I think about the state of South Carolina where I live, seeing the Covid-19 cases going up daily. I think about the implications for my work as our university has gone exclusively to online teaching, as in the case presumably for universities all over the world. I think about my two middle-school-age sons at home, who have had to adapt to online teaching and learning and adjust to social isolation.

When I reflect on the global, national, and local impact of Covid-19, it is once again a loud cow bell on how these types of events (e.g., natural disasters, accidents, sickness, financial adversities) remind us that we are ultimately not in control. No matter how much we may prepare to confront the forces of nature, to anticipate and prevent accidents of every stripe, to take care of our heath, and to financially save, in reality, all of it can be gone with the proverbial snap of the finger. Covid-19 is teaching us just that. And perhaps that is not a bad thing.

It is responsible, of course, to make every effort to live a safe, healthy, and prosperous life. But, it is also good to let go of our illusion of control, which actually might just liberate us to live more freely, to love more deeply, to 
empathize more regularly, to respond more meaningfully with the transcendent, and, to be more aware of the plight our neighbour, realizing that many do not have the privilege of access, opportunity, and resources, simply depending on a civil society that values the common good, to look out for one another. When we get to the other side of Covid-19, hopefully we will remember.

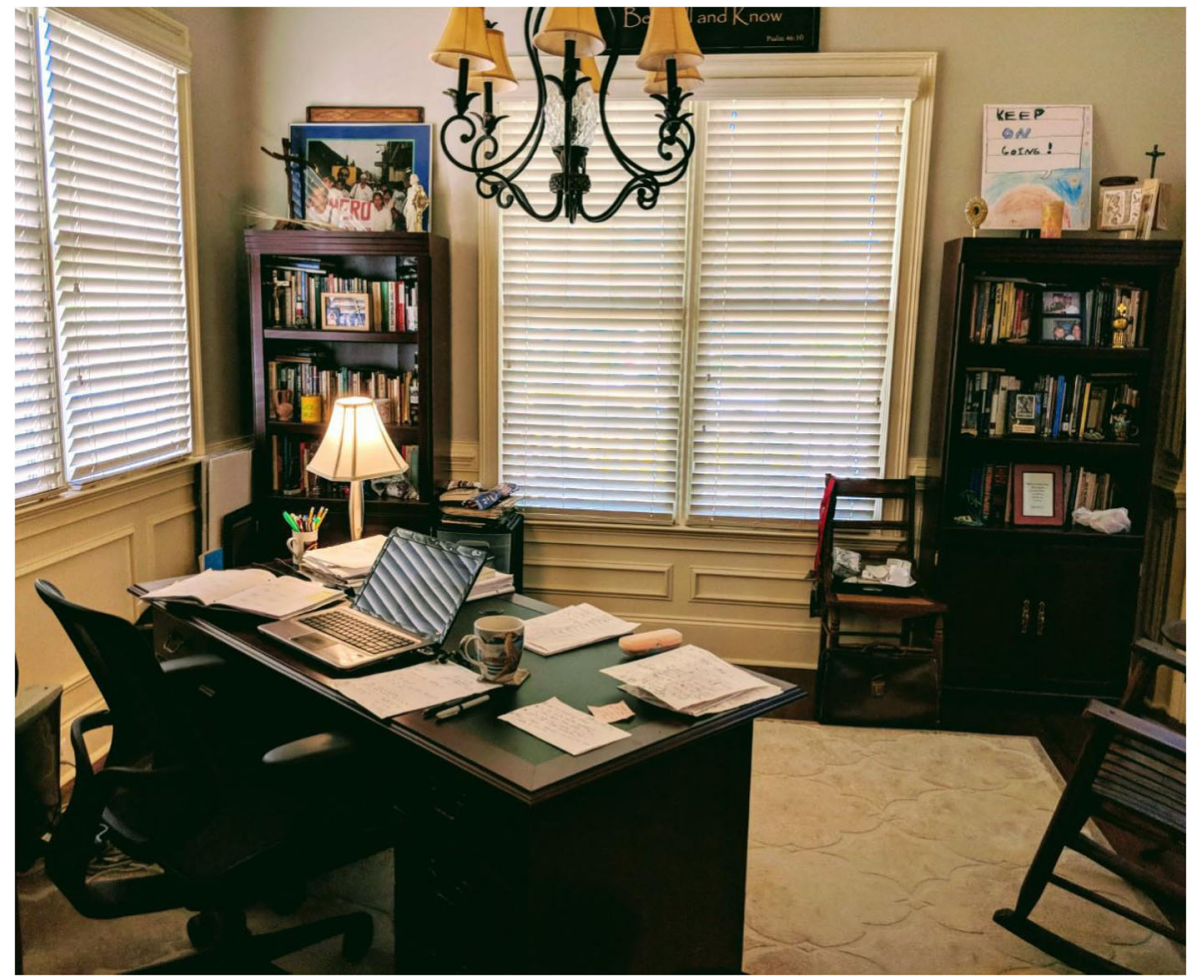

Fig. 38 This is my workspace office in my home for which I am very grateful

\section{Untitled}

Ivana Batarelo Kokić, Split, Croatia, 1 April

Ivana Batarelo Kokić is professor at the University of Split, Faculty of Humanities and Social Sciences, Croatia. Ivana is 48 years old and lives in Split, Croatia, with her husband and two children.

While staying at home this semester, I teach two graduate-level courses for future teachers: Distance Education and Comparative Education. Distance Education was initially designed as a blended course with face-to-face lectures and online seminars, and this structure had worked well in the past semesters. The 
Comparative Education course was designed as a traditional course, including both lectures and seminars in face-to-face mode. Materials for both courses are organized and displayed at a wiki page on my university webspace. Our faculty does not have a Moodle platform administrator, and the generic faculty website lacks features I commonly use in my teaching, so wiki has become my tool of choice for creating and managing course documents and assignments.

Due to the Covid-19 outbreak and measures, transfer to online teaching happened in the third week of 15-week courses. So far, there are no major technical obstacles. I made some quick adjustments in assignments and added forum discussions, which are directly linked to weekly lectures. I transferred lectures to a virtual classroom (virtual meeting room under the commercial platform), where I teach synchronously. Also, I record online classes and place links to weekly lectures at the course website.

Thinking about my teaching, I rely on my previous online experiences. Between 2000 and 2008, I taught online courses in Special Education at Arizona State University. These courses were designed as a team effort of area specialists and instructional designers. Although there are several online activities that I commonly use in blended format, I am aware of instructional design obstacles that are unavoidable in the fast and unexpected transfer to online teaching. Most of the course materials, assignments, and evaluations, which are linked to course outcomes, are not designed for online delivery. While trying to follow the course syllabi, it is necessary to change teaching materials, adjust and change course assignments, and consider ways in which evaluation should be changed.

Thinking about prospects, while staying at home with my husband and children, I hope that we will manage to protect our health and the health of elderly members of our family. These days, my daily routine is geared by my children's school assignments. They are attending the second and third grade of elementary school. Every morning, their teachers send daily assignments to a parents' group on WhatsApp. I am thinking about all those children whose parents are working outside home, not being able to help their children with school work, and the impact that this educational improvisation will have on them. 


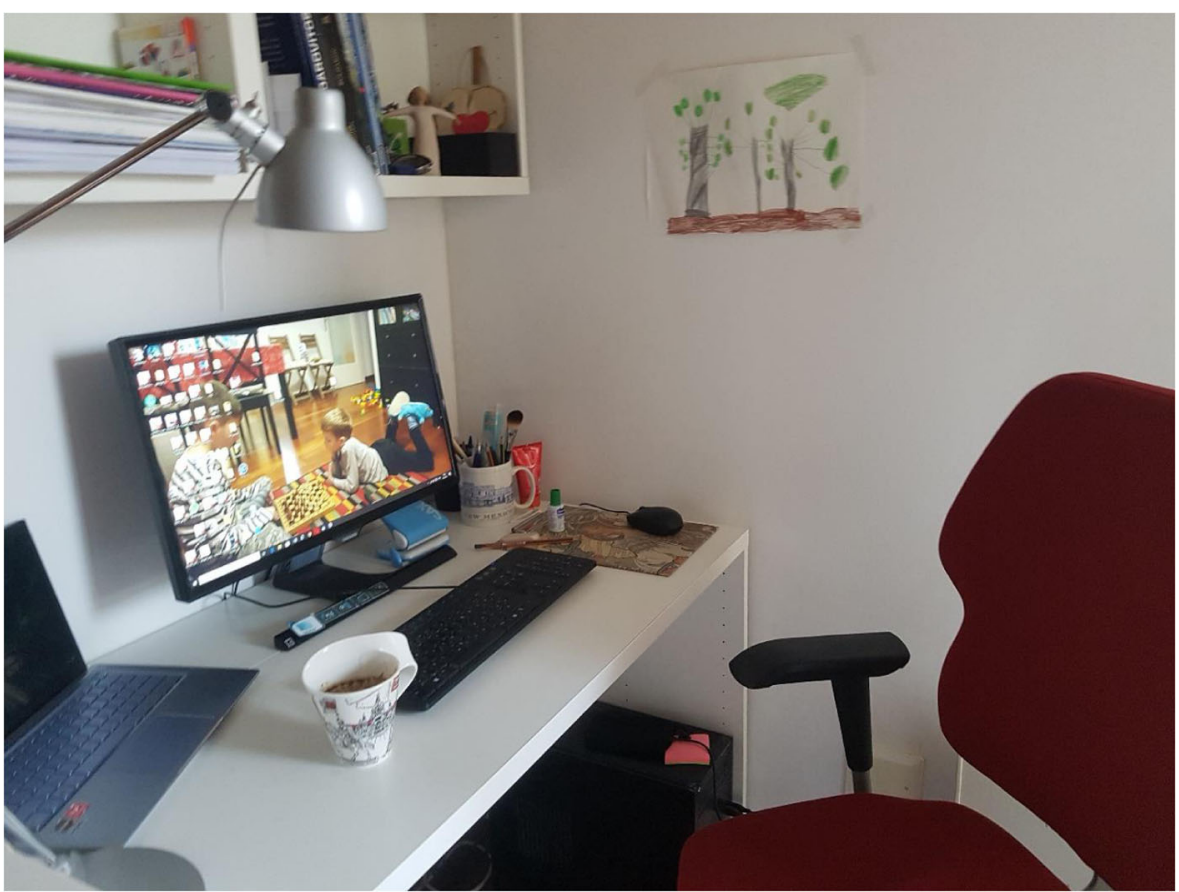

Fig. 39 This is my work desk at our home office, which I am sharing with my husband

\section{Thunderclap of a Butterfly's Wingbeat}

Georgina Tuari Stewart, Whangarei, 1 April

Georgina Tuari Stewart is associate professor in the School of Education at AUT (Auckland University of Technology) in Auckland, Aotearoa New Zealand. When not in lockdown, she commutes weekly between Auckland and her family home in Whangarei, Northland.

In educational research, we are ill-prepared to write to the timeline of a pandemic. April Fool's Day seems the most fitting of all days of the year on which to write about this global emergency. Asked to respond to the global outbreak of the novel coronavirus infection, all my impulses (the 'pedagogy of the pandemic' and so on) are liable to unoriginality, to having already been made into memes. My title comes from the postmodernist motif that links a butterfly to weather patterns. Two weeks ago, this virus felt remote and hypothetical from here in Aotearoa New Zealand; now, we are in national lockdown for four weeks, barred from our campus and all activities other than food shopping, and medical and essential services.

At first, I thought I could take advantage of the break to visit my coastal cabin, a 90-minute drive away, but it was quickly clarified that private travel was restricted to essential and local trips only, to reduce as far as possible the demand on emergency services. Visits to the supermarket across the road quickly 
became both a serious excursion for the designated 'bubble' shopper (me) complete with new queues and protocols, and a welcome change from home. We reduced visits in frequency from daily to twice-weekly, and made a list for the whole household. Our family dog sadly missed his daily ride in the car to run around at the park a few kilometres from the house (walks on leash around the block did not quite cut it), so a week into the lockdown period, I decided to reinstate that part of our normality (taking care not to let him play with other dogs). We rediscovered how nice filter coffee is. I made 2-ingredient bread (flour and yoghurt) in my air fryer, and planned meals with much more than usual care, both for mental distraction and to keep up the spirits in my bubble (surely the 2020 word of the year). It made me realise how lazy and dependent on eating out I had become. What a circuit breaker!

How fortunate I am to be an academic, which means being able to continue to work, especially with my research students, in some ways almost as usual. I know how much worse it is for almost everyone else. Traffic on my Facebook page has taken predictable turns. I am guilty of checking the daily tariffs, and moved by the clarity of message from our prime minister Jacinda Ardern, leading her country with grace through another crisis, posting live video from home, dressed in an old green sweater to answer questions from the public about the pandemic response. This kind of message was world class politics, and a paradigmatic example of educational leadership.

This pandemic, for those of us who neither are global owners nor mesmerised by Trumpian portrayals of 'reality', as well as being an absolute tragedy on a global scale, also seems to be the sign of hope in the world for which we have been waiting: the event that triggers the start of the collapse of late capitalism, revealing the baseless greed of the rich and famous and the covert brutality of the neoliberal philosophy underpinning current forms of economics. How will humanity answer the test question of Covid-19? Let us wait and see. 


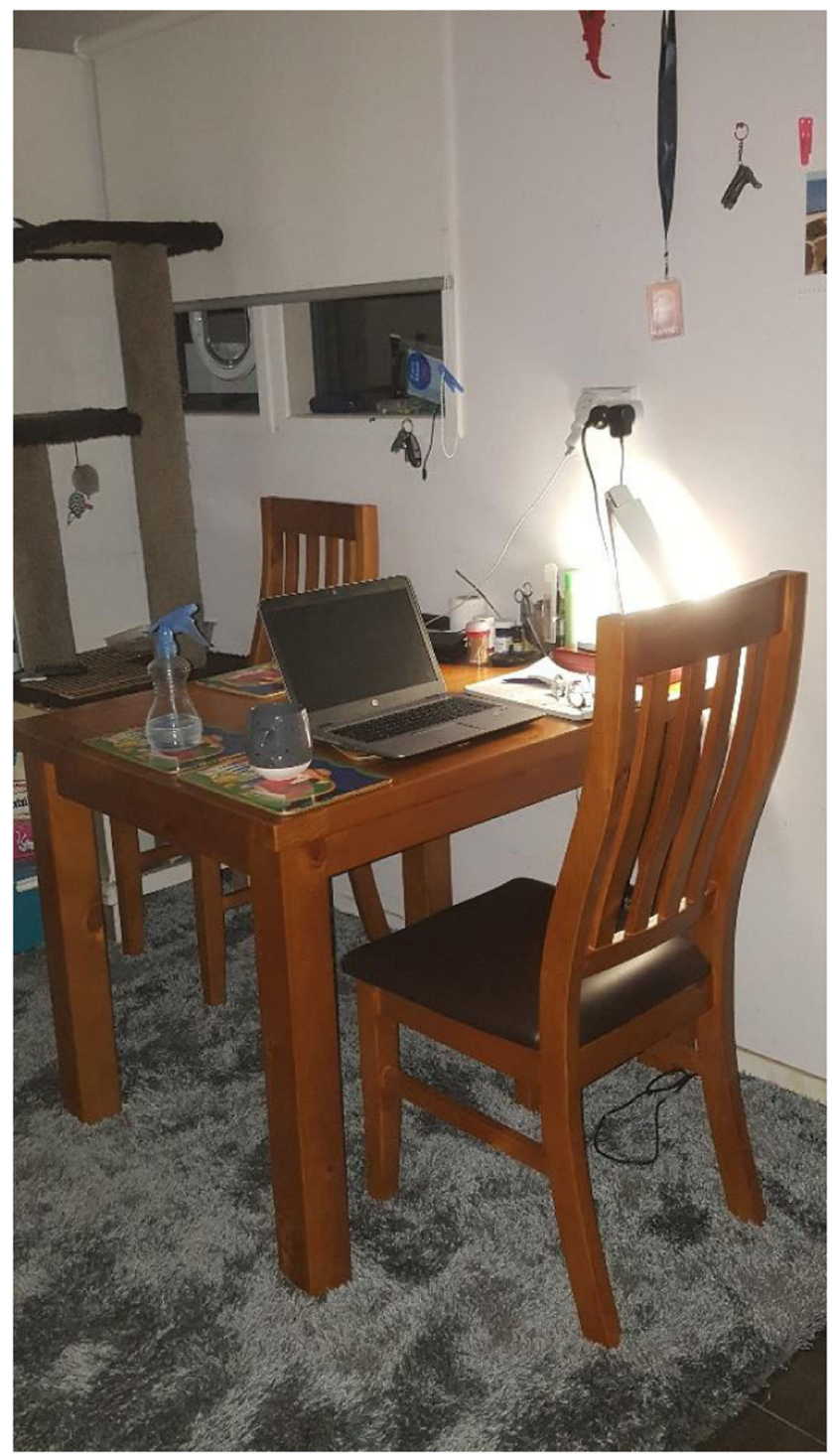

Fig. 40 I get up early to work at the small table while my partner is still sleeping 


\section{Virological Encounters}

Glenn Rikowski, East London, UK, 2 April

Dr. Glenn Rikowski is a visiting fellow in the College of Social Science, University of Lincoln, UK. Glenn is 68 years old and lives with Ruth, in Forest Gate, east London.

I am a visiting fellow in the College of Social Science at the University of Lincoln, UK. I live in east London. In the current Covid-19 crisis, I am rather a non-visiting fellow. As my appointment involves minimal teaching, I will talk about virological encounters, in their computer, academically conceptual, and biological forms, with additional family-related material.

Beginning in the mid-1990s, I was concerned with viruses invading my home computer. Back then, anti-virus software mirrored the primitive nature of organic viruses. I tried different brands; all incorporated vulnerabilities. This came to a head in 2001 when I attended the May Day Monopoly events in London. I distributed a leaflet (see Rikowski 2001: 44-47) at the event—with my email address on it! Barely avoiding being kettled for 6 hours in Oxford Circus, I arrived home just in time to let two of my kids in from school. Turning on my computer, I found it had been infected with a bunch of viruses. Coincidence? Maybe.

Around the same time, I was researching and writing on the business takeover of schools in England. I likened the process to capital virusing state-financed public education. This met opposition when writing an article entitled 'The Profit Virus: The business takeover of schools' (Rikowski, 2003). The editors insisted on deleting the first part of the title. They wanted references to 'virus(es)' and 'medical metaphors' extinguished too. I complied.

By around 2007-2008, I had pretty much solved my computer virus issues but was then dealing with capitalist crisis in the form of the Great Recession. We now face a much more serious crisis in Covid-19, with dire health, economic, social and political consequences. I gathered a huge amount of material on the events of 20072009 , and by 2013, I was starting to write on the concepts of 'crisis' and education crisis. At the point I was preparing to give my first paper on 'Crisis and Education' at a Marxism and Education: Renewing Dialogues Seminar, in May 2013, I stumbled across Hippocratic Writings on the shelves of the book exchange on Stratford station! Hippocrates emphasised that a crisis can return, something our youngest son and my wife fear in relation to Covid-19. Our son caught the virus on holiday in Thailand. A month after suffering its worst effects, he still wakes up some nights struggling for breath. My wife has Covid-19 as I write-we isolate within the house-with everyday chores requiring strategic planning. Both Ruth and our son hope that having Covid-19 once gives some immunity.

Our other two sons are working from home. Alexander works in a university medical library, frequented by NHS staff. Our daughter-in-law, a doctor and cardiological researcher, has been drafted onto Covid-19 testing research. 
A few days ago, via The Guardian, I discovered that students at the University of Lincoln's School of Engineering are making safety visors and ventilators for local hospitals. The Student as Producer at its finest!

Viruses and capitalist crises plague our lives. If only capitalism was a mere ghost!

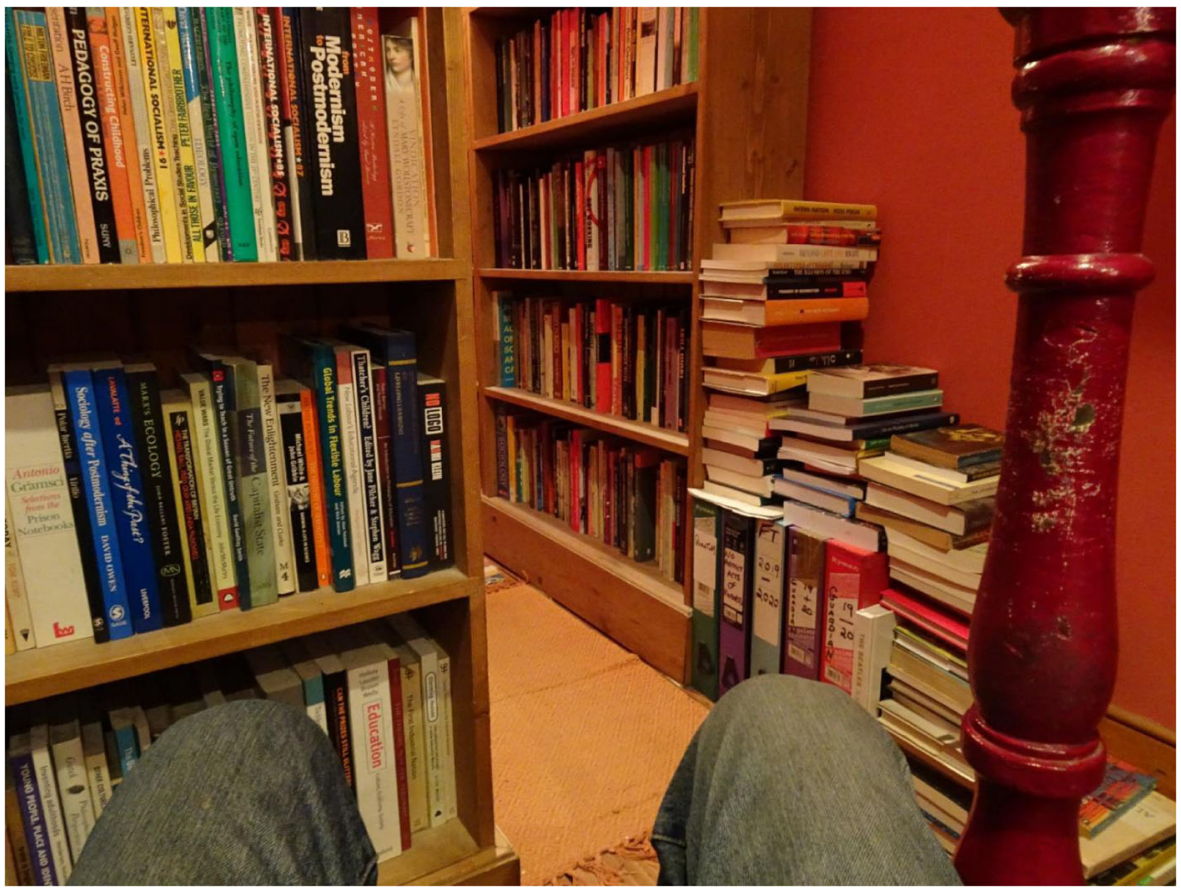

Fig. 41 View of the first floor landing. Piles of books = lack of space!

\section{Untitled}

Line Lisberg, Christensen, Aalborg, Denmark, 3 April

Line Lisberg Christensen is a research assistant at the Department of Communication and Psychology, Aalborg University, Denmark. Line is 28 years old and lives in Aalborg, Denmark, with her partner.

As I sit in my temporary office at home, we have reached our third week of lockdown on March 31, 2020. Covid-19 has reached all corners of the world and we are all feeling the effects. Aalborg University, my place of employment, has sent us emails about the Covid-19 since the end of February, often in a stream of 2 or 3 emails at once. Thankfully, many of us are able to work from home and provide similar results using online platforms for teaching, Skype for meetings and online word-versions for co-writing. 
Despite our capabilities of maintaining a seemingly 'normal' everyday life, our televisions and radios bombard us with news and scary images of what seems to be an apocalyptic horror movie, but this is our current reality. Fears of hoarders and frantic citizens have led to a massive increase in the price of hand sanitizers and wipes. Our government maintains weekly press meetings with new information and actions taken to flatten out the curve of the coronavirus spread. Police cars are patrolling the streets more than ever, and fines are handed out to those that do not comply with governmental measurements. Our hands are sore, and the skin is splitting from sanitizing. Kisses, hugs and handshakes are prohibited, and social media suddenly feels like a poor means to stay connected.

Distrust is now, more than ever, a big part of our everyday lives: can we trust our neighbours to sanitize their hands before touching the handles in the corridors? Will the supermarket clerks clean areas that are often touched? Can we hug our family members without prejudice and mistrust? Will the social awkwardness vanish, once the restrictions are lifted? Will our society return to 'normal'? Only time will tell what the effects of this pandemic will be.

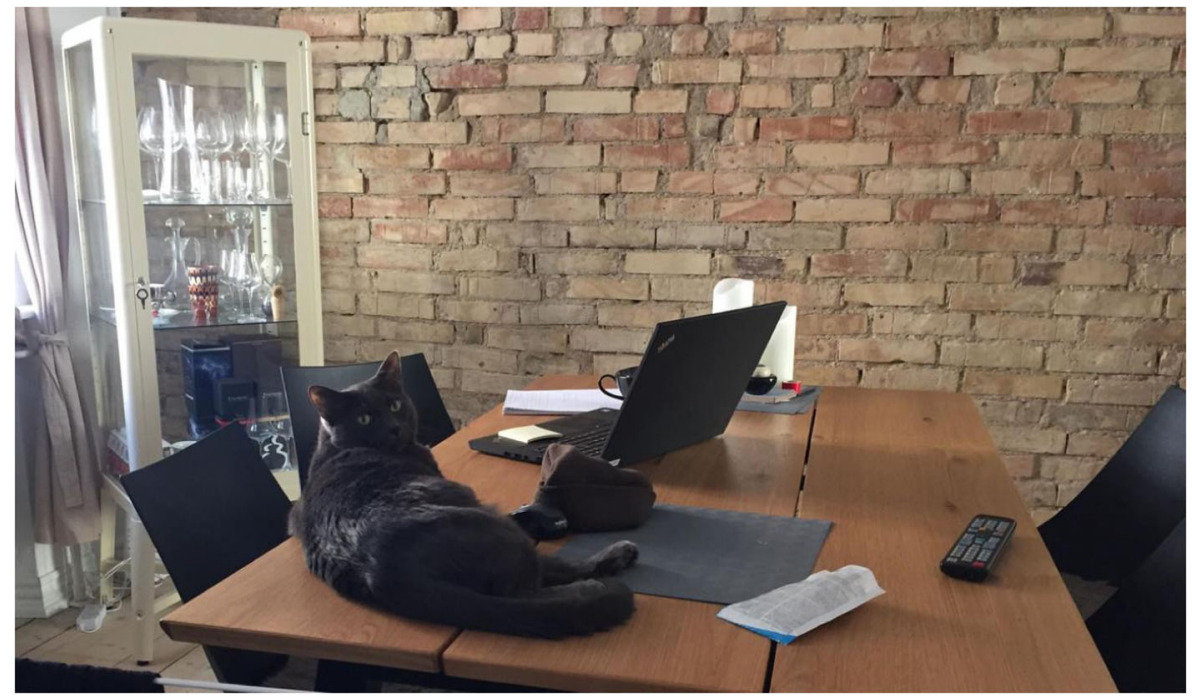

Fig. 42 This is my workspace: but also partly my dining room, living room and personal space where I normally share with my partner the details and experiences of the day

\section{From Brunswick, Melbourne}

Sonja Arndt, Melbourne, Australia, 3 April

Sonja Arndt is a lecturer in the Melbourne Graduate School of Education at the University of Melbourne, Australia. Born in Melbourne, she returned in late 2019, having lived most of her life in Aotearoa New Zealand. 
Moving to Melbourne was a dream; I had a position at the University of Melbourne and was coming home! In 2019, when I arrived, the city was buzzing - with summer looming, its vibrancy and a love of life were palpable: rooftop bars were full, the Yarra River weaving through; close by, beach areas inspired road trips, and cafés, restaurants, galleries, shows, music venues, enticed, delighted and entertained - it was, as it boasted, a very liveable city! Then, late in 2019, the bushfires that had started in September in many regions spread to envelop huge chunks of the country (Hadden 2020)! Melbourne itself was spared from the flames but became cloaked in thick smoky air on enough days to call for restrictions: to stay indoors and to wear masks when outside.

Already during the summer's bushfires, many staff, students and families at the university were affected, depending on support and emergency arrangements as people became stranded, fought fires, looked after family or fulfilled other essential roles in support of community. Fundraisers were arranged for the firefighters (or 'firies'), and for wildlife and struggling businesses in many very badly affected areas.

By the time the coronavirus began to spread, many Australians had already been through unimaginably difficult times. Too many businesses either had already collapsed or were on the brink of collapsing, bushfire 'refugees' were left having to rebuild or salvage homes and the health of far too many was affected by the smoke and the emotional turmoil ravaged by the monster fires.

Then came the virus and Covid-19. The big unknown! In our academic lives many of us promote, call for, engaging with uncertainties, embracing the uncomfortable, being open to diverse possibilities - but this uncertainty blindsided us and every level of society. This invisible, non-human microscopic virus at first ignited panic, anxiety and irrationality. The palpable buzz of the city gave way to a palpable fear. And it is not just localised; all of these elements are repeated at a global level, shared, meeting by meeting, zoom by zoom.

Who knows what the outfall of Covid-19 will be? Of course, over some weeks, new routines evolved: lectures continue, online; tutorials continue, online; meetings continue, online-but how much online is too much? Life is anything but normal. Streets are empty, with all but the hardiest of takeaway coffee shops and essential services opening their doors, very tentatively. Everybody is at home; the virus has sucked the life out of the city... but, in all kinds of communities, a reimagination is underway, a quiet revolution, rekindling relationships, closeness and togetherness in creative ways. While it's hard to imagine, perhaps Covid-19, in all its horrors and death, may have an underlying effect, reshaping our dreams, forming a permanently altered buzz, in academia, life and all of our worlds? 


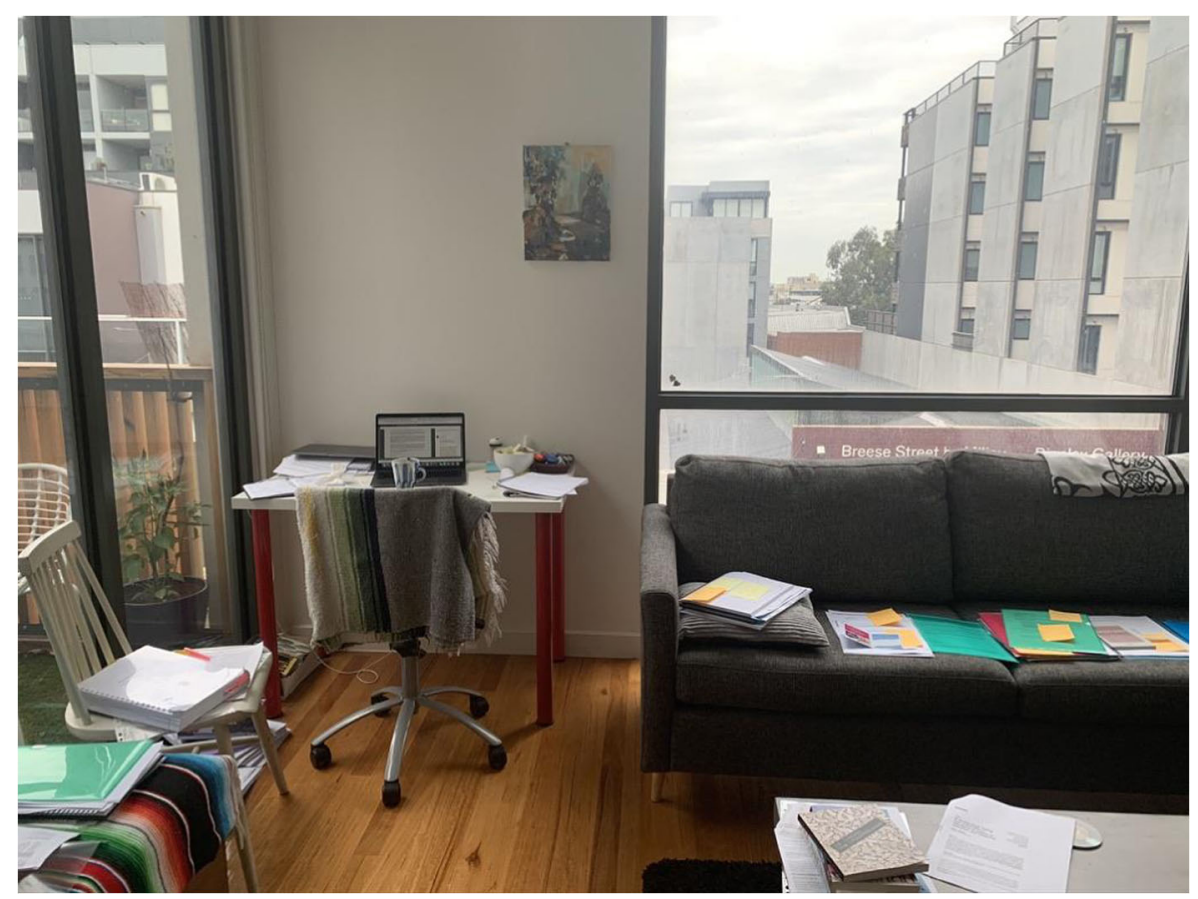

Fig. 43 Reconfigured office-living-exercise-dining space in Brunswick

\section{Untitled}

Olli Pyyhtinen, Helsinki, Finland, 3 April

Olli Pyyhtinen is associate professor of sociology at New Social Research (NSR) programme, Tampere University, Finland.

I am writing this text at my partner's flat in Helsinki, Finland, where I have been in lockdown with her for three weeks now. The campus facilities of Tampere University where I work were closed on 18 March due to the Covid-19, and it is quite likely that all teaching, learning, and staff meetings will take place online until summer, or who knows how long this strange limbo will last. The week before the coronavirus broke out here in Finland, I was still teaching in class and had a meeting with my colleagues, which seems like another world now. My partner and I have discussed how we, and perhaps all of us, were living in an age of innocence before the outbreak. The coronavirus was assumed to be no different from a seasonal flu. Yes, some people will get sick, we figured, a few others will even die, sadly so, and the economy will suffer from severe blows for sure, but we nevertheless naively thought that only individuals or people in a vulnerable position would be affected. Subsequently, 
it has, however, become obvious that the situation touches each and every one, not only each of us individually, but all of us together, all our actions and all that happens to us, possibly the entire world order as we know it.

Until the last few days, I had no teaching during my time in lockdown. Originally, I was supposed to leave for a visit at the University of Bologna in mid-March and stay there until early April, so I had been exempt from all teaching duties. It is only after my virtual homecoming, never actualized because of not leaving home in the first place, that I have engaged in teaching again. I taught two online seminars and participated in a couple of meetings. They went unexpectedly smoothly, without any significant technical or other problems, apart from the minor detail that in one of the two sessions I had been talking to the students for a while before I realized that I had my microphone turned off. Overall, the students seem to manage the technology a lot better than I do. It was them who suggested that we'd have our thesis webinar on another conferencing platform than the one I used for staff meetings with my colleagues. One of my students even sent the rest links with instructions.

All this time I have also been separated from my kids, which is the longest time we have ever been apart. But we have found other ways of being together. For example, we have had video calls with my son reading a book to me, and others during which I have done some stretching together with my daughter. The peculiar contrast and mixture of spatial distance and social, mental, or emotional closeness appear to reach its culmination during this time of selfdistancing.

My own feelings towards the coronavirus situation are mixed. I feel like we are experiencing and living amidst a violent collision of two realities. On the one hand, there is a reality of containment, where everything stands still and the world seems to have been brought to a halt, which produces an eerie sense of calmness. This is a world of being. Even time itself seems to have stopped or it goes around in circles. On the other hand, this Euclidean space collides with a fluid reality, a relational world of becoming. In it, things fluctuate, mix, and mutate uncontrollably; there are encounters, contagions, and transformations; people get ill and die like flies. Containers - such as buildings, our bodies, packages - block incessant flow and keep in place what would otherwise fluctuate endlessly. Yet life refuses to be contained. It has a way of leaking and outpouring. The paradox we are thus faced with is that staying alive requires at once both containment and leakage. Personally, I find this utterly distressing, but I also have faith in the fact that we will find a balance between them. That will get us out of this. 


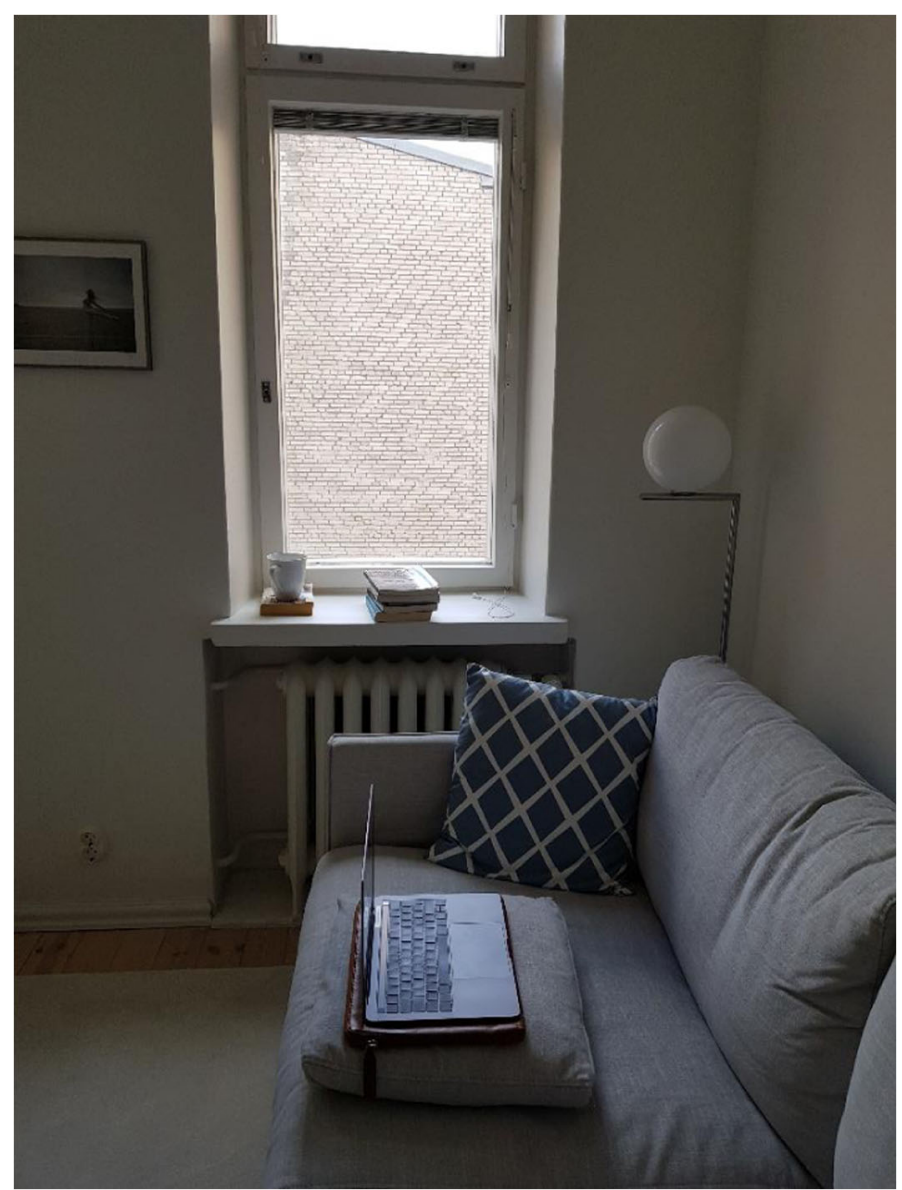

Fig. 44 This is my workspace in our living room. On the sofa we also regularly enjoy our morning tea and coffee and binge-watch Netflix

\section{'Everything Depends on Labor'-Critical Thinking Across the Curriculum} Today

Charles Reitz, Kansas City, 3 April

Charles Reitz is the author of Ecology and Revolution: Herbert Marcuse and the Challenge of a New World System Today (Routledge 2019); Philosophy \& Critical Pedagogy: Insurrection and Commonwealth (Peter Lang 2016); Crisis and Commonwealth: Marcuse, Marx, McLaren (Lexington Books, 2015); Art, Alienation and the Humanities: a Critical Engagement with Herbert Marcuse (SUNY Press, 2000). 
A problem-posing unit for all teachers at all levels: What has the Covid-19 crisis taught us about ourselves and our society, about our image of ourselves and others as independent individuals? What have we learned about how we, and society, are sustained?

Points for directed discussion: The Covid-19 crisis has unveiled the crucial role of the lower-wage labor force in our society: truck drivers, grocery stockers, cashiers, and of course higher-paid medical professionals. This revelation is actually a profound philosophical and political truth: the workforce overall is the sustaining force in the economy. Private ownership of business is clearly not necessary for economic activity or production overall. The necessary component is labor. Everything depends on labor.

Today labor is precarious. Can one think of oneself as a critical thinker and not question why society today perpetuates this precarity? What are the political sources of society's inequalities of wealth and income? What are the roles of class, race, and gender? How about the role of racial scapegoating as deflection of anger away from the real if hidden sources of our precarity?

Labor is our resource: it is how human beings care for one another. Labor is the essence of the sociability of our species. Humanity's earliest ethic of holding property in common is rooted in our essentially shared species life and our being as humans. African proverbs teach the survival power of partnership and cooperation and the advantages of empathy, reciprocity, and hospitality in ubuntu. 'I am who I am because of who we all are.' Our right to a partnership economy, politics, and culture resides in our common work. Yet today labor is unfree, controlled by finance capital.

Of course Marx famously grounded partnership politics in the activity of and the needs of labor. There is also a stupendously supportive quote from Abraham Lincoln (1861: 10) on this: 'Labor is prior to, and independent of, capital. Capital is only the fruit of labor and could never have existed if labor had not first existed. Labor is the superior of capital and deserves much the higher consideration.'

Against capitalism, the pivotal power of labor is the general strike blocking capitalism's income flow. Today Covid-19 is having a similar effect. Labor needs to take possession of capital stock and transform it into common property, common wealth.

The latent power of labor is central to emancipatory theory and praxis. Commonwealth labor is not only a social and productive force, making possible economic abundance and productive freedom, but also racial equality, women's equality, ecological balance, leisure, abundance, and peace. 


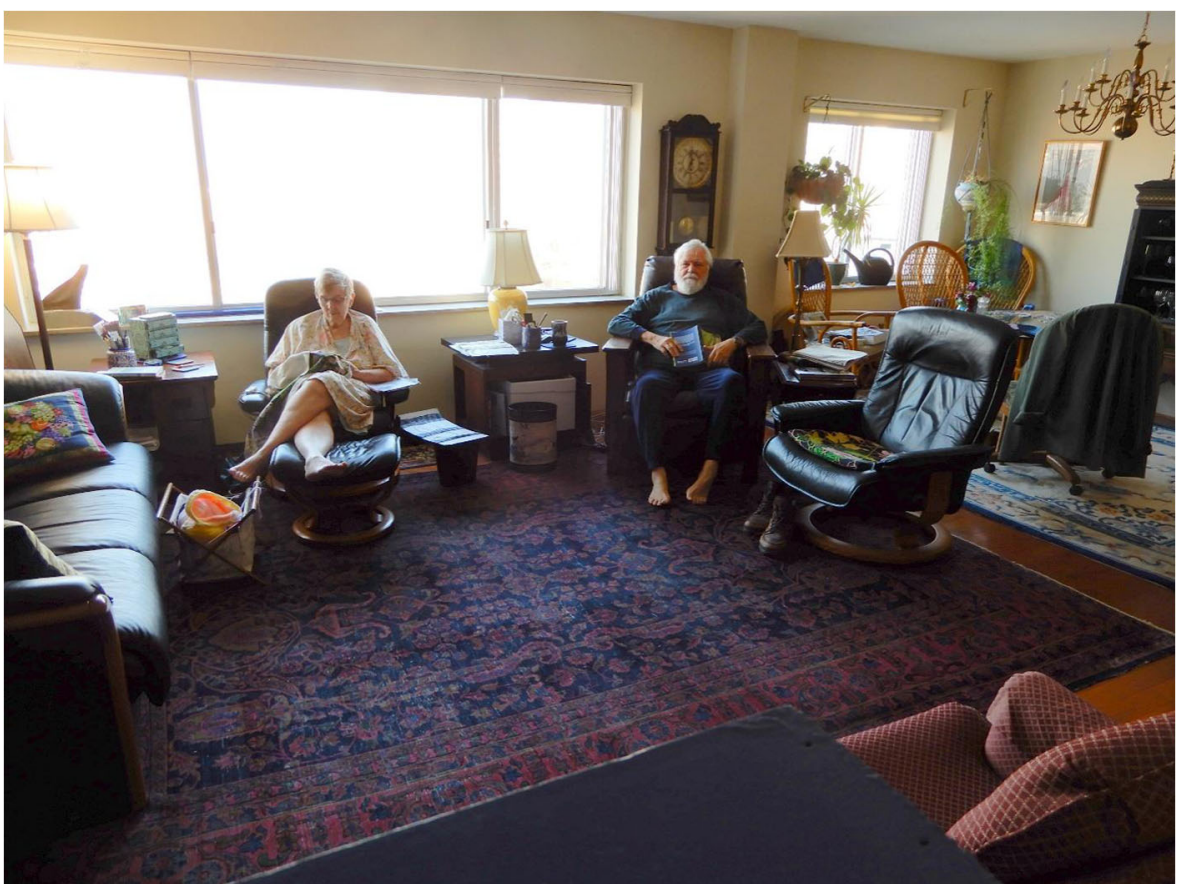

Fig. 45 This is my actual workspace in retirement: apartment living room, with my life's companion of 42 years

\section{The Work That Work Requires}

Mikkel Lodahl, Randers, Denmark, 4 April

I teach at Dania Academy's games department, Dania Games, in Grenaa, Denmark. The academy moved their entire teaching effort online from one day to the next in response to Covid-19. I have been expected to support colleagues in this, advise students, and conduct an online exam.

Tuesday the 10th of March. I gave my students their project assignments for the last class I am teaching this semester.

Wednesday, the government closed down the entire country.

Thursday, we closed down the campus. Students, who were not ordered home until Friday, walked around the campus in a daze. We tried to reassure them, though we had no real idea how long this would go on for, or what exactly we were going to do. 
I suggested two online faculty stand-up meetings every week. We have been doing these meetings since the beginning of lockdown, and they work pretty well to give a sense of cohesion to the department, even though we have not seen each other for almost a month.

Most of the students work within our framework - the HAGI model, which I designed-where we teach them knowledge and skills for about a week, and then they use their acquired knowledge and skills in a project to build working software. The foundations are the model's principles of acting (Danish: Handling) to build artifacts (Danish: Artefakt), while the teaching staff ensures transparency (Danish: Gennemsigtighed) in assessments and syllabus design, all in an atmosphere of inclusion (Danish: Inklusivitet). Most students were in their project phases. We moved their advising sessions online, using Discord, which all our students already use.

My colleagues had to move their classes online. I produced a list of suggestions for online teaching, encouraging a mix of synchronous and asynchronous methods using the tools we already had access to, sidestepping as many General Data Protection Regulation (GDPR) issues as possible. Most teaching since then has used my suggestions, and the students are so far satisfied.

The students report they generally work well in this new situation. However, some of the strongest students are having the most difficulty with not being able to meet up physically. Physical proximity remains an underrated part of excellence in computer science work.

Conducting an online exam is interesting. The ministry had issued a paranoid rules document to compensate for students not having witnesses present at home. After forcing students to film under their desks with their webcams, the exams proceed well — in general, students are much more relaxed and less anxious. Perhaps something to be adopted after?

My main challenges in this situation are personal. My partner and I have two small children at home. This makes it impossible to get work done during the day, unless one of us takes both children, who require great amounts (but different sorts!) of attention. We're both exhausted at night, which makes it difficult to catch up. For the exams, I had to visit my parents and bring our youngest along.

I think we, academics, can learn from this. Professionally, we can solve almost anything. As individuals and in teams, we can do wonders. But this is only because many aspects of our personal lives are professionalised and taken care of-by other great professional individuals and teams. No matter how rightly proud of our achievements we feel, they are built upon the work of many other people, who allow us the time to do that work. Remembering this when the pandemic is all over could combat the ivory tower effect of an academic life focused on producing and publishing. 


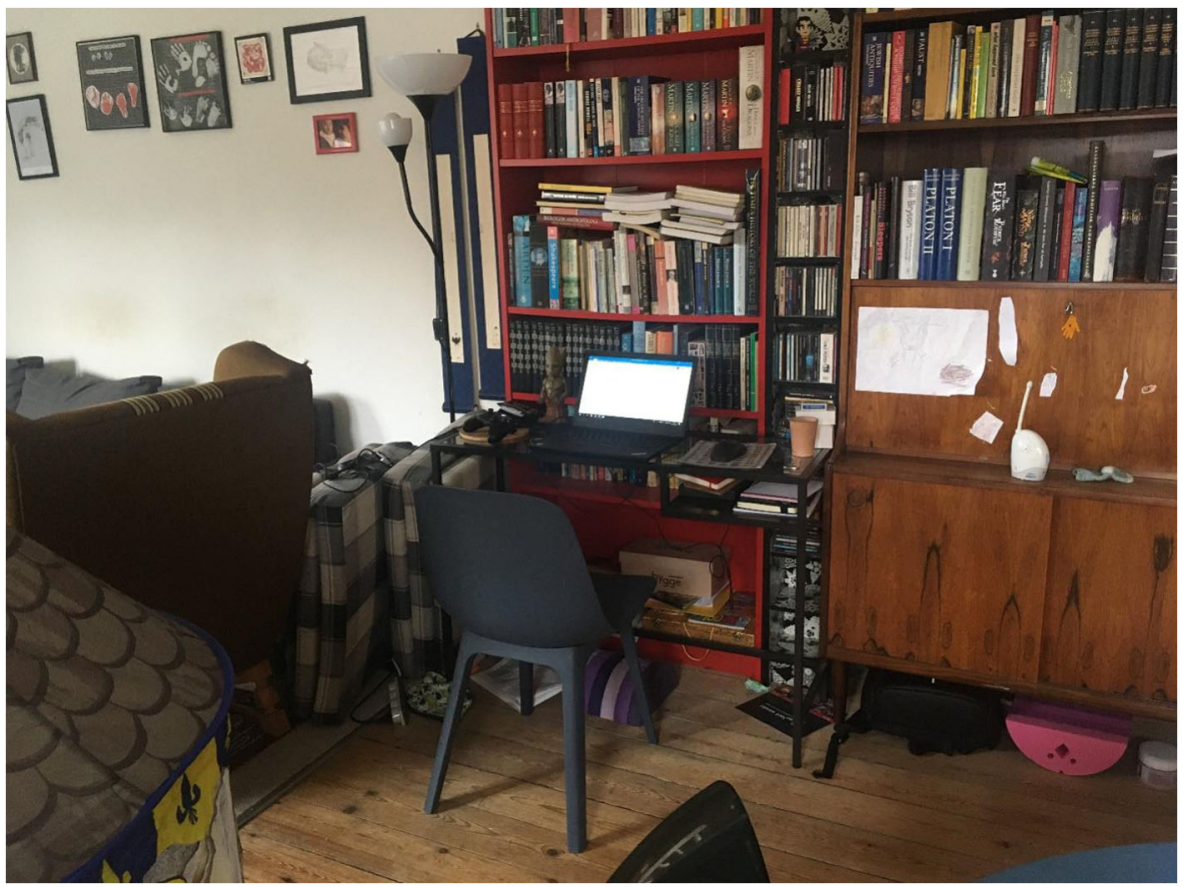

Fig. 46 A small desk we did not use and a dining room chair has been put in front of one of our bookcases in the living room to make my workspace. Randomly discarded toys and clothes from the children are strewn around it decoratively, with personal pictures, gifts and mementoes hanging on the wall. I would later add an extra monitor on loan from work

\section{Untitled}

Niklas Humble, Östersund, Sweden, 4 April

Niklas Humble is a PhD student in Computer and System Science at Mid Sweden University. Niklas is 33 years old and lives in Östersund (Sweden) with his wife and son.

I am a PhD student in Computer and System Science at Mid Sweden University, and it has been a couple of weeks since the university recommended that personnel work from home and limit their travel. These recommendations have become stricter and stricter, and an increasing number of teaching and research activities have been cancelled or moved online.

My work has not been affected as much as it has been for others. At my department, we are quite experienced with online meetings and online teaching. I am researching the use of programming tools in K-12 education (kindergarten to grade 12), and some of my research is dependent on visiting schools and interacting with teachers and students. Since many schools have closed or no longer allow visitors, that part of my work has been more affected. 
Newsflashes on TV and on my mobile phone keep reminding me of what is happening all around the world, as do all my conversations. Which stores have closed? Who is sick? Which countries have closed their borders? How many people have died? Everything and everyone is seen through a lens of this disease.

It feels a bit strange to not meet my co-workers during the day, to keep distance from other people in the stairwell of my building, and to see face masks at the grocery store. I am also worried for my parents and older relatives that live in another part of Sweden, that I have not been able to visit for some time. I am worried for many people and many aspects of our society, as I am sure that many others are.

But these times also remind me of what I have and what I am grateful for. I am grateful for extra time I get to spend with my wife and our child during coffee breaks and lunch. I am grateful for long and peaceful walks we take in the forest with our two dogs. I am grateful for technology that allows me to keep doing my job from a distance and, more importantly, allows us to see and talk to our friends and relatives.

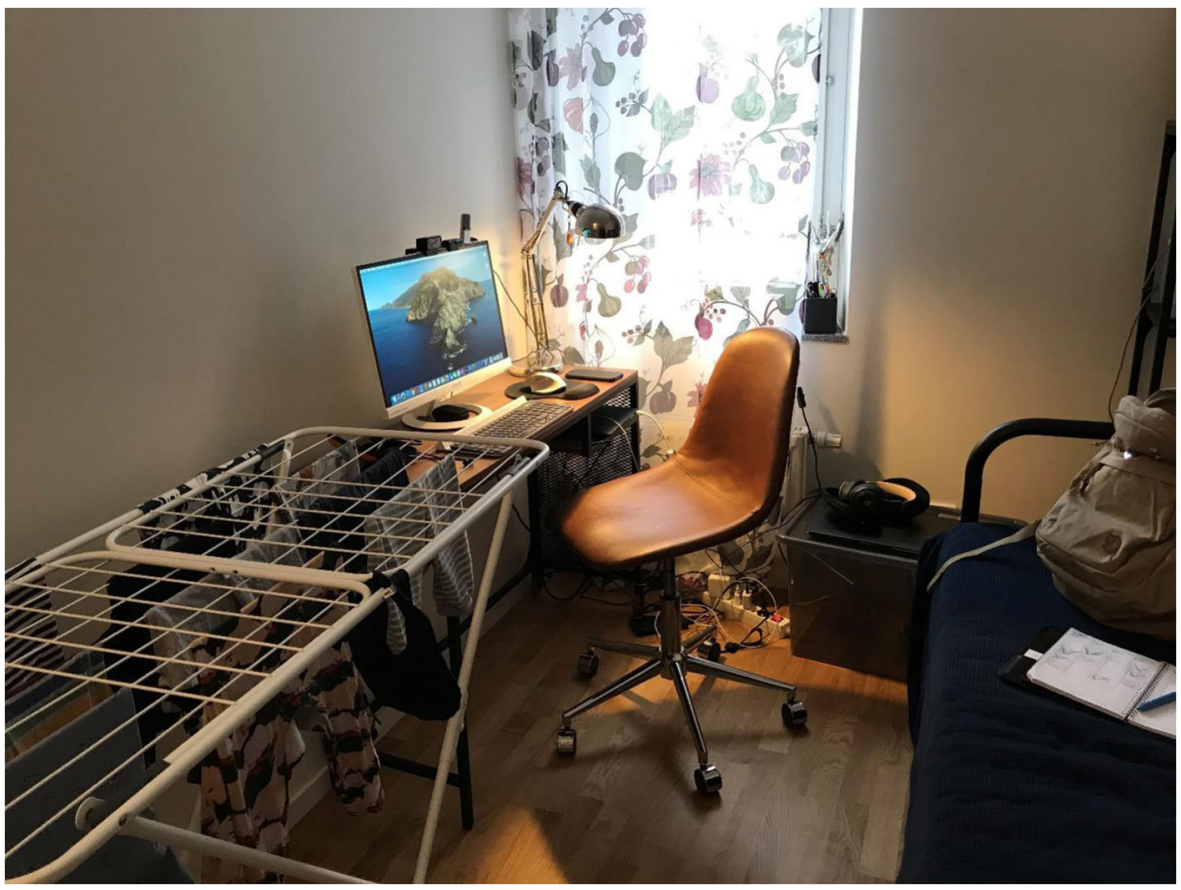

Fig. 47 This is my small and provisional workspace, located next to where me and my wife change our son's diapers and do laundry

Apocalypse Now? The View from a School of Education in the Time of Covid-19 Rachel Buchanan, Newcastle, Australia, 4 April

Rachel Buchanan is the deputy head of school (Postgraduate Teaching and Learning) for the School of Education, University of Newcastle, Australia. Rachel is 41 years old and lives in Newcastle, Australia, with her husband, three children, two dogs and a cranky parrot. 
I'm writing this on the morning of Saturday 4th April. I had meant to write it earlier, but it feels like it is only now that I've had a chance to catch my breath. I am writing from a makeshift home office in suburban Newcastle, Australia, from where I anxiously check the numbers daily. Many of the Covid-19 cases in the area are readily explained; travellers returned from cruise ships and international air travel. These cases mainly represent people who went into quarantine and did not spread the infection. However, there are a number of unexplained cases, representing a low level of community transfer. This worries me. Will it reach the university? It seems inevitable. When will it touch us?

The University of Newcastle, my employer, is the largest employer in the local area. In normal circumstances, thousands of people work, study and interact daily. The potential for the university to become an infection hot spot is real. Callaghan campus, near where I live, is nearly deserted. In my role, I am required to physically go to work once a week as part of a skeleton staff until such time as the campus officially closes and the buildings can be physically locked. The campus has changed; hand sanitiser stations have appeared seemingly overnight, as have taped lines on the ground to remind the few people still on campus to stay apart.

The university's initial response to Covid-19 was to cancel all international travel. That was my first inkling of what was coming. Incrementally at first, then all at once, the ways things were done changed, culminating in a paradox. Students were now to be taught in a 'study from home' mode, but the university was also to remain 'open for business'. That is, until the government shuts the universities, our campuses remain open for students who need to use the facilities.

This is the first week in which face-to-face courses were all taught online. The rapid pivot to 'study from home' teaching meant my team oversaw a quality assurance process to ensure that the 180 education courses making this shift did so in a manner that did not disadvantage our students, allowed for some form of synchronous contact with them, provided equivalent education to the course in its usual form and met the requirements of the universities' accrediting bodies. While staff have been herculean in their efforts to shift, there were a number of pedagogical discussions with lecturers with little experience in online education. Can it be done? How can it be done rapidly? Easily?

My own view is that we are not providing online education; we are providing education in a crisis using online tools.

My students are exhausted. Some have lost their livelihoods with the governmentmandated shutdowns of many businesses. Many are struggling to study from homeespecially those with children. As with universities, there have been weeks of vacillating debate around schools. Will they, will not they, when will they close? Currently, the situation is that schools are open for the families of essential workers, with all others to learn from home. A number of my students are struggling with the demands of their own education and the education of their children.

My students who are teachers are frantic in their efforts to learn how to work from home and attempt to provide continuity of learning for their own schools' students. They want to continue their studies but their worlds have turned inside out.

My students who are preservice teachers worry about when they will be allowed back into schools for placements. How can they earn their degree if they cannot 
practice in schools? Their stress speaks to the uncertainty of the situation. Schooling has changed. What will it look like post crisis?

University has changed; what will universities be like post crisis?

Academic conferences have been indefinitely cancelled; post Covid-19, academic travel will likely be a luxury rather than a normal part of the job. While our campuses look postapocalyptic, eerily empty, we are in the midst of an economic and educational apocalypse.

I cannot imagine what it will be like on the other side; I'm exhausted from decision-making, from trying to make predictions in rapidly changing contexts, from unmaking decisions, from re-evaluating as new information comes to hand. My body is a testament to this stress, my guts are marinating in anxiety, my neck and shoulders tense and taut, my jaw sore from clenching; sleep is a battle.

It's time for me to stop future gazing, to be present to this, to being cocooned with my family in a shrinking horizon of isolation.

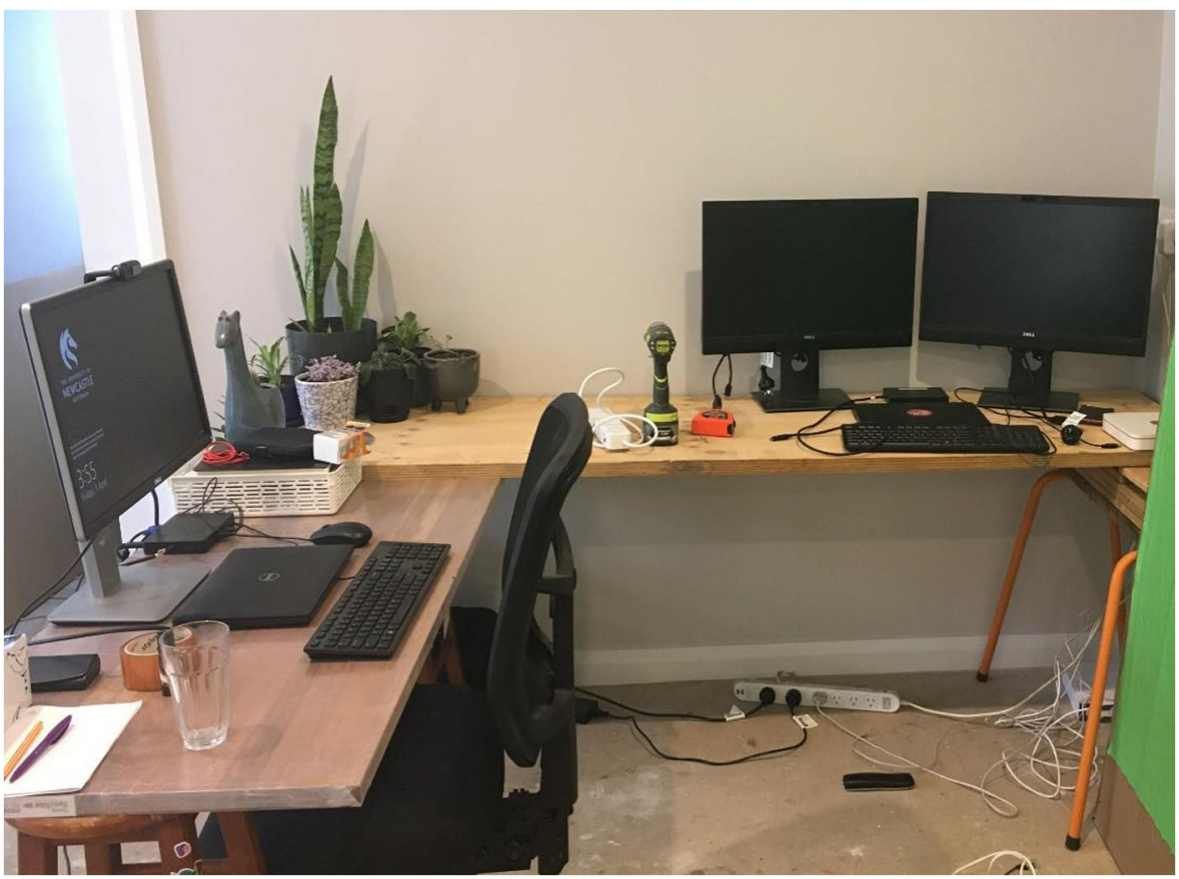

Fig. 48 This is the makeshift workspace that I share with my husband; our house is being renovated, so the workspace was without proper flooring when this picture was taken

\section{Reflections on a Changing Life}

Daniella J. Forster, Newcastle, Australia, 4 April

Daniella J. Forster is senior lecturer at the School of Education, University of Newcastle, specialising in educational ethics. Daniella lives with her partner, 5- 
year-old daughter, 9-year-old son and dog, in inner city Newcastle, in a house with a garden.

We sleep in a little later. The kids come downstairs and pile into the middle under the covers for cuddles. We take the time to turn the inevitable squabbles and wriggles into an imaginative rocket ship take off from Dad's knee. Their play evolves over breakfast whilst my partner and I make tea. There is no rush to work, day care or school; it is only a few steps away. We are coming into our third week of self-isolation, keeping in touch with grandparents by WhatsApp. When one of us does drive the car now, it is only to the supermarket or the farmers' market to get fresh local produce. Hand sanitiser is everywhere, and contactless payment is the norm.

Just before the government's increasingly demanding isolation rules, when I was still teaching face to face, I drove down to the university's Central Coast campus. Along the highway, there were very few cars, really only trucks between Sydney and Newcastle. The sky seemed bluer, not up high, but down low, nearer the horizon where the hazy yellow pollution usually sits. At that stage, the kids were still at school or day care, but all their social plans had been cancelled. No assembly, no athletics carnival, no swimming lessons, and my son's after-school care programme which mingled everyone in play, had separated kids from different schools, taking temperatures before they were allowed in.

At that point, my partner was working long hours to shift the entire university teaching approval system into online mode on a beta project that should've taken weeks but was rolled out in 3 days. His was the backend database to enable multi-faculty approvals of changes in teaching and learning activities to course outlines and publish weekly study schedules to minimise student confusion. He's still fixing bugs, but the whole Learning Design and Teaching Innovation team now works from home.

So am I. After ten years of principled resistance to the push to put my ethics and philosophies of teaching course into online mode, that is exactly the case. Not ideal, but I am satisfied with the result. There are established pedagogies and practices. My students are appreciating both synchronous and asynchronous activities and that the assessment tasks were already amendable to online mode. But ethics in teaching is the kind of learning that is as much about one's moral manner as it is about the capacity for dialogue around complex or mundane dilemmas. Our collaborate webinar sessions really cannot touch this dimension. My brain is buzzing with the explosion of ethical dilemmas facing teachers and early learning carers right now.

Our family's routine has shifted, although we keep bedtimes and breakfast times steady. The challenge is juggling two full-time roles whilst home schooling two kids who are four years apart in age. At least we still have jobs; most of my students have lost theirs unless it was stacking shelves in supermarkets, or working in pharmacies or aged care. Correction, what my partner and I are doing is not real home schooling but crisis learning; no long-term learning plans except the daily email and occasional phone call from my son's teacher with a list of activities which we never seem to complete. He and his sister are too busy playing. In this enriched family state, we can take the time for homemade meals, random hugs and giggling tickle fights. 


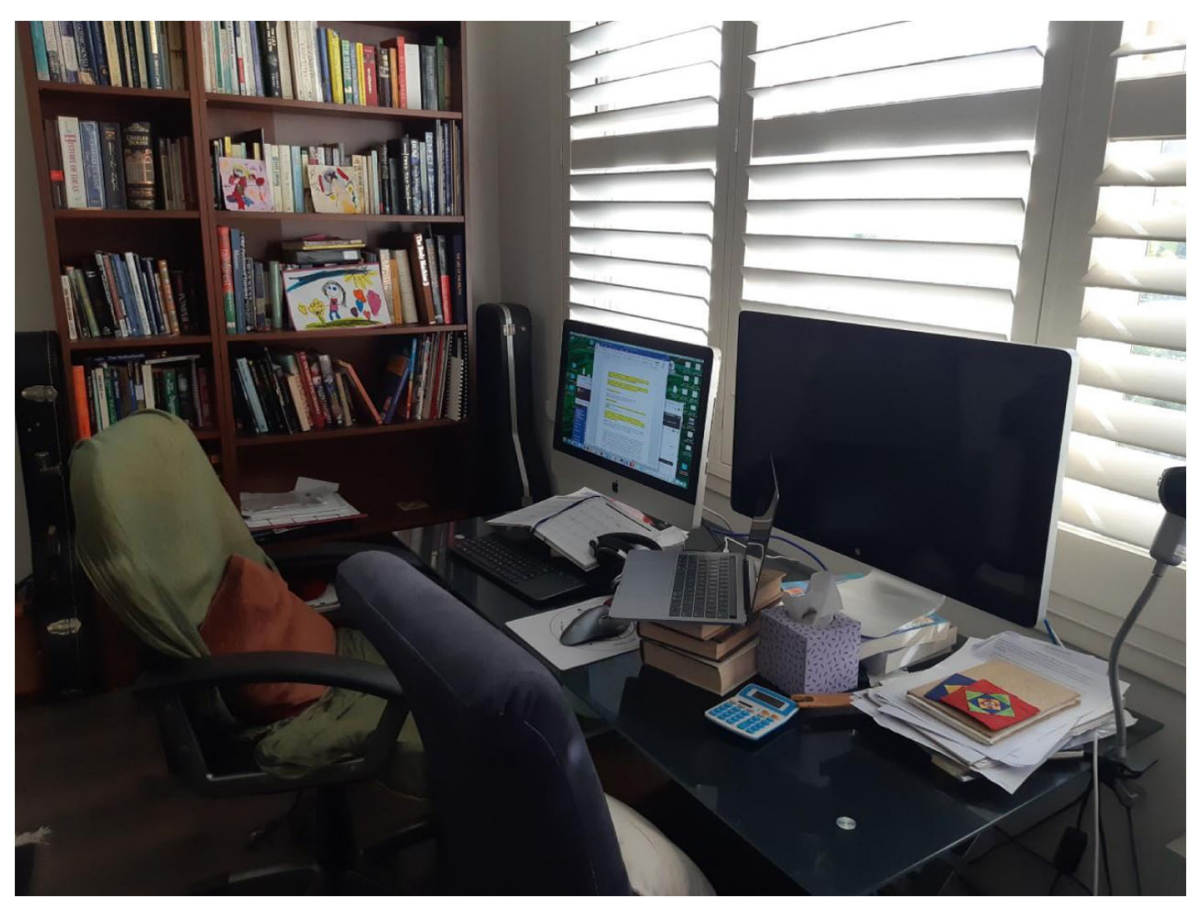

Fig. 49 Sunny morning at a shared desk

\section{Life in the Time of Covid-19}

Pallavi Kishore, New Delhi, India, 5 April

Pallavi Kishore is professor at Jindal Global Law School, O.P. Jindal Global University, Sonipat, India. She lives in New Delhi, India.

It was heartening to see this call for papers on the eleventh day of the threeweek lockdown in India. Immediately, I thought of writing down my experiences.

I teach at Jindal Global Law School, some sixty kilometres away from my home in New Delhi. The university announced its closure from 14 March onwards with online classes beginning on 18 March. I did at least eleven recordings to ensure things were working fine before I started teaching online. Unfortunately, they were not. I could not hear my recorded voice. I spoke to the relevant officials but things improved only marginally. Meanwhile, the university announced the stoppage of online classes due to infrastructure problems, with face-to-face classes set to resume on 4 May. I do not know what will happen on 4 May, so I am not sure if stoppage of online classes was a good idea.

I thought I would use this time to work on an article which has been on my mind for a long time. I did all the research. The university library helped me; in fact, it has been extremely thoughtful in providing off-campus access to online resources knowing that we cannot visit the campus. But nothing can beat this time of the year in India. It is the 
end of one financial year and the beginning of another. This implies deferring all activities and instead, spending long hours calculating and paying one's taxes as per a complicated tax system.

I am holding on to the hope of reading all the downloaded research. Normally, I only read hard copies which I annotate. Now, I am compelled to read on my computer which, by the way, is not functioning properly due to a technical problem. Moreover, (usual) work such as allocation of courses for the next semester, corresponding with students, modifying assessments, drafting exams and planning for next year goes on.

Clearly, life continues during this very unique crisis. There are challenges and chores to be done after the lockdown, but I cannot say that I am stressed. Gradually, my diet and my desire to consume comfort food are going up. For the moment, however, I am managing well. I appreciate the time and want to make the best use of it for my research and writing, but I hope I will also be able to relax and practice my hobbies.

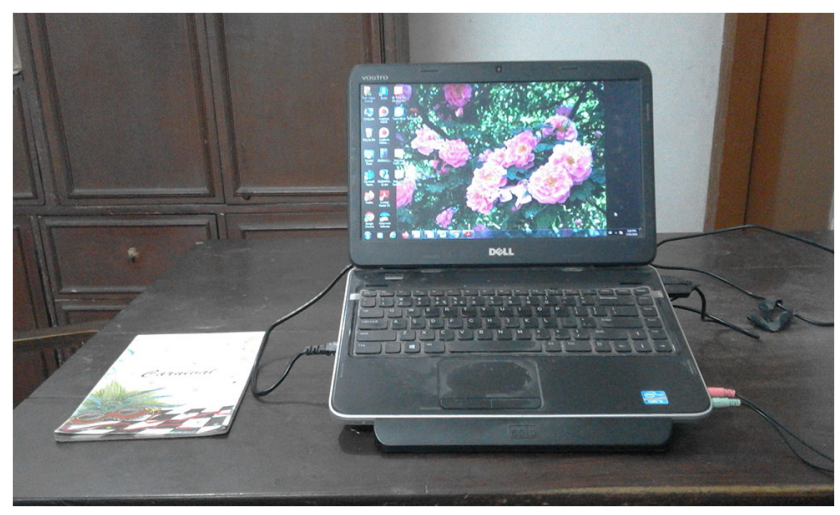

Fig. 50 This is my workspace in my bedroom where I perform myriad other activities apart from my work, such as telephonic chores and planning vacations

\section{Living in a Covid-19 World}

Jānis (John) Ozoliņ̌̌, Ballarat, Australia, 5 April

Jānis (John) T. Ozoliņš is professor at the University of Notre Dame Australia; visiting professor at the University of Latvia, Latvia; and adjunct lecturer at the Catholic Theological College, University of Divinity, Melbourne, Australia. He 
lives in Ballarat, Victoria, and in Riga, Latvia, with his wife. He has four adult children.

When it was first announced, what now seems an age ago, that the world was facing a pandemic, that there were thousands of cases in China, it was hard to take it seriously. Australia had perhaps 10 cases across the country, and it seemed that it was somewhat premature to get worried about it. January came and went as normal; February too seemed to pass without much incident. A short time later, with the number of cases still very low, the Great Toilet Roll Hoarding began. It is hard to now remember exactly when, but very shortly, at the beginning of March, supermarket shelves were soon devoid of toilet paper. For a number of weeks, it seemed like Australia's supply of toilet rolls had completely disappeared. Soon after, facial tissues and paper towels also became scarce and disappeared from shelves. There appears to be no rational explanation for the toilet roll hoarding, though of course, as soon as some appeared, towards the end of March, one felt that one had to buy some, even if one did not need them. This, no doubt, has contributed to their continued scarcity.

As numbers infected increased, the government (both State and Federal) began to ramp up measures to prevent its spread. Given that the majority of deaths from the virus have been those aged over 70 (in Australia, thus far, they have all been over 70), older people were urged to stay in their homes in voluntary lockdown. Since then, the Australian states and territories have introduced more stringent restrictions. Only essential travel, such as to buy food or visit a doctor, is allowed. Sporting contests have all been cancelled and groups of more than two banned. Restaurants and clubs have been closed down. Visiting relatives or friends is banned. Weddings may have a maximum of 5 people-celebrant, couple and two witnesses. Many workers have been stood down; as far as possible, work is to be conducted from home. Zoom has become the new way of contact for business and education. Social distancing, where people are to remain 2 metres apart, has been introduced. Hand washing has become a much more frequent occurrence. Most people have accepted these restrictions, though not all; large numbers of mainly young people have gathered on beaches, flouting the rules about social distancing. As someone remarked, 'Our parents and grandparents were sent to war, all we are being asked to do is to sit on our couches for a while.'

Cruise ships, which to a significant degree have been unwitting carriers of Covid-19, lie for the most part forlornly in various harbours, like a fleet of doomed Marie Celestes, waiting for somewhere to dock and let their passengers disembark. Many governments refuse permission, and the ships are forced to move on to somewhere more hospitable. Their passengers, forced to remain on board, are on a floating prison, locked in their cabins, seeking to avoid infection. There is nowhere to hide on a boat. 
No one knows how long this pandemic will last and what the world will be like after it is gone. That we will survive is certain, just as human beings have survived worse, but it is likely that the world will be much changed.

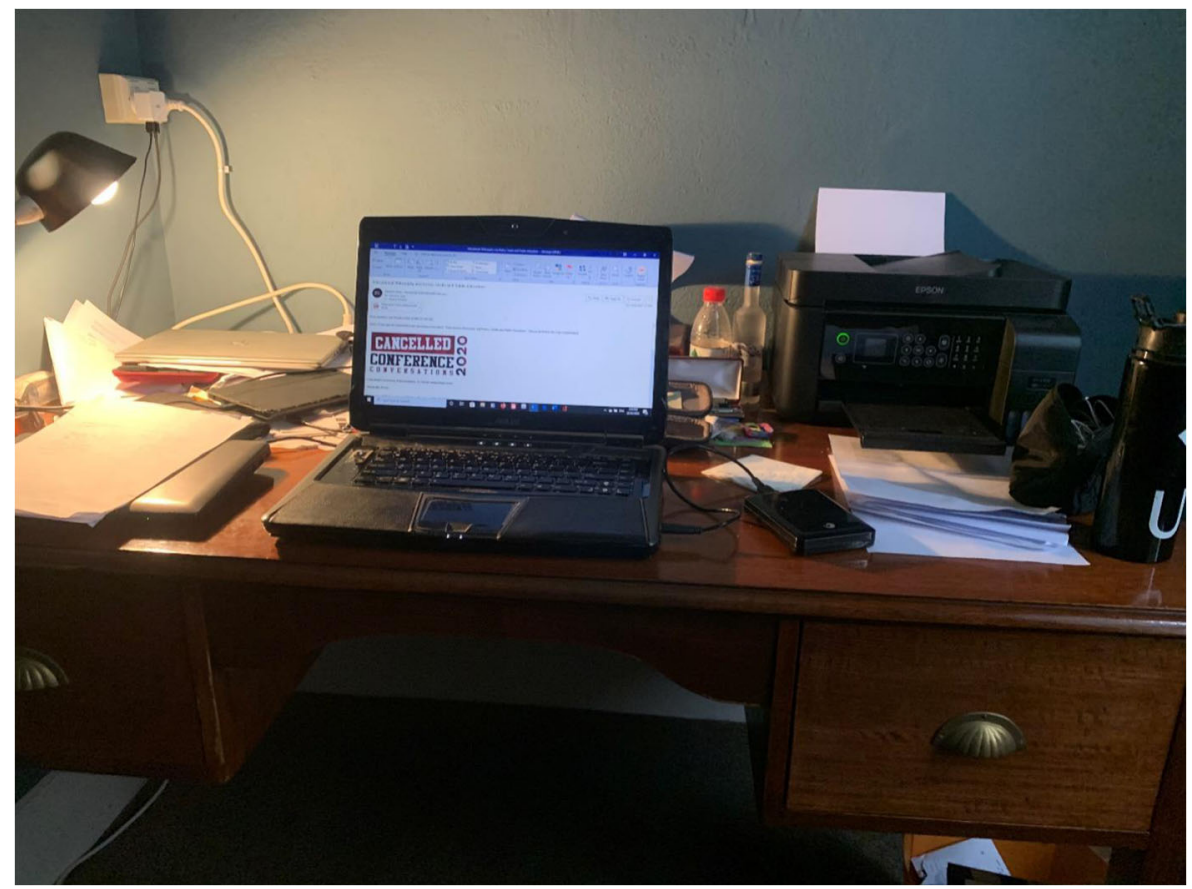

Fig. 51 This is my workspace in my study at home in Ballarat. I am spending a much larger time in there than I did before because of the strict lockdown in Victoria, Australia

\section{Covid-19: Keep Going in the Challenging Times}

Navreeti Sharma, South Delhi, India, 5th April

Dr. Navreeti Sharma is an assistant professor, Global Languages Centre of O.P. Jindal Global University. She has done her $\mathrm{PhD}$ in French studies and lives in Delhi, India.

$$
* * *
$$

Covid-19 is a vicious invisible enemy, which has taken away our freedom to breathe fresh air and move around.

It is 5th April 2020. I am confined to my house in South Delhi, having returned from Sonipat. Still 8 days left for the lockdown to be over, but will it be over? This question keeps recurring in my mind.

I joined O.P. Jindal Global University as assistant professor of French this semester, with avidness, to broaden my horizon and share my expertise with my colleagues and students. I now feel nostalgic for my university days; reading in the library, participation in conferences, productive time spent with 
my students and admiring their enthusiasm in the class. The virus has indubitably deprived me of the delectation I perceived, through my active presence on the campus. However, I keep up the momentum, as I continue to write articles and do a lot of reading.

The unanticipated shift to online teaching has created some sort of lacuna between teachers and students. On campus I had continuous communication with my students, which is indeed significant, as they are learning a foreign language. But given the ongoing crisis, online teaching seems to be the best option, better than leaving our students in the lurch. Our higher-ups and administration are very supportive and highly proactive in providing strong emotional and academic support to the professors and to the students. From time to time, emails on how to keep oneself mentally and physically fit are circulated by our health experts. In addition, we have off-campus access to the library; entire books and articles can be accessed through the eBook Collection Database, etc. Microsoft Teams permits constructive interaction between the students and the teachers, and we can move on successfully with course completion and preparing the students for the exams. At times, of course, there are a few technical glitches, but we are surely all capable of overcoming the impediments.

As far as I am concerned, it seems that online teaching has been smooth and I am so impressed with the positive response of my students. We are in regular touch and we work on different components of French language: oral, listening, written and grammar.

To end this contribution, I quote few of my students, highlighting their mixed reaction to online classes.

I thought virtual learning experience would be impossible, but I was wrong.

With equal dedication from the instructor and the students, $[\ldots]$ with worksheets and the technology that brings us together, it makes learning French easy. (Mahita V., French level 4)

Online courses are fun, they are much more comfortable $[\ldots]$ however it reduces my attention span. (Ishita Bhanot, French level 4)

The distance mode of learning has helped students to study in a much more flexible way and in safety [...] but even today internet connectivity is a major issue. Thus, not all students, as well as educators, have proper access to broadband connectivity. (Sanskrita Tripathi, French Level 2) 


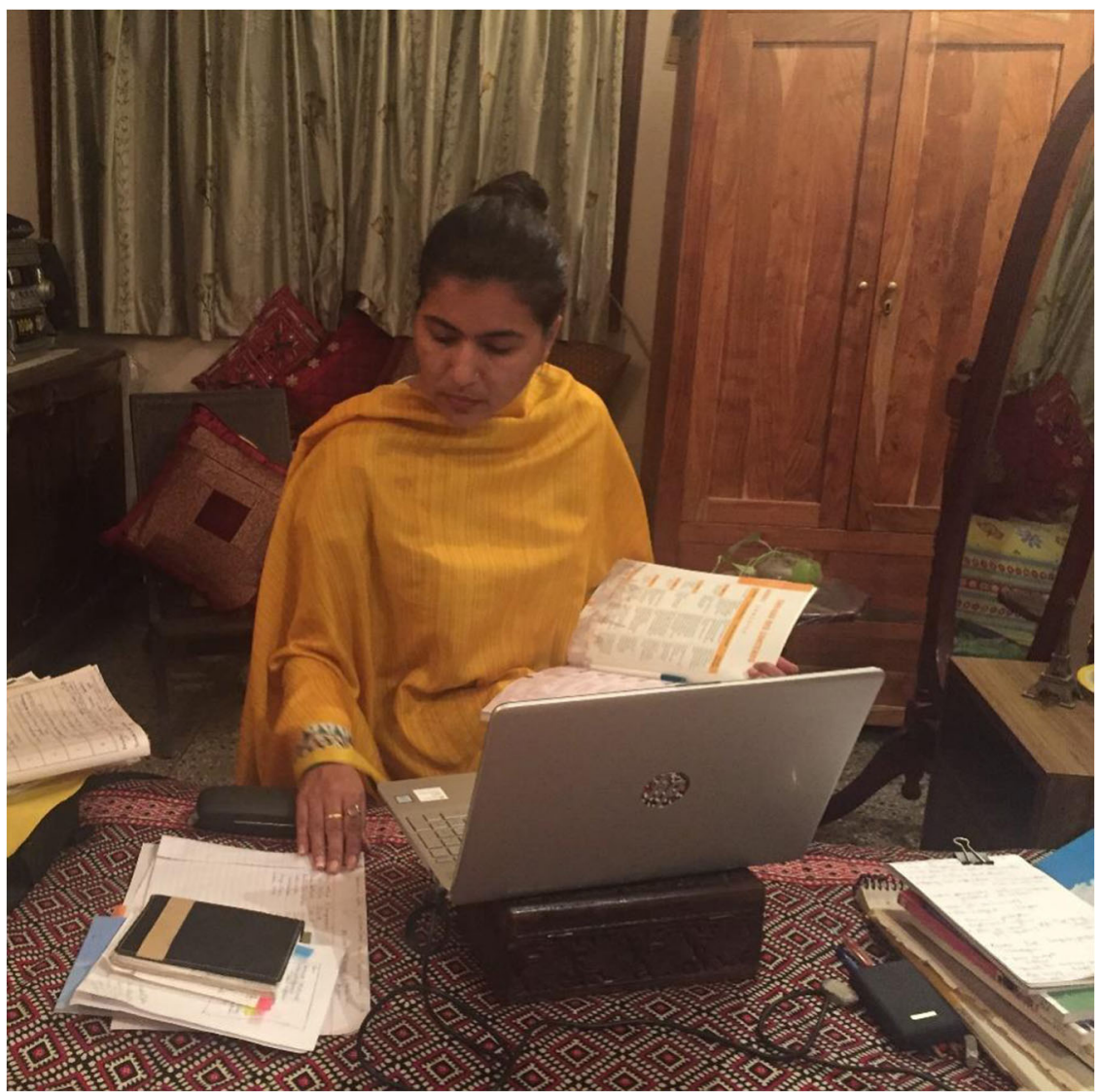

Fig. 52 My bedroom is my workspace, from where I conduct interactive sessions with my students through Microsoft Teams. Also, I devote time preparing and checking assignments, worksheets, and writing articles. Not to forget, I have an opportunity to straighten my back and take a short walk in my adjoining terrace

\section{University in the Times of Corona}

Shreya Urvashi, New Delhi, India, 5 April

Shreya Urvashi is a doctoral fellow researching student culture and universities at Tata Institute of Social Sciences, Mumbai. Her academic profile consists of degrees in physics and sociology. Her research interests include sociology of higher education, sociology of identity and politics. 
$* * *$

With students at multiple universities protesting and striking for varied reasons ranging from fee hike to challenging the country's proposed citizenship act, it was an exciting time as a sociologist working on student culture and student politics to observe, read and write. I was in Delhi, which was the epicentre of the protests, when virus-induced panic started in the country. The day before I had to go back to my university in Mumbai; we received an advisory from the university to travel as little as possible. Several emails and telephone exchanges later, I was able to postpone my planned meetings. After some days, all universities gradually published such circulars and a huge number of students (including protestors) went back to their homes. Those who remained had to stay inside their hostels with minimal interaction from outside. Physical protests, therefore, are down for the time being. Stuck in Delhi then, with no protests to follow, no meetings to attend and no group discussions to do, I decided to judiciously use my time to get back to reading relevant literature. My idea was to gain more conceptual clarity which will be useful when I go and talk to fellow students again.

Initially, the biggest distraction from my 'plan' was the news. Every day, locked at home, listening to the news, is much scarier than it sounds. I study the effects of the institution of the university on students, but here is something that affects the university and its students simultaneously and in unimaginable ways. A couple of days into the government-mandated national lockdown, amidst a whole lot of household work, I started contemplating my plan. What good is the intelligence, the academic and technical skills, which our universities cultivate, in these times? There is an underlying perception in all social institutions that the lockdown period should not be wasted. Like employees of a company, students and teachers in schools and colleges must keep their 'normal' activities alive. Virtual platforms are being encouraged to continue the interactions so that academic productivity does not stop.

However, we have a choice - to keep reading the same books and doing the same assignments, or to work towards deriving new meanings from existence in these uncertain times. The pandemic is our opportunity to imagine the world anew, to reflect honestly and rigorously; this is the time to understand where we have gone wrong.

Some features of the 'modern' university need to exist. After this is 'over', we will still fight for justice, we will still work to understand more of the universe and more of ourselves. We need to read more, listen more and learn more. Yet we need to change our obsession with logic and productivity. Our arrogance of getting the better of nature needs to be replaced with connectedness. In times of social, or rather physical, distancing, we need to find the importance of and solace in togetherness. 


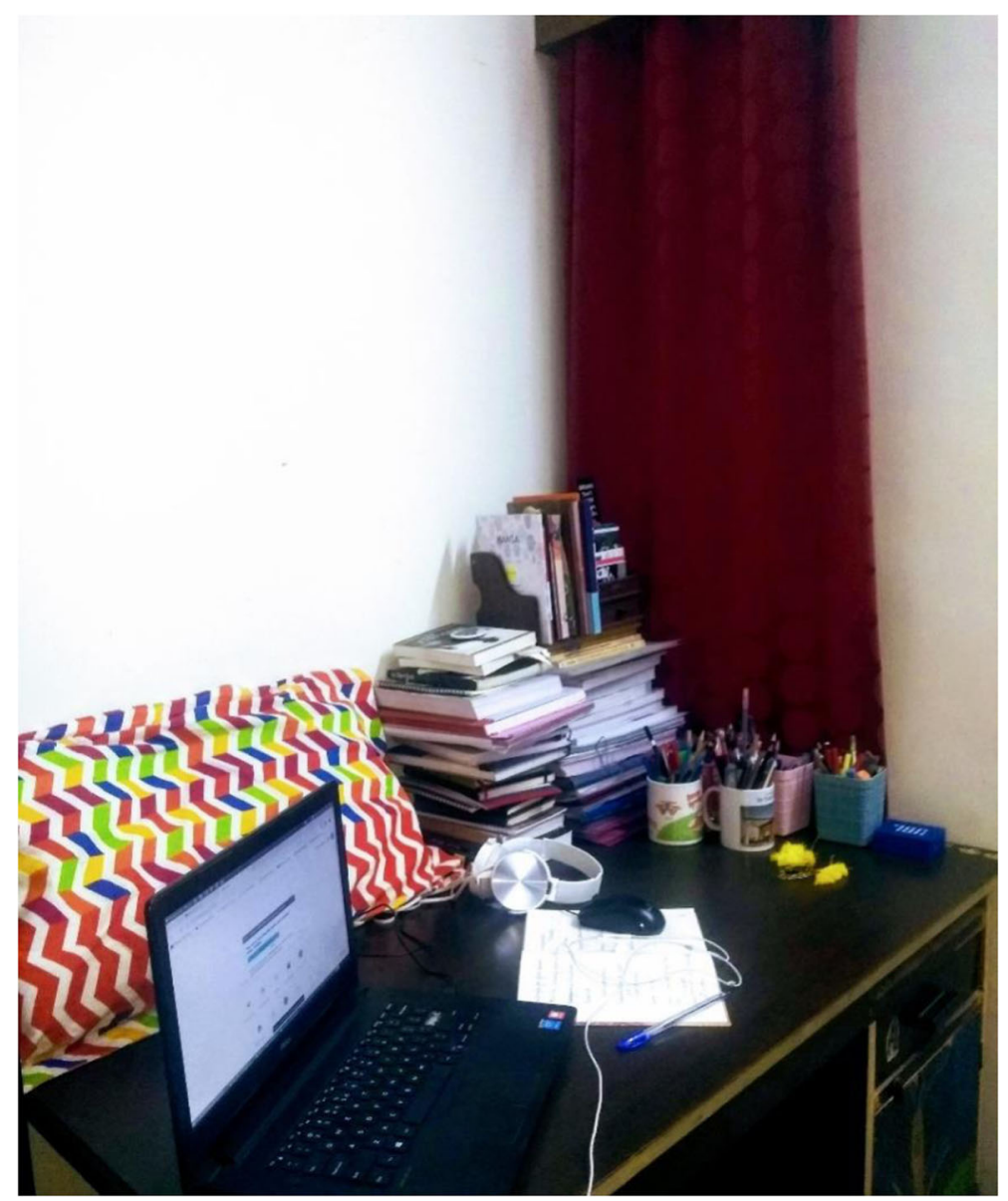

Fig. 53 This workspace is in a corner of my room, where I happen to spend the maximum of my waking time. The piles of books in the corner comprise notes of my research

\section{Untitled}

Harry G. Nejad, Haryana, India, 5 April

Harry is an associate professor in psychology who just moved to India in February, and then, the dreadful full-blown lockdown in India began in mid-March.

$$
\text { *** }
$$

I am an associate professor at a university in India close to New Delhi. My principal duty here is to conduct research with some teaching hours at a $\mathrm{PhD}$ level. I am also the chair of the committee that is supposed to create a new school of psychology at my institution.

I came to India in late January 2020, and the complete lockdown in India began around March 20th without any warning (at least I was not aware of it). Our university had closed its doors to students, faculties, and staff, and sent everyone home a few days 
before full lockdown. Being in a new country, not knowing local and national languages, and not having access to TV and cables, the lockdown caught my wife and $\mathrm{I}$ in a full-blown surprise. At that point, we felt we had only two choices, either be defeated or stand up and adapt to these new, harsh, and challenging life circumstances. We chose the latter; hence, we knew that we must adapt and self-regulate mentally, physically, and emotionally.

We only have access to a very small shop in the university complex which does not carry much in stock. Therefore, we decided to ration our groceries to last us for as long as possible. All my research projects that required the Ethics Committee's approval and assembly of participants were stopped. I continued my research online as much as I could. I began my literature review earlier than planned and I worked on my research logistics.

At the beginning of April, the university began to conduct faculty e-meetings about an action plan for dealing with the educational needs of our students. Management also postponed summer vacations to curve this difficult time. Every day we try to look at the bright side and encourage one another to stay positive and learn from this new experience. We are working on resetting our reference points to help us get through this dire and challenging time. At the same time, we work on our hedonic adaptation capital to assist us to remain buoyant and resilient. The ability to regulate and adjust our cognitive adaptability, emotional adaptability, and behavioural adaptability are the salient factors in dealing with life's challenging, uncertain, variable, and harsh situations.

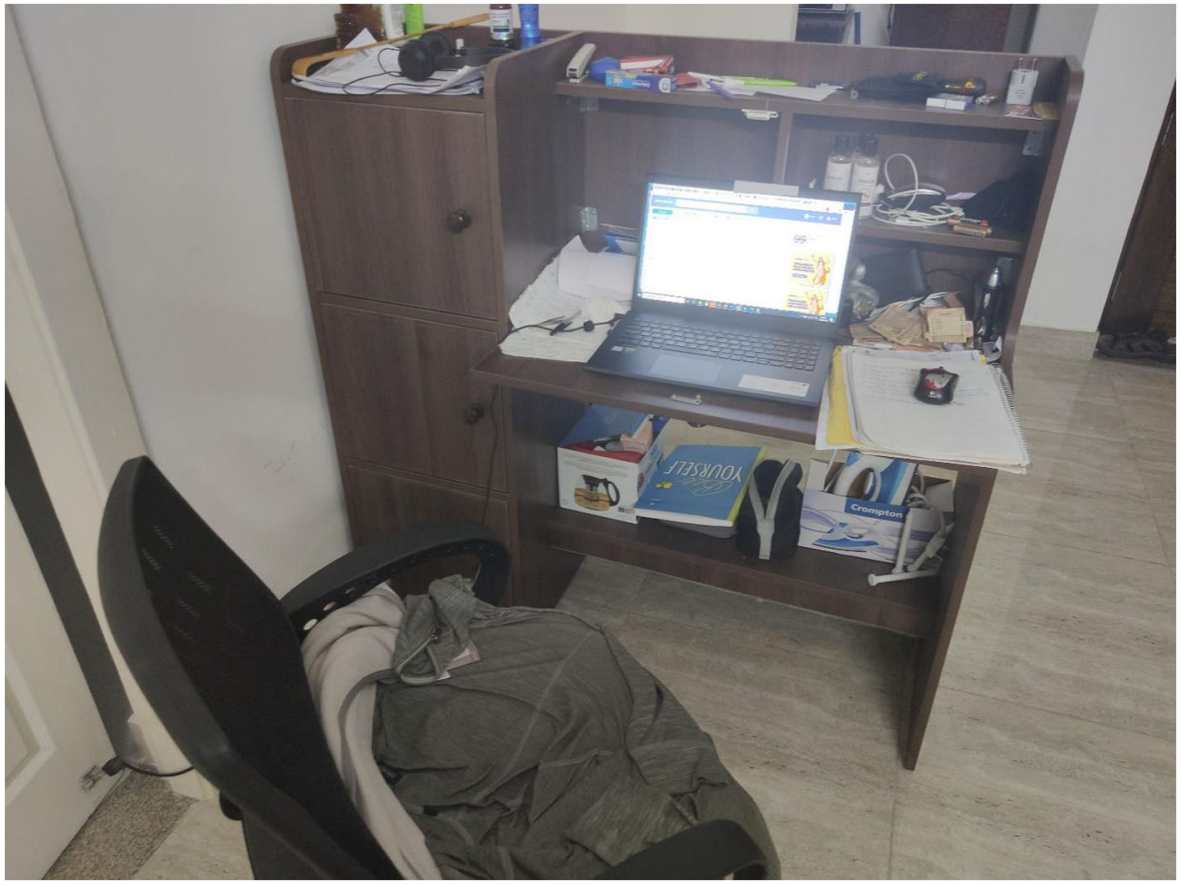

Fig. 54 This desk is my working space where every day I use my own laptop to do the work that I am supposed to do. As it can be understood, there is no separation between my personal and work life. This desk is stationed in my living room since this is the only room that has air conditioning in this flat amid extremely hot (over $45^{\circ} \mathrm{Celsius}$ ) weather 


\section{Covid-19: a New Ontology of Ourselves as Academic Subjects}

Nina Hood and Marek Tesar, Auckland, New Zealand, 6 April

Nina Hood is a senior lecturer at the University of Auckland and the founder of the notfor-profit organisation The Education Hub. Marek Tesar is an associate professor and associate dean international at the University of Auckland. They live in Auckland, New Zealand, with their son.

We write this nearly two weeks into New Zealand's lockdown, which has seen the closure of all early childhood centres, schools and universities, and people limited to their houses, trips to the supermarket and daily walks around their neighbourhood. Both of us are employed by the University of Auckland, and Nina also runs The Education Hub, a not-for-profit organisation with a mission to bridge the gap between research and practice in education by providing resources and learning opportunities to early childhood and school-level teachers. Our thoughts below explore initial understandings, ideas and challenges emerging from the three contexts with which we are involved: The Education Hub, the university, and our domestic lives.

The work of The Education Hub provides some interesting insights into how New Zealand teachers, school principals and parents are coping with the lockdown and closure of schools. Tracking users online suggests that currently concise, practical advice is what is most valued by educators and parents. Resources dealing with supporting schools to set up systems, processes and structures-be those to support their teachers, engage with parents or design learning models - are of less interest than resources that provide immediate activities or practical tools. This focus is hardly surprising given that people are in 'fire-fighting' mode, simply trying to survive and slowly adjust to the current situation. However, with the uncertainty over how long the lockdown will continue, it's likely that educators' focus will at some stage need to move beyond the immediate. As an organisation focused on the translation of research, the current situation has thrown into relief the scarcity of research in the area of distance learning at the school level. And, as a final observation, a growing concern and significant challenge is how the shift to distance learning is amplifying the inequities that exist within New Zealand society and the education system.

With Marek currently on research and study leave, and Nina employed only very part time for the university, we have not been thrust immediately into online teaching and, as a result, have been able to watch from something of a distance to see how the university has responded to the current situation. The sudden shock of the new reality, in which all of the university teaching, learning, research and services are conducted online, was perhaps exacerbated by the university's slowness to act early, in anticipation of what many saw as a certain lockdown period. And while now there are teething issues adjusting to the current situation, and the nature of courses and teaching has changed substantially, most academics seem to have taken the changes in their stride. 
However, the question looming over all of us at the moment is what will happen when the Covid-19 crises is over? And what will a post-Covid-19 university and academic look like?

Finally, personally for us, our major challenge remains how to balance continuing to work while also caring for our very energetic 21-month-old son, for whom we have lost childcare. We have regularly returned to Albert Camus's Plague, and the many telling statements he has left us with. Perhaps most pertinent, 'I have no idea what's awaiting me, or what will happen when this all ends. For the moment I know this; there are sick people and they need curing' (127).

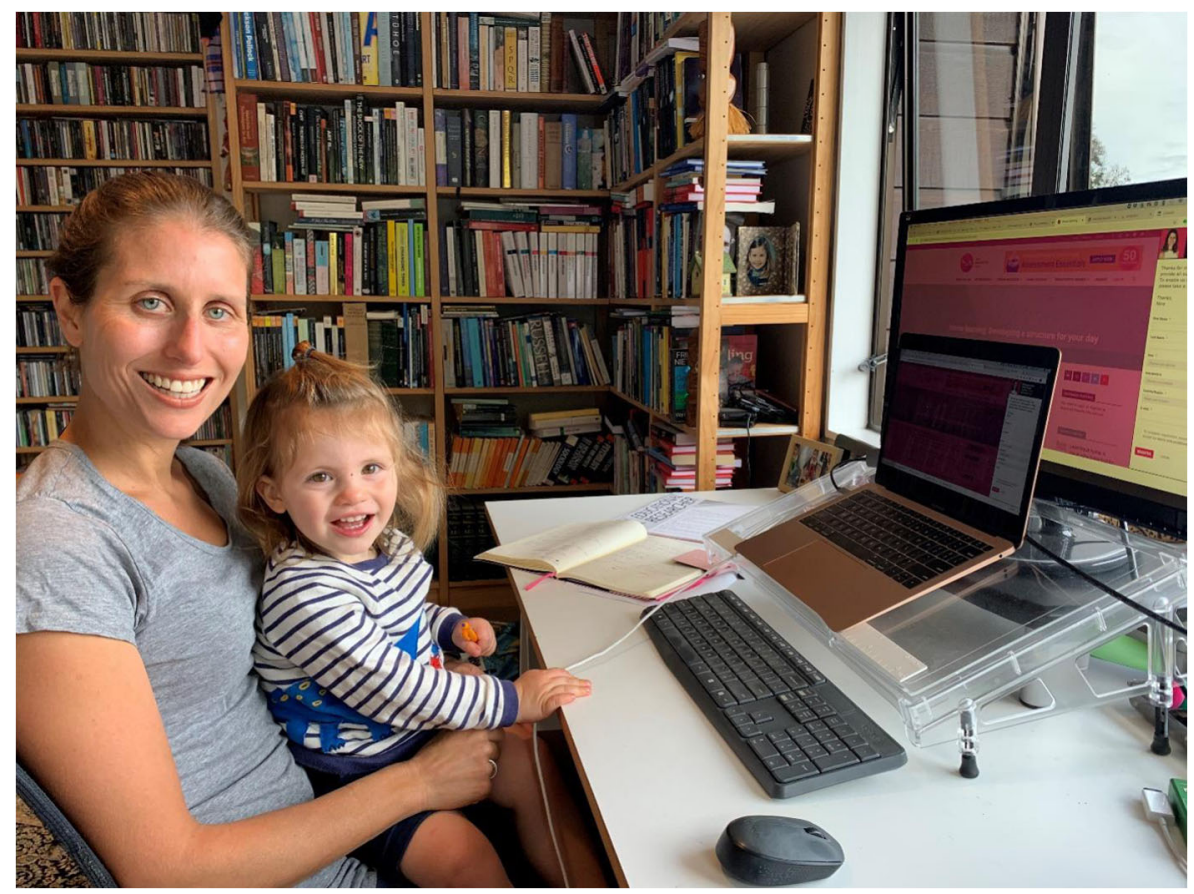

Fig. 55 This is our workspace in our office, where we take turns to work, often while entertaining our toddler

\section{How and What to Teach in the Age of Covid-19 in Beijing?}

Yang Wang, Beijing, China, 6 April

Yang Wang is an Ed.D student at Beijing Normal University, and secondary teacher at Keystone Academy. She has taught Chinese to both Chinese and international students for 7 years. Yang is 31 years old and lives in Beijing.

As a middle school Chinese teacher in a Beijing bilingual school, I belong to the first wave of teachers who had to put their classes online, starting from 3 February. After eight weeks, our school decided to have a one-week break after 
such a challenging period. I am now in the break, having some time to stand and stare.

\section{How to Teach in the Age of Covid-19?}

Covid-19 brings uncertainty to all aspects of life. A robust emergency online teaching plan is implemented with policies which change every two weeks. Changing policies include lesson content, percentage of synchronous interaction, intensity of teaching, homework load, preferred communication channels, tracing student procedure, etc. We try our utmost to be flexible and adaptable.

Before the beginning of online teaching, I was nervous. How should I transform my teaching into online environments? How should I motivate my students' learning spirit? Soon after, I handled the transformation and met all expectations. I also regarded this period as a chance to reach out of my comfort zone. I tried different applications and different online teaching approaches. After two weeks, I felt comfortable with online teaching. It was not that difficult to transform classes and communication with students, and unless you rely on whole-body-response teaching approaches, things are not that different from regular classes. After four weeks, I began to share my online strategies with peers.

\section{What to Teach in the Age of Covid-19?}

Covid-19 is a teachable moment. In my literature class, I teach grade 9 Chinese students. They were experiencing what I was experiencing: isolated, overwhelmed by the news, fear, and mistrust; our moods went up and down. In this turbulent and unstable period, I and my colleagues chose to read Albert Camus' Plague with students. The story is similar to our current reality and can inspire students. My teaching focused on cultivating in-depth, philosophic thought of what is happening now, how to resolve negative emotions, and how to confront the world. Besides, my Language Acquisition students only have basic Chinese proficiency. I and my colleagues taught a Covid-19 comic book to raise awareness of the pandemic situation and to help students protect themselves. To raise students' spirits and provide social activities, I also designed advisory activities, such as cooking healthy beverages, sharing your life support activities, etc.

\section{It Was the Best of Times. It Was the Worst of Times}

How to cope with teaching during the Covid-19 pandemic? Other than bemoaning, remain optimistic and active. During the past eight weeks, I accompanied my students, developed novel teaching strategies, and organized my Ed.D. studies better. I read, wrote, and exercised much more than usual. I slowed down and reflected. I also cherished the time with my husband and my parents; this is the longest time I spent with my parents since I grew up.

However, I feel more and more uncertain about the future. We are all stuck in a haze of uncertainty. This unpredictable and unstable feeling does not only result from the outbreak of Covid-19 but also reflects how different countries deal with the outbreak 
and rethink the world order. We all have a strong feeling that we cannot control what is happening now and what will happen to the world after Covid-19. Managing ourselves becomes the only thing we can do.

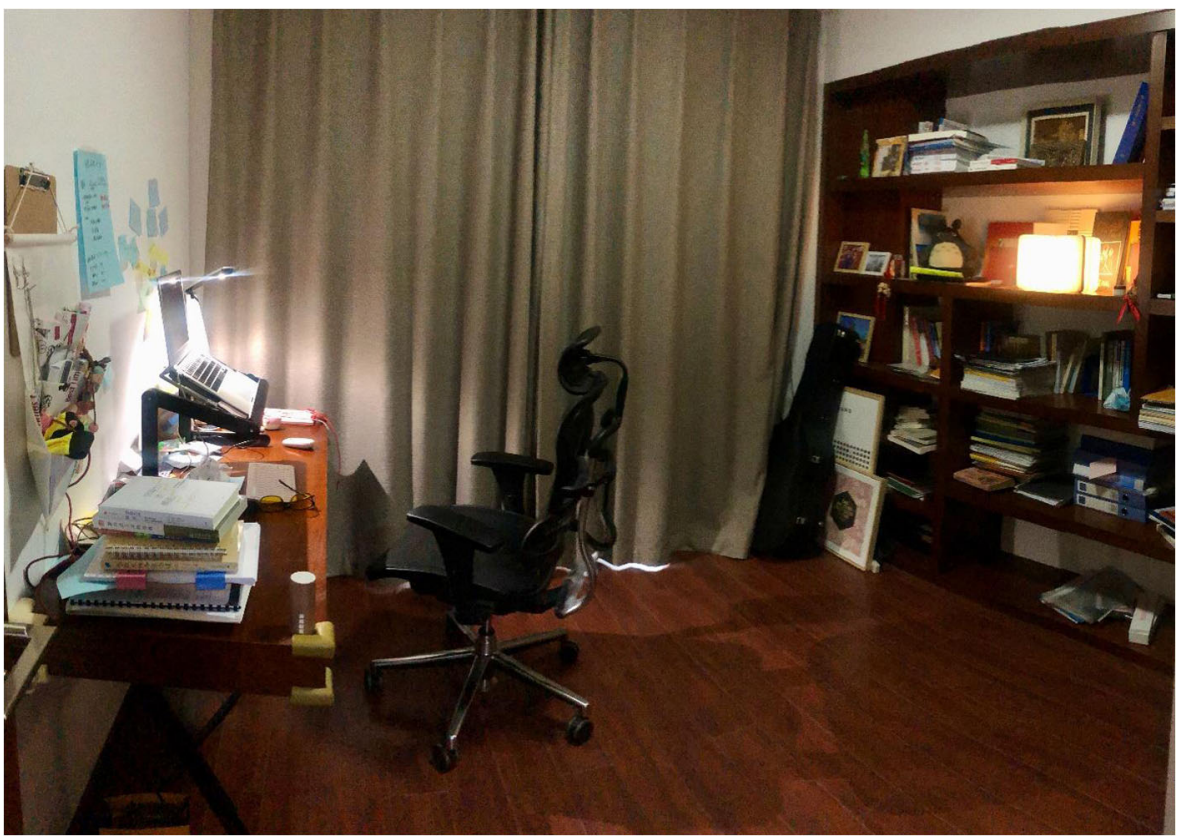

Fig. 56 I work in my own study room. I also bought an ergonomic chair and computer stand to protect myself while teaching on computers for long hours

\section{Change, Worry, and Covid-19}

Jake Wright, Rochester, MN, USA, 6 April

Jake Wright is a senior lecturer of philosophy at the University of Minnesota Rochester's Center for Learning Innovation, where he teaches philosophy courses and conducts research into the ethical and pedagogical justifications for in-class practices at the introductory level.

I am a senior lecturer of philosophy at the University of Minnesota, Rochester, a small, public university in the USA. As much as I might prefer, I do not have a coherent, well-organized response to my experience of a global pandemic. At some point, I suppose I must accept the fact that a more-or-less stream of consciousness collection of thoughts is appropriate when cataloguing one's response to an unfolding crisis.

Today is Monday, April 6, 2020. The last in-person class offered at my institution was one month ago today; faculty and staff have been directed to work from home. We 
have been under a stay-at-home order since March 27 which aims to slow the spread of Covid-19.

The direction to work from home, and now the order to stay at home, has upended my life. The opportunity to interact with my students brings me purpose and energy that cannot be replaced via emails and video messages. Research projects either seem to have lost their import or feel like a depressing waste of time. On the one hand, it seems difficult to care about previous projects like the intricacies of syllabus design, while on the other hand, writing about timely subjects related to the pandemic is a major bummer (to use a nontechnical term) whose impact seems uncertain, given the speed at which academic research seems to proceed.

I've tried to make contributions where I can via immediate forums like blog posts and online panel discussions, but I worry that these hopefully helpful contributions will not be recognized by higher education gatekeepers who value journal articles and monographs über alles.

My work as a teacher and researcher are both foundational aspects of my selfidentity, and their upending in the midst of this pandemic has helped make me feel like a wreck. I worry about seemingly everything, from the budgetary impact the pandemic will have on my university (and thus, my continued employment) to the wellbeing of my students.

My university focuses exclusively on health sciences and the health professions. Thus, my students' choices will place them directly on the front lines of our collective response to the pandemic, if they are not there already. Each one of them is beyond admirable and I'm incredibly fortunate to teach them, but I worry about them. My academically at-risk students must suddenly navigate whatever complications Covid-19 has added to their lives, in addition to the regular challenges they face, in a hastily thrown-together, suddenly-online environment that will not predispose them to success.

On top of this, I'm asked to get what work I can done while parenting two suddenly-at-home small children and being a good husband to my spouse, who is also working from home. I feel as though there are days where I've been a good philosopher and days where I've been a good parent and partner, but no day where I've been both. I worry about the health of my immediate and extended family, many of whom are seniors or frontline healthcare workers. Though it is, at some level, irrational, the progression of the disease and the fact that I am not impervious to it lead me to wonder if, every time I hug or kiss my family, it will be the last time.

Whatever effective leadership has been shown by state, local, and university officials - and there has been plenty at each of these levels - is offset by national leadership overseen by a churlish buffoon seemingly more interested in good television ratings than saving lives. As a result, it's difficult to know how long this crisis will continue. Certainly, it feels as though it will continue well beyond the point it should, and whatever state we find ourselves in after all of this is done, it will not be recognizably normal from our pre-pandemic viewpoint. 


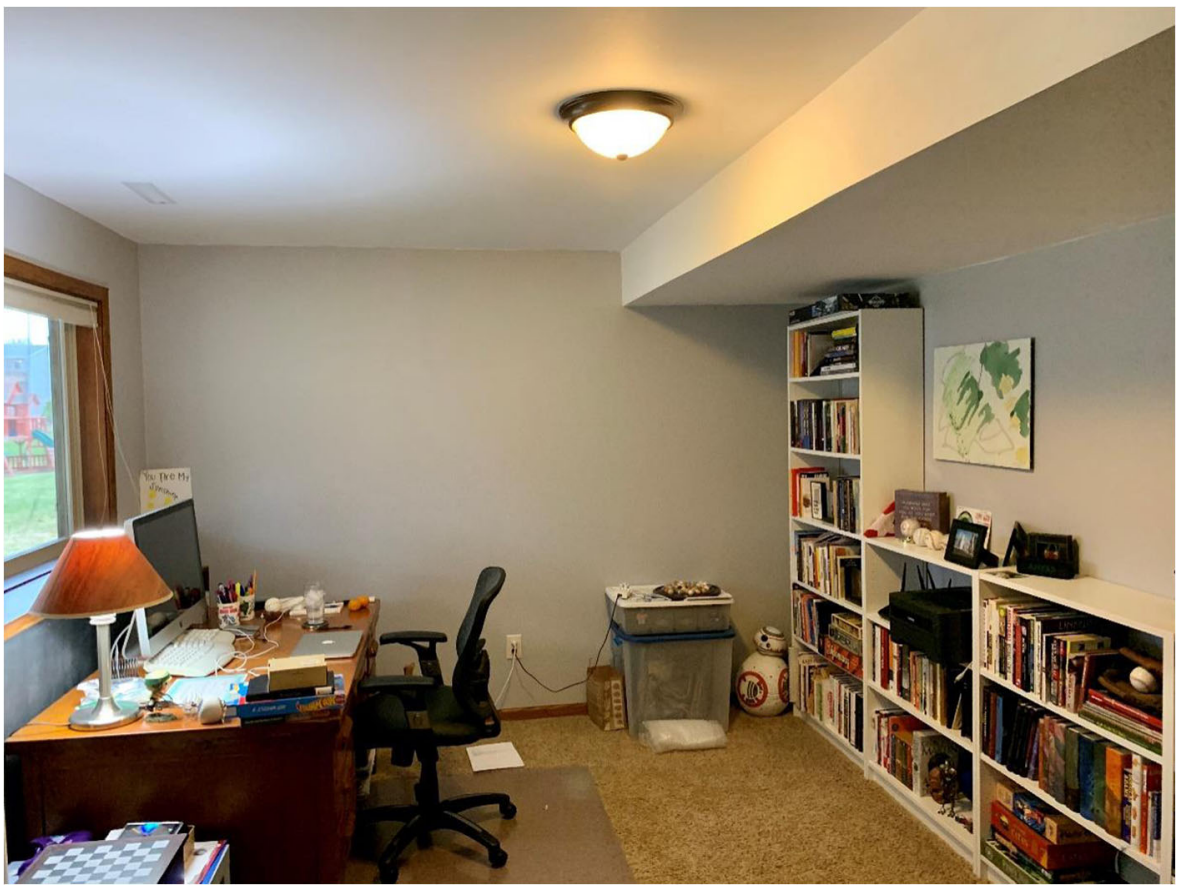

Fig. 57 My home office, a converted basement bedroom

\section{Teaching in the Age of Covid-19: the Design Studio Meets Its Match}

James Benedict Brown, Umeå, Sweden, 6 April

James Benedict Brown is an associate professor of architecture at Umeå School of Architecture in northern Sweden. James' research is concerned with architectural pedagogies and representation.

The living room of my suburban apartment looks much the same as it did two weeks ago except for the height-adjustable desk, orthopaedic office chair, and computer monitor in the corner of the room.

After I 'Brexited' from the UK to Sweden in August 2019, I had to visit the offices of various public institutions to get my personnummer, identity card and driving licence. What was remarkable in all of these workplaces was the universal provision of a height-adjustable desk for every employee. These were considered a luxury in the UK: something my wife had requested for months from one employer before she finally bought one for herself.

When I started to teach design to forty undergraduate students at the Umeå School of Architecture last autumn, I was struck by the almost universal recognition my students held for workplace rights. Teaching architectural design, one must always provoke young students to think deeply about the dayto-day needs of the people who use buildings. Toilets usually provoke these 
conversations. Students tend to box off surplus floor area and copy/paste a wildly excessive number of toilet stalls from their CAD library. Until they are challenged, they tend not to question whether the door to the gents should open directly into a restaurant dining room.

Architecture students in Sweden make the same mistakes, but unlike those in Britain, they manifest the Nordic respect for the working environment. Even when I omit it from a schedule of accommodation, they never fail to design buildings with staff rooms, often thoughtfully located out of sight of the working environment and with an outside space for the sacred morning and afternoon fika.

Homeworking has now become a matter of both intellectual and pragmatic concern for academics working in my discipline (Cass Culture 2020a, b). In Sweden, it is also an urgent political matter. After the government instructed that all universities should close their premises and move teaching online, my managers made sure that we were adequately equipped. A technician from my department loaded my office furniture onto a truck with a tail lift and delivered it to my apartment. He visited the home of every employee in the department, making sure they had the equipment they needed to continue working.

At the time of writing (early April 2020), the Swedish government is persevering with a radically different approach to the Covid-19 pandemic than most European countries. There is no mandatory curfew, and social distancing is advisory rather than mandatory. For a team of teachers working in English and representing more than a dozen nationalities, it has been very difficult to relate the actions of the governments of our homelands with the apparently laissez-faire attitude of the Swedes. Now denied the possibility of travelling home to our families, we are particularly exposed to the intellectual contradictions in the global treatment of this pandemic.

(Personally, I am also fed up with older people in Sweden ignoring the coloured tape on the floor of the supermarket check-out while loudly repeating that this is 'just another flu'.)

Architecture educators around the world are facing a major challenge to our pedagogical assumptions. We rely heavily on the 'signature pedagogy' of the architectural design studio (Larson 1977; Crowther 2013), fatally theorised by Donald Schön (1985 and 1987) and only corrected many years later by Webster (2008) and others. How we adapt this problematic pedagogical framework to distance learning will be a matter of great importance. (Brown, 2020).

The studio is simultaneously the name of an open-plan space for learning and teaching and an implied pedagogical method: one which is shaped as much by habit rather than by any sound pedagogical theory (Stevens 1998). What has become evident in the early weeks of the new post-Covid-19 paradigm is that the space and pedagogy of the design studio cannot be recreated in its entirety in the cloud. While our department is trialling digital graphics tablets to use the Zoom video conferencing annotation tool during tutorials, it is an imprecise and 
unsatisfying replacement for sitting next to a student and 'drawing out' the problem. We can no longer sustain entire days of one-to-one design tutorials. For both students and teachers, the impracticality of the design studio is intolerable when it is brought into the home. My solace is that the famous Swedish social democracy has guaranteed my right to have good posture while I squint at a pixelated image of a student's sketchbook.

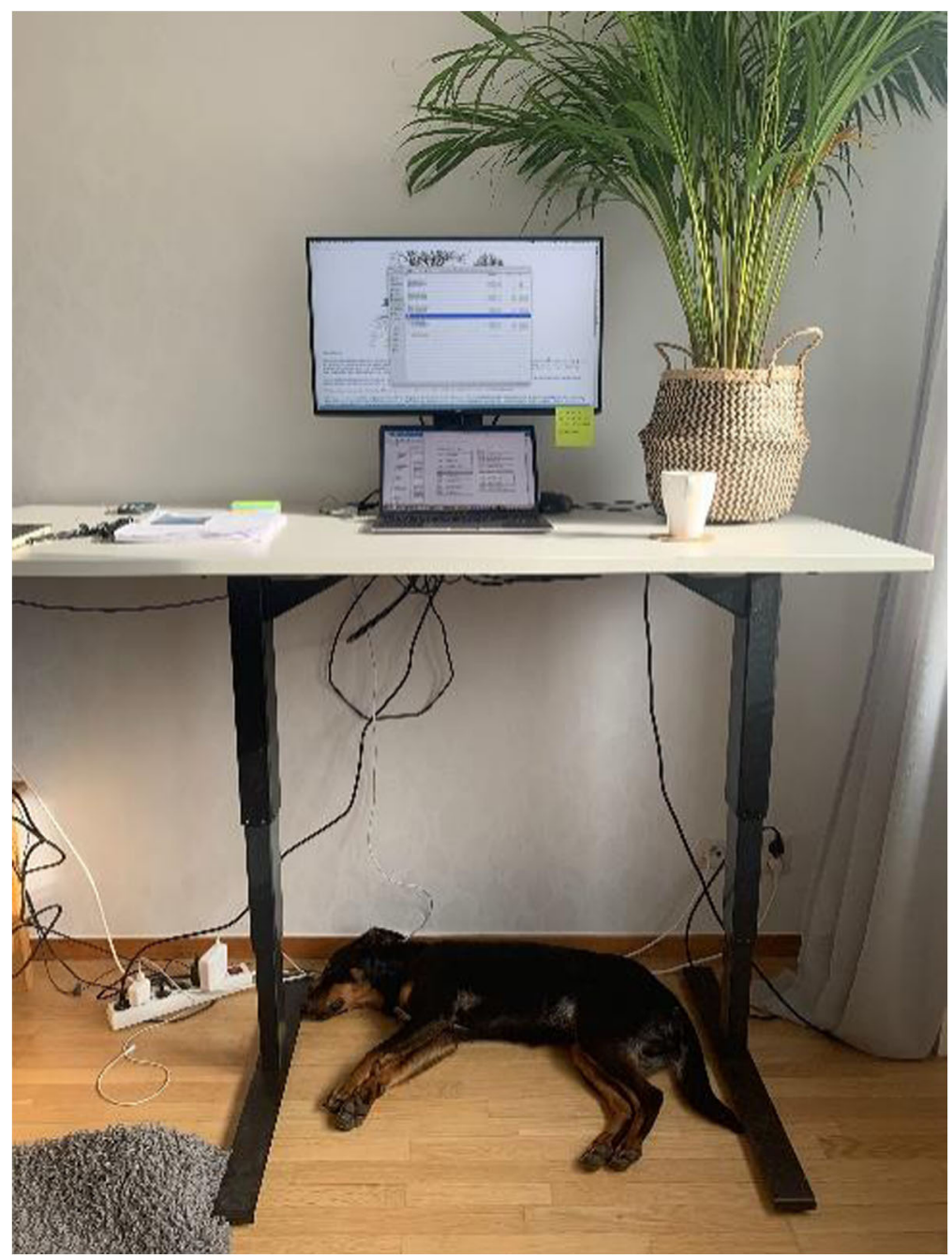

Fig. 58 My adjustable desk in the corner of our living room. Guillam the dog (adopted on the same weekend our university closed) has taken up residence at my feet during design tutorials 
Ceci n'est pas une réflexion. This Is Not a Reflection (with Apologies to René Magritte)

Paul Prinsloo, Pretoria, South Africa, 6 April

Paul Prinsloo is a research professor in Open and Distance Learning in the Department of Business Management at the University of South Africa (UNISA), South Africa. Paul is 61 years old and lives in Pretoria, South Africa, with his partner.

When this call came out to share personal reflections about 'Teaching in the age of Covid-19', I had so much to say, to share. Most of it was about my own daily routine during the lockdown of exercising, reading, eating healthily and taking care of myself, and being a good, caring and responsible son, brother, colleague, employee, teacher, researcher, citizen and human. There was a certain pride and arrogance in my ability to keep going, to actually feel/claim that I am coping and keeping up with my publication targets, my feedback to students_-performing being a scholar, researcher and educator in these precarious times.

I am writing this reflection, on a Saturday morning early, just having had my $100 \%$ fruit and vegetable juice blend (apple, strawberry, blackberry, beetroot and cranberry). My study is well furbished and lit, the smell of incense in the air and a candle burning in the corridor. This reflection falls outside the neat 'types' of scholarly reflection we prescribe for ourselves and our students - reflection-for-action, reflection-in-action and reflection-on-action. Somehow performing these 'types' of conscious and intentional, structured reflection and meta-cognition is just not possible, or possibly, not appropriate, for me, for now. I cannot, and do not want to 'seize the day'; I do not want to be encouraged to 'make the most' of this time, I refuse to think-about-my-thinking in an acrobatic act of meta-meta-cognition.

This is not a reflection. It is a testimony. I bear witness. I am witness to the immense privileges playing out in my entangled whiteness-tenuredness-maleness as I type this testimony with my red 'Fly Emirates' flight socks, drinking good coffee, listening to classical music in a house I own, while outside, beyond my security gates and palisade fencing and alarm systems, the Covid-19 angel of death roams the streets, begging for attention with millions of unemployed South Africans, thousands without running water, unable to wash their hands for 20 seconds as frequently as possible. For millions of South Africans, social distancing is simply not possible and is a brutal testimony of an intergenerational lasting entanglement with inequality.

It therefore, somehow, feels disingenuous, at least for me, to testify how I reach out to students, how flexible I am with providing extensions for assignments, how understanding I try to be when they cannot login to the course site, 
either because they do not have sustainable and/or affordable Internet access, or just simply because they are accessing the course site from a mobile phone and the number of unopened discussion threads on a small screen is just too big an effort while sharing their living-cooking-sleeping-surviving spaces with many others.

In comparison, it feels obscene and even vulgar to confess my fear of dying alone, of admitting my own insecurities of not having enough - enough toilet paper, enough mouthwash, enough paracetamol, just in case. So, I exorcise my fears and insecurities, sucking my third vitamin $\mathrm{C}$ lozenge while performing normality, filling in my Performance Agreement, applying for the next grant and asking for yet another extension for the review of an article that was due two weeks ago.

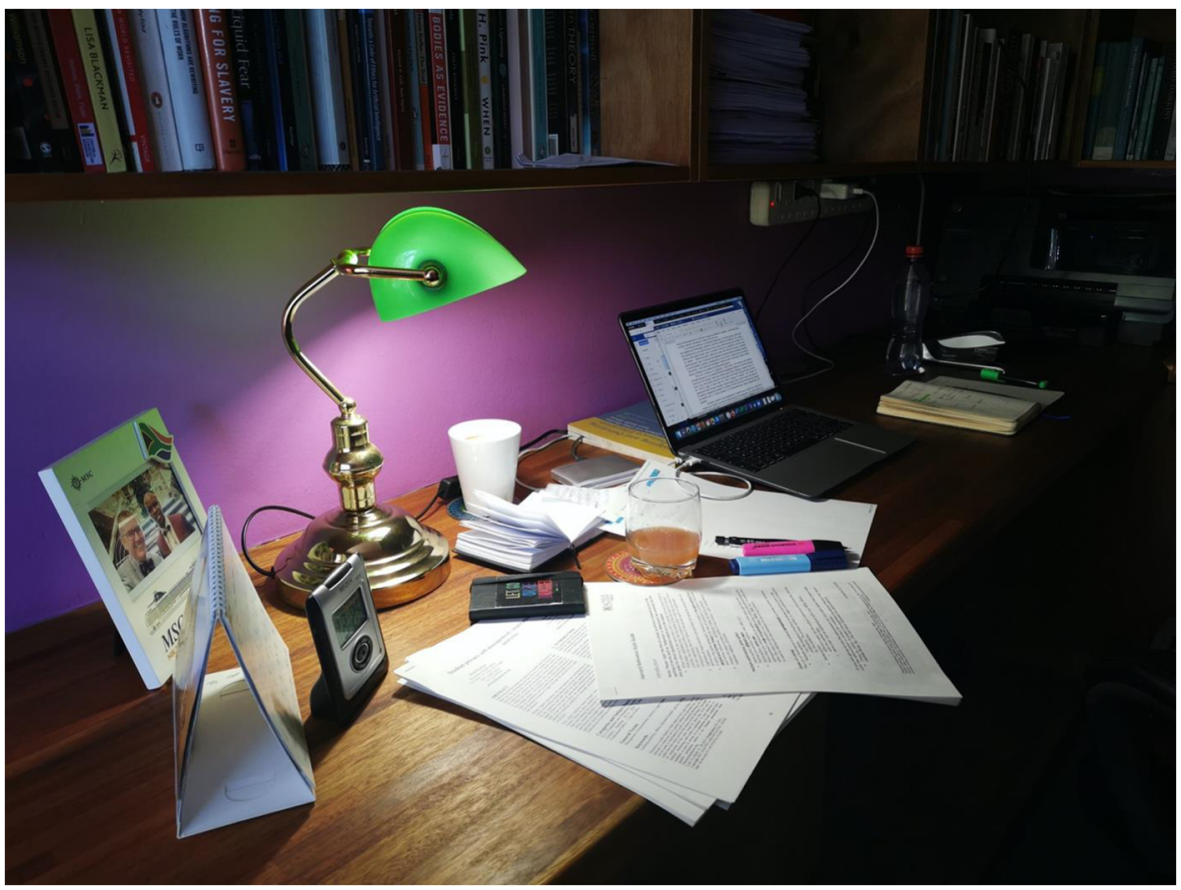

Fig. 59 My workspace, my sanctuary, my place of torture and solace

\section{Exploration - A New Me}

Dr. Kulpreet Kaur, Delhi, India, 6 April 2020

Kulpreet Kaur is an assistant professor at Jindal Global Business School and fellow at Jindal Institute of Behavioural Sciences at O.P. Jindal Global University, Sonipat, India. She is 47 and lives in Delhi with her mother, spouse and two sons. 
As I pen down my thoughts at 4.00 a.m. on 6th April, I have no fright of being late for my meeting scheduled at 11.00 a.m. with the dean for contingency academic planning or attending it half asleep. I have no anxiety of choosing which dress to wear; there is no traffic to fight and lunch boxes to fill. Since our university locked down for Covid-19, I am not sleep deprived, I have worn the most tattered clothes only to cover them with psychedelic scarves for the meetings, and cooked as per the demand of my gut. The obvious nightmares are over but the partially lost battle has just begun.

I am in my 25th year of teaching, and since I started my job, the sixty-fourthousand-dollar question has remained the same: Will virtual classrooms take over physical classrooms? Belonging to generation $\mathrm{X}$, my answer has always remained 'No', partially because the angst of uncontrollable technology overpowering one's forte makes me excruciatingly uncomfortable. Belonging to a noble teaching profession, I have no aptitude for turning raw data into flashy slides, making dramatic bar graphs for analysis and preparing comprehensive presentations overnight. Over the past month, however, I am forced by the unknown virus to hone my skills in giving online classes for the advantage of my students as unanimously decided by university authorities. The challenge is not handling one portal but multiple portals distinctive for meetings and interviews; reviewing literature from the library database; searching online books; making, receiving and grading take-home exam papers and assignments; submitting student feedback; and so on. Some administrative duties even use more than one portal at the same time.

I always believed that there are huge lessons to be learned from millennials, and efficiently handling online portals is the most important of these lessons. Two of my young adult boys, too busy with their own online classes, expressed sarcastic surprise at my incapability. They guided me through another search engine, YouTube, to satiate my quest to learn. Online learning to make online teaching possible seemed interesting. The worst brings the best in people, and that is exactly what I experienced. My incompetency was ameliorated by regenerating the new brain cells and getting all my five senses equally involved in the two-dimensional virtual world.

The first baby step was conversion of my living room into an office space with only a laptop and silence as my weapons. But I miss the dust of chalks over command buttons, strength of the duster over the delete key, the power of scribbling points of discussion with red ink over fastidious-typed feedbacks and, of course, the cacophony of student questions and the feeling of pride during appreciative moments reflected through their beaming eyes.

To my surprise, I love the taste of this virtual blood so I enrolled into an online course to sharpen my axe. At this time of global distress, when doctors, scientists and researchers are not able to make any sense of the corona, I optimistically see it as a time for repair. While mother earth is repairing itself during this forced isolation, I pledge to regenerate and acclimatize my brain cells to a new technological revolution in order become a progressive facilitator while in self-isolation. Lost battles will eventually be won. 


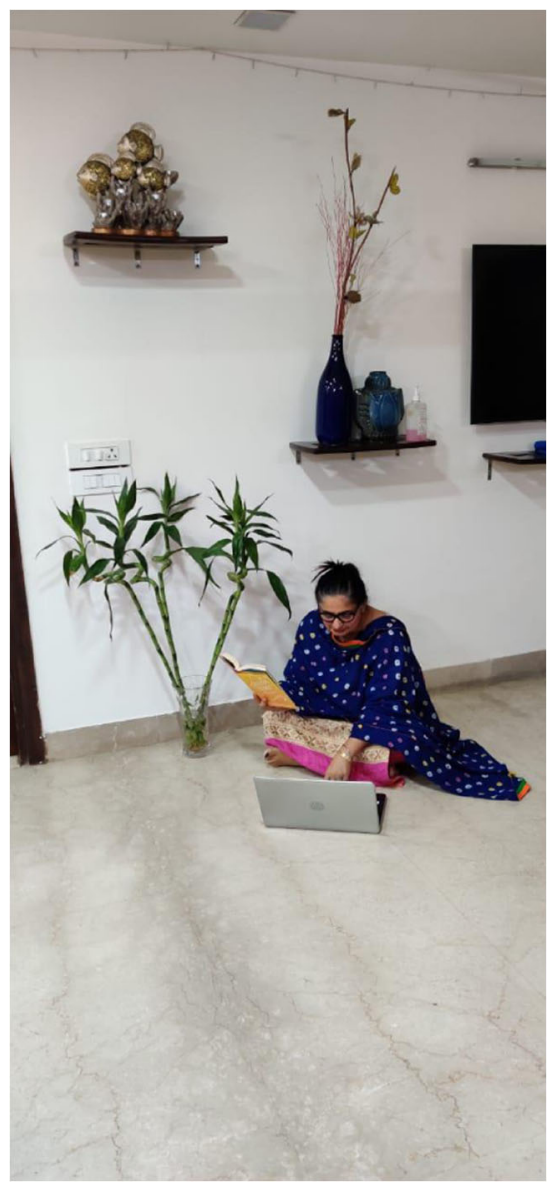

Fig. 60 When all rooms are occupied with a 'DO NOT DISTURB' sign, I often snuggle at the corner of my house to connect with the tranquillity of earth for easy flow of ideas and mindfulness

\section{Awakening Bodhisattva while Teaching in a World of Corona}

Mousumi Mukherjee, Delhi, 6 April

Mousumi Mukherjee is an associate professor and deputy director of the International Institute for Higher Education Research and Capacity Building at O.P. Jindal Global University in Sonipat, India. She is a fellow of the Society of Transnational Academic Researchers and a Research Standing Committee member of the World Council of Comparative Education Societies. She has 20 years' experience in the higher education sector in the USA, Australia and India.

\section{Setting the Context}

I work at a new private university in India, which has gained local and global recognition for its innovative pedagogic work within the Indian higher education space during the 
first decade of its existence. Rather than employing a mainstream Indian model of discipline-based theoretical education, inherited since British colonial times, the university promotes a social science and humanities-based interdisciplinary curriculum and focuses on experiential learning pedagogy. Internships, capstone research projects, clinical methods and field-based education are integral to the teaching and learning process at my institution.

\section{Expectations}

Under the Covid-19 national lockdown, most of our faculty are caught in a dilemma: How to offer the same pedagogical experience through online teaching and learning? Students in programmes such as arts and architecture, journalism and communications, and so on generally work in studios and labs. Even law, business, public policy and liberal arts programmes follow project-based learning methods, which require group work and fieldwork. This is not possible at all with the Covid-19 crisis and lockdown.

I am the member secretary of our Research Ethics and Review Board. Since we are mostly a social science and humanities-based university, and many researchers do fieldbased research, we are facing a major ethical dilemma about faculty and student research projects. How to provide ethics guidelines to continue existing and start new research projects with 'social distancing' as the new norm until a vaccine for Covid-19 is discovered? We are now working to produce a comprehensive research ethics guideline for research in the age of Covid-19.

With regard to online teaching, I had an extensive experience of teaching in a fully online graduate programme while I was in the USA. I have also taught an online course for two semesters while in Melbourne, Australia, in collaboration with colleagues in London and Toronto. I utilize that knowledge in my current work in India, and I also assist other colleagues. Compared to a state Ivy League university in the USA and the top research university in Australia, the rapid switch to online learning with limited technological resources is a major challenge here in India.

\section{Feelings}

Like most of my colleagues around the world, I am anxious and apprehensive about the future. There is no doubt education cannot stop. We need to educate future citizens in this age of Covid-19. We need to teach them about the 'free world' we inherited from our ancestors, who fought against colonial oppressors. We need to teach them about mistakes that we have made in the age of the Anthropocene; mistakes that have created this dystopic Orwellian 'world of corona'. We need to teach them how they can continue to live, learn and work in the 'world of corona'. We need to provide them with intellectual tools they will need to build a better world in the future. But, how to do this teaching purely online in the age of Covid-19? It feels like a Herculean effort with family, finances, work-related uncertainties and daily existential challenges.

\section{Experience}

I am going back to traditional Buddhist philosophy to awaken the Bodhisattva inside of me. I am learning how to live in the present. I am working to teach online in the age of Covid19 , without worrying about the uncertainty of outcomes associated with online teaching and learning. I am hoping one day we will be free again from this 'world of corona'! 


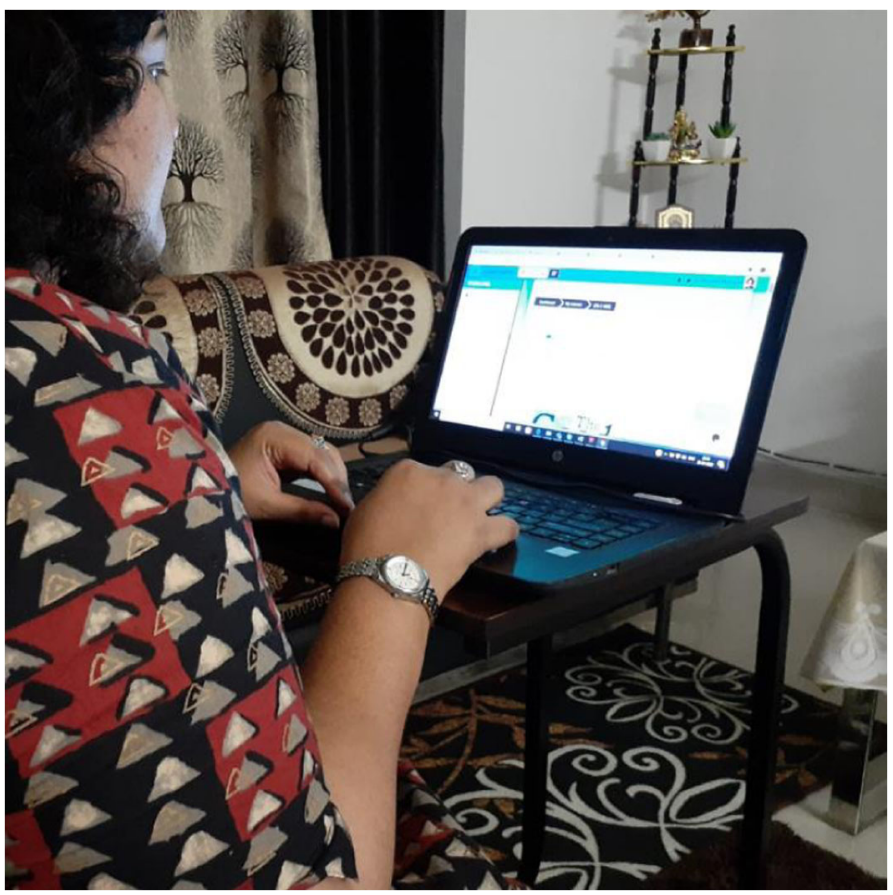

Fig. 61 This is my workspace in my living room, where I work on my laptop during the lockdown. Otherwise, this would be a space, where my mother would watch TV or, we would socialize with guests

\section{My Three Online Roles in Lockdown in New Zealand} Rene Novak, Tauranga, New Zealand, 6 April

Rene Novak, has a strong passion for early childhood pedagogy and technology education. He is currently supporting Tauranga centres as a professional services manager for BestStart and is a published $\mathrm{PhD}$ candidate with his thesis focusing on developing new methodologies to study the importance of play involving virtual reality, as a tool and a method.

As I am pouring my thoughts into this contribution at the beginning of April 2020, I am reminiscing about my naïve past self, which only a few weeks ago thought of himself as being well isolated from the dangers of Covid-19, by living in New Zealand, an island nation in the Pacific. Little did I know that I was to experience a vastly different meaning of the word isolation.

I see myself as well entangled in the educational landscape of New Zealand, where I currently operate in three distinctive roles in relation to formal teaching and learning. My primary income stems from my pedagogical leadership and management role at BestStart, the largest provider of early childhood education in New Zealand. Alongside I am a lecturer and tutor for two early childhood education courses at the University of Waikato and also a $\mathrm{PhD}$ student at the same institution. 
As Covid-19 transgressed our borders, our government took fast and drastic measures to prevent community transmission. People of New Zealand had 2 days to prepare for full lockdown, with every household self-isolating themselves. This sweeping response turned my world upside down in a matter of minutes. I felt uncertain about how my employers will treat the situation and how they will be able to retain and pay their workforce including myself. With a sinking feeling, being a single-income mortgage payer, I started to worry about my job security and my ability to continue to provide for myself. Fortunately, the government provided generous packages to all businesses that enabled both of my employers to continue paying me as normal.

Several drastic changes were introduced to my primary job, where play-based learning experiences sanctioned by our national early year's curriculum were moved into the online space. Suddenly, all my teachers, who are native to handson teaching with their young learners, were expected to learn the use of communication technologies to help bridge the divide between them and their treasured learners. My work became focused on supporting teachers with their facilitation of online learning through conference calls and messaging systems. The organisation was quick to respond with an online learning webinar and supportive resources.

The university flooded us with daily information and updates, and provided a week's breathing space for everyone to transition to online learning. In the tertiary sector, the transition was easier to facilitate as online learning is already very familiar. One of the courses I am teaching was already fully online, while the other one was transitioned using recorded lectures and Zoom meetings. My $\mathrm{PhD}$ mentoring meetings also moved online effortlessly, as I am used to and prefer to work self-sufficiently.

After a very hectic and at times stressful first week, I have managed to acclimatise to my new normal. It always surprises me how resilient and adaptive humans are in the face of adversity. In general, I feel that the situation got handled very well and that I was very well supported by my employers, and that enabled me to be supportive towards my teachers and students.

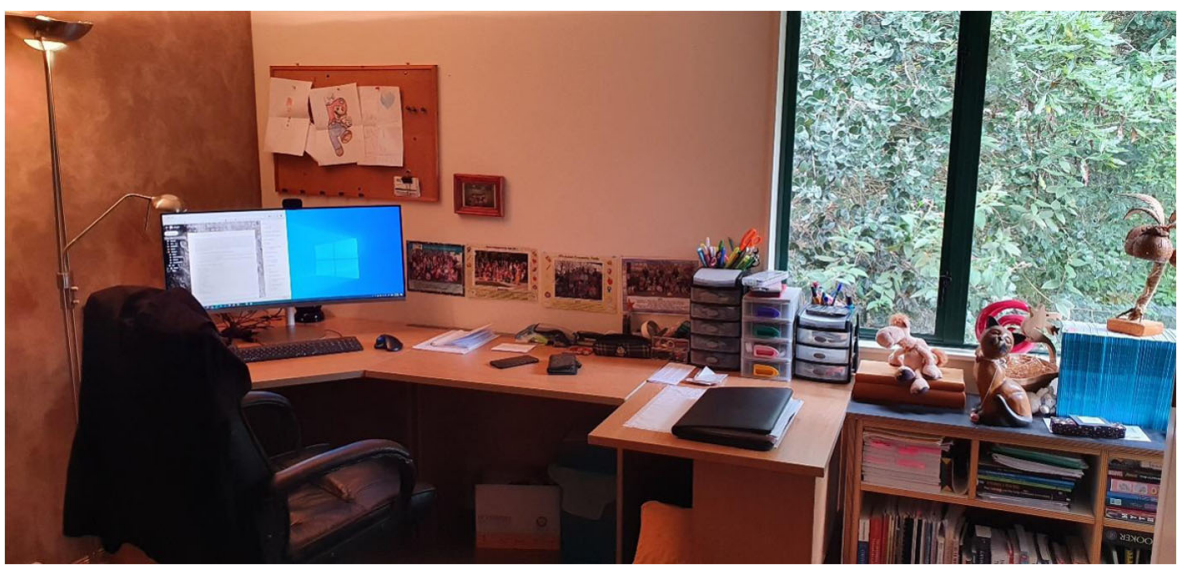

Fig. 62 This is my office space at home. I would put the work shirt on (on the chair) before any video meetings 


\section{Philosophy of Online teaching: a Philosopher's Perspective}

Richa Shukla, Sonipat, India, 6 April

Richa Shukla is an assistant professor at the O.P. Jindal Global University, Sonipat, India. She is a philosopher. Richa stays in Sonipat, Haryana. Her theoretical leanings stand for Continental Philosophy, Feminist Philosophy and Contemporary Indian Philosophy.

Crisis has different effects on anyone, everyone, as well as on collectives too. It reshapes, moulds, and asks us to think who we really are. Being a philosopher, I have my own set of doubts, crushed, crumbled and at times defeated ideas and curiosities in regard to Covid-19. In between all this, my university has decided that it is in the best interest of students and faculty that we shift to online teaching. I have never been in a situation like this, and I feel like an acquaintance to myself. As if my pedagogy is trying to fool around with me, asking me to live in contingency. Pondering on questions of if, but, why. So, now what? It's a feminist wink which my pedagogy was throwing at me.

With a wee bit of doubt and curiosity, I started my online lectures. This testimony is about online classes, yet it is impossible to talk about an object without understanding the subject. If I put myself in my student's shoes, would I find it difficult or challenging to adapt to this new way of learning? While I was trying to deliver my lectures, my students showed compassion, kindness, and lots of understanding. One of the biggest challenges is to experience the shift from dialogue to monologue. Largely all my face-to-face lectures are dialogue-based. I like them that way, because of all philosophy is a dialogue, right? But with the switch to online teaching, dialogue becomes challenging.

Philosophically, I believe that any crisis acts as a mirror of society and of individuals. It posits a foundational question to our existence. Having said that, the Internet is full of videos which torment me-videos in which faculty members are being heckled, and looked down upon, while they are having a tough time delivering lectures. This is a pattern of a set of students trying to exercise their liberty without understanding how is it standing in violation of the instructor's liberty and other students' liberty to study. As a philosopher, the concept of freedom has always perplexed me. How do we navigate through it amidst the presence of so many selves around us. Continuously interrupting the teacher, not allowing the class to take place, creating a nuisance, these make me think about several questions on freedom, situated selves and responsibilities. Jean Paul Sartre rightly said, "your freedom ends at the tip of your nose."

For instance, how precarious the existence and presence of faculty members can become following this technological advancement? In the name of freedom and autonomy, where do we draw the line between teachers and participants during online teaching? How do we understand compassion and empathy, when being reduced by other people to objects? These times, as a faculty, it had taught me tremendously to be comfortable in silence. These and many other questions make me rethink challenges thrown at us. Needless to say, of all and above all, let us try and be humans to each other. 


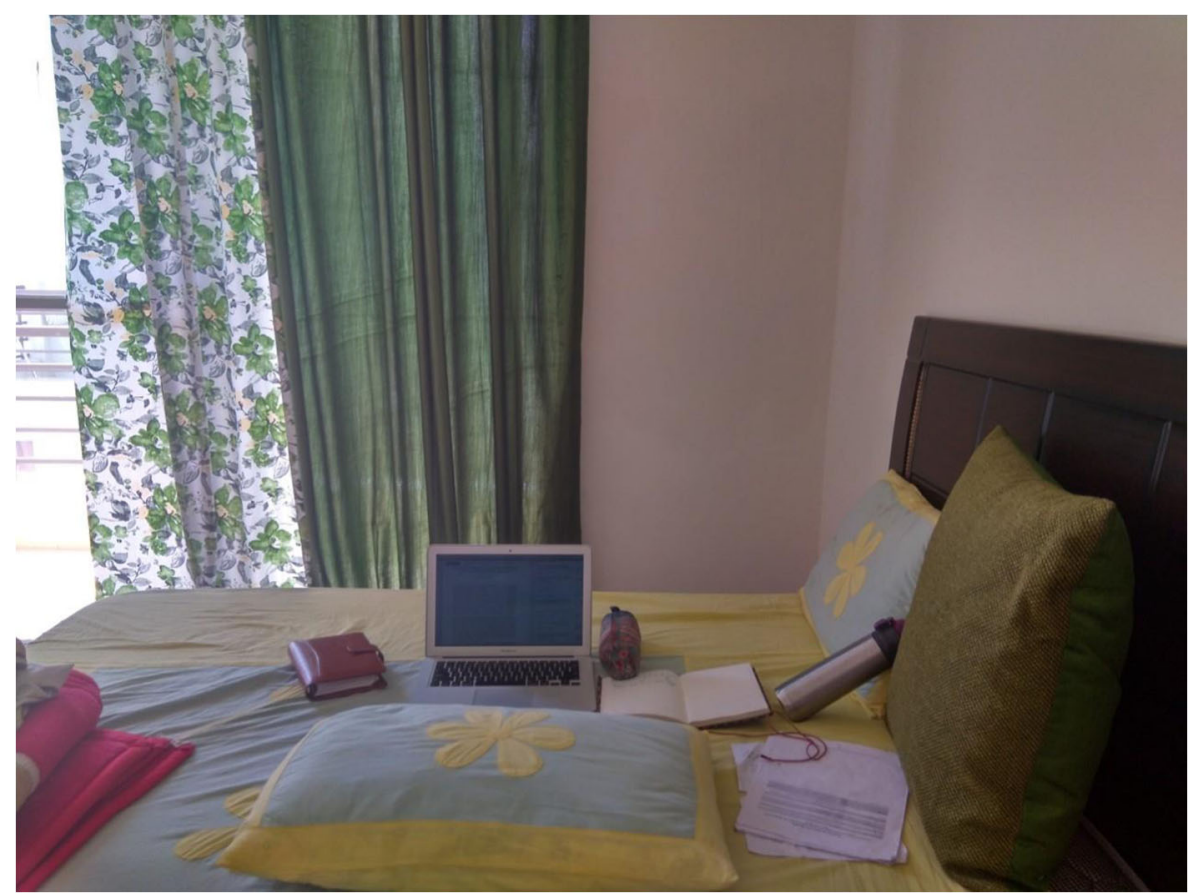

Fig. 63 I doubt if I can call the above space my only workplace during Covid-19. As Covid-19 was mocking many aspects of our existence, it laughed at my fixed patterns too. It taught me to re-define and accept my changing spaces in workplace, and above all, to add a plural $\mathrm{S}$ to the singular idea of workplace!

\section{PhD Research in the Time of Covid-19}

Stephanie Hollings, Phoenix, AZ, USA, 6 April

Stephanie Hollings is a second-year PhD student in Educational Leadership and Policy/ Comparative Education at Beijing Normal University. Stephanie is 32 years old and splits her time between Phoenix, AZ, USA, and Beijing, China.

$$
\text { *** }
$$

As a second-year $\mathrm{PhD}$ student at Beijing Normal University, I should at this very moment be conducting research in Chinese international schools. I left China in early January, after having passed my proposal defence and with the understanding that after the Chinese New Year, I would accompany my supervisor throughout her trips in various megacities of China and begin collecting data.

It is April, I am still in the USA, and the impact of Covid-19 is being felt stronger than ever globally. Attending a Chinese university has meant that for this entire semester my classes have been moved online and for students like me residing in the USA, which has fated plenty of late nights with classes often starting after 10 p.m. Like most $\mathrm{PhD}$ students, my office is at home, and suddenly, my sister, a financial company employee, shares that office. This has led to the result that most of my research is now being done in the confines of my closet, albeit a big closet, as it is the only place in 
which I cannot hear her never-ending phone calls, as it seems Covid-19 has created a busy time for financial companies. It is difficult to be a Chinese university student, being expected to still attend and contribute to classes in Chinese time, do research, and still live the life of an American office worker, as my sister is still expected to and which will ultimately mean that I am forced too also, unless I learn to sleep deeper.

The influence of Covid-19 can be numerated by the loss of profits for universities, but for some of those at the epicenter, the impact is harder to quantify in numbers. How can it be quantified in terms of students and their ability to do research? Many of us are now stuck in the limbo of our home life and school life, which often seem incompatible. We are geographically separated from our supervisors and professors. We have had to turn to digital meetings and often the hiatus of our research. Being a PhD student in the time of Covid-19 has provided many challenges to students like myself, stuck in a realm of uncertainty.

I am lucky enough to have defended my proposal; many second-year students at my university have not yet done so. What will they do? Will the university find a way to have online proposal defences as they have done with pre-defences for some third-year students? Is that the future for PhD students? Online defences? What about online research? Will virtual interviews and data collecting be the future of research? While the possibilities are exciting, it also means that for students like me, a whole new dynamic has been created. Covid-19 will continue to affect and re-define our work, as its impacts will be felt throughout our research, and as we continue to learn how much of the $\mathrm{PhD}$ process can be done virtually. We are the $\mathrm{PhD}$ students in the time of Covid-19.

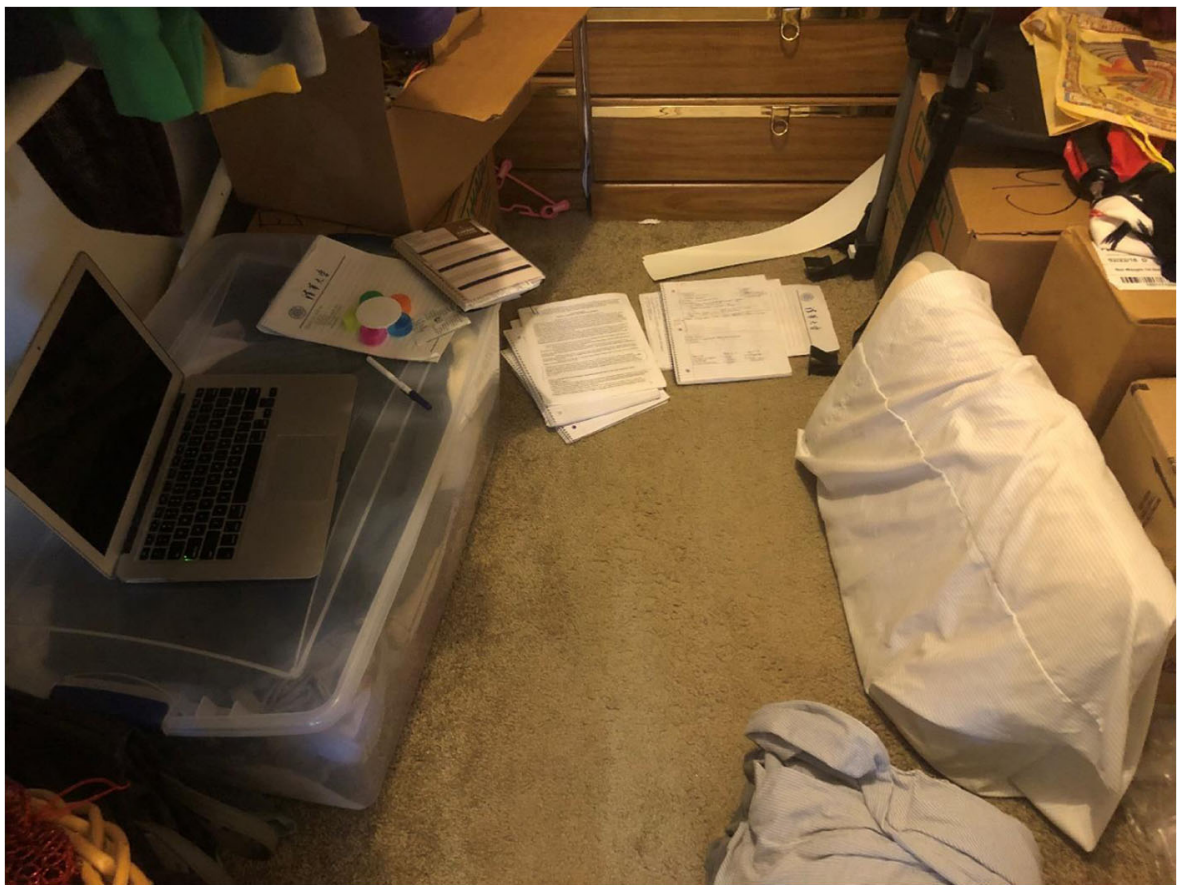

Fig. 64 This is my makeshift workspace in my closet, as my sister had laid claims to the living room/dining room area of our apartment (where the Internet connection is the strongest) 


\section{Working Together, but Separately \\ Ulla Konnerup, Aalborg, Denmark, 6 April}

Ulla Konnerup is a Ph.D, Special Consultant at The Faculty of Humanities, Aalborg University, Denmark. Ulla is 57 years old and lives in Hjoering, Denmark, with her spouse. Ulla has two adult children, both living and studying at Aarhus University.

At the time of writing this testimony, I'm sitting in my home office finishing the last work assignments before I can turn on the auto mail and shut down my computer. I have a week of Easter holidays ahead of me, which is so much needed. As the Danish government ordered the closure of schools, daycares, restaurants, cafes and gyms, and closed down borders to most foreigners, I have been working from home. Aalborg University's strategy during this period is to close down totally for all activities. No one at all is allowed to enter the university's buildings.

Driving home on March 13, I did not envisage that I would still be at home 4 weeks later. It is still surreal.

My research area is ICT-enhanced learning and online teaching. Moreover, a part of my position is developing strategies for digitizing the university's study activities. I have been a part of the corona preparedness team for digitally supported teaching during the closure period and I have been supporting teachers to redesign their teaching. For most teachers and researchers is has been challenging to 'reinvent' their practices within new digital tools and formats. It has been challenging for me to virtually guide colleagues with limited digital competencies. I have been working many hours per day and during weekends. My phone has been open and we have been struggling to set up a website with 'how you can teach digitally' video guidance. Over the weeks, there have been fewer and fewer support-related enquiries. Most teachers have adapted to new formats over a very short period and they have been extremely creative in developing their own solutions.

I live in the countryside $60 \mathrm{~km}$ from the university. My children are adults living in another city. I have a very good and cosy home office. For me, it is not uncommon to work at home and be in online contact with colleagues and students. However, I've never done it for such a long period of time. I miss my colleagues. Because of the fluid working hours, balance between private commitments and work are challenged. However, I am more or less finding my way.

The whole situation fills me with anxiety. Right now, it seems that we are doing okay in Denmark. Our healthcare system has the capacities to cope. But that is not the case all over the world. Frightening scenarios are happening in other countries and there is no cure in sight.

I am concerned about the consequences of these enforced behaviours. What will be the impact of less bodily contact? How will it affect children if mothers are wearing masks during breastfeeding? However, I have confidence in scientists, especially when I see how intensely they are working to find vaccines and medicines. 


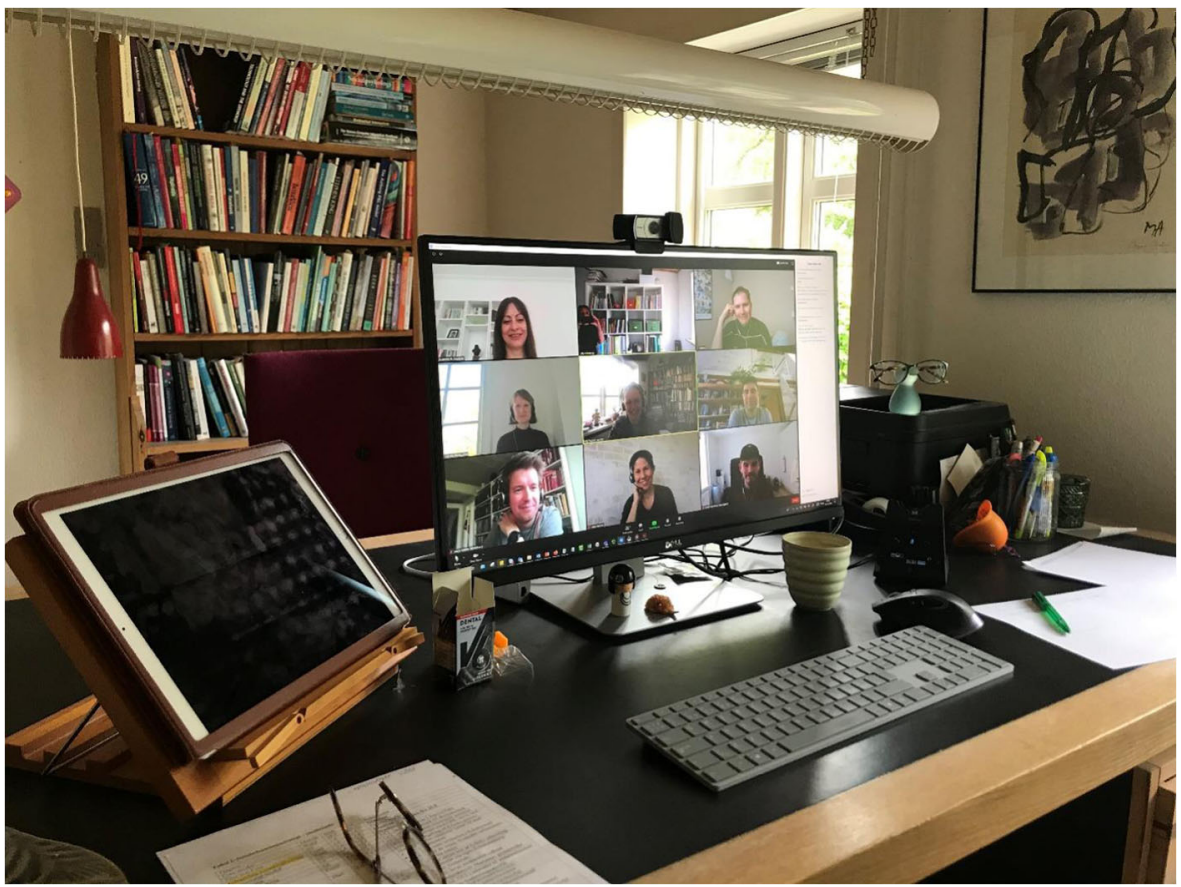

Fig. 65 This is my home office. I have the workspace for myself all alone, and can close the door when I need to. My only company is my poodle, Ella

\section{An Opportunity to Strengthen Alternatives to Classroom Teaching} Madhav Mallya, Sonipat, India, 6 April

Madhav Mallya is a lecturer at the Jindal Global Law School, Sonipat, Haryana. He lives in Sonipat with his wife and is passionate about teaching and helping students think critically about the law.

One of the hallmarks of education, whether primary, secondary or post-secondary, is critical engagement with students. The greatest joy for a teacher is to converse with students, encourage them to read literature beyond the textbook and then finally engage with their different viewpoints. The conversation resulting from this engagement in the classroom is far more valuable than ordinary textbooks and rote learning-after all, textbooks are only meant to be basic material. Yet, in the midst of this global pandemic, teachers around the globe are forced to teach online-a process which may often be marred by technological difficulties, logistical and personal challenges and, above all, the reduced opportunity to converse with students and hear their ideas.

I teach labour law at the Jindal Global Law School, Sonipat, India. I am in the fourth year of my career as a teacher. For me, the highlight of teaching, that special moment in 
the classroom, is the opportunity to pose challenging questions to the class. These questions may often go beyond the syllabus and sometimes, in fact, contradict the prescribed critical opinion, text or case law. I also learn from the ensuing discussions and try to leave the classroom with different perspectives on an issue.

As I write this short piece, India continues to be under a complete lockdown. Confined to my home, I taught my first ever online class. While I was initially apprehensive, I must admit that it is possible to replicate critical classroom discussions through online modes of teaching. However, there are a few challenges to the process.

Logistical and technological issues aside, it can be strenuous to communicate with so many students when you cannot see them and gauge their reactions. It is also difficult to engage in critical in-depth thinking; the opportunity for joint debates and discussions is reduced. From a student's point of view, it is difficult to maintain concentration when the speaker is often just a voice or face miles away. Students are often also surrounded by the distractions of home.

Isn't classroom teaching a privilege that we take for granted? There are millions of students around the world who attend online classes because they work hard to support families and cannot afford tuition fees. There are teachers who do not have the privilege of teaching on green and plush campuses with lovely libraries and auditoriums. To put bread on the table, they earn on a class-wise basis by teaching online.

While I am sure that discipline and respect for social distancing norms will help us overcome the spread of the Covid-19 virus, I also believe that online classes are here to stay and will be a regular component of our future academic lives. While there is no substitute for the excitement of the classroom, I believe this pandemic is a wake-up call to us in the teaching profession to strengthen modes of online teaching and engagement and to develop software to aid critical thinking.

We may be in the midst of social crisis, but we must not forget our duty to help students think for themselves.

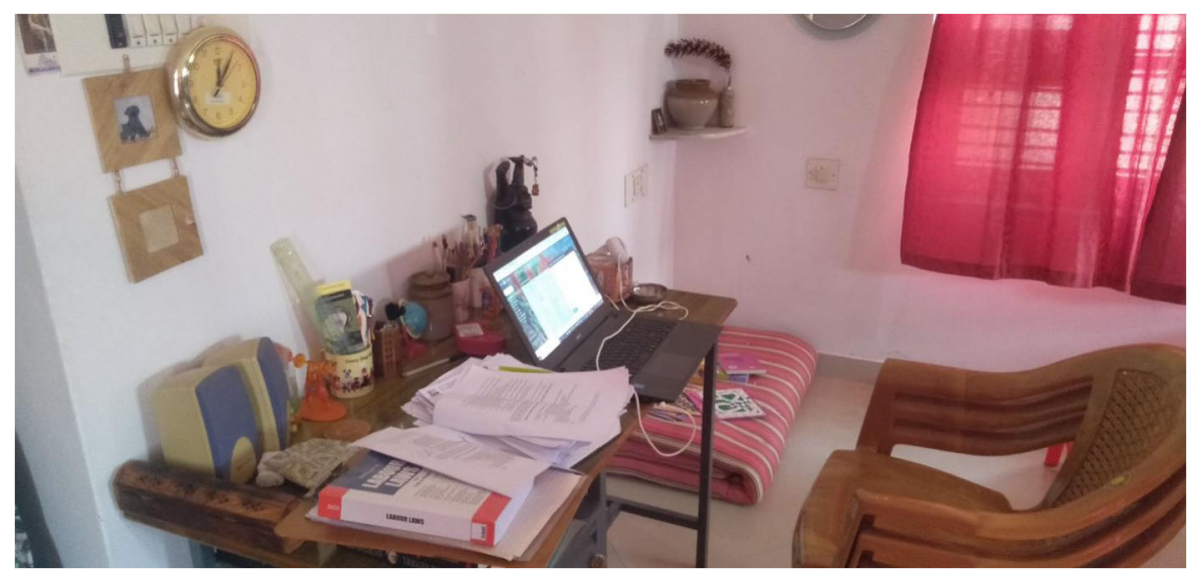

Fig. 66 This is my wife's cheerful and cosy study in Mysore, India, which I shared during the lockdown and till we could travel back home 


\section{Untitled}

Anthony Olorundare, Changchun, China, 6 April

Anthony Olorundare is from the western part of Africa, Nigeria, and is currently a master's student in Applied Psychology at the Northeast Normal University China. Anthony is 26 years old and lives in Changchun, Jilin Province, China.

The coronavirus pandemic has various effects: heightened pressure on healthcare, crippled economic activities, restricted movement and social interactions, paralyzed industrial processes, restrictions in local and international transit, and so on. Virtually every aspect of human activity is shot dead by this fierce and highly destructive virus.

The outbreak has necessitated a high level of interdependence among individuals, states/regions within a country, and between various countries. It is obvious that no single individual and country can control the spread and treatment of the disease, and this has necessitated a global restriction of movement.

My university in China took adequate measures. All students who travelled within China and returned in the first week of February were quarantined for a period of 14 days. Dormitory students are restricted from moving out of school premises, and their basic needs are met. All dormitory students are expected to contribute to the fight against Covid-19 by abiding with university regulations and a hygienic lifestyle.

We resumed online classes at the end of February. Although it is impossible to have a proper classroom, it is good to know that class activities are continued online. Academic activities have not been the same, but measures to avoid a complete halt on academic activities have been put in place. A good number of students and lecturers are not conversant with online lectures, so this is a welcome avenue to explore teaching and learning in another dimension.

One of the major challenges I face is network disruption. We have to connect with our colleagues abroad, where network reception is not as good as ours; hence, a break in transmission is inevitable and does not allow smooth communication. Another hurdle is the difficulties in explaining certain concepts which require mathematical and diagrammatic representation. Lecturers are unable to deliver on certain topics and we are left to do more research. Another challenge is the lack of concentration. During online lectures, I tend to lose focus, and that may not have occurred in a classroom setting in the same way.

Conclusively, online classes are flexible and they provide me with the opportunity to plan study time around the rest of my day.

Thanks. 


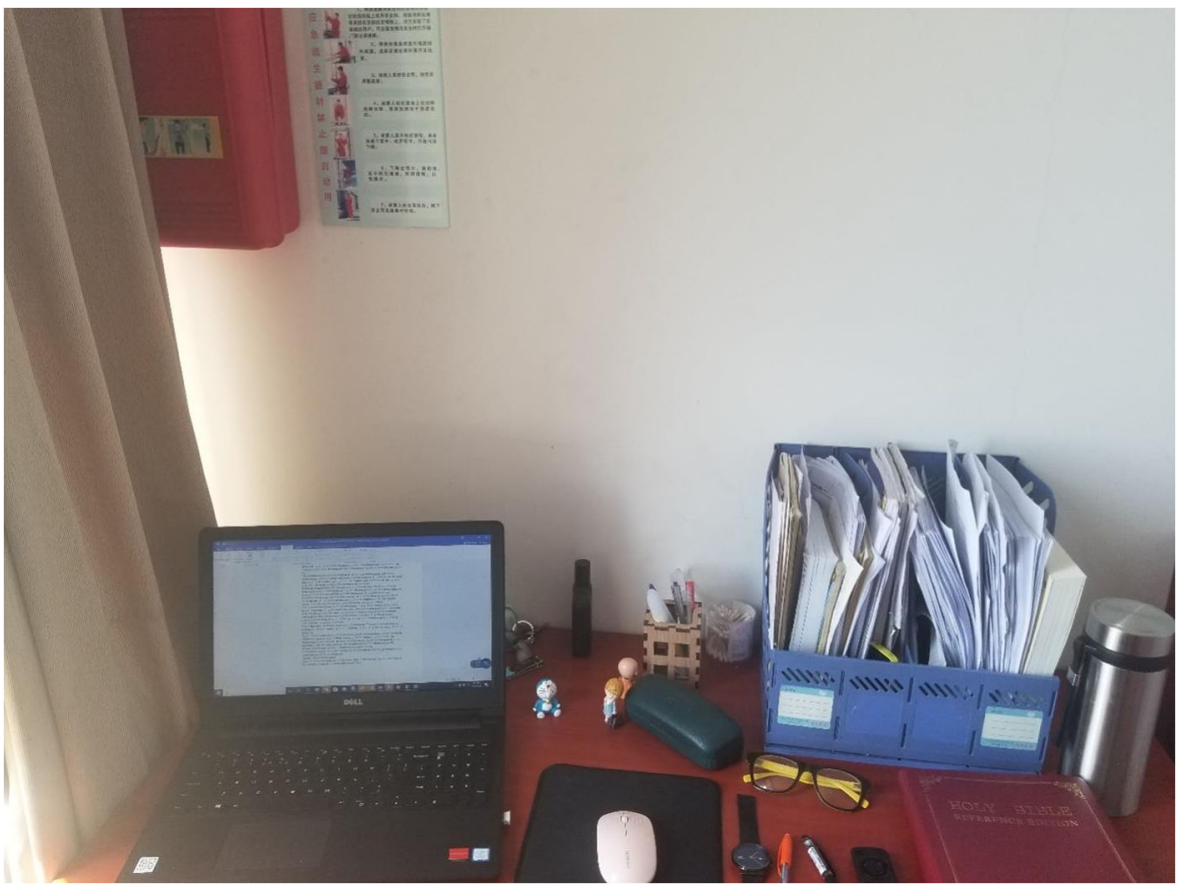

Fig. 67 This is my workspace in my room, where I take turns in class activities such as assignments, online presentation, and online class

\section{'Koth biro, koth biro chwe'}

\section{Dholuo: the Rains Are Coming; It Is Going to Pour}

Charlotte Achieng-Evensen, Orange, CA, USA, 6 April

Charlotte Achieng-Evensen is a K-12 educator and academic. Currently, she serves her school district as a teacher specialist focusing on research and college and careers preparation. At the university level, Charlotte teaches a variety of teacher education courses.

$$
* * *
$$

I feel closed in, claustrophobic. As if, somehow, the world has turned itself into a looking glass. I am both on the outside looking in, and on the inside looking out. What is happening? It is week four of the remain 'safe-at-home' mandate. Officials repeatedly tell us Angelinos we aren't under martial law, but we must follow orders for social distancing. Most paid attention; a great deal did not. They went to the beaches, jogged trails, visited playgrounds. At first, the sentiment was this cannot be that bad, can it? But now, schools are closed, offices are closed, grocery stores have empty shelves, lines around them. Unfathomably, I cannot find toilet paper or household cleaners.

According to California Government Code Section 3100-3109, I am now a disaster service worker. I have not generally equated 'educator' with disaster service, but we are in an untypical moment. Usually, I am a K-12 teacher specialist. My work includes program coordination, in-service teacher professional learning, system analysis and 
support. In this post-Covid-19 world, my job is to look for ways to mitigate negative outcomes. I am still grappling what this means. I am also a university lecturer attempting to move instruction to an online format, rapidly. We are, indeed, making it-but something is just a bit lacking. There is an echoing dissonance. It is not merely the Wi-Fi connection.

Tents are up outside of hospitals. They are getting ready for drive-through Covid-19 testing. The thing is, there are not enough tests. So, we do not know the actual scope of those infected. And even if there were, there now seems to be some indication that early testing may not actually identify the virus. But that is just the beginning; there are not enough protective gear for health professionals to access. Again, I am beyond confused; how can a country with a GDP of \$21.43 trillion (BEA 2020) struggle with the production of masks, of ventilators?

Meanwhile, Covid-19 numbers, in Los Angeles County, are rising. Now I know people who have contracted the disease and are in actual quarantine. No longer are they merely to be 'safe at home.' Every hour, the number of diagnosed people increases. The hospital in proximity to our K-12 district came looking for any supplies that our school sites may have. Supplies that healthcare workers desperately need to tend to patients but cannot get. So, they are borrowing from schools. Our teachers are partnering with universities to run their 3D-printing machines. They will manufacture masks, supplying whatever they can to hospitals. There is something very wrong with this picture. And I am worried. What will happen to our students facing lack of security-food, shelter, mental health, medical care? What about the adults losing economic security? Somewhere here, there is a healing space. I see it in individuals helping each other. I hear it in the chattering voices of children playing outside. Still, koth biro, koth biro chwe.

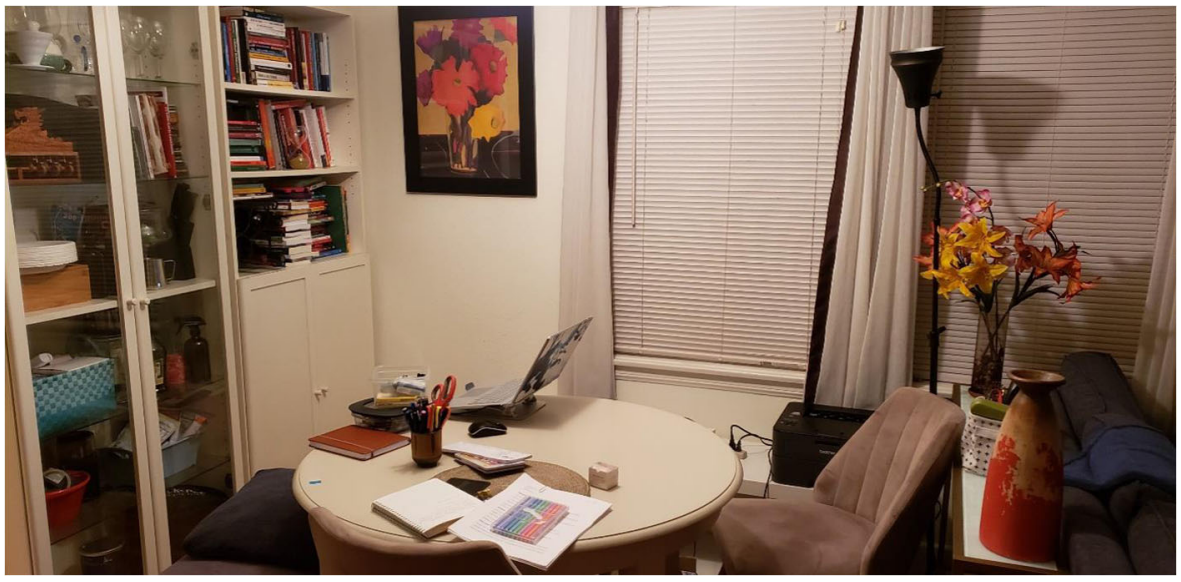

Fig. 68 This is my dining table-office workspace. I purchased some new furniture, reorganized the shelves, and added some office 'resources' to make it somewhat aesthetically functional 


\section{Teacher's Perspective About Online Learning Due To Covid-19}

Abey P Philip, Miri, Malaysia, 6 April

Abey Philip is a senior lecturer at the Curtin University Malaysia, in Northern Borneo. He lives in Miri, Sarawak, with his wife and three sons.

I work at Curtin University Malaysia, one of the major offshore campuses of Curtin University Australia. Curtin Malaysia is in a unique position whereby it needs to adhere to both Malaysian and Australian government lockdown guidelines. Due to Covid-19, the Malaysian government has announced a complete lockdown of all universities and educational institutions for three weeks, which was then extended for three more weeks, and it might be extended further. Complying with the government instructions, all face-to-face classes are shifted to online platforms. The university already has a learning platform called Blackboard Collaborate Ultra, with real-time video-conferencing tools and facilities to share videos, files, and virtual whiteboards.

Lecturers are supposed to provide online classes through the virtual platform without much expertise or practice. We conduct lectures and tutorials online. Hopeful that the practice would make us perfect, almost all staff are using Blackboard Collaborate, where we offer real-time online classes to our students. It is also expected that we consult and mark using these online facilities. Bruce Lee said, 'If you want to learn to swim, jump into the water', and we are literally in the water learning how to swim in real time. Teachers keep in touch with each other and assist each other navigating the online platform. Students have created a WhatsApp group and included me so I can answer any questions or doubts which may arise.

Online learning presupposes that the student takes full responsibility for their own learning. We cannot expect this from undergraduate students who are used to classroom learning and face-to-face interaction. But the raging pandemic does not offer us many options. For an academic who cherishes classroom interactions like me, online learning is a bleak landscape to begin with. I try my best to make these classes as engaging and useful as possible. The online platform is uni-directional, and I cannot see whether students are actually participating in online classes. I struggle to pick up nonverbal hints from online students that might suggest class effectiveness. The principal factors of successful learning are student motivation, self-efficacy, attention, and engagement. With online learning, all these aspects are at risk.

I feel that online classes can never replace classroom teaching. It is true that these desperate times need desperate measures and this is the best we can do given the present circumstances. I also think that online teaching cannot make full use of students' imagination and can even make them self-centred rather than oriented towards group work. All institutions that have switched to online classes due to the coronavirus may face the same problems. At the end, I believe that our students are at the receiving end of this unexpected shift.

I am the father of three boys, one in secondary school and two in primary school. They also go online every day. With three kids doing online classes, 
and their father giving online classes, all in one PC and one laptop, our house looks more like a busy call centre during working hours. Obviously, the limited number of computers is a major challenge, so is poor Internet connection at times. My wife, who is currently doing her PhD, has to step back and compromise her work for myself and three children. Covid-16 brings us a lot of uncertainty and discomfort, yet it brings hope for our survival. I hope we all come out from this crisis with a new appreciation for the sense of community, the students in the classrooms and hallways, the queues in the cafeteria, the normalcy of all the things we used to take for granted.

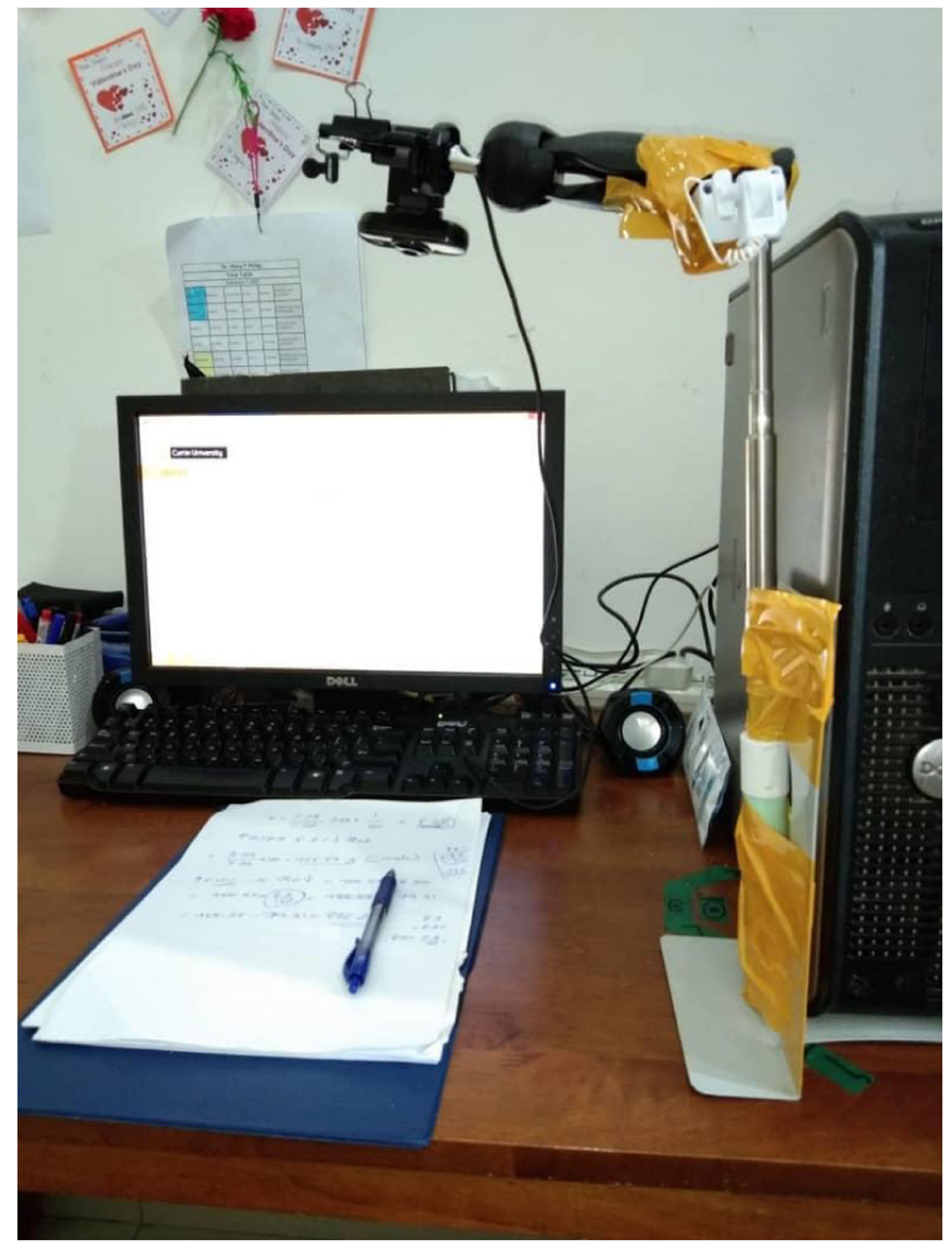

Fig. 69 This is my current workplace, which I share with my oldest son. The improvised conundrum on the right is a selfie stick and a webcam stuck together precariously on a book stand with loads of tape so that my diagrams and working of problems are clearly visible to the students 


\section{My Personal Experience}

Moses Kayode Hazzan, Abode, Nigeria, 6 April

Moses Kayode Hazzan is a PhD student at the Department of Educational Management, University of Ibadan, Oyo State, Nigeria, and a teacher in Great Visionary Educators (a centre for training both ' $\mathrm{O}$ '- and 'A'-level students) in Ibadan. Hazzan is 42 years old and lives in Ibadan, Oyo State, Nigeria, with his partner and daughter.

My name is Hazzan Moses Kayode, a citizen of Nigeria and a PhD student at the Department of Educational Management, Faculty of Education, University of Ibadan, Ibadan, Nigeria. I am using this medium to 'showcase' my testimony for the global pandemic of Covid-19 and its serious impact on academic activities at my school, the University of Ibadan. I am writing this testimony from my place in Abode (specifically, Akingbile, Moniya, Ibadan in Oyo State, Nigeria). As a teacher who is invariably peripatetic in his freelance service, I face the huddle of being constrained by time and movement because of the curfew imposed recently by the state government.

On December 2019, an outbreak of severe coronavirus infections occurred in Wuhan, Hubei Province, and spread across China and beyond. On February 12, the World Health Organisation officially named the disease caused by the novel virus the Coronavirus Disease 2019 (Covid-19). At first, morbidity remained low, but it soon reached a tipping point in mid-January. Followed by an exponential growth until January 23, the outbreak spread to other countries, attracting extensive attention around the world.

In response to this awful global phenomenon, the management of the University of Ibadan unequivocally announced the suspension of all academic and non-academic activities that may warrant gathering ten or more people on campus. The suspension culminated in school closure until further notice. Movements in and out of university premises are restricted and utterly monitored by school security officials. This new reality posits many challenges in my professional, private, and family engagements.

Professionally, restriction of movement has seriously affected numbers of students in my teaching appointment. My PhD supervisor did not come to the office; she could only be contacted by phone. A strike organised by the Academic Staff Union of Universities (ASSU) equally jeopardises contact with most lecturers. Hence, I had to put my thesis in 'suspended animation' while I engage in other academic activities such as co-writing articles with international students who happen to be my friends in other countries such as China and USA, editing theses sent by friends from China, and reading more journal articles of international repute to widen my intellectual horizons.

Despite the academic 'gridlock' emanating from most of the Nigerian universities due to government directives about restricted movements of people, this period opens new vistas of academic engagements for me. The situation affords me more opportunities to be sedentary and busy with other rewarding academic activities, and most importantly to access cross-fertilisation of ideas with other scholars around the world. 


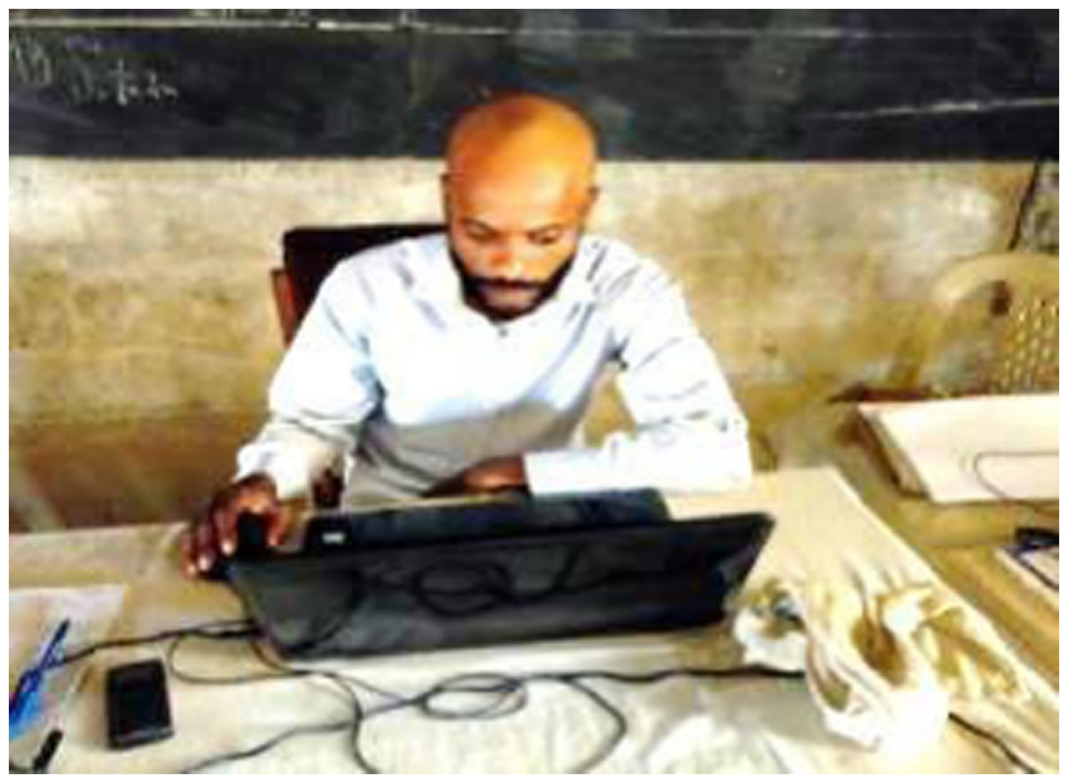

Fig. 70 This is my workspace near our living apartment where I take turns in working with my partner, Marvellous, and hold a meeting with my teachers

\section{New Realities, New Meanings}

Kevin Stockbridge, Orange, CA, USA, 6 April

Kevin Stockbridge is a clinical assistant professor of Teacher Education at Chapman University, USA. Kevin is 39 years old and lives in Santa Ana, CA, with his fiancé.

It's early April as I type these words at my new workspace at home in Southern California. I write in the midst of a time of uncertainty and fear across the world as we face the Covid-19 pandemic. And yet, mitigating the spread of this virus through social distancing and 'stay at home' orders has also meant that we cannot actually face each other. It is a new separation of which we are all trying to make sense.

This is my first year as a full-time faculty member - a title that I have looked forward to since I started my PhD program in 2012. I remember how excited I was only a handful of months ago when I walked into my own office, surrounded by my professor-colleagues. The academic year has already brought on a lot - a full load of new classes to prepare and teach, a group of new committees to join, new relationships to establish at work, and a new research project to develop. Now, I find myself trying to learn how to do all these things online as my newly found mentors are struggling with the same.

I am immensely grateful for the weeks that I had the chance to share a classroom with my students before my institution moved all classes online. This shared space and time established the kind of trust and rapport that have allowed us to navigate this new reality together. In the first week, I took a lot of time to step back and re-imagine the 
best way that teaching and learning could happen in our context. I planned new modes of engagement that I thought would best serve our learning outcomes. Each week, however, I am faced with new issues that I had not foreseen which require on-the-spot decisions. Syllabus changes abound. In all this, I embrace the imperfect and unfinished nature of teaching.

Personally, I find myself wrestling daily with levels of anxiety and stress that I have never experienced before. I have set limits on my intake of news-not as a denial of reality but as a practice of mental health. My greatest strength is the presence and love of my fiancé. Even though he and I have had to postpone our wedding, we see this time isolated together as an opportunity to grow closer. I reach out to friends and family on a regular basis over numerous videoconferencing platforms to find community. I have also engaged in more yard work and house cleaning than I thought possible. Each day, I face my addiction to the myth of control. Ultimately, I am reminded of the wisdom of Viktor Frankl who insisted that our saving grace comes not in what life offers us but in the meaning we confect for ourselves in relation to each other and our history. May we make meanings of hope and love in the face of crisis.

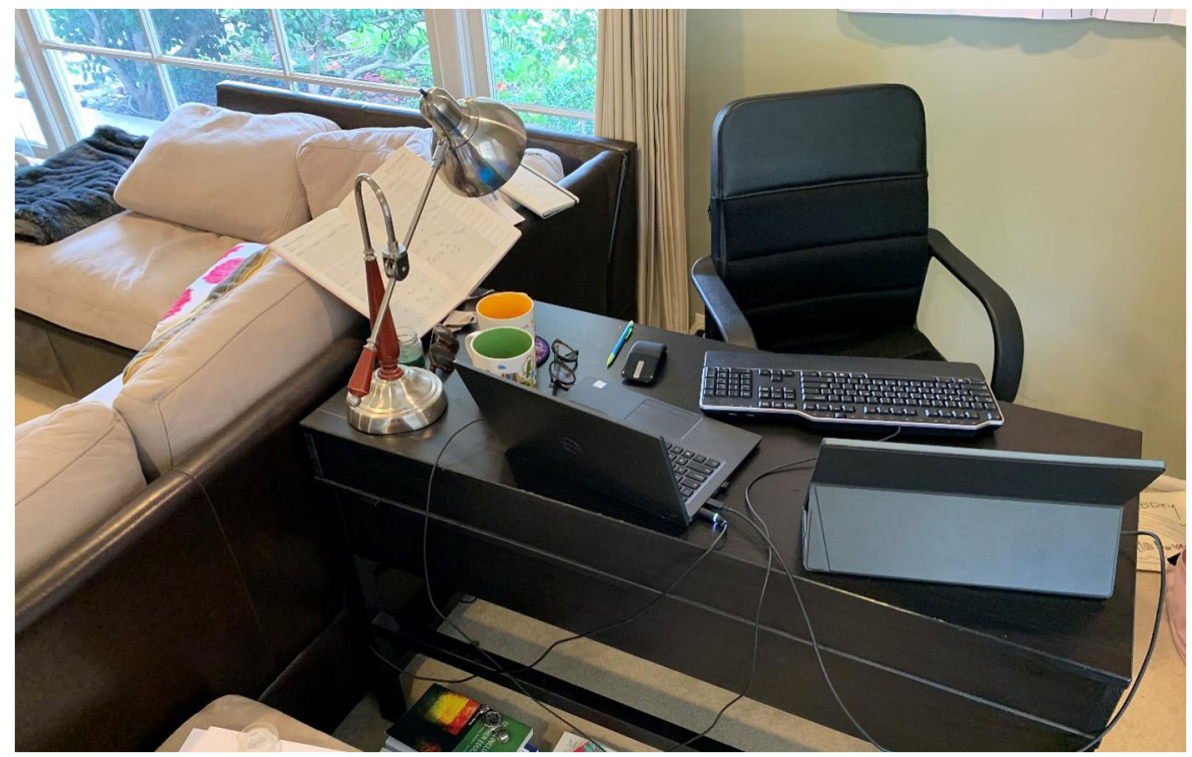

Fig. 71 This is my desk, where I work and teach, tucked behind the couch in our front room

\section{Covid-19 Containment Strategies for International Students} Blessing Funmi Komolafe, Jinhua, China, 7 April

Blessing Funmi Komolafe is an assistant lecturer at the Adekunle Ajasin University, Nigeria, and doctoral scholar at the Zhejiang Normal University, China, under the sponsorship of Chinese Government Scholarship. Blessing is 36 years old and lives in China with her husband. 
Consternation in China after thousands of lives have been lost to the Covid-19 pandemic is still irretrievable. As a Nigerian doctoral scholar living in Jinhua, Zhejiang Province, with many academic tasks to be accomplished, I was fortunate that my school was already in winter vacation and also in festive period (Chinese New Year festival). I travelled to Suzhou City in Jiangsu Province to meet my husband who is also a $\mathrm{PhD}$ Scholar at the Suzhou Institute of Biomedical Engineering and Technology; I cherished the companionship of my husband amid the lockdown. My research was not interrupted because I already finished my coursework.

It was a trying moment in China, even at my school, as school management mandates all international students to fill in a frustrating daily online health status questionnaire which must be completed before 12 noon. In addition, below is an extract from regulations imposed by management of my university on international students.

In order to resolutely contain the transmission of the novel coronavirus, minimize the flow of personnel, and maximize the safety and health of international students studying in China, the following regulations will be implemented to comply with local government requirements:

1. Students who have not yet returned to campus and freshmen entering in the spring semester are prohibited from coming to campus without approval.

2. Students who live on campus are not allowed to leave without approval.

3. All students living off-campus are not allowed to enter campus without approval.

4. Students who live in Jinhua are not allowed to leave Jinhua City proper without approval.

5. All students in concentration quarantine or home quarantine are not allowed to go out without authorization.

6. In accordance with the Emergency Response Law of the People's Republic of China, the Regulations on Disciplinary Actions for Students of Zhejiang Normal University and other relevant laws and regulations, anyone who violates one of the above provisions or has one of the following behaviors shall be given a warning, a serious warning, expelled from the university, or prosecuted depending on the severity of the misconduct:

(a) Not registering one's address with the public security bureau

(b) Not updating one's new address with the university or the public security bureau after moving

(c) Providing shelter for others and not registering with the university or the public security bureau

(d) Intentionally concealing outsider information or covering up contact history with personnel in key epidemic areas

(e) Not cooperating with epidemic prevention and control endeavors or not reporting truthful, up-to-date personal information

(f) Issuing or disseminating false statements or falsified facts and causing impact or consequences 
My only saving grace is that I'm not at school. My supervisor and officers from both my college and the international office phoned to inform me not to come back to school until approval. Presently, the situation is better as life gradually comes back to normal. Fear and anxiety are now becoming a mirage. My school is yet to reopen but all students are offered online coursework.

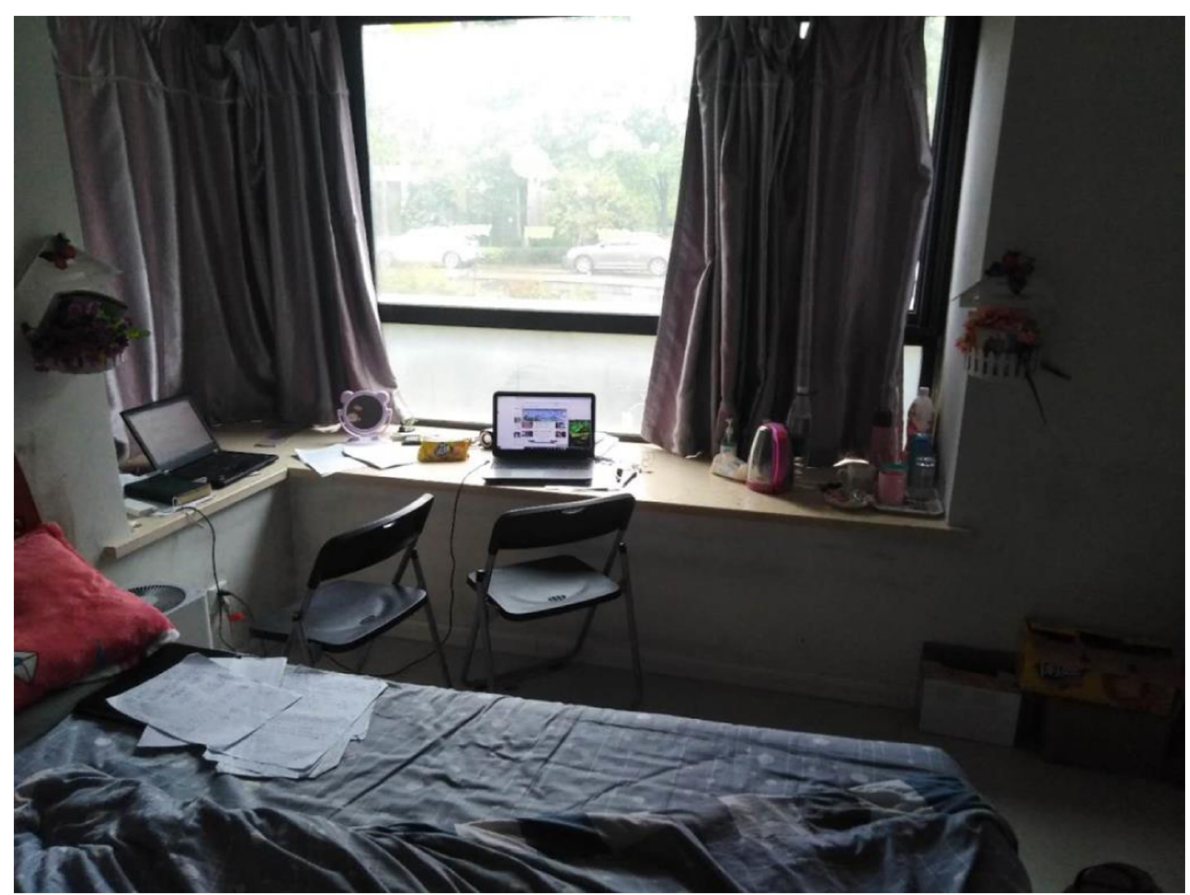

Fig. 72 Workspace in our bedroom, where I do my research work with my husband Emmanuel-a Biomedical Engineering student who writes codes on image reconstruction

\section{Covid-19, Student Fate}

Ogunyemi Folasade Bolanle, Beijing, China, 7 April

My name is Ogunyemi Folasade Bolanle; I am from the western part of Africa, Nigeria, and I am currently a post graduate student in Comparative Education at Beijing Normal University in China. I am 31 years old and live in Beijing, China.

$$
* * *
$$

On 23 January, Beijing Normal University came up with new rules and regulations due to the coronavirus outbreak. Visitors are no longer allowed in the dormitory. That was the last day international students saw the outside of the university. We are required to immediately fill in questionnaires and reply to all emails. We need to fill in personal health information through the system daily from 00:00 to 12:00 noon, Beijing time, whether we are in or outside China. 
On 10 February, regulations became stricter. Students living in dormitories are not allowed to leave the university, and abroad, students are not allowed to return to campus without university approval. Students with fever and cough are sent to a quarantine and medical observation centre. Students who violate university gate management regulations, and those who return without university approval, are seriously punished.

We resumed online classes on the third week of February. At first, this wasn't a pleasant experience due to differences in time zones, network congestion, poor network services, and non-responsive applications. However, after the first online lectures, we all adjusted and accepted the new digital teaching world. I was initially sceptical about online classes because of my fear of the unknown. Yet my lecturers are flexible and they record lectures, so we can always go back and listen.

I became addicted to updates on the pandemic at international news channels such as CNN, Aljazeera, and BBC. There are currently over 250,000 cases globally, with over 13,000 deaths. Chinese medical personnel are working around the clock and are determined to confront and defeat the deadly coronavirus.

I appreciate BNU for ensuring minimal disruption to teaching and learning amid the pandemic through online learning. There can be no victory without a battle. Things are stormy at this moment, but it will not rain forever. When the pandemic is over, and the sky clears up after the rain, we will all rejoice.

Thanks.

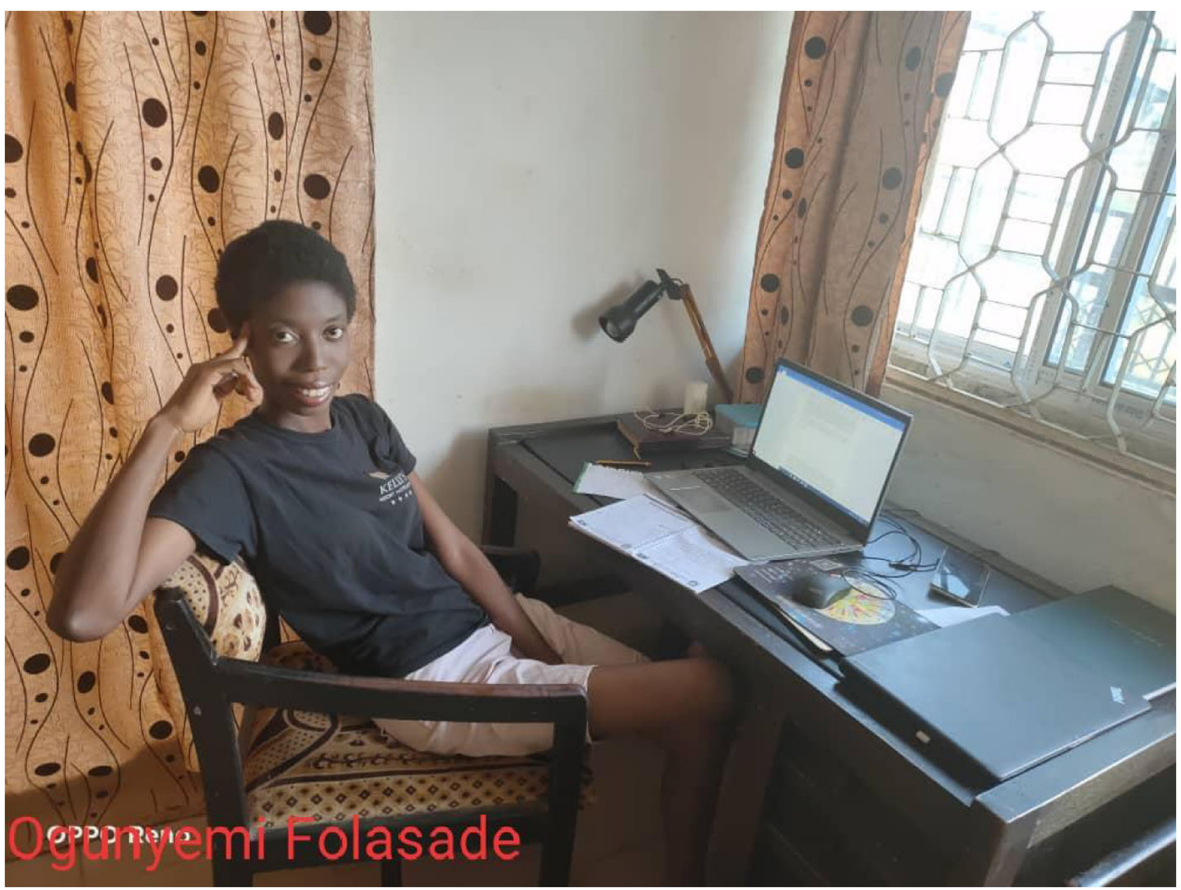

Fig. 73 This is my workspace in our living room, where I take turns in working and receiving my online classes, coupled with my siblings, Dr. Solabomi and my younger brother Niyi who writes his homework here as well 


\section{Adjusting to the Pivot Online}

Michael Hogan, Galway, Ireland, 7 April

Michael Hogan is a lecturer at the National University of Ireland, Galway, where he teaches Social Psychology, Developmental Psychology, Positive Psychology, Critical and Collaborative Thinking, and Applied Systems Science Design Methods. Michael is 46 years old and lives in Moycullen, Galway, with his wife, Vicky, also a lecturer at NUI, Galway, and three children, Siona, Oisin, and Freya.

On March 12th, from 9 a.m. to 11 a.m., we ran our last Collaborative Enquiry and Applied Systems Science class at the School of Psychology, NUI, Galway, Ireland. The shutdown of the university was immanent, but it wasn't made official until that same day, when we were asked to leave the building by 6 p.m. and not come back. Our Collaborative Enquiry and Applied Systems Science class had much work to do-five teams working to develop design solutions to societal problems using applied systems science and scenario-based design methods and tools. We now needed to pivot online.

The following Monday, I was due to begin teaching the final block to our 415 firstyear psychology students - the focus here was a series of lectures on the importance of collaboration and teamwork in modern society. A timely topic, but how to teach it to such a large group online? Solutions were needed. Fortunately, we had access to tools and supports. On Thursday afternoon, at 3 p.m., before I had to leave the university, I tested the Blackboard Collaborate (Virtual Classroom) service with some of my finalyear students. It worked fine. On Friday morning, I tested our Kaltura screen capture video-recording software, which can be used to record lectures by capturing your screen content and audio input from your microphone. It worked fine.

I recorded my first short video lecture on Friday morning, March 13th, and posted it on Blackboard, notifying my first-year students that we were pivoting online. The lectures for first years would not proceed on Monday as scheduled, but I managed to post my first set of lectures March 16th, and more lectures later that week and next week. I then met with available first-year students in the virtual classroom, where students largely used the chat (text) function to submit question and comments, to which I would voice an answer and they would follow-up with thumbs up and additional questions and comments. Sometimes, they turned on their microphone and we had a chat. Broadly speaking, it worked very well.

With my final-year students, we had to engineer a more complex multiple virtual classroom teaching environment, where multiple teams worked and then met back in the 'main room' to engage in dialogue and to receive procedural guidance as they worked on next steps in their applied systems science design projects. The work is ongoing, with presentations on Thursday morning. The level of commitment and engagement from the final-year students has been outstanding.

Meanwhile, my three children work across multiple platforms here at home and Vicky works in parallel to teach her university students online. Lessons learnt: we are fortunate as teachers to have access to the tools and technology, but not all students have the same level or quality of access; maintaining 
engagement and motivation is challenging, but I have experienced some success here and am very grateful to our wonderful students; we are continuing to learn how to best communicate and learn together online; many aspects of teaching in the future could change as we collectively learn better ways of working online. However, it will take time to fully understand what it is we are currently learning, as much work is ongoing and time for reflection has been limited.

Personally, I expect I will move from a stage of 'doing' to a stage of 'reflection' in a couple of weeks, after I work to help my students 'over the line,' as best I can. I leave open the opportunity for ongoing engagement, and the questions arrive in my Inbox as I write this short reflection. We are still very much in medias res, in the middle of things. In reality, I have found it both very challenging and very rewarding-and I value this opportunity to reflect here this evening, even if only for a brief moment.

I will turn my attention more fully to the wider world again soon, as I have work to do in other domains. But for now, like many, I am busy with my students, colleagues, and family: doing, adapting, working to get 'over the line.' I'm not sure where that line is exactly. Indeed, I'm not sure any of us know where that line is. The world is in flux at the moment, and we are all moving as best we can in the shifting tide of change. Sincere best wishes to all during these challenging times. Amidst all the death, suffering, and chaos, I see such wonderful compassion, cooperation, creativity, solidarity, and collective strength all around the world every day and I'm proud to stand among you all. Let us continue to teach, and let us continue to work hard. 


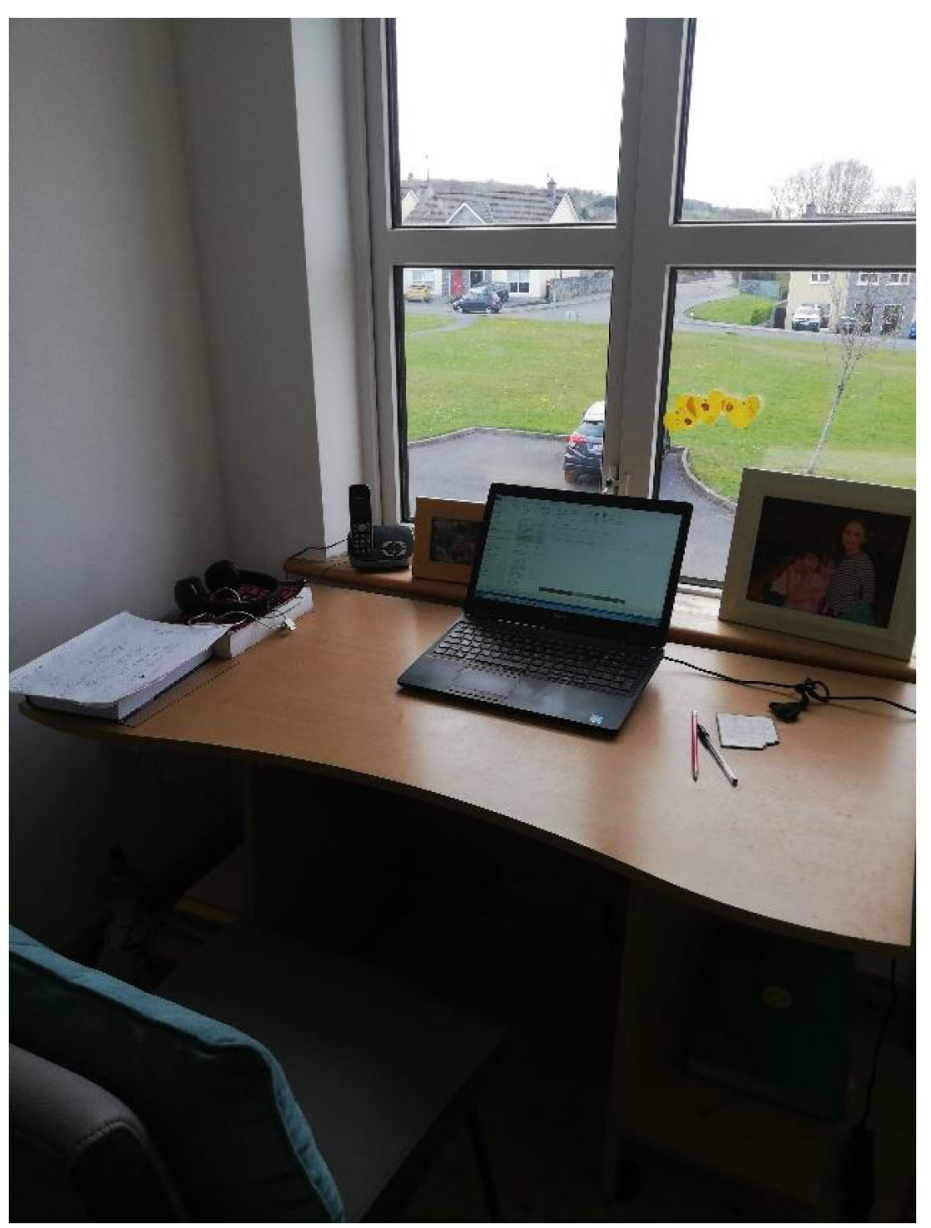

Fig. 74 This is my workspace in the upstairs box room. Vicky is in the new room downstairs; my eldest daughter, Siona, is above working in the attic; my son, Oisin is two doors down working in his bedroom, and my youngest child, Freya, works and chats with everyone at the kitchen table 


\section{What a Difference an Hour Makes}

Bridgette Redder, Cambridge, New Zealand, 7 April

Bridgette Redder is a programme leader, lecturer and researcher at Te Rito Maioha Early Childhood New Zealand. Bridgette lives in a multi-generational home with her family aged between 20 and 84 years of age.

Aotearoa New Zealand was one of the first countries to go into lockdown with low numbers of Covid-19 cases. Day 12 of lockdown, or as Te Rito Maioha Early Childhood New Zealand, the bicultural educational institution I work for, terms it $r a \bar{h} u i$ (from indigenous Māori language $r \bar{a}=$ restriction, hui=gathering). Life as those of us in Aotearoa New Zealand know it continues to change rapidly - no longer by the week, or by the day, but by the hour. From February 28, when the first case of Covid-19 was detected in Aotearoa New Zealand, until today, April 6, business as usual feels very different! Initially, the government's actions to implement travel bans for China and Iran in response to the increasing rate of Kiwi Covid-19 cases escalated quickly to self-isolation for 14 days for people entering New Zealand and the banning of indoor gatherings of 100 people or more. This directive meant that graduation of our Bachelor of Teaching students on March 21 was postponed to a future date. By March 23, New Zealand had moved to Alert Level 3 and within $48 \mathrm{~h}$ was at Alert Level 4, and a state of emergency was declared to eliminate the virus.

As an early childhood lecturer, programme leader and researcher for an organisation whose programmes are either fully online or blended, the physical transition from working at a base located 90 kilometres from where I live to working from home was smooth. Indeed, I welcomed the decision made by senior management on March 23, guided by the Ministry of Health, for all staff to work from home. The reason for applauding this decision was because in the two weeks leading up to the rāhui, I was concerned that the rapid rate of person-to-person and potentially object-to-person transmission experienced by other countries could take hold in Aotearoa New Zealand. As someone who lives in a multigenerational home, I felt that I had an immense social responsibility to members of my family, two of whom are over 70 (the 'at risk' group). I did not want to bring the virus home and be responsible for the potential deaths of those closest to me. With self-isolation came relief. The expectation from my employer was and still is to work safely and securely from my home bubble, connecting face to face with those in it and virtually with students, colleagues and educational networks.

The Covid-19 pandemic has not just ushered in the era of teaching in a fully online world from home but also meeting virtually throughout the day and into the night in order to ensure students and their early years services (mostly closed except for the children of essential workers) feel supported and to ensure connections with colleagues are maintained. This poses a challenge at times in demarcating my professional and personal lives_-work life has definitely left its footprint on time with family, and often, the lines between the two are blurred. 
The necessary establishment of meetings, to support students with their studies and emotional well-being, has meant organising these sessions mostly at night using video-conferencing software such as Zoom Pro. Night meetings are fast becoming the norm because many students have their own commitments to work and family during the day. A makeshift green screen is now a necessity to ensure home office spaces provide a professional and at other times creative backdrop, through the use of virtual backgrounds. Arrangements have been implemented for events that typically occurred in a face-to-face world such as block courses and noho marae (marae stay) to take place virtually. This has meant exploring ways to maintain the emotional connection inherent in cultural events such as this and finding ways to maintain social distance, which has resulted in cultural customs involving human touch being altered and, in some circumstances, replaced by technology. With domestic and international travel banned, conferences have been postponed or cancelled and research work is also taking place in virtual worlds.

The emotional, physical, social, mental and moral fatigue that is felt as the struggle to keep people safe and meet professional responsibilities requires individuals to pay attention to their bodies in ways that promote well-being. A positive outcome from the global situation we all find ourselves in is the real sense of connection and coming together as a nation and a world family that is felt because we are all in this waka (traditional Māori canoe) together. 


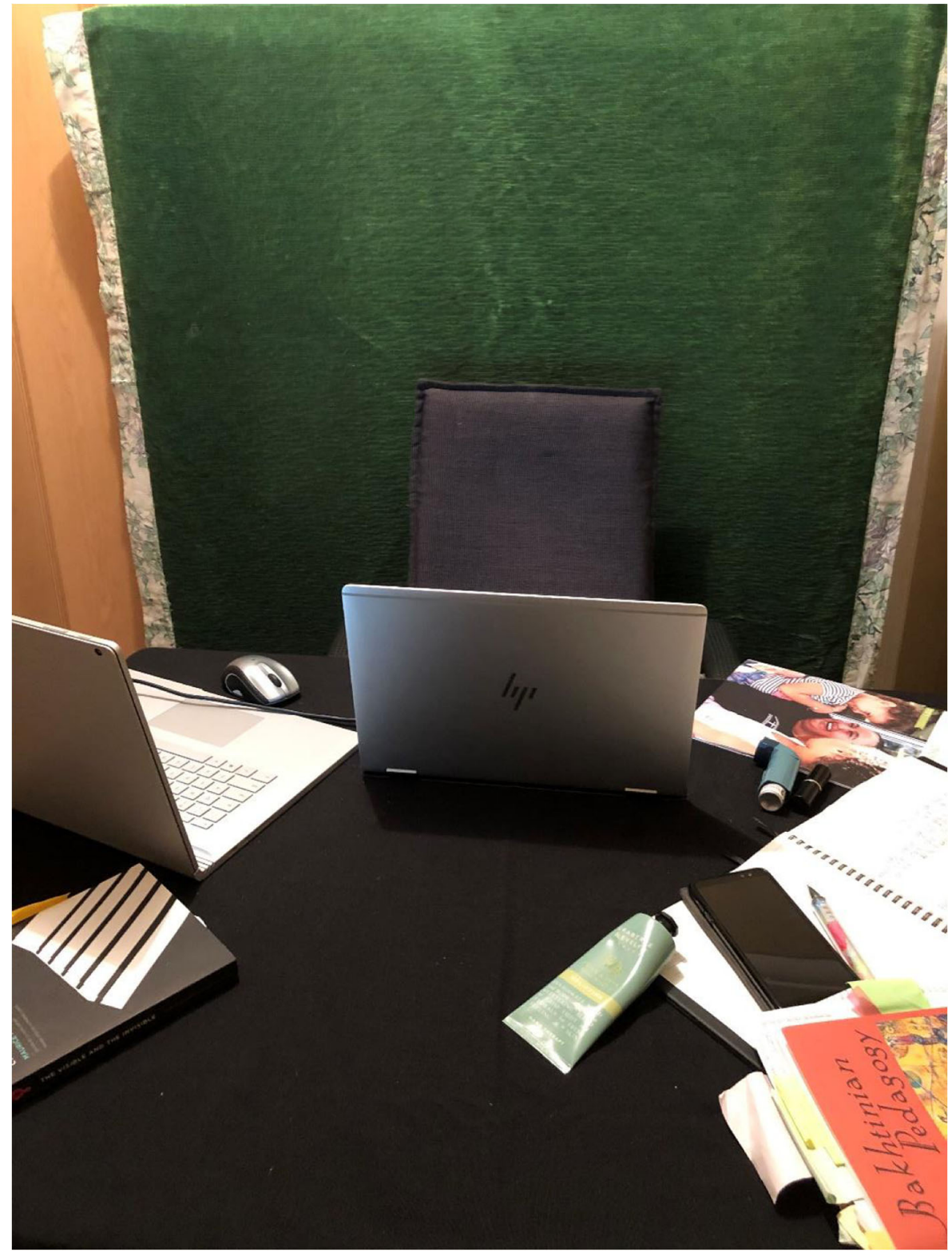

Fig. 75 This is my quiet workspace in an area of our home, where I can receive fast and stable Internet speeds. The green blanket is my makeshift green screen-and works a treat! 


\section{Examining the Hearts of the Machine in the Midst of Covid-19}

Sahar D. Sattarzadeh, Burlington, Vermont, USA, 8 April

Sahar D. Sattarzadeh is assistant professor of Education Studies at DePauw University and Research Associate with the Chair for Critical Studies in Higher Education Transformation (CriSHET) at Nelson Mandela University in Port Elizabeth, South Africa.

Even when they are dangerous examine the hearts of those machines you hate. before you discard them (Audre Lorde 1997)

National press coverage of reported Covid-19 cases emerging across the USA began during Champlain College's spring term break in late February 2020. As a number of higher education institutions (HEIs) announced closing their campuses and transitioning to remote instruction, Champlain College followed by extending the break for an additional week to give teaching staff some time to prepare for a transition to remote instruction.

Champlain College is a predominantly white private college established in 1878 in Burlington, Vermont, in the northeastern USA and located on the traditional and unceded lands of the Abenaki of the Wabanaki Confederacy. Since its creation, Champlain College has offered a 'career-oriented education,' boasting employment secured by a record 94\% of graduated students in 2018 (Champlain College 2020). Such career-driven branding has me wondering about the machine's relevance to the current Covid-19 crisis and our shift to virtual teaching.

Working (in my case, teaching) and learning remotely are privileges not everyone has access to, and if they do, access is not equal nor equitable. Therefore, before even deciding what and how to teach, it was a priority to learn whether our remote classrooms would be characteristic of justice and equity. I designed surveys for all four courses to assess students' Internet accessibility and quality, digital proficiency and citizenship, and data security and privacy, as well as personal safety, comfort, and concerns of such an abrupt move to remote learning. Within one week, $89 \%$ of the students had responded.

Over $92 \%$ of students shared they have consistent access to the Internet or Wi-Fi from their remote locations. More than $65 \%$ had never enrolled in a remote/online course prior to our transition; and out of those students who have previously studied remotely/online (34\%), $100 \%$ of them had never enrolled in more than one course at a time. At Champlain College, students are enrolled in an average minimum of five courses per semester, while maintaining a job or some form of work in their respective fields of study. Such a student load may not be unique to a career-focused institution, but it conjures images of efficiency, mass production, and human capital — qualities characteristic of the machine.

Conjured images of the machine trigger my reflexes to advocate for the metaphor of the body instead for the diversity, interconnectedness, and unity of all its parts. Thus, I am concerned for my students' academic, mental, physical, and spiritual wellbeing, especially at this time. I am pleasantly reminded that 'emergency remote teaching' (Hodges et al. 2020) should not be synonymized with 'online [or distance] learning' and that as an educator, I should likewise have compassion for myself — not just for my students.

Academic, social media, press, and other digitized outlets saturated with Covid-19-related discourse forced me to reimagine the respective design of all courses for the remaining six weeks of the academic term. Social actions of unity and oneness 'spreading' and 'going 
viral' around the globe in spite of such a threatening, fatal crisis are inspiring. We have evidence that physical distancing concurrently demands 'social solidarity, or the interdependence between individuals and across groups. .. [that it] is an essential tool for combating infectious diseases and other collective threats. .. [and] motivates us to promote public health, not just our own personal security' (Klinenberg 2020). Arundhati Roy (2020) likewise prompts us that pandemics have a historical reputation for teaching us to break with the past and reimagine our 'world anew'. Roy writes of this current pandemic concluding, 'This one is no different. It is a portal, a gateway between one world and the next.'

This moment of uncertainty and unfamiliarity teaches me a vital reminder that this world will be different from the next. This 'portal' or 'gateway' pivots the necessity of being a highly effective educator, commands a humble posture of learning at all times. In all honesty, it has been liberating to surrender to the course-related expectations I had for face-to-face instruction. Instead of adhering to the structure initially presented in my course syllabi, I assigned students to design and implement a social solidarity project to help serve their own needs, as well as those of a community they are a part of. The 'catch' is that the social solidarity project must creatively align with the content and objectives of the respective courses, but I must say that students' project ideas and outcomes, thus far, strengthen my faith that there is more to the machine 'than meets the eye' (Hasbro 2020). Examining 'the heart' of these machines is what fuels my research, teaching, mentoring, and service work, because even within the machine, there is always the capacity for an upgrade.

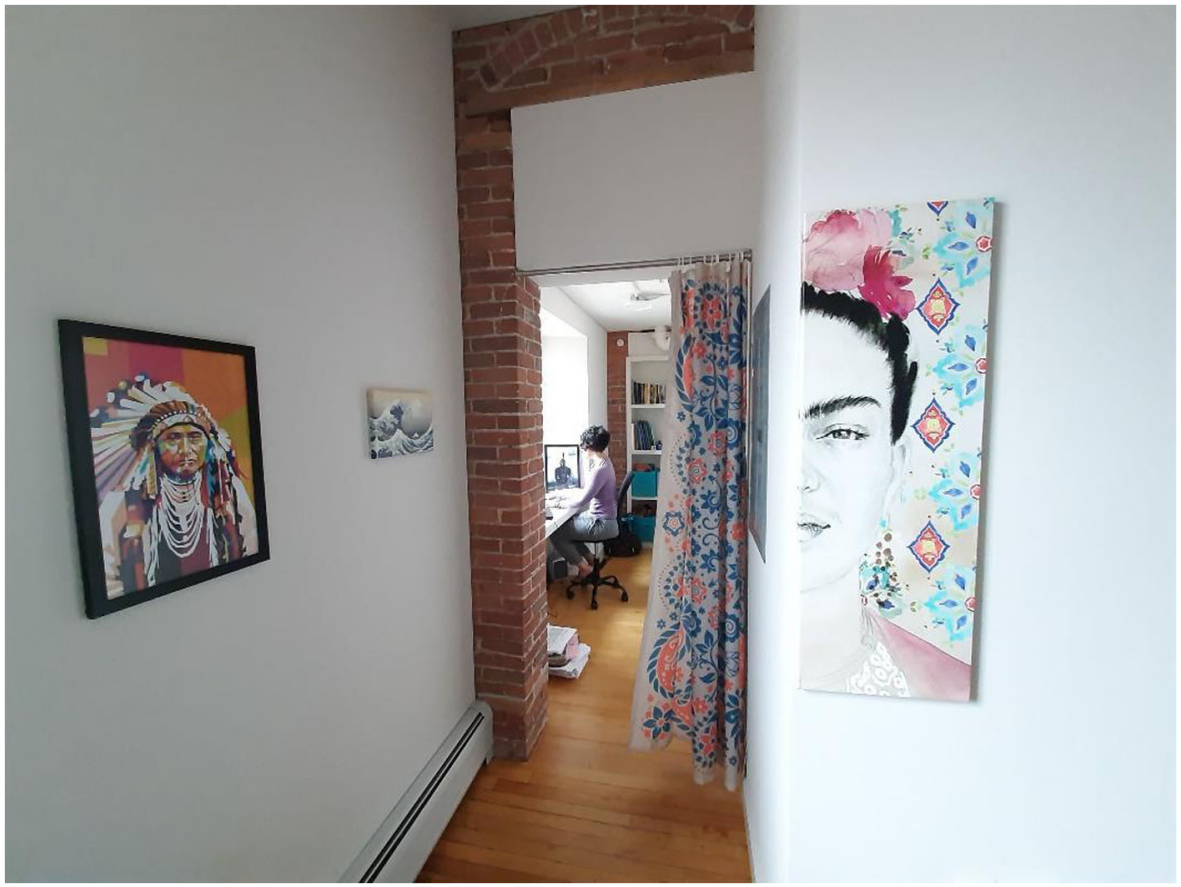

Fig. 76 This 'nook' is the primary workspace in my studio apartment, which includes a beautiful view of Lake Champlain and the Adirondack Mountains 


\section{Another Mimesis}

Michael Jopling, Berlin, Germany, 9 April

Michael Jopling is professor of Education and director of the Education Observatory in the University of Wolverhampton, UK. He lives in England but spends quite a lot of time in Germany.

\section{$* * *$}

One of the most prominent texts on the first-year undergraduate reading list when I was a student was Erich Auerbach's Mimesis: The Representation of Reality in Western Literature. I have no idea if it is still on such lists; in our arrogance, it seemed old fashioned in the 1980s. While I never actually read the book, the fact that Auerbach wrote his remarkable survey of world literature while in exile in Istanbul between 1942 and 1945 without any books from his library has stayed with me. Things are different now. While all of us find ourselves in a different kind of exile, the Internet means that access to knowledge is easy and (mimetic) online communication with others is constant but disembodied. But this reversal of Auerbach's situation has also created a strange and intense sense of unreality.

I lead the Education Observatory, a research centre located at the University of Wolverhampton in the UK. In the UK, we are in the paradoxical position of having reacted sluggishly as a nation to Covid-19, but much faster as organisations. My responsibility is for research. On 13 March, we closed down all face-to-face fieldwork and meetings indefinitely. The university followed suit later that week, as the UK inched towards lockdown. Professionally, this has been relatively straightforward. Teaching is online, as are meetings (now generally larger and more efficient), doctoral supervisions and examinations. We have finished research projects where fieldwork was completed or near completion and are moving other data collection online. In many ways, it is impressive how robustly and quickly colleagues have all responded to the changes. However, agile approaches have had to flex further to accommodate paper-based systems and rigid university workload models, rather than vice versa. Innovation has its limits.

Some hope that changes in ways of working will persist once the lockdown is relaxed. This tends to mean using technology more widely and effectively, but it would also be nice if the blurring of the personal and the professional also endures. Parents tend to get flustered or apologise when their young children wander into online meetings. Instead we should celebrate their success in managing their professional and personal lives. I am fortunate in that my children are old and settled enough to stay where they were when things closed down. Required to self-isolate, my parents are the same. I have some anxiety about what would happen if any of them became ill and fears about the social and economic consequences of the pandemic, but also hopes that it might offer an opportunity to regroup and reassess our priorities in the longer term. And the irony of it all is that, unlike Auerbach, I have been able to exile myself in Berlin with my partner for the past few weeks, extending a short, planned trip indefinitely. I have access to books and articles and to a garden. I also have time finally to address that backlog of writing but feel uncertain about its urgency or value in a changed world. Is Mimesis available online? 


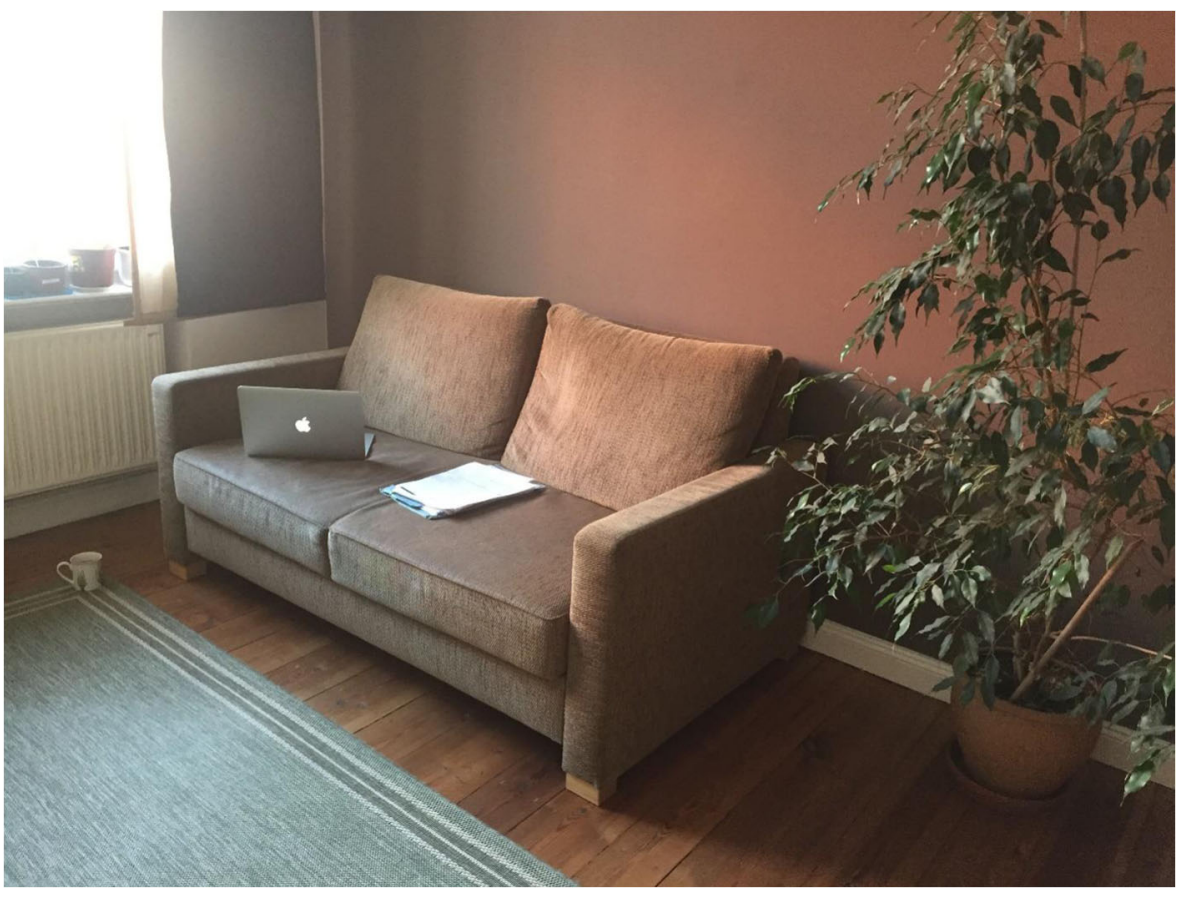

Fig. 77 This is my workspace in my partner's study. I'm not sure I could write at a desk any more

\section{When Things Change, What Stays the Same?}

Suzanne SooHoo, Orange, CA, USA, 10 April

Suzanne SooHoo is professor emeritus at the Attallah College of Educational Studies at Chapman University in Orange, CA, USA. She teaches part time and is active on dissertation committees. She has two grown children and lives with her husband and dog, Chewy.

$$
* * *
$$

My colleague and I presented a paper together at American Educational Research Association conference two years ago. Our study asked, 'When things change, what stays the same?' The question becomes more relevant than ever during the Covid-19 pandemic as we think about our futures as educators. What essential learnings will survive or risk extinction as a result of our new normal of physical distancing? What challenges am I facing that will not be temporary accommodations but permanent fixtures in the modern landscape of learning? How will my role change and my teaching redirect?

\section{Relational Literacy}

In my Freirean classroom, cultivating relational literacy is an intentional attempt to humanize our classroom experiences. Beyond sharing stories about schooling, 
cultures, and histories, one also learns to hug: to give a hug and to receive a hug. At the end of the semester, we culminate our time together with a group hug. Student evaluations have reported sentiments of appreciation, e.g., 'I love it when I hug someone, and just when I'm about to let go, they hug me even tighter' (Heartfelt Love and Life Quotes 2020). Will the art form of hugging survive post Covid-19?

\section{Transitioning Online}

My calendar is now punctuated with Zoom meetings: Zoom classes, Zoom meetings, Zoom family sessions, Zoom telehealth sessions, etc. The novelty of wearing bedroom slippers to the Zoom meeting soon wears out as my body that is suffering from quarantine fatigue is aching to bolt out of the desk chair. Like in class, I scan the portrait gallery for the one face with the reassuring smile, the one face that re-energizes me, the face that anchors me. It's a digitalized, pixelated version of a face. I cannot feel the accompanying human spirit. But it's better than people sending their avatars to class (as I suddenly catapult mentally to a dystopian future).

\section{Who Are My Students?}

Who is in the Zoom room with my students? Is that Angie's boyfriend? Is Kevin's mother joining our class for the evening? Who are those little kids running back and forth in the background of Lilia's living room? Charlotte is holding a cat. Thank heavens this is a virtual class session, I'm allergic to cats. Who am I speaking to in tonight's class?

\section{Where Do These New 'Students', Who Are Not Officially on My Class Roster, Fit In?}

Do they get to enjoy participating in the privilege of a Ph.D. seminar for the rest of the semester? What is the fate of our beginning-of-the-semester Vegas rule- 'What happens in Vegas stays in Vegas.'? Our agreement to maintain the confidentiality of our stories within classroom walls collapses.

\section{Who Else Is In the Zoom Room That Is Not Visible?}

Fox News journalists? White nationalists, who have graffitied our campus this past year? Will I see my words out of context published in tomorrow's newspaper? I am suddenly aware that I am educating Ph.D. students with friends and neighbors. My talks and my pedagogy are on public display. I am now more mindful than before of how my words, out of context, can be misunderstood. I find myself involuntarily recasted from professor to public intellectual.

When things change, what stays the same?

Seemingly Nothing. 


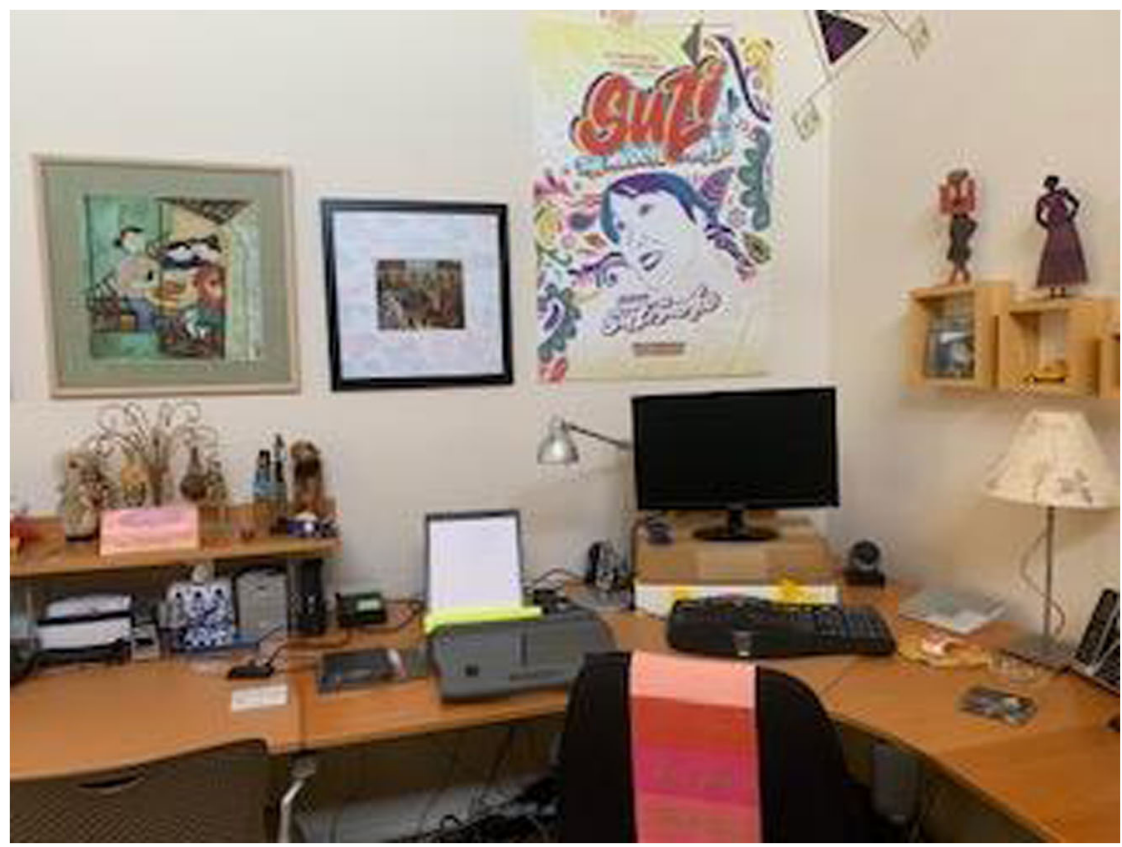

Fig. 78 This is my starship communication hub: Zoom center, writing workbench, classroom, library, research lab, meditation perch

\section{Notes on a Pandemic}

Nesta Devine, Birkenhead, Auckland, New Zealand, 5 May

Nesta Devine is professor of Philosophy of Education at the Auckland University of Technology. She lives with her son and has a wide family scattered around the world.

My position is perhaps a little different to most, but if there is one thing we have learnt from feminist writers like Helen Cixous, it is that the personal is not only political but also philosophical.

My experience of the pandemic has been tied up with family - as will be the case for many of us in our lockdown state. I am in the age group delicately described as 'vulnerable', and I have enjoyed a degree of care from my children that reflects our different relationships. Because I am locked down with one of them, the strength of our relationship has been crucial to survival. I have been lucky, or perhaps it's not luck: both of us have worked hard at establishing a quality of relationship that can survive such unremitting intimacy. The fact that we both have jobs that allow 'working from home' has undoubtedly been a big contributor to amity, as has the presence of a large, loving hairy dog which requires walks and cuddles. 
But on the other side of the ledger, my mother, in her mid-90s has become totally inaccessible. Her rest home locked down even before the rest of the community, and beyond that, within a couple of days, just as the lockdown in Aotearoa New Zealand became general, she broke her leg really badly. She was rushed to hospital, of course, where the rule, already, was no visitors. Sadly for the rules, however, my mother is a very feisty if not very rational person, and the medical staff could not control her. Consequently, I was invited into the Emergency Department to cajole and bully her into submission while the medical staff straightened out the bones. I was there for four hours. I have not seen her since-that is now 7 weeks ago. My fear throughout has been that she will die alone.

I am very conscious that things could be worse. For families with children, families without income, or with inadequate income, new arrivals without support systems of any kind, people with other illnesses, people already in frail relationships, lockdown could be purgatory. There is a delicate balance here for politicians between public health-here understood as the survival of the most possible - and the well-being of the community, not understood purely in economic terms, although that is the case for some, but also in terms of emotional and social health.

My mother might be seen as an extreme case of social and emotional ill health, as a consequence of the care given to preserving her life. When a person whose memory is already failing is cut off from all meaningful social and family contact, those links may be hard to re-establish. My mother's hold on her daughters' identities was already fragile: she often thought I was her sister or her mother. I do not really expect her now to recognise me at all. Of course, this will be no loss to her-she will recognise her mother or a sisterbut it will be a significant loss to me. What other elements of her social and cognitive skills she may have lost in 7 weeks of lockdown I cannot yet know. One of the medical staff reflected, whilst I was trying to hold my mother still so they could straighten her broken bones out, that it is well established that people recover quicker and better if they can have contact with loved ones.

Yet I totally support our government's decision to lock down hard and fast. In other jurisdictions, 'harvesting' of the old in rest homes has been seen as an acceptable price to pay for continued economic and perhaps emotional, social and mental health in the majority of the population. This is utilitarianism at its most stark. Would I accept higher risk to my mother's life as the price for her continued social engagement? Do I accept significant cognitive injury to her as the price for continued life for her peers? I have to say yes, I do support the damage done to her-and to others, dying alone, giving birth alone, suffering alone, intensifying psychological illnesses, physical deprivation and poverty-as the price for the physical protection of the lives of our oldest populations. But I do not deny that there is a question, and a judgement, here that is not yet easy to ask or easy to decide. 


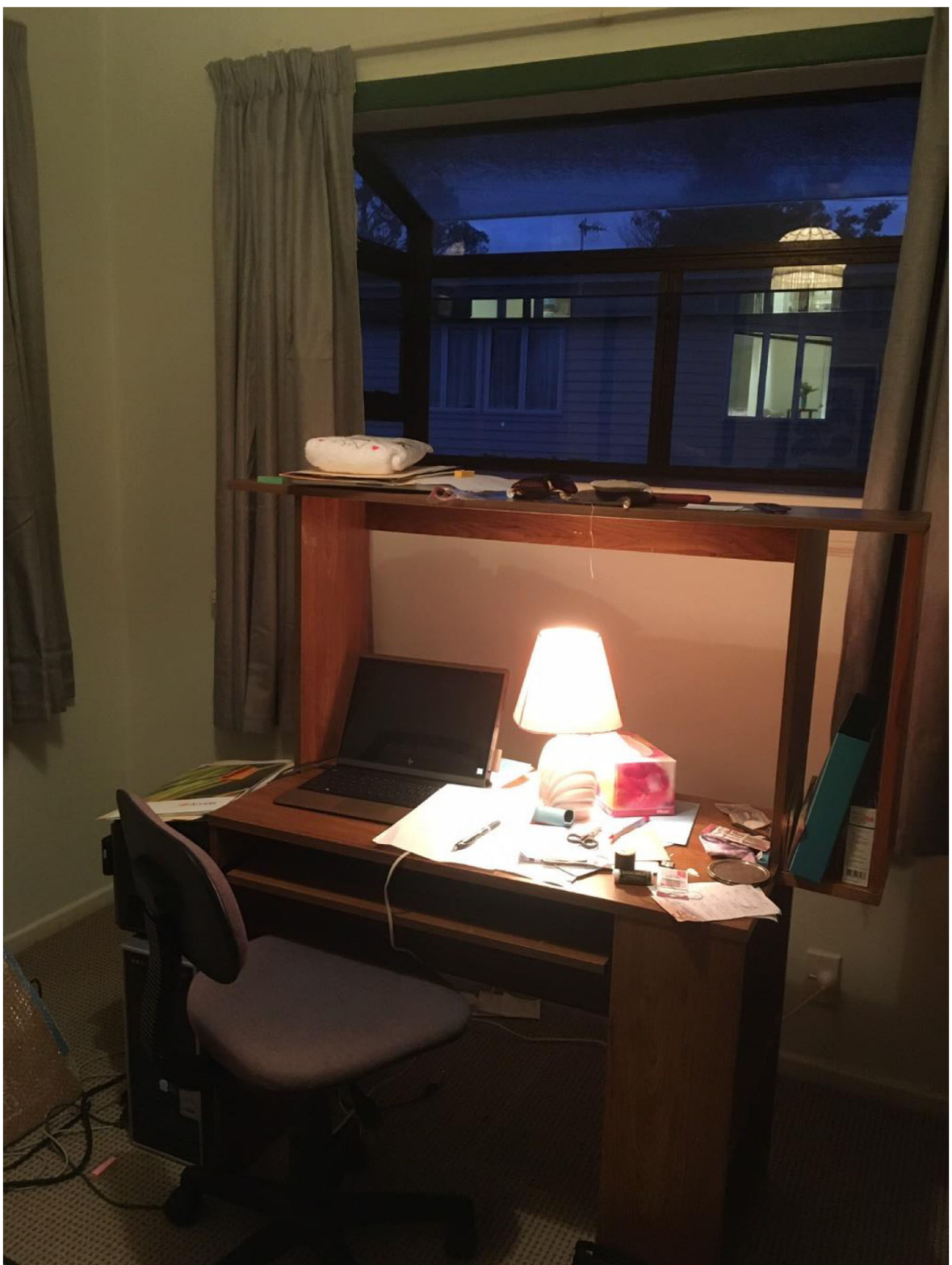

Fig. 79 This is my workspace in my mother's house, where I am staying during lockdown. The tea towel on the top left of the desk is embroidered with the image of Dr. Bloomfield, the New Zealand Director of Health and also a folk hero who has guided us through the pandemic! 


\section{Not Concluded Yet...}

Sarah Hayes, Worcester, UK, 31 May

Sarah Hayes is a professor of Higher Education Policy in the Education Observatory at University of Wolverhampton. Sarah is 57 years old and she, her partner David, and her two sons are collectively owned by a cat called Jasmine.

On a beautiful sunny weekend at the end of May 2020, I have read each word of every testimony in this collection, sitting in a shady place in the garden, occasionally pausing to chat with my partner, my sons, my neighbours, or my cat. Stunning sunny weather (pretty scarce in the UK) has been persistent throughout the pandemic, an uncanny reward for our compliance in staying home perhaps, but one that some people can enjoy more than others, depending on the living spaces they occupy. Lockdown is being tentatively relaxed in England, but many businesses are still closed and families who do not live together are limited in ways to meet.

Covid-19 became real for my partner and I during a visit to Edinburgh in early March. We had enjoyed eating out and visiting family, including my partner's mum who is 95, in care in Dundee, and who has since survived catching Covid-19. Yet by the end of that week... we were socially distancing from all family - and not even because we had fallen out with them! As we travelled home to the Midlands, we realised lockdown was imminent. My conferences and international teaching plans were cancelled, along with our holiday to Spain. Concerns over Brexit were on hold, roads and airports grew silent, toilet paper and hand sanitiser became scarce... As one author put it, they sensed 'at once a shrinking and stretching of horizons'.

By mid-March our eldest son was home from university. We have since all been residing, working, supervising, researching, studying and caring for vulnerable and elderly family members... in these oddest of circumstances. Life has never felt more postdigital, when I have not visited campus since February and even a family funeral was held via a webcast. Yet simultaneously, we have family members who cannot use the Internet and are more isolated than ever, including a father with dementia and a sister who has been mentally unwell since her teens. I think of them, as I leave my computer windows for a moment, to open physical windows, and I hear the sound of applause for carers. I reflect on a testimony I have just read, which caused me to wonder, in this time of crisis: does the digital network now support the social, or does the social now support the digital?

When Petar first contacted me to discuss editing these Covid-19 testimonies together, we had a long Skype conversation. Just two days later, he was caught 
up, not only in the ongoing lockdown in Zagreb, but in a terrifying earthquake too. He had to move his family from his damaged flat, despite the requirement to stay at home. Yet still he persisted in collecting the responses that flooded his inbox in a far larger number than he had anticipated. This call reached people at a time when they needed to express their 'postdigital positionality', as their personal contexts changed shape during lockdown (Hayes forthcoming 2020, Jandrić et al. 2018). Over the years, Petar and I have edited many publications together, enjoyed seeing powerful academic arguments gather alongside one another, in shared editions. Yet as I have reviewed this collection, it has taken a different form. I have laughed and cried in quick succession, whilst correcting an occasional typo or missing reference, in these beautiful, living narratives from across the globe. I am touched to be asked to conclude such a personal collective article. I am also aware that whatever I write now is at a time when things are easing for some, but not others, and for many-this is still a time of deep uncertainty.

I began the editing process reflecting on what it means to share workspaces at home, with children or pets, or to occupy them alone, as opposed to turning up to a busy office, classroom or campus. The diverse images authors provided, alongside their descriptions, caused me to think about spaces that have been important to me too during confinement. Our battered, pine, dining room table where we have gathered during the night, lighting a candle and drinking a tea or a beer, when sleep has been scarce and concerns ever-present. It is the place where we FaceTime family members, but often where we sit without any digital device. Authors have described the positioning of their workspace, those humans and pets who share it, the view, items in it, the strength or weakness of their Internet connection, the temperature, the garment they keep ready for a work meeting when they are on camera and the fact that there is no separation between their personal and work lives. As I read, these spaces feel tangible to me. Our neoliberal society and institutions have shaped our lifestyles in return for variable rewards, but in these unprecedented circumstances, many authors are taking stock of these realities, as the pandemic has (at least temporarily) arrested the excesses of capitalism and they currently have time for 'homemade meals, random hugs and giggling tickle fights'.

One author voiced that 'what seemed important in their academic lives yesterday, seems less so today', others try to remain motivated, whilst juggling the demands of home-schooling ('crisis learning') and providing care to others in the community. Another observes that in academia: "no matter how rightly proud of our achievements we feel, they are built upon the work of many other people, who allow us the time to do that work'. Many express concerns about how disproportionately affected those already vulnerable are, pointing to inequalities that our current dependence on technology simply intensifies for those without such devices, or skills. Another argues that a rapid shift to online work has left all of us susceptible to viral threats that take a different form to Covid-19. The commercial online platforms that enable our remote activities arrive at a price, when data is routinely collected on us, through 'digital profiling we would normally resist', were we not so dependent. 
Students too, in their diverse contexts, need to make sense of online learning environments of variable quality, when this is all that they have. As one author pointed out, they may be using their own data plans from their mobile phones to follow their classes, sharing workspaces with others, have issues in finding electricity for charging devices, or even light for late-night studies, depending on their location in the world. The term 'digital divide' is perhaps misleading, as it sounds as if people reside on either side of a simple access to digital technology, when in fact what disadvantages people is multidimensional, and dialectical with so many individual aspects of their personal, economic and cultural contexts. Though educational policy discourse has proclaimed the unquestionable enhancements that technology brings to 'the student experience', whilst frequently failing to refer to the humans involved (Hayes 2019, Hayes and Jandrić 2018), it is (in the end) a global pandemic, not decades of policy, that has necessitated all learning to be moved online. As one author put it: 'then comes Covid-19 and school closures, and it seems as if the digital leap has happened overnight'.

Yet learning that was designed to be experienced face to face takes time, skills and academic experience to translate to platforms where a teacher is not physically present (Fawns, Aitken, and Jones 2019). It is not a simple 'pivot'. There are rewards reported too by some who have seen attendance rise and class discussions deepen. Others describe their exhaustion from working on this endeavour at speed, for the sake of their students. One author points out: 'the workforce overall is the sustaining force in the economy'.

Authors here are a formidable workforce, supporting their learners' lives and future work aspirations, against the odds. Their words make visible all aspects of academic labour that policy fails to illuminate (Hayes 2018). This includes anxieties and emotions, but also humour, as expressed by one author-who discussed the dilemma of managing their own breathing patterns that could just be 'a stress response', or indeed, 'the start of the virus...' and another who suggested their title of visiting fellow might more aptly be renamed during lockdown as non-visiting fellow...

With so many rich narratives that speak for themselves in diverse voices, I wondered how to conclude this moving, collective piece, which is not about to conclude any time soon. It feels more like the start of something than an ending, when there are many more questions than we currently have answers. Where I work, in the Education Observatory at University of Wolverhampton, we run a live debate series that aims to raise regional voices from the universities located in the Midlands, in the UK, as too often national policy discourse seems to be all that is heard (Hayes et al. 2020). Whilst these written accounts were not 'live' or voiced from a shared room in a regional university, they almost feel in their vibrancy as if they could have been.

Observing the dates on which these testimonies were written, many authors penned their stories at the same time as each other, from different parts of the globe. People shared the intimate spaces in which they live and work through images, or rich descriptions. I have listened (whilst reading), and silently responded (as if in dialogue with each author), to words that could just as 
easily have been spoken in my presence, not typed from a distance. Perhaps this is another dimension of postdigital communication? Where before we placed forms of communication (broadcasting, debating, writing) in neat categories, linked to the means of communication (radio, television, newspapers, journals), now what is written and spoken (in person or online) seems less tied to the format or device through which it once originated. Yet now, as I draw this article to a close, it is still written words that I turn to, placed here by authors from around the world. I pick these statements and questions simply because they seem to represent us all, at this moment in time:

Everybody is at home, the virus has sucked the life out of the city ... but, in all kinds of communities a reimagination is underway, a quiet revolution, rekindling relationships, closeness and togetherness in creative ways. While it's hard to imagine, perhaps Covid-19 in all its horrors and death, may have an underlying effect, reshaping our dreams, forming a permanently altered buzz, in academia, life and all of our worlds?

$* * *$

[This is a time] when universities could embrace and offer something more emergent, sustainable and healthy.

$* * *$

[This is a time] to invent new stories, new purposes and new identities-ones which can address the concerns of local communities and the global society.

$* * *$

[This is a time] for building caring institutions valuing the collective and individual.

$* * *$

To avoid an even deeper crisis in the aftermath of the current situation, the critical voice from the university might be crucial. A critical question is, will we be allowed by society to take that role?

$* * *$

There are still difficult days ahead. The struggle continues, individually and collectively. Voices and the stories hidden in this struggle have never been so necessary, and that is why we must not silence them.

***

-but how much online is too much? Life is anything but normal.

****

Let us learn from this - after Covid-19, no return to normal, comrades! $* * *$

How will humanity answer the test question of Covid-19? Let us wait and see. 


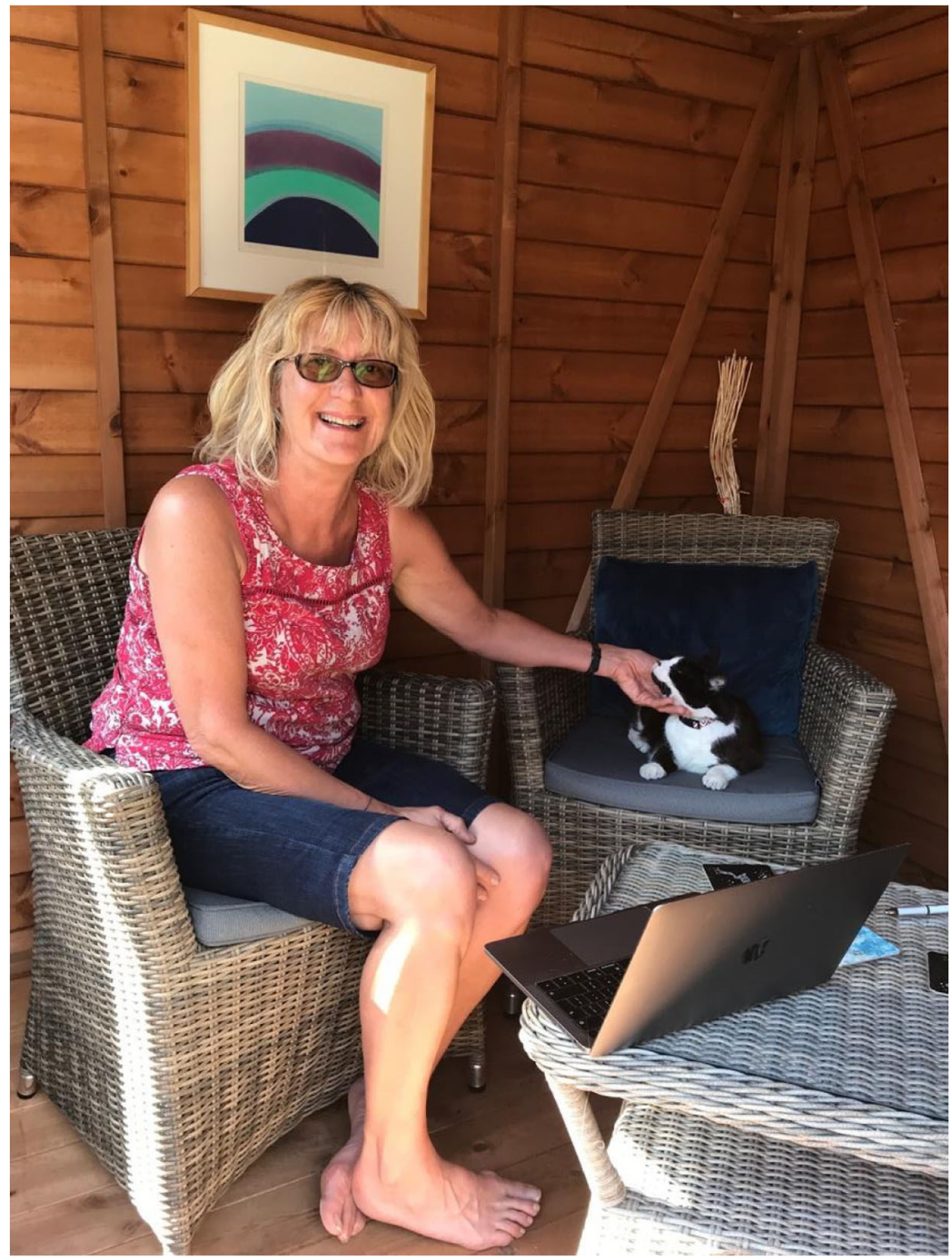

Fig. 80 Despite appearances, not a sauna... but a little garden hut where I have been working, meeting students and colleagues over Skype and in Teams, and occasionally falling asleep...

\section{References}

Brown, J. B. (2020). From denial to acceptance: a turning point for design studio in architecture education. Distance Design Education, 11 May.https://distancedesigneducation.com/2020/05/11/from-denial-toacceptance-a-turning-point-for-design-studio-in-architecture-education/. Accessed 20 May 2020.

California Coronavirus (COVID-19) Response. (2020). Schools and childcare. 24 March. https://covid19.ca. gov/stay-home-except-for-essential-needs/\#school. Accessed 28 March 2020.

California State Government. (2020). Essential Critical Infrastructure Workers. 22 March. https://covid19.ca. gov/img/EssentialCriticalInfrastructureWorkers.pdf. Accessed 28 March 2020. 
Camus, A. (1960). The Plague. Trans. S. Gilbert. Harmondsworth, England: Penguin.

Cass Culture. (2020a). Cass Research Seminar: Top Tips for Sane. Home Work. London: London Metropolitan University, 26 March. https:/www.youtube.com/watch?v=4dR9Z64xIQ8\&t=9s. Accessed 19 May 2020.

Cass Culture. (2020b). Cass Research Seminar: Delight in Home. Based Work. London: London Metropolitan University, 30 March. https://www.youtube.com/watch?v=8PKV4Q-IcE0.

Champlain College. (2020). Champlain at a glance. https:/www.champlain.edu/about-champlain/quick-factsand-history. Accessed 19 May 2020.

Crowther, P. (2013). Understanding the signature pedagogy of the design studio and the opportunities for its technological enhancement. Journal of Learning Design, 6(3), 18-28 https://doi.org/10.5204/jld.v6 i3.155.

Fawns, T., Aitken, G., \& Jones, D. (2019). Online learning as embodied, socially meaningful experience. Postdigital Science and Education, 1(2), 293-297. https://doi.org/10.1007/s42438-019-00048-9.

Hadden, J. (2020). Australia's bushfires are ravaging the country: Here's how it all happened. Insider, (8 January). https://www.insider.com/when-how-australia-bushfires-started-in-2019-2020-1. Accessed 19 May 2020.

Hasbro. (2020). Transformers. https://transformers.hasbro.com/en-us. Accessed 19 May 2020.

Hayes, S. (2018). Invisible labour: Do we need to reoccupy student engagement policy? Learning and Teaching, 11(1), 19-34. https://doi.org/10.3167/latiss.2018.110102.

Hayes, S. (2019). The Labour of Words in Higher Education: is it time to reoccupy policy? Leiden: Brill.

Hayes, S. (forthcoming 2020). Postdigital Positionality: developing powerful narratives for learning, teaching, research and policy in higher education. Leiden: Brill.

Hayes, S., \& Jandrić, P. (2018). Resisting the iron cage of 'the student experience'. Šolsko polje, 29(1-2), 127143.

Hayes, S., Jopling, M., Hayes, D., Westwood, A., Tuckett, A., \& Barnett, R. (2020). Raising regional academic voices (alongside data) in Higher Education (HE) debate. Postdigital Science and Education. https://doi.org/10.1007/s42438-020-00131-6.

Heartfelt Love and Life Quotes (2020). I love it when I hug someone, and just when I'm about to let go, they hug me even tighter. https://heartfeltquotes.blogspot.com/2014/11/i-love-it-when-i-hug-someone-andjust.html. Accessed 19 May 2020.

Hodges, C., Moore, S., Lockee, B., Trust, T., \& Bond, A. (2020). The difference between emergency remote teaching and online learning. EDUCAUSE Review, (27 March) https://er.educause.edu/articles/2020 /3/the-difference-between-emergency-remote-teaching-and-online-learning. Accessed 19 May 2020.

Jackson, L. (2020). Weary from the Future. Hong Kong. Postdigital Science and Education. https://doi. org/10.1007/s42438-020-00116-5.

Jandrić, P. (2020a). A Message to You, Rudy: Hear Reason, Or Nature Will Make You Feel Her. Knowledge Cultures.

Jandrić, P. (2020b). Corona-Party at the Ruins of an Earthquake. Social Epistemology Review and Reply Collective, 9(5), 34-39.

Jandrić, P. (2020c). Postdigital Research in the Time of Covid-19. Postdigital Science and Education, 2(2), 233-238. https://doi.org/10.1007/s42438-020-00113-8.

Jandrić, P., Knox, J., Besley, T., Ryberg, T., Suoranta, J., \& Hayes, S. (2018). Postdigital Science and Education. Educational Philosophy and Theory, 50(10), 893-899. https://doi.org/10.1080 /00131857.2018.1454000.

Jandrić, P., Ryberg, T., Knox, J., Lacković, N., Hayes, S., Suoranta, J., Smith, M., Steketee, A., Peters, M. A., McLaren, P., Ford, D. R., Asher, G., McGregor, C., Stewart, G., Williamson, B., \& Gibbons, A. (2019). Postdigital Dialogue. Postdigital Science and Education, 1(1), 163-189. https://doi.org/10.1007/s42438018-0011-x.

Jandrić, P., \& Hayes, S. (2020). Writing the History of the Present. Postdigital Science and Education. https://doi.org/10.1007/s42438-020-00168-7.

Klinenberg, E. (2020). We need social solidarity, not just social distancing, The New York Times, 14 March. https:/www.nytimes.com/2020/03/14/opinion/coronavirus-social-distancing.html. Accessed 19 May 2020.

Kropotkin, P. (1902). Mutual Aid: A Factor of Evolution. Hamilton: McMaster University Archive for the History of Economic Thought.

Larson, M. S. (1977). The Rise of Professionalism: A Sociological Analysis. Berkley, CA: University of California. 
LeBlanc, P. (2020). Texas Lt. Gov. Dan Patrick: 'I'm all in' on risking my health to lift social distancing guidelines for economic boost. CNN, (24 March). https://edition.cnn.com/2020/03/23 /politics/coronavirus-texas-social-distancing-guidelines/index.html. Accessed 19 May 2020.

Lincoln, A. (1861/1988). Lincoln's Annual Message to Congress, December 3, 1861. In M. Parenti, Democracy for the Few (p. 10). New York: St. Martin's Press.

Lorde, A. (1997). The collected poems of Audre Lorde. New York: W. W. Norton \& Company.

Oreskes, B., Alpert Reyes, E., \& Zahniser, D. (2020, Mar.). In wild hearing, federal judge grills L.A. officials over coronavirus and homeless shelters. Los Angeles Times, 19 March. https://www.latimes. com/homeless-housing/story/2020-03-19/coronavirus-homeless-shelter-federal-court-emergency-hearinglos-angeles. Accessed 20 May 2020.

Percival, R. (1995). Carry on learning: Learning Cyberspace. The New Scientist, (18 November). https://www. newscientist.com/article/mg14820045-300-carry-on-learning-learning-cyberspace/?ignored=irrelevant. Accessed 20 May 2020.

Peters, M. A., Jandrić, P., \& McLaren, P. (2020a). Viral modernity? epidemics, infodemics, and the 'bioinformational' paradigm. Educational Philosophy and Theory. https://doi.org/10.1080 /00131857.2020.1744226.

Peters, M. A., McLaren, P., \& Jandrić, P. (2020b). A Viral Theory of Post-Truth. Educational Philosophy and Theory. https://doi.org/10.1080/00131857.2020.1750090.

Plachta, A. (2020). LAUSD families pick up some solace in 'grab n go' meals amid coronavirus school shutdown. Los Angeles Daily News, (18 March). https://www.dailynews.com/2020/03/18/lausd-familiespick-up-some-solace-in-grab-n-go-meals-amid-coronavirus-school-shutdown/. Accessed 20 May 2020.

Rikowski, G. (2001). The Importance of Being a Radical Educator in Capitalism Today. Warwick, UK: University of Warwick. https:/www.academia.edu/6329166/The_Importance_of_Being_a_Radical_ Educator_in_Capitalism_Today. Accessed 1 April 2020.

Rikowski, G. (2003). The Profit Virus: The business takeover of schools (Draft), February. https://www. academia.edu/6076612/The_Profit_Virus_The_Business_Takeover_of_Schools. Accessed 1 April 2020.

Roy, A. (2020). Arundhati Roy's 'The pandemic is a portal,' Financial Times, 3 April. https://www.ft. com/content/10d8f5e8-74eb-11 ea-95fe-fcd274e920ca.

Sanger, D. E., Lipton, E., Sullivan, E., \& Crowley, M. (2020). Before Virus Outbreak, a Cascade of. Warnings Went Unheeded. New York Times, 19 March. https://www.nytimes.com/2020/03/19/us/politics/trumpcoronavirus-outbreak.html. Accessed 19 May 2020.

Schön, D. (1985). The design studio: an exploration of its traditions and potentials. London: RIBA Publications.

Schön, D. (1987). Educating the Reflective Practitioner. San Francisco: Jossey-Bass.

Stevens, G. (1998). The favored circle: the social foundations of architectural distinction. Cambridge, MA and London: MIT Press.

Ungar, L. (2020). Pandemic. http://www.lynnungar.com/poems/pandemic/. Accessed 26 March 2020.

Webster, H. (2008). Architectural Education after Schön: Cracks, Blurs, Boundaries and Beyond. Journal for Education in the Built Environment, 3(2), 63-74. https://doi.org/10.11120/jebe.2008.03020063.

Žižek, S. (2020). Biggest threat Covid-19 epidemic poses is not our regression to survivalist violence. but BARBARISM with human face. RT, (19 March). https://www.rt.com/op-ed/483528-coronavirus-worldcapitalism-barbarism/. Accessed 23 March 2020.

\section{Affiliations}

Petar Jandrić $^{1,2}$ - David Hayes ${ }^{3}$ - Ian Truelove ${ }^{4}$ Paul Levinson $^{5} \cdot$ Peter Mayo $^{6}$. Thomas Ryberg $^{7}$ • Lilia D. Monzó ${ }^{8}$ - Quaylan Allen ${ }^{8}$ • Paul Alexander Stewart ${ }^{9}$. Paul R. Carr ${ }^{10} \cdot$ Liz Jackson $^{11}$. Susan Bridges ${ }^{11}$. Carlos Escaño ${ }^{12}$.

Dennis Grauslund ${ }^{13}$. Julia Mañero ${ }^{12}$ • Happiness Onesmo Lukoko ${ }^{14}$. Peter Bryant ${ }^{15}$. Ana Fuentes-Martinez ${ }^{16,17}$. Andrew Gibbons ${ }^{18} \cdot$ Sean Sturm ${ }^{19}$. $^{2}$ Jennifer Rose ${ }^{20}$. Mohamed Muhibu Chuma ${ }^{21}$. Eva Biličić ${ }^{1}$ - Sarah Pfohl ${ }^{22}$. Ulrika Gustafsson ${ }^{23}$. Janine Aldous Arantes ${ }^{24,25}$. Derek R. Ford ${ }^{26}$. Jimmy Ezekiel Kihwele ${ }^{27}$ - Peter Mozelius ${ }^{28}$ • Juha Suoranta ${ }^{29} \cdot$ Lucija Jurjević $^{1}$. Matija Jurčević ${ }^{1}$ - Anne Steketee ${ }^{8}$. Jones $\operatorname{Irwin}^{30} \cdot$ E. Jayne White ${ }^{31}$. 


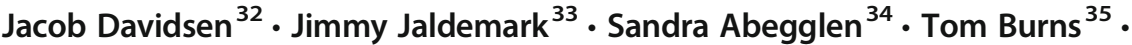
Sandra Sinfield ${ }^{35}$. James D. Kirylo ${ }^{36}$. Ivana Batarelo Kokić ${ }^{37}$.

Georgina Tuari Stewart ${ }^{38}$. Glenn Rikowski ${ }^{39}$ • Line Lisberg Christensen ${ }^{40}$. Sonja Arndt ${ }^{41}$. Olli Pyyhtinen ${ }^{42}$. Charles Reitz ${ }^{43}$. Mikkel Lodahl ${ }^{44}$.

Niklas Humble ${ }^{45}$. Rachel Buchanan ${ }^{46}$. Daniella J. Forster ${ }^{46}$. Pallavi Kishore ${ }^{47}$. Jānis John Ozolinšs ${ }^{48,49}$ • Navreeti Sharma ${ }^{50}$. Shreya Urvashi ${ }^{51}$. Harry G. Nejad ${ }^{52}$ - Nina Hood ${ }^{53}$. Marek Tesar ${ }^{53}$. Yang Wang ${ }^{54,55}$. Jake Wright ${ }^{56}$. James Benedict Brown ${ }^{57}$. Paul Prinsloo ${ }^{58}$. Kulpreet Kaur ${ }^{59}$. Mousumi Mukherjee ${ }^{60}$. Rene Novak ${ }^{61}$. Richa Shukla ${ }^{62}$. Stephanie Hollings ${ }^{63}$. Ulla Konnerup ${ }^{64}$. Madhav Mallya ${ }^{65}$. Anthony Olorundare ${ }^{66}$.

Charlotte Achieng-Evensen ${ }^{8}$. Abey P Philip ${ }^{67}$. Moses Kayode Hazzan ${ }^{68}$. Kevin Stockbridge ${ }^{8}$. Blessing Funmi Komolafe ${ }^{69,70}$.

Ogunyemi Folasade Bolanle ${ }^{71} \cdot$ Michael Hogan $^{72} \cdot$ Bridgette Redder $^{73}$. Sahar D. Sattarzadeh ${ }^{74} \cdot$ Michael Jopling $^{2} \cdot$ Suzanne SooHoo $^{8}$.

Nesta Devine $^{75}$. Sarah Hayes ${ }^{2}$

\author{
Petar Jandrić \\ pjandric@tvz.hr \\ David Hayes \\ hayes210358@gmail.com \\ Ian Truelove \\ i.a.truelove@leedsbeckett.ac.uk \\ Paul Levinson \\ Levinson.paul@gmail.com \\ Peter Mayo \\ peter.mayo@um.edu.mt \\ Thomas Ryberg \\ ryberg@hum.aau.dk \\ Lilia D. Monzó \\ monzo@chapman.edu \\ Quaylan Allen \\ qallen@chapman.edu \\ Paul Alexander Stewart \\ p.stewart@tees.ac.uk \\ Paul R. Carr \\ prcarr@gmail.com \\ Liz Jackson \\ lizjackson@hku.hk \\ Susan Bridges \\ sbridges@hku.hk \\ Carlos Escaño \\ jcescano@us.es \\ Dennis Grauslund \\ dgr@ucn.dk
}


Julia Mañero

julmancon@gmail.com

Happiness Onesmo Lukoko

happinessonesmo@gmail.com

Peter Bryant

peter.j.bryant@sydney.edu.au

Ana Fuentes-Martinez

ana.fuentes@lund.se

Andrew Gibbons

agibbons@aut.ac.nz

Sean Sturm

s.sturm@auckland.ac.nz

Jennifer Rose

Jrose02@qub.ac.uk

Mohamed Muhibu Chuma

chumamohamed@gmail.com

Eva Biličić

eva.bilicic@tvz.hr

Sarah Pfohl

pfohls@uindy.edu

Ulrika Gustafsson

ulrika.gustafsson@umu.se

Janine Aldous Arantes

Janine.arantes@uon.edu.au

Derek R. Ford

derekford@depauw.edu

Jimmy Ezekiel Kihwele

jikihwele@mzumbe.ac.tz

Peter Mozelius

Peter.Mozelius@miun.se

Juha Suoranta

juha.suoranta@tuni.fi

Lucija Jurjević

ljurjevic@tvz.hr

Matija Jurčević

mjurcevic@tvz.hr

Anne Steketee

Steke101@mail.chapman.edu

Jones Irwin

Jones.Irwin@dcu.ie

E. Jayne White

jayne.white@rmit.edu.au 
Jacob Davidsen

Jdavidsen@hum.aau.dk

Jimmy Jaldemark

jimmy.jaldemark@miun.se

Sandra Abegglen

sandra.abegglen@ucalgary.ca

Tom Burns

t.burns@1ondonmet.ac.uk

Sandra Sinfield

s.sinfield@londonmet.ac.uk

James D. Kirylo

kiryloja@mailbox.sc.edu

Ivana Batarelo Kokić

batarelo@ffst.hr

Georgina Tuari Stewart

georgina.stewart@aut.ac.nz

Glenn Rikowski

Rikowskigr@aol.com

Line Lisberg Christensen

1lc@hum.aau.dk

Sonja Arndt

sonja.arndt@unimelb.edu.au

Olli Pyyhtinen

olli.pyyhtinen@tuni.fi

Charles Reitz

charlesreitz@sbcglobal.net

Mikkel Lodahl

milo@eadania.dk

Niklas Humble

niklas.humble@miun.se

Rachel Buchanan

Rachel.Buchanan@newcastle.edu.au

Daniella J. Forster

daniella.forster@newcastle.edu.au

Pallavi Kishore

kishorepallavi@hotmail.com

Jānis John Ozoliṇš

John.ozolins@nd.edu.au

Navreeti Sharma

navreeti@jgu.edu.in

Shreya Urvashi

mp2018sss003@tiss.edu 
Harry G. Nejad

mgnejad@jgu.edu.in

Nina Hood

n.hood@auckland.ac.nz

Marek Tesar

m.tesar@auckland.ac.nz

Yang Wang

201932120008@mail.bnu.edu.cn

Jake Wright

jwwright@r.umn.edu

James Benedict Brown

james.brown@umu.se

Paul Prinsloo

prinsp@unisa.ac.za

Kulpreet Kaur

kkaur@jgu.edu.in

Mousumi Mukherjee

mmukherjee@jgu.edu.in

Rene Novak

proronny@gmail.com

Richa Shukla

rshukla@jgu.edu.in

Stephanie Hollings

shollings88@hotmail.com

Ulla Konnerup

ullak@hum.aau.dk

Madhav Mallya

mmallya@jgu.edu.in

Anthony Olorundare

anthonyolorundare@yahoo.com

Charlotte Achieng-Evensen

achiengevensenphd@gmail.com

Abey P Philip

abeypp@curtin.edu.my

Moses Kayode Hazzan

moseshazzan4@gmail.com

Kevin Stockbridge

kstock@chapman.edu

Blessing Funmi Komolafe

blessing.komolafe@aaua.edu.ng

Ogunyemi Folasade Bolanle

niyititi@yahoo.co.uk 
Michael Hogan

michael.hogan@nuigalway.ie

Bridgette Redder

bridgetteredder@gmail.com

Sahar D. Sattarzadeh

saharsattarzadeh@depauw.edu

Michael Jopling

m.jopling@wlv.ac.uk

Suzanne SooHoo

soohoo@chapman.edu

Nesta Devine

Nesta.devine@aut.ac.nz

Sarah Hayes

Sarah.Hayes@wlv.ac.uk

Zagreb University of Applied Sciences, Zagreb, Croatia

2 Education Observatory, University of Wolverhampton, Wolverhampton, UK

3 Further Education, Worcester, UK

4 Leeds Beckett University, Leeds, UK

5 Fordham University, New York City, NY, USA

6 University of Malta, Msida, Malta

7 Depatment of Communication and Psychology, Aalborg University, Aalborg, Denmark

8 Attallah College of Educational Studies, Chapman University, Orange, CA, USA

9 MIMA School of Art and Design, Teesside University, Middlesbrough, UK

10 Département des sciences d l'éducation, Université du Québec en Outaouais, 283, boulevard AlexandreTaché, C.P. 1250, succursale Hull, Gatineau, Québec J8X 3X7, Canada

11 The University of Hong Kong, Hong Kong, China

12 University of Seville, Seville, Spain

13 University College of Northern Denmark, Aalborg, Denmark

14 Higher Education \& Student Affairs, Beijing Normal University, Beijing, China

15 University of Sydney, Sydney, Australia

16 Katedralskolan (Lund), Lund, Sweden

17 University West, Trollhättan, Sweden

18 School of Education, Auckland University of Technology, Auckland, New Zealand

19 Faculty of Education and Social Work, University of Auckland, Auckland, New Zealand

20 School of Social Science, Education and Social Work, Queen's University Belfast, Belfast, Northern Ireland, United Kingdom

21 Faculty of Education, Beijing Normal University, Beijing, China

22 Department of Art \& Design, University of Indianapolis, Indianapolis, IN, USA

23 Department of Applied Educational Science, Umeå University, Umeå, Sweden 
University of Newcastle, Callaghan, Australia

Victoria University, Melbourne, Australia

DePauw University, Greencastle, IN, USA

Department of Education, Mzumbe University, Morogoro, Tanzania

Mid Sweden University, /Stockholm, Östersund, Sweden

Faculty of Social Sciences, Tampere University, Tampere, Finland

School of Human Development, Institute of Education, Dublin City University, Dublin, Republic of Ireland

RMIT, Melbourne, Australia

Aalborg University, Aalborg, Denmark

Department of Education, Mid Sweden University, Sundsvall, Sweden

School of Architecture, Planning and Landscape, University of Calgary, Calgary, Canada

Centre for Professional and Educational Development, London Metropolitan University, London, UK

University of South Carolina, Columbia, USA

Department of Pedagogy, Faculty of Humanities and Social Sciences, University of Split, Split, Croatia Auckland University of Technology, Aotearoa, Auckland, New Zealand

College of Social Science, University of Lincoln, Lincoln, UK

Department of Communication and Psychology, Aalborg University, Aalborg, Denmark

Melbourne Graduate School of Education, University of Melbourne, Melbourne, Australia

Faculty of Social Sciences, Tampere University, Helsinki, Finland

Community College, Kansas City, MO, USA

Institute for Danish Game Development, Dania Academy, Grenaa, Denmark

Department of Computer and System Science, Mid Sweden University, Östersund, Sweden

School of Education, University of Newcastle, Newcastle, Australia

Jindal Global Law School, O.P, Jindal Global University, Sonipat, India

College of Philosophy and Theology, University of Notre Dame Australia, Fremantle, Australia

Faculty of History and Philosophy, University of Latvia, Riga, Latvia

Global Language Centre, O.P. Jindal Global University, Sonipat, India

Centre for Studies in Sociology of Education, Tata Institute of Social Sciences, Mumbai, India

Jindal Institute of Behavioural Sciences, O. P. Jindal Global University, Haryana, India

Faculty of Education, University of Auckland, Auckland, New Zealand

Chinese Language \& Culture College, Beijing Normal University, Beijing, China

Keystone Academy, Beijing, China

Center for Learning Innovation, University of Minnesota Rochester, Rochester, MN, USA

Umeå School of Architecture, Umeå University, Umeå, Sweden

University of South Africa, Pretoria, South Africa

Jindal Global Business School, Jindal Institute of Behavioural Sciences, O.P Jindal Global University, Sonepat, India

60 International Institute for Higher Education Research \& Capacity Building, O.P. Jindal Global University, Sonipat, Delhi, India 
61 University of Waikato and BestStart, Tauranga, New Zealand

62 OP Jindal Global Business School, OP Jindal Global University, Sonipat, India

63 Faculty of Education, Beijing Normal University, Beijing, China

64 Faculty of Humanities, Aalborg University, Aalborg, Denmark

65 Jindal Global Law School, Jindal Global University, Sonipat, Haryana, India

66 Northeast Normal University, Changchun, China

67 Department of Banking and Finance, Faculty of Business, Curtin University, Miri, Malaysia

68 Department of Educational Management, Faculty of Education, University of Ibadan, Ibadan, Nigeria

69 Science Education Department, Adekunle Ajasin University, Akungba, Nigeria

70 Curriculum and Pedagogy, College of Teacher Education, Zhejiang Normal University, Jinhua, China

71 Beijing Normal University, Beijing, China

72 School of Psychology, National University of Ireland Galway, Galway, Ireland

73 Te Rito Maioha Early Childhood New Zealand, Rotorua, New Zealand

74 DePauw University, Greencastle, IN, USA

75 Faculty of Culture and Society, Auckland University of Technology, Auckland, New Zealand 